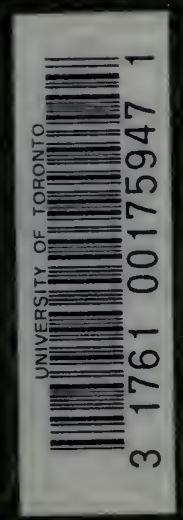



Digitized by the Internet Archive in 2007 with funding from Microsoft Corporation 



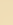




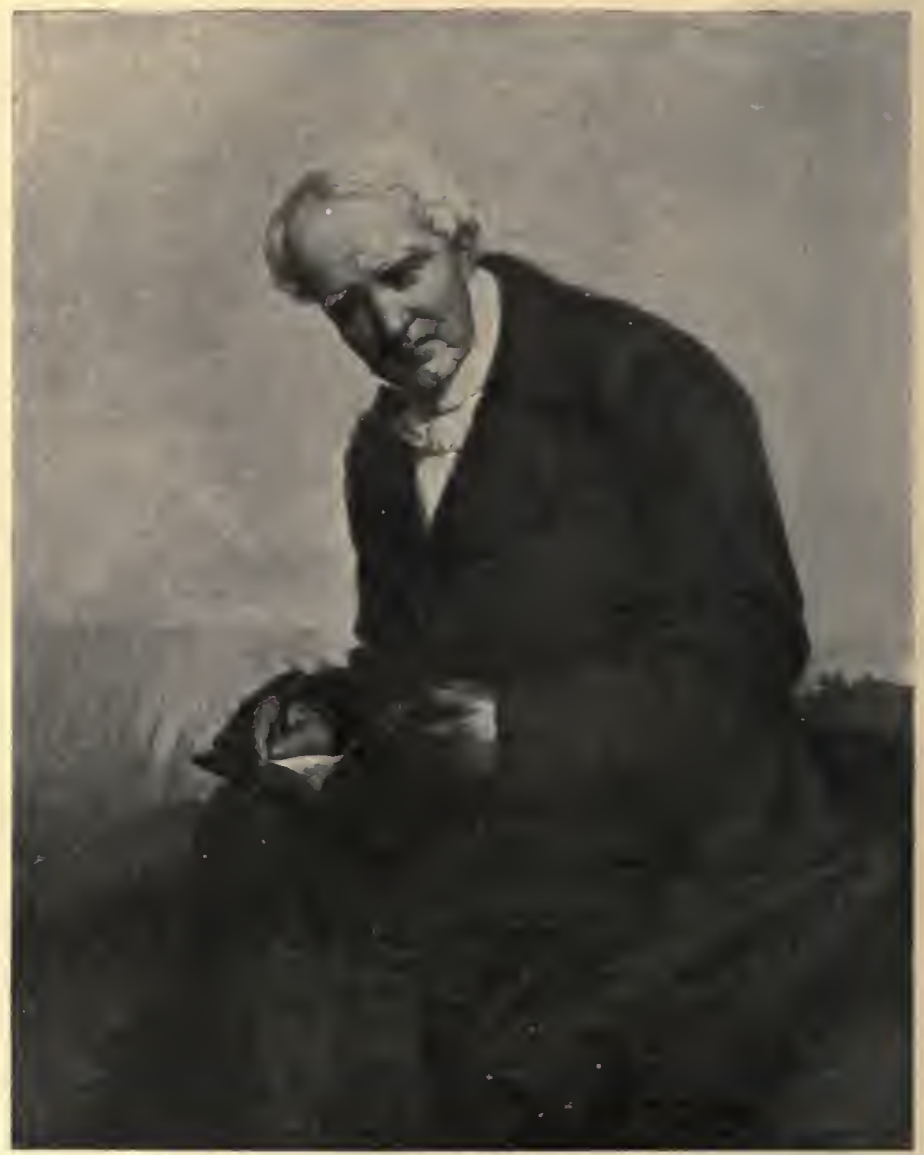

\section{BARON ALEXANDER VON HUMBOLDT}

From the painting by Professor Julius Schrader, Esq., at the American Juseum of Natural History, owned by Jorris K. Jesup 


\title{
THE STORY OF
}

\section{NINETEENTH-CENTURY}

\section{SCIENCE}

BY

HENRY SMITH WILLIAMS, M.D.

\author{
ILLUSTRATED
}

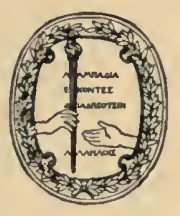

HARPER E BROTHERS PUBLISHERS NEW YORK AND LONDON I 90 I 


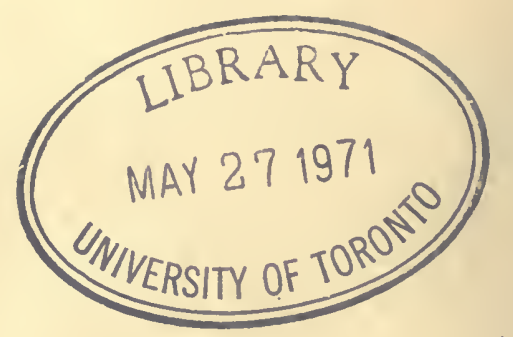

$$
\begin{aligned}
& Q \\
& 125 \\
& \text { W683 }
\end{aligned}
$$

Copyright, 1900, by Henry Smith Williams. All rights reserved. 


\section{CONTENTS}

CHAPTER

1. Science at the Beginying of the Century . . . 1

II. The Century's Progress in Astronomy . . . . . 44

III The Century's Progress in Paleontology . . . 88

IV. The Century's Progress in Geology . . . . . . 123

V. The Cextury's Progress in Meteorology . . . . 157

VI. Thi Century's Progress in Physics. The "ImpoxDerables" . . . . . . . . . . . 192

V11. The Ethei and Pondeibable Matter . . . . . 230

VIII. The Century's Progress ix Chemistry . . . . . 252

IX. The Century's Progress in Biology. Theories of Organic Evolution . . . . . . . . . 288

X. The Century's Progress in Anatomy and PhysOLOGY . . . . . . . . . . . . . . . . 321

XI. The Century's Progress ix Scifentific Mledicine . 354

XiI. The Century's Progress in Experimental Psychol$\mathrm{OGY}$. . . . . . . . . . . . . . 395

XIII. Some Ussolved Sciextific Problems . . . . . . 433

I. Solar and Telidric Problems . . . . 435

II. Physical Problems . . . . . . . . 443

III. Life Problems . . . . . . . . . . . . 449

INDEX . . . . . . . . . . . . . . . 459 



\section{L L U S T R A T I O N}

PAGE

BARON ALEXANDER VON IIUAHBLLT . . . . . Frontispiece IIUMIPHIRY DAVY . . . . . . . . . . . . . . 3

JOSIAII WEDGWOOD . . . . . . . . . . . . . . . . . 6

HERSCHEL AND HIS SISTER AT THE TELESCOPE • . . . . . 9

JAMES LOUIS LAGRANGE . . . . . . . . . . . . 14

JAMES HUTTON • . . . . . . . . . . . . . . . . 18

BENJAMIN THOMPSON-COUNT RUMFORD . . . . . . . . 25

JOSKPII PRIESTLY . • . . . . . . . • . . . . . 30

LAVOISIER IN HIS LABORATORY . : . . . . . . . . 37

EDWARD JENNER • . . . . . . . . . . . . . 4 41

FIRIEDRICH WILHELM BESSEL . . . . . . . . . . . . 45

HEINRICII WLLELM MATTHIAS OLIBERS . . . . . . . . . 55

SIR JOIIN HEIRCHEL . . . . . . . . . . . . . . . 61

THE GREAT REFRACTOI OF TIE NATIONAL OBSERVATORY AT

WASHINGTON . . . . . . . • . . . . . . 67

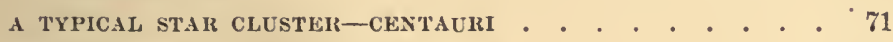

SPECTRA OF STARS IN CARINA . . . . . . . . . . 73

STAR SPECIRA. . . . . . . . . . . . . . . . 75

LORD ROSSE'S TELESCUPE . . . . . . . . . . . . 77

No. 1-Sidereal TIME, 15 IIUUirs, 50 miNutes . . . . . $\} 81$

YO. 2-SIDEREAL TIME, 17 IOURS, 50 IINUTES . . . . . $\}$

THE OXFORD HELIOMETER . . . . . . . . . . . . . 85

GEORGES CUVIEIR • . . . . . . . . . . . . . . . 92

THE WARREN MASTODON, FOUND NEAR NEWBURG, ON THE HUDSON . . . . . . . . . . . . . . 94 


\section{ILLUSTRATIONS}

THE SKULL, LACKING THE LOWER JAW, OF EOBASILELS CORNUTUS, COPE.

METAMYNODON, OR SWIMMING RHINOCEROS, FROM SOUTH DAKOTA

HYRACHYUS, OR RUNNING IRHINOCEROS, FROM SOUTHERN WYOMING

PROFESSOR E. D. COPE . . . . . . . . . . . . . . 106

PROTOROHIPPUS, THE ANCESTRAL FOUR-TOED HORSE . . . . 110

PROFESSOR O. C. MARSII . . . . . . . . . . . . . 112

THE EVOLUTION OF A HORSE'S FOOT AND OF A HOIRE'S IIEAD $11 j$ FOO'TPRINTS OF REPTILES FOUND IN CONNECTICUT SAND-

STONE . . . . . . . . . . . . . . . . 118

TITANOTHERE FROM SOUTH DAKOTA. . . . . . . . . . 120

THE RESULTS OF EROSION BY IRUNNING WATER . . . . . . 127

THE RESULTS OF EROSION BY WIND . . . . . . . . . . 131

A MOUNTAIN CARVED FRON IORIZONTAL STRATA . . . . . 133

LOUIS JEAN RODOLPH AGASSIZ . . . . . . . . . . $\} 135$

ADAM SEDGWICK, F.IR.S. . . . . . . . . . . . .

JAMES DWIGHT DANA . . . . . . . . . . . \{ 137

SIR RODERICK IMPEY MURCHISON ...........

WILLIAM SMITH, LL.D. . . . . . . . . . . . . . . 139

GEORGE POULETte scrope, F.IR.S. . . . . . . . . . $\} 141$

SIR CHARLES T.YELL, BART., F. IR S.

A LANDSCaPe AND MaMmal of THE TEkTiary AgE . . . . 143

A LANDSCAPE AND TERRESTRLAL REPTILE OF THE MLSOZOIC

TIME •. . . . . . . . . . . . . . 147

MANHATTAN ISLAND IN THE QUATERNARY AGE-TIE MASTO-

DON .

151

SIR RICHAIR OWEN. . . . . . . . . . . . . . . 155

A METEORIC STONE . . . . . . . . . . . . . . . . 150

CIRIRS Clouds . . . . . . . . . . . . . . . 163

CUMULUS ClOUDS . . . . . . . . . . . . . . 165

STRATUS CLOUDS. . . . . . . . . . . . . 168

JEAN BAPTISTE BIOT . . . . . . . . . . . . 173

LIEUTENANT MATTHEW FONTAINE MAURY . . . . . . . . 179

A WHIRLWIND IN A DUSTY ROAD . . . . . . . . . . . 183

WATERSPOUTS IN MID-ATLANTIC . . . . . , . . 185 


\section{ILLUSTRATIONS}

A SAND-STORM ON TIIE MOJAVE DESER'T . . . . . . . . 187

TIIONAS YOUNG

IIANS CHRISTIAN OERSTED

DOMINIQUE FRANÇOIS ARAGO

AUGUSTIN JEAN FRESNEL

JAMES CLEIK MAXWELI

MICHAEL FARADAY .

JAMES PRESCOTT JOULE

WILLIAM TIOMSON (LOID KELVIN)

JULIUS ROBERT MAYER

JOHN TYNDALL

HERMANN LUDWIG FERDINAND HELMIIOLTZ

JOIIN DALTON .

254

JOSEPH LOUIS GAY-LUSSAC

JOIIAN JAKOB BERZELIUS .

261

JUSTUS VON LIEBIG.

267

ROBERT WILLIAM BUNSEN

277

GUSTAV ROBERT KIRCIIHOFF

279

LOUIS JACQUES MANDÉ DAGUERRE

JOIIN W. DRAPER

EIRASMUS DARWIN

JEAN BAPTISTE DE LAMARCK

ÉTIENNE GEOFFROY SAINT-IIILAIRE

CHARLES ROBERT DARWIN

304

ALFRED IRUSSELL WALLACE .

308

THOMAS IIENRY IIUXLEY .

311

ASA GRAY

ERNEST HAECKEL

MARIE FRANÇOIS XAVIER BICHAT .

WIILIAM IIYDE WOLLASTON .

MATTHIAS JAKOB SCHLEIDEN

KARL ERNST VON BAER

JOIIANNES MÜLLEI .

WILLAM BENJAMIN CARPEN'TER

HUGO VON MOHI,

JEAN BAPTISTE DUMAS. 


\section{ILLUSTRATIONS}

CLAUDE BERNARD

LAËNNEC, INVENTOR OF TIIE STE'THOSCOPE, AT THE NECKER IlOSPITAL, PARIS . . . . . . . . . . . . 357 RUDOLF VIRCHOW . . . . . . . . . . . . . . 364 WILliAM T. G. MORTON . . . . . . . . . . . . 367 CRAWFORD W. LONG . . . . . . . . . . . . . . 371 THEODOR SCHWANN . . . . . . . . . . . . . 377 SIR JOSEPII LISTER . . . . . . . . . . . . . . 383 LOUIS PASTEUR . . . . . . . . . . . . . . . . 391 PINEL AT LA SALPÊ'TRIÈRE, IN 1795, RELEASING TIIE INSANE FROM THEIR MANACLES . . . . . . . . . . . . 397 SIR CHARLES BELL . . . . . . . . . . . . . . . 402 FIRANÇOIS MAGENDIE . . . . . . . . . . . . 403 EMIL DU BOIS-REYMOND . . . . . . . . . . . 408 GUSTAV THEODOR FECIINER . . . . . . . . . . . . 413 JEAN MARTIN CHARCOT . . . . . . . . . . . 416 . PAUL BROCA . . . . . . . . . . . . . 421 


\section{THE STORY OF NINETEENTH. CENTURY SCIENCE}





\section{THE STORY OF NINETEENTH- CENTURY SCIENCE}

\section{CHAP'TER I}

SCIENCE AT THE BEGINNING OF THE CENTURY

Noт many months ago word came out of Germany of a scientific discovery that startled the world. It came first as a rumor, little credited; then as a pronounced report; at last as a demonstration. It told of a new manifestation of energy, in virtue of which the interior of opaque objects is made visible to human eyes. One had only to look into a tube containing a screen of a certain composition, and directed to wards a peculiar electrical apparatus, to acquire clairvoyant vision more wonderful than the discredited second sight of the medium. Coins within a purse, nails driven into wood, spectacles within a leather case, became clearly visible when subjected to the influence of this magic tube; and when a human hand was held before the tube, its bones stood revealed in weird simplicity, as if the living, palpitating flesh about them were but the shadowy substance of a ghost.

Not only could the human eye see these astounding revelations, but the impartial evidence of inanimate 
chemicals could be brought forward to prove that the mind harbored no illusion. The photographic film recorded the things that the eye might see, and ghostly pictures galore soon gave a quietus to the doubts of the most sceptical. Within a month of the announcement of Professor Röntgen's experiments comment upon the "X ray" and the "new photography" had become a part of the current gossip of all Christendom.

It was but natural that thoughtfnl minds should have associated this discovery of our boasted latter-day epoch with another discovery that was made in the earliest infancy of our century. In the year 1801 Mr. Thomas Wedgwood, of the world-renowned family of potters, and Humphry Dary, the youthful but already famous chemist, made experiments which showed that it was possible to secure the imprint of a translucent body upon a chemically prepared plate by exposure to sunlight. In this way translucent pictures were copied, and sliele tal imprints were secured of such objects as leares and the wings of insects-imprints strikingly similar to the "shadorgraphs" of more opaque objects which we secure by means of the "new photography" to-day. But these experimenters little dreamed of the real significance of their observations. It was forty years before practical photography, which these observations foreshadowed, was developed and made of any use outside the laboratory.

It seems strange enough now that imaginative menand Dary surely was such a man-should have pansed on the very brink of so great a discovery. But to harbor that thought is to misjudge the nature of the human mind. Things that have once been done seem easy; things that have not been done are difficult, though they 


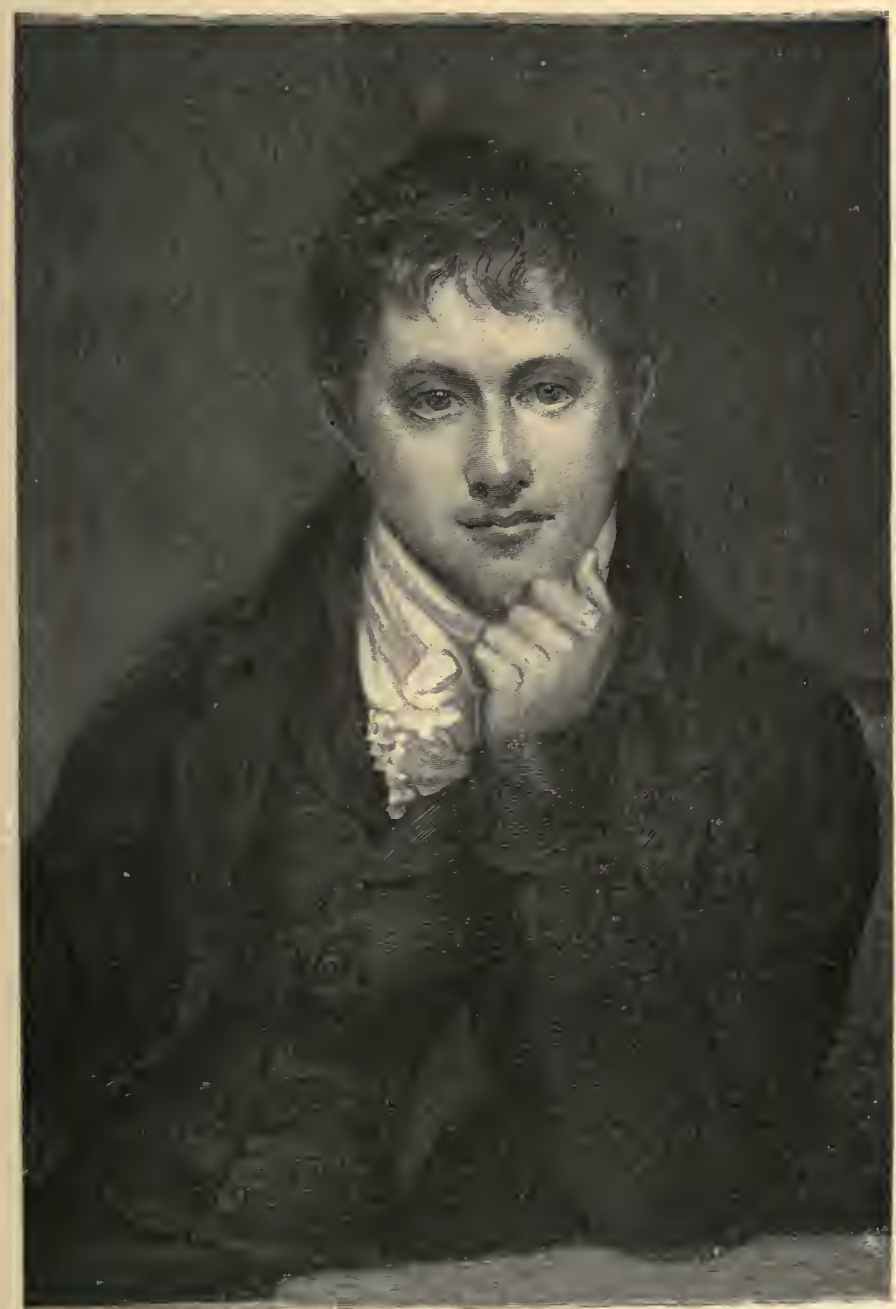

IIUMPIRY DAVY

From the painting by H. Howard 

lie but a hair's-breadth off the beaten track. Who can to-day foretell what revelations may be made, what useful arts developed, forty years hence through the agency of what we now call the new photography?

It is no part of my purpose, however, to attempt the impossible feat of casting a horoscope for the new photography. $\mathrm{My}$ present theme is reminiscent, not prophetic. I wish to recall what knowledge of the sciences men had in the days when that discovery of Wedgwood and Davy was made, almost a hundred years ago; to inquire what was the scientific horizon of a person standing at the threshold of our own century. Let us glance briefly at each main department of the science of that time, that we may know whither men's minds were trending in those closing days of the eighteenth century, and what were the chief scientific legacies of that century to its successor.

In the field of astronomy the central figure during this closing epoch of the eighteenth century is William Herschel, the Hanoverian, whom England has made hers by adoption. He is a man with a positive genius for sidereal discovery. At first a mere annateur in astronomy, he snatches time from his duties as musicteacher to grind him a telescopic mirror, and begins gazing at the stars. Not content with his first telescope, he makes another, and another, and he has such genius for the work that he soon possesses a better instrument than was ever made before. His patience in grinding the curved reflective surface is monumental. Sometimes for sixteen hours together he must walk steadily about the mirror, polishing it, without once remoring 


\section{THE STORY OF NINETEENTH-CENTURY SCIENCE}

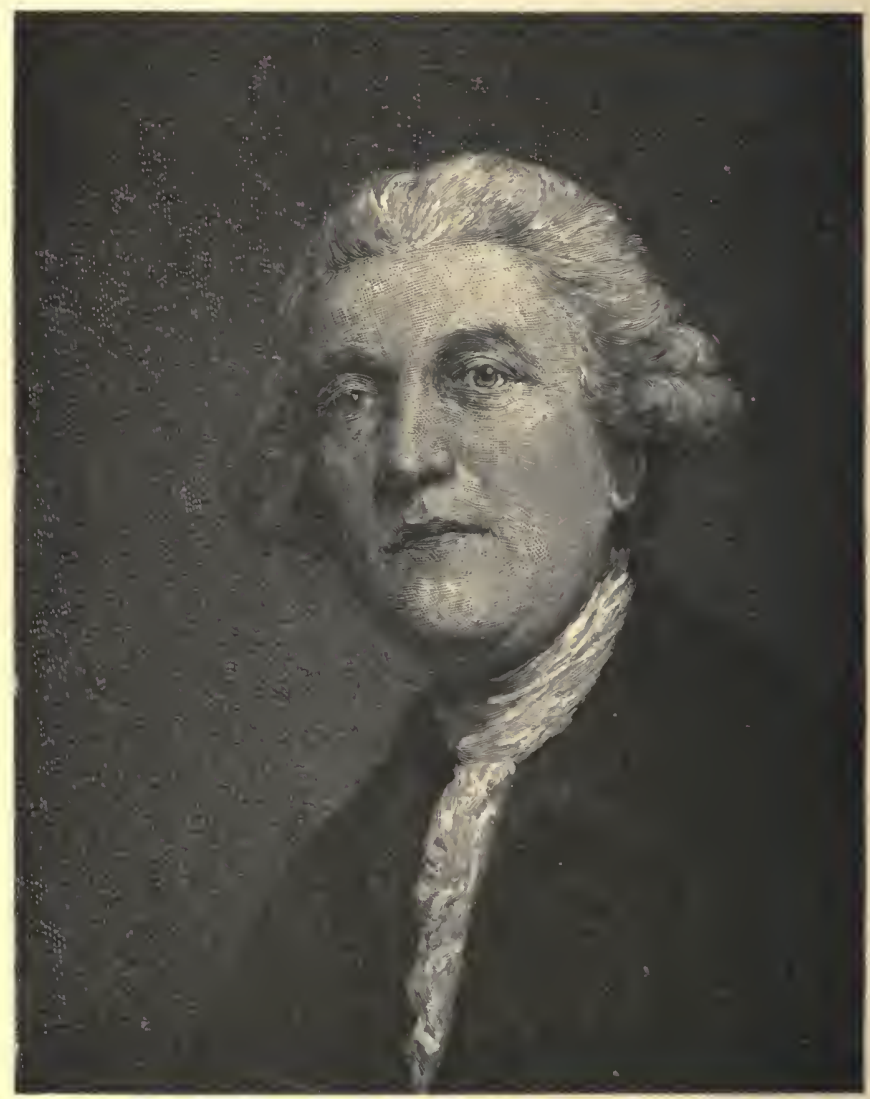

JOSIAH WEDGTOOD

From a painting by Sir Joshua Reynolds

his hands. Meantime his sister, always his chief lieutenant, cheers him with her presence, and from time to time. puts food into his mouth. The telescope completed, the astronomer turns night into day, and from sunset to sunrise, year in and year out, sweeps the heavens unceas- 
ingly, unless prevented by clouds or the brightness of the moon. His sister sits always at his side, recording his observations. They are in the open air, perched high at the mouth of the reflector, and sometimes it is so cold that the ink freezes in the bottle in Caroline Herschel's hand; but the two enthusiasts hardly notice a thing so commonplace as terrestrial weather. They are living in distant worlds.

The results? What could they be? Such enthusiasm would move mountains. But, after all, the moving of mountains seems a Liliputian task compared with what IIerschel really does with those wonderful telescopes. He moves rorlds, stars, a universe-even, if you please, a galaxy of universes; at least he proves that they move, which seems scarcely less wonderful; and he expands the cosmos, as man conceives it, to thousands of times the dimensions it had before. As a mere beginning, he doubles the diameter of the solar system by observing the great outlying planet which we now call Uranus, but which he christens Georgium Sidus, in honor of his sovereign, and which his French contemporaries, not relishing that name, prefer to call Herschel.

This discovery is but a trifle compared with what Herschel does later on, but it gives him world-wide reputation none the less. Comets and moons aside, this is the first addition to the solar system that has been made within historic times, and it creates a veritable furor of popular interest and enthusiasm. Incidentally King George is flattered at having a world named after him, and he smiles on the astronomer, and comes with his court to lave a look at his namesake. The inspection is highly satisfactory; and presently the royal favor 


\section{THE STORY OF NINETEENTH-CENTURY SCIENCE}

enables the astronomer to escape the thraldom of teaching music, and to derote his entire time to the more congenial task of star-gazing.

Thus reliered from the burden of mundane embarrassments, he turns with fresh enthusiasm to the slies, and bis discoveries follow one another in bewildering profusion. He finds various hitherto unseen moons of our sister planets; he makes special studies of Saturn, and proves that this planet, with its rings, revolves on its axis; he scans the spots on the sun, and suggests that they influence the weather of our earth; in short, he extends the entire field of solar astronomy. But very soon this field becomes too small for him, and his most important researches carry him out into the regions of space compared with which the span of our solar system is a mere point. With his perfected telescopes he enters abysmal vistas which no human eye erer penetrated before, which no human eye had hitherto more than vaguely imagined. He tells us that his forty-foot reflector will bring him light from a distance of "at least eleren and three-fourths millions of millions of millions of miles"-light which left its source two million years ago. The smallest stars visible to the unaided eye are those of the sixth magnitude; this telescope, he thinlis, has power to reveal star's of the $13+2$ d magnitude.

But what does Herschel learn regarding these awful depths of space and the stars that people them? That is what the world wishes to know. Copernicus, Galileo, Kepler, have given us a solar system, but the stars have been a mystery. What says the great reflector-are the stars points of light, as the ancients taught, and as more than one philosopher of the eighteenth century has still contended, or are they suns, as others hold? Herschel 


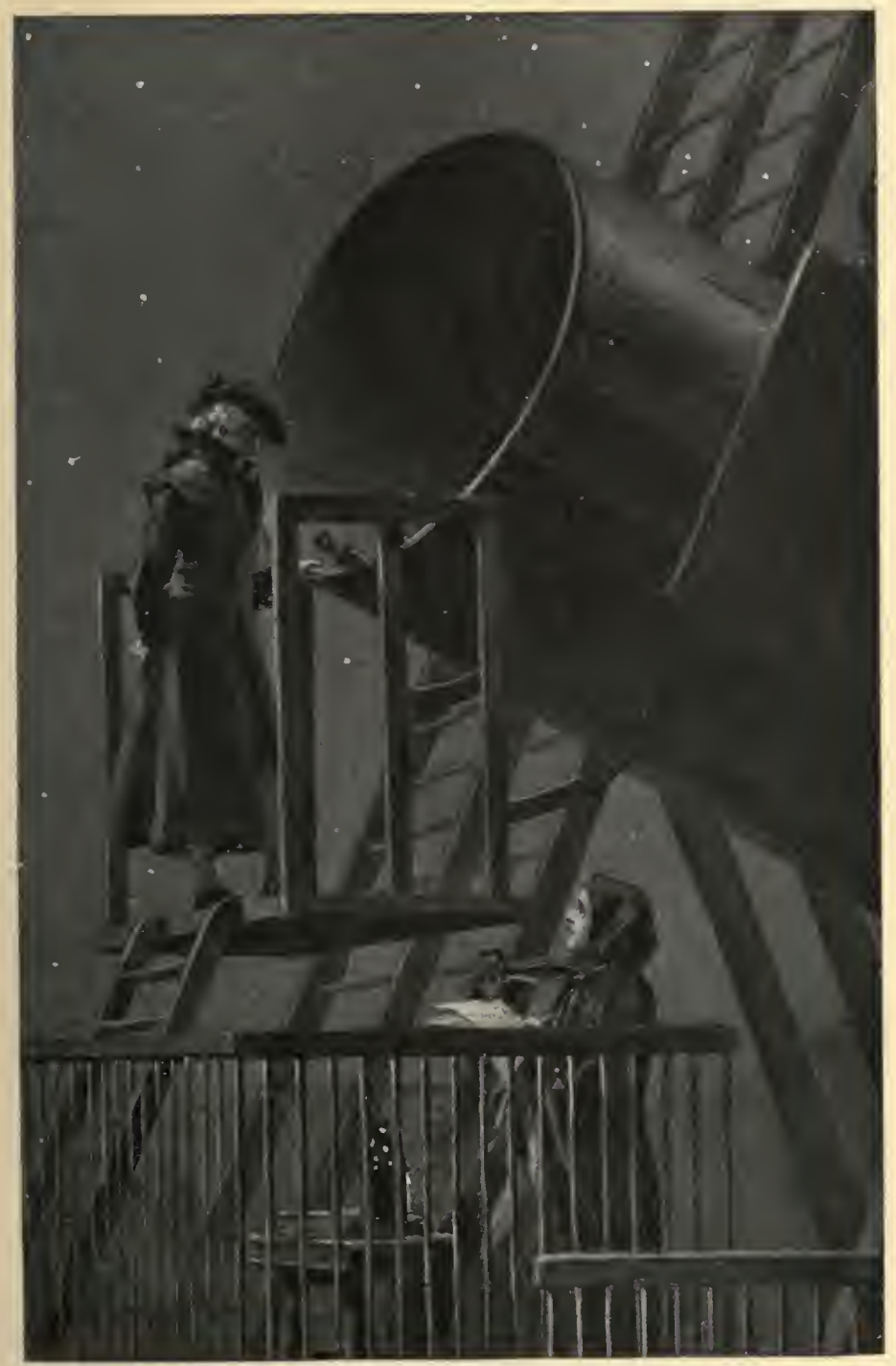

HERSCHEL AND HIS SISTER AT THE TELESCOPE 

answers, they are suns, each and every one of all the millions-suns, many of them, larger than the one that is the centre of our tiny system. Not only so, but they are moving suns. Instead of being fixed in space, as has been thought, they are whirling in gigantic orbits about some common centre. Is our sun that centre? Far from it. Our sun is only a star, like all the rest, circling on with its attendant satellites-our giant sun a star, no different from myriad other stars, not even so large as some; a mere insignificant spark of matter in an infinite shower of sparks.

Nor is this all. Looking beyond the few thousand stars that are visible to the naked eye, Herschel sees series after series of more distant stars, marshalled in galaxies of millions; but at last he reaches a distance beyond which the galaxies no longer increase. And yet - so he thinks-lie has not reached the limits of his vision. What then? He has come to the bounds of the siclereal system; seen to the confines of the universe. He believes that he can outline this system, this universe, and prove that it has the shape of an irregular globe, oblately flattened to almost disklike proportions, and divided at one edge - a bifurcation that is revealed even to the naked eye in the forking of the Milky Way.

This, then, is our universe as Herschel conceives it-a vast galaxy of suns, held to one centre, revolving, poised in space. But even here those marvellous telescopes do not pause. Far, far out beyond the confines of our universe, so far that the awful span of our own system might serve as a unit of measure, are revealed other systems, other universes, like our own, each composed, as he thinks, of myriads of suns, clustered like our galaxy into an isolated system-mere islands of matter in an 


\section{THE STURY OF NINETEENTH-CENTURY SCIENCE}

infinite ocean of space. So distant from our universe are these new universes of Herschel's discovery that their light reaches us only as a dim nebulous glow, in most cases invisible to the unaided eye. About a hundred of these nebula were known when Herschel began his studies. Before the close of the century he has discoreredabout two thousand more of them, and many of these had been resolved by his largest telescopes into clusters of stars. He believes that the farthest of these nebulx that he can see is at least 300,000 times as distant from us as the nearest fixed star. Yet that nearest star is so remote that its light, travelling 180,000 miles a second, requires three and one-half years to reach our planet.

As if to give the finishing-touches to this novel scheme of cosmology, Herschel, though in the main very little given to unsustained theorizing, allows himself the pririlege of one belief that he cannot call upon his telescopes to substantiate. He thinks that all the myriad suns of his numberless systems are instinct with life in the human sense. Giordano Bruno and a long line of his followers had held that some of our sister planets may be inhabited, but Herschel extends the thought to include the moon, the sun, the stars-ail the heavenly bodies. He believes that he can demonstrate the habitability of onr own sun, and reasoning from analogy, he is firmly convinced that all the sums of all the systems are "well supplied with inhabitants." In this, as in some other inferences, Herschel is misled by the faulty physics of his time. Future generations, working with perfected instruments, may not sustain him all along the line of his observations even, let alone his inferences. But how one's egotism shrivels and shrinks as one grasps the import of his sweeping thoughts ! 
Continuing his observations of the innumerable nebulæe, Herschel is led presently to another curious speculative inference. He notes that some star groups are much more thickly clustered than others, and he is led to infer that such varied clustering tells of varying ages of the different nebulæ. He thinks that at first all space may have been evenly sprinkled with the stars, and that the grouping has resulted from the action of gravitation. Looking forward, it appears that the time must come when all the suns of a system will be drawn together and destroyed by impact at a common centre. Already, it seems to him, the thickest clusters have "outlived their usefulness," and are verging towards their doom.

But again, other nebulæ present an appearance suggestive of an opposite condition. They are not resolraable into stars, but present an almost uniform appearance throughout, and are hence believed to be composed of a shining fluid, which in some instances is seen to be condensed at the centre into a glowing mass. In such a nebula Herschel thinks he sees a sun in process of formation.

Taken together, these two conceptions outline a majestic cycle of world formation and world destructiona broad scheme of cosmogony, such as had been vaguely adumbrated two centuries before by Kepler, and in more recent times by Wright and Kant and Swedenborg. This so-called "nebular hypothesis" assumes that in the beginning all space was uniformly filled with cosmic matter in a state of nebular or "fire-mist" diffusion, "formless and void." It pictures the condensation-coagulation, if you will-of portions of this mass to form segregated masses, a.t the nitimate derel- 
THE STORY OF NINETEENTH-CENTURY SCIENCE

opment out of these masses of the sidereal bodies which we see. Thus far the mind follows readily; but now come difficulties. How happens it, for example, that

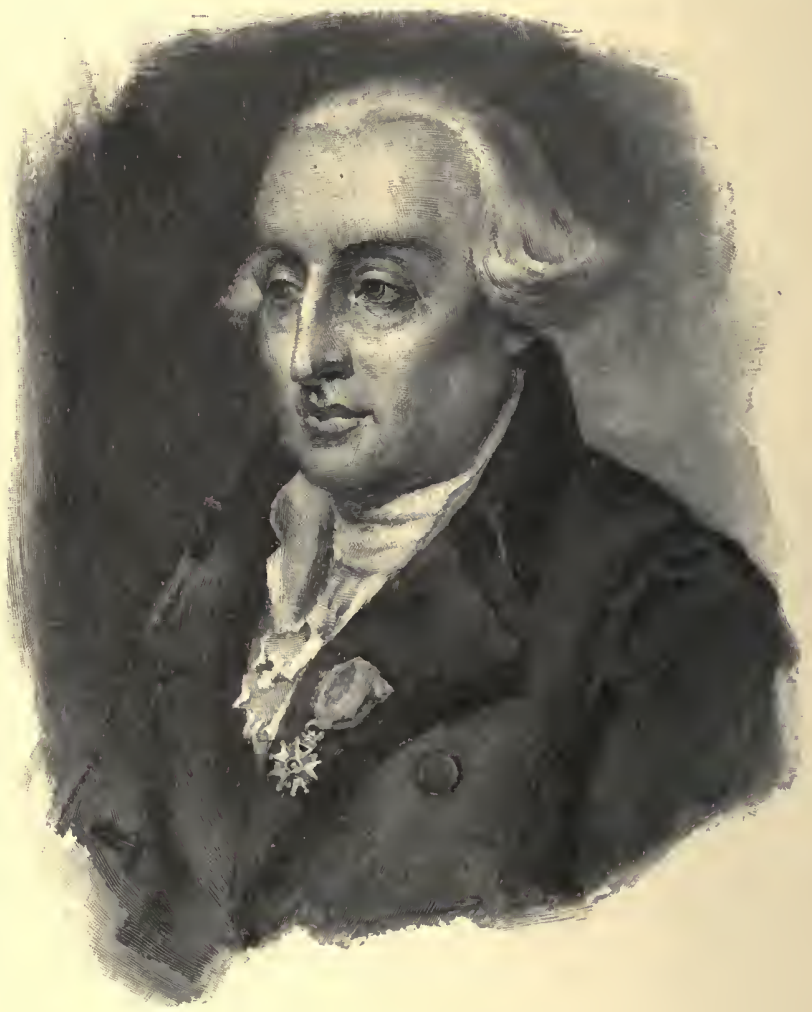

JAMES LOUIS JAAGRANGE

the cosmic mass from which was born our solar system was divided into several planetary bodies instead of remaining a single mass? Were the planets struck off from the sun by the chance impact of comets, as Buffon 
has suggested? or thrown out by explosice volcanic action, in accordance with the theory of Dr. Darwin? or do they owe their origin to some unknown law? In any event, how chanced it that all were projected in nearly the same plane as we now find them?

It remained for a mathematical astronorner to solve these puzzles. The man of all others competent to take the subject in hand was the French astronomer Laplace. For a quarter of a century he had devoted his transcendent mathematical abilities to the solution of problems of motion of the heavenly bodies. Working in friendly rivalry with his countryman Lagrange, his only peer among the mathematicians of the age, he had taken up and solved one by one the problems that Newton left obscure. Largely through the efforts of these two men the last lingering doubts as to the solidarity of the Newtonian hypothesis of universal gravitation had been removed. The share of Lagrange was hardly less than that of his co-worker; but Lagrange will longer be remembered, because he ultimately brought his completed labors into a system, and incorporating with them the labors of his contemporaries, produced in the Mécanique Céleste the undisputed mathematical monument of the century, a fitting complement to the Principia of Newton, which it supplements and in a sense completes.

In the closing years of the century Laplace takes up the nebular hypothesis of cosmogony, to which we have just referred, and gives it definitive proportions; in fact, makes it so thoroughly his own that posterity will always link it with his name. Discarding the crude notions of cometary impact and rolcanic eruption, Laplace fills up the gaps in the hypothesis with the aid only of well-known laws of gravitation and motion. He assumes 
that the primitive mass of cosmic matter which was destined to form our solar system was revolving on its axis even at a time when it was still nebular in character, and filled all space to a distance far beyond the present limits of the system. As this vaporous mass contracted through loss of heat, it revolred more and more swiftly, and from time to time, through balance of forces at its periphery, rings of its substance were whirled off and left revolving there, to subsequently become condensed into planets, and in their turn whirl off minor rings that became moons. The main body of the original mass remains in the present as the still contracting and rotating body which we call the sun.

The nebular lyypothesis thus giren detailed completion by Laplace is a worthy complement of the grand cosmologic scheme of Herschel. Whether true or false, the two conceptions stand as the final contributions of the eighteenth century to the history of man's ceaseless efforts to solve the mysteries of cosmic origin and cosmic structure. The world listens eagerly and without prejudice to the new doctrines; and that attitude tells of a marvellous intellectual growth of our race. Nark the transition. In the year 1600 , Bruno was burned at the stake for teaching that our earth is not the centre of the universe. In 1700, Newton was pronounced "impious and heretical" by a large school of philosophers for declaring that the force which holds the planets in their orbits is universal gravitation. In 1800, Laplace and Herschel are honored for teaching that gravitation built up the system which it still controls; that our universe is but a minor nebula, our sun but a minor star, our earth a mere atom of matter, our race only one of myriad races peopling an infinity of worlds. Doctrines 


\section{SCIENCE AT THE BEGINNING OF THE CENTURY}

which but the span of two human lives before would have brought their enunciators to the stake were now pronounced not impious, but sublime.

III

One might naturally suppose that the science of the earth, which lies at man's feet, would at least have kept pace with the science of distant stars. But perhaps the very obviousness of the phenomena delayed the study of the crust of the earth. It is the unattainable that allures and mystifies and enchants the developing mind. The proverbial child spurus its toys and cries for the moon.

So in those closing days of the eighteenth century, when astronomers had gone so far towards explaining the mysteries of the distant portions of the universe, we find a chaos of opinion regarding the structure and formation of the earth. Guesses were not wanting to explain the formation of the world, it is true, but, with one or two exceptions, these are bizarre indeed. One theory supposed the earth to have been at first a solid mass of ice, which became animated only after a comet had dashed against it. Other theories conceived the original globe as a mass of water, over which floated vapors containing the solid elements, which in due time were precipitated as a crust upon the waters. In a word, the various schemes supposed the original mass to have been ice, or water, or a conglomerate of water and solids, according to the random fancies of the theorists; and the final separation into land and water was conceiverl to have taken place in all the ways which fancy, quite unchecked by any tenable data, could invent. 


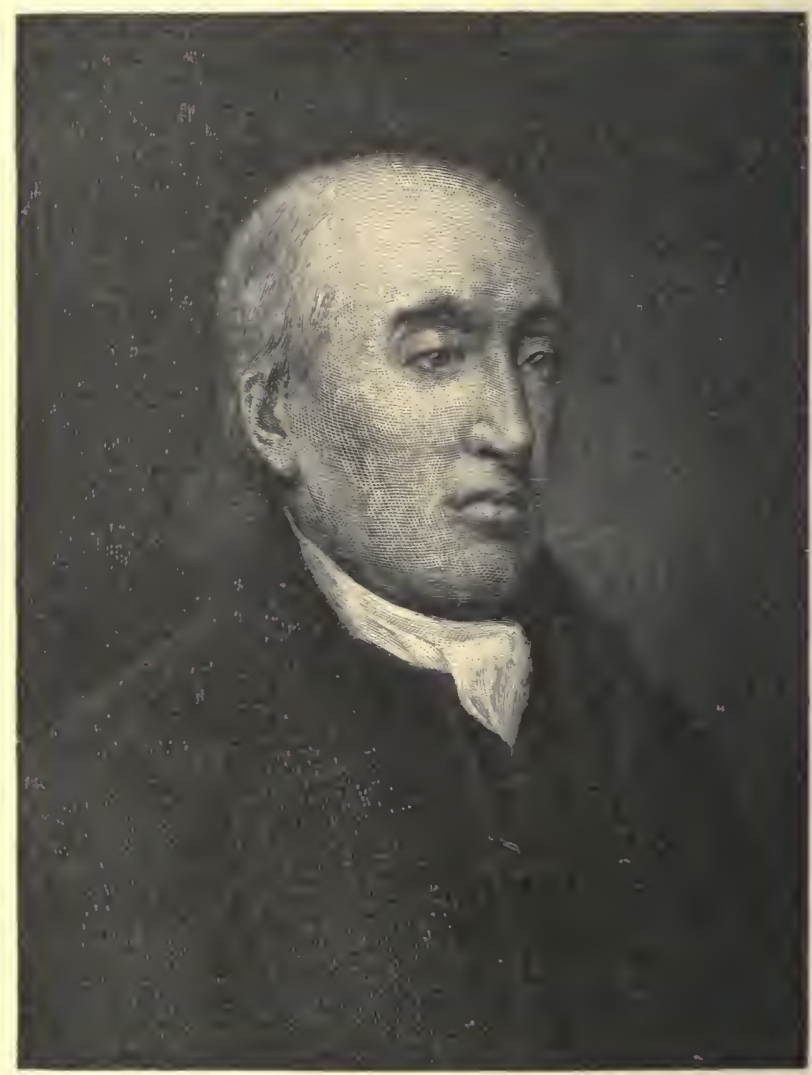

JAMES HUTTON

Whaterer important changes in the general character of the surface of the globe were conceived to have taken place since its creation were generally associated with the Mosaic deluge, and the theories which attempted to explain this catastrophe were quite on a par with those which dealt with a remoter period of the earth's history. 
Some speculators, holding that the interior of the globe is a great abyss of waters, conceived that the crust had dropped into this chasm and had thus been inundated. Others beld that the earth had originally revolved on a rertical axis, and that the sudden change to its present position had caused the catastrophic shifting of its oceans. But perhaps the favorite theory was that which supposed a comet to have wandered near the earth, and in whirling about it to have carried the waters, through gravitation, in a rast tide orer the continents.

Thus blindly groped the majority of eighteenth-century philosophers in their attempts to study what we now term geology. Deluded by the old deductive methods, they founded not a science, but the ghost of a science, as immaterial and as unlike anything in nature as any other phantom that conld be conjured from the depths of the speculative imagination. And all the while the beckoning earth lay beneath the feet of these visionaries; but their eyes were fixed in air.

At last, howerer, there came a man who had the penetration to see that the phantom science of geology needed before all else a body corporeal, and who took to himself the task of supplying it. This was Dr. James Hutton, of Edinburgh, physician, farmer, and manufacturing chemist; patient, enthusiastic, lerel-headed derotee of science. Inspired by his love of chemistry to study the character of rocks and soils, II utton had not gone far before the earth stood revealed to him in a new light. He saw, what generations of predecessors had blindly refused to see, that the face of nature everywhere, instead of being rigid and immutable, is perennially plastic, and year by year is undergoing metamorphic 


\section{THE STORY OF NINETEENTH-CENTURY SCIENCE}

changes. The solidest rocks are day by day disintegrated, slowly, but none the less surely, by wind and rain and frost, by mechanical attrition and chemical decomposition, to form the pulverized earth and clay. This soil is being swept away by perennial showers, and carried off to the oceans. The oceans themselves beat on their shores, and eat insidiously into the structure of sands and rocks. Everywhere, slowly but surely, the surface of the land is being worn away; its substance is being carried to burial in the seas.

Should this denudation continue long enough, thinks Hutton, the entire surface of the continents must be worn away. Should it be continued long enough! And with that thought there flashes on his mind an inspiring conception-the idea that solar time is long, indefinitely long. That seems a simple enough thought-almost a truism - to the nineteenth-century mind; but it required genius to conceive it in the eighteenth. Hutton pondered it, grasped its full import, and made it the basis of his hypothesis, his "theory of the earth."

The hypothesis is this-that the observed clanges of the surface the earth, continued through indefinite lapses of time, must result in conveying all the land at last to the sea; in wearing continents away till the oceans overflow them. What then? Why, as the continents wear down, the oceans are filling up. Along their bottoms the detritus of wasted continents is deposited in strata, together with the bodies of marine animals and vegetables. Why might not this débris solidify to form layers of rocks-the basis of new continents? Why not, indeed?

But have we any proof that such formation of rocks in an ocean-bed has, in fact, occurred? To be sure we 
have. It is furnished by every bed of limestone, every outcropping fragment of fossil-bearing rock, every stratified cliff. How else than through such formation in an ocean-bed came these rocks to be stratified? How else came they to contain the shells of once living organisms emberded in their depths? The ancients, finding fossil shells embedded in the rocks, explained them as mere freaks of "nature and the stars." Less superstitious generations had repudiated this explanation, but had failed to give a tenable solution of the mystery. To Hutton it is a mystery no longer. To him it seems clear that the basis of the present continents was laid in ancient sea-beds, formed of the detritus of continents yet more ancient.

But two links are still wanting to complete the chain of Hutton's hypothesis. Through what agency has the ooze of the ocean-bed been transformed in to solid rock? And through what agency has this rock been lifted above the surface of the water, to form new continents? Hutton looks about him for a clew, and soon he finds it. Everywhere about us there are outcropping rocks that are not stratified, but which give evidence to the observant eye of having once been in a molten state. Different minerals are mixed together; pebbles are scattered through masses of rock like plums in a pudding; irregular crevices in otherwise solid masses of rock-so-called veinings-are seen to be filled with equally solid granite of a different variety, which can have gotten there in no conceivable way, so Hutton thinks, but by running in while molten, as liquid metal is run into the moulds of the founder. Even the strati. fied rocks, though they seemingly have not been melted, give evidence in some instances of having been sub- 


\section{THE STORY OF NINETEENTH-CENTURY SCIENCE}

jected to the action of heat. Marble, for example, is clearly nothing but calcined limestone.

With such evidence before him, Hutton is at no loss to complete his hypothesis. The agency which has solidified the ocean-beds, he says, is subterranean heat. The same agency, acting excessively, has produced rolcanic cataclysms, upheaving ocean-beds to form continents. The rugged and uneren surfaces of mountains, the tilted and broken character of stratified rocks everywhere, are the standing witnesses of these gigantic upheavals.

And with this the imagined cycle is complete. The continents, worn a way and carried to the sea by the action of the elements, have been made orer into rocks again in the ocean-beds, and then raised once more into continents. And this massive cycle, in Hutton's scheme, is supposed to have occurred not once only, but orer and over again, times without number. In this unique view ours is indeed a world without beginning and without end its continents have been making and unmaking in endless series since time began.

Hutton formulated his hypothesis while yet a young man, not long after the middle of the century. He lirst gave it publicity in 1781 , in a paper before the Royal Society of Edinburgh, a paper which at the moment neither friend nor foe deigned to notice. It was not published in book form till the last decade of the century, when Hutton had lired with and worked orer his theory for almost fifty year's. Then it caught the eye of the world. A school of followers expounded the IIuttonian doctrines; a rival school, under Werner, in Germany, opposed some details of the hypothesis; and the educated world as a whole riewed disputants askance. The very novelty of the new views forbade their 
immediate acceptance. Bitter attacks were made upon the "heresies," and that was meant to be a soberly tempered judgment which in 1800 pronounced Hutton's theories "not only hostile to sacred history, but equally hostile to the principles of probability, to the results of the ablest observations on the mineral kingdom, and to the dictates of rational philosophy." And all this because Hutton's theory presupposed the earth to have been in existence more than six thousand years.

Thus it appears that though the thoughts of men had widened, in these closing days of the eighteenth century, to include the stars, they had not as yet expanded to receive the most patent records that are written everywhere on the surface of the earth. Before Hutton's views could be accepted, his pivotal conception that time is long must be established by convincing proofs. The evidence was being gathered by William Smith, Cuvier, and other devotees of the budding science of paleontology in the last days of the century, but the record of their completed labors belongs to another epoch.

\section{IV}

The eighteenth-century philosopher made great strides in his studies of the physical properties of mat. ter, and the application of these properties in mechanics, as the steam-engine, the balloon, the optic telegraph, the spinning-jenny, the cotton-gin, the chronometer, the perfected compass, the Leyden jar, the lightning-rod, and a host of minor inventions testify. In a speculative way he had thought out more or less tenable conceptions as to the ultimate nature of matter, as witness the theories of Leibnitz and Boscovich and Davy, to which 


\section{THE STORY OF NINETEENTH-CENTURY SCIENCE}

we may recur. But he had not as yet conceived the notion of a distinction between matter and energy, which is so fundamental to the physics of a later epoch. He did not speak of heat, light, electricity, as forms of energy or "force"; he conceived them as subtile forms of matter-as highly attenuated yet tangible fluids, subject to gravitation and chemical attraction; though he had learned to measure none of them but heat with accuracy, and this one he could test only within narrow limits until late in the century, when Josiah Wedgwood, the famous potter, taught him to gauge the highest temperatures with the clay pyrometer.

He spolie of the matter of heat as being the most universally distributed fluid in nature; as entering in some degree into the composition of nearly all other substances; as being sometimes liquid, sometimes condensed or solid, and as having weight that could be detected with the balance. Following Newton, he spolie of light as a "corpuscular emanation" or fluid, composed of shining particles which possibly are transmutable into particles of heat, and which enter into chemical combination with the particles of other forms of matter. Electricity he considered a still more subtile kind of matter-perhaps an attenuated form of light. Magnetism, "vital fluid," and by some even a "gravic fluid," and a fluid of sound, were placed in the same scale; and talien together, all these supposed subtile forms of matter were classed as "imponderables."

This view of the nature of the "imponderables" was in some measure a retrogression, for many serenteenthcentury philosophers, notably Hooke and Iluygens and Boyle, had held more correct views; but the materialistic conception accorded so well with the eighteenth- 


\section{SCIENCE AT THE BEGINNING OF THE CENTURY}

century tendencies of thought that only here and there a philosopher, like Euler, called it in question, until well on towards the close of the century. Current speech referred to the materiality of the "imponderables" unlquestioningly. Students of meteorology - a science that was just dawning-explained atmospheric phenomena

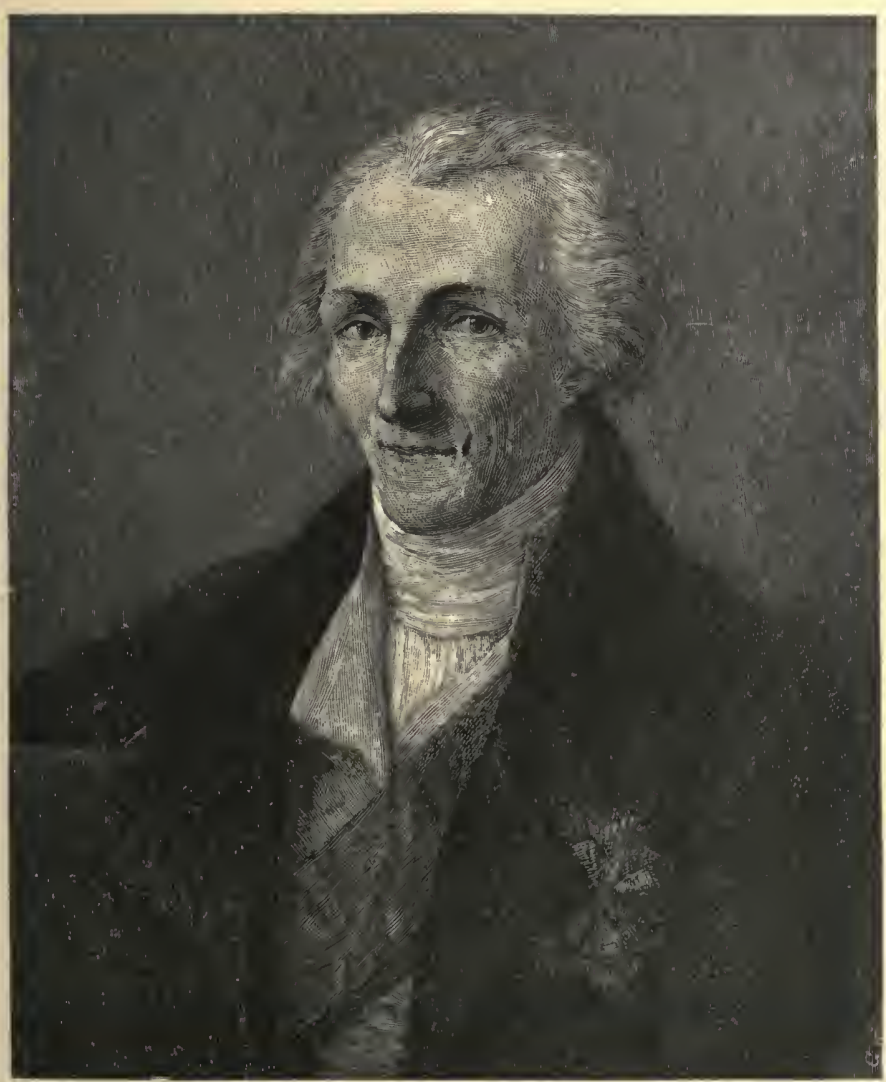

BENJAMIN THOMPSON-COUNT RUMFORD 


\section{THE STORY OF NINETEENTH-CENTURY SCIENCE}

on the supposition that heat, the heaviest imponderable, predominated in the lower atmosphere, and that light, electricity, and magnetism prevailed in successively higher strata. And Lavoisier, the most philosophical chemist of the century, retained heat and light on a par with oxygen, hydrogen, iron, and the rest, in his list of elementary substances.

But just at the close of the century the confidence in the status of the imponderables was rudely shaken in the minds of philosophers by the revival of the old idea of Fra Paolo and Bacon and Boyle, that heat, at any rate, is not a material fluid, but merely a mode of motion or vibration among the particles of "ponderable" matter. The new champion of the old doctrine as to the nature of heat was a very distinguished philosopher and diplomatist of the time, who, it may be worth recalling, was an American. He was a sadly expatriated American, it is true, as his name, given all the official appendages, will amply testify; but he had been born and reared in a Massachusetts village none tlie less, and he seems always to have retained a kindly interest in the land of his nativity, even though he lived abroad in the service of other powers during all the later years of his life, and was knighted by England, ennobled by Bavaria, and honored by the most distinguished scientific bodies of Europe. The American, then, who championed the ribratory theory of heat, in opposition to all current opinion, in this closing era of the eighteenth century, was Lieutenant-General Sir Benjamin Thompson, Count Rumford, F. R. S.

Rumford showed that heat may be produced in indefinite quantities by friction of bodies that do not themselves lose any appreciable matter in the process, 
and claimed that this proves the immateriality of heat. Later on he added force to the argument by proving, in refutation of the experiments of Bowditch, that no body either gains or loses weight in virtue of being heated or cooled. He thought it proved that heat is only a mode of motion.

But contemporary judgment, while it listened respectfully to Rumford, was little minded to accept his verdict. The cherished beliefs of a generation are not to be put down with a single blow. Where many minds have a similar drift, however, the first blow may precipitate a general conflict; and so it was here. Young Humphry Dary had duplicated Rumford's experiments, and reached similar conclusions; and soon others fell into line. Then, in 1800, Dr. Thomas Young-"Phenomenon Young" they called him at Cambridge, because he was reputed to know everything-took up the cudgels for the vibratory theory of light, and it began to be clear that the two "imponderables," heat and light, must stand or fall together" but no one as yet made a claim against the fluidity of electricity.

But before this speculative controversy over the nature of the "imponderables" had made more than a fair beginning, in the last year of the century, a discovery was announced which gave a new impetus to physical science, and for the moment turned the current of speculation into another channel. The inventor was the Italian scientist Volta; his invention, the apparatus to be known in future as the roltaic pile-the basis of the galvanic battery. Ten years earlier Galvani had discovered that metals placed in contact have the power to excite contraction in the muscles of animals apparently dead. Working along lines suggested by this discovery, 


\section{THE STORY OF NINEYEENTH-CENTURY SCIENCE}

Volta developed an apparatus composed of two metals joined together and acted on by chemicals, which appeared to accumulate or store up the galvanic influence, whatever it might be. The effect could be accentuated by linking together several such "piles" into a "battery."

This invention took the world by storm. Nothing like the enthusiasm it created in the philosophic world had been known since the invention of the Leyden jar, more than half a century before. Within a few weeks after Volta's announcement, batteries made according to his plan were being experimented with in every important laboratory in Europe. The discovery was made in March. Early in May two Englishmen, Messrs. Nicholson and Carlyle, practising with the first battery made in their country, accidentally discovered the decomposition of water by the action of the pile. And thus in its earliest infancy the new science of "galvanism" had opened the way to another new science-electro-chemistry.

As the century closed, half the philosophic world was speculating as to whether "galvanic influence" were a new imponderable or only a form of electricity; and the other half was eagerly seeking to discover what new marrels the battery might reveal. The least imaginative man could see that here was an invention that would be epoch-making, but the most visionary dreamer could not even vaguely adumbrate the real measure of its importance. Hitherto electricity had been only a laboratory aid or a toy of science, with no suggestion of practical utility beyond its doubtful application in medicine; in future, largely as the outgrowth of Volta's discovery, it - was destined to become a great economic 
agency, whose limitations not eren the enlarged vision of our later century can pretend to outline.

Of all the contests that were waging in the rarious fields of science in this iconoclastic epoch, perhaps the fiercest and most turbulent was that which fell within the field of chemistry. Indeed, this was one of the most memorable warfares in the history of polemics. It was a battle veritably Napoleonic in its inception, scope, and incisiveness. As was fitting, it was a contest of France against the world; but the Napoleonic parallel fails before the end, for in this case France won not only speedily and uncompromisingly, but for all time.

The main point at issue concerned the central doctrine of the old chemistry-the doctrine of Becher and Stahl, that the only combustible substance in nature is a kind of matter called phlogiston, which enters into the composition of other bodies in varying degree, thus determining their inflammability. This theory seems crucle enough now, since we know that phlogiston was a purely fictitious element, yet it served an excellent purpose when it was propounded and it held its place as the central doctrine of chemical philosophy for almost a century.

At the time when this theory was put forward, it must be recalled, the old Aristotelian idea that the four primal elements are earth, air, fire, and water still held sway as the working foundation of all chemical philosophies. Air and water were accepted as simple bodies. Only a few acids and alkalies were known, and these but imperfectly; and the existence of gases as we now 


\section{THE S'TORY OF NINETEENTH-CENTURY SCIENCE}

know them, other than air, was hardly so much as suspected. All the known facts of chemistry seemed then

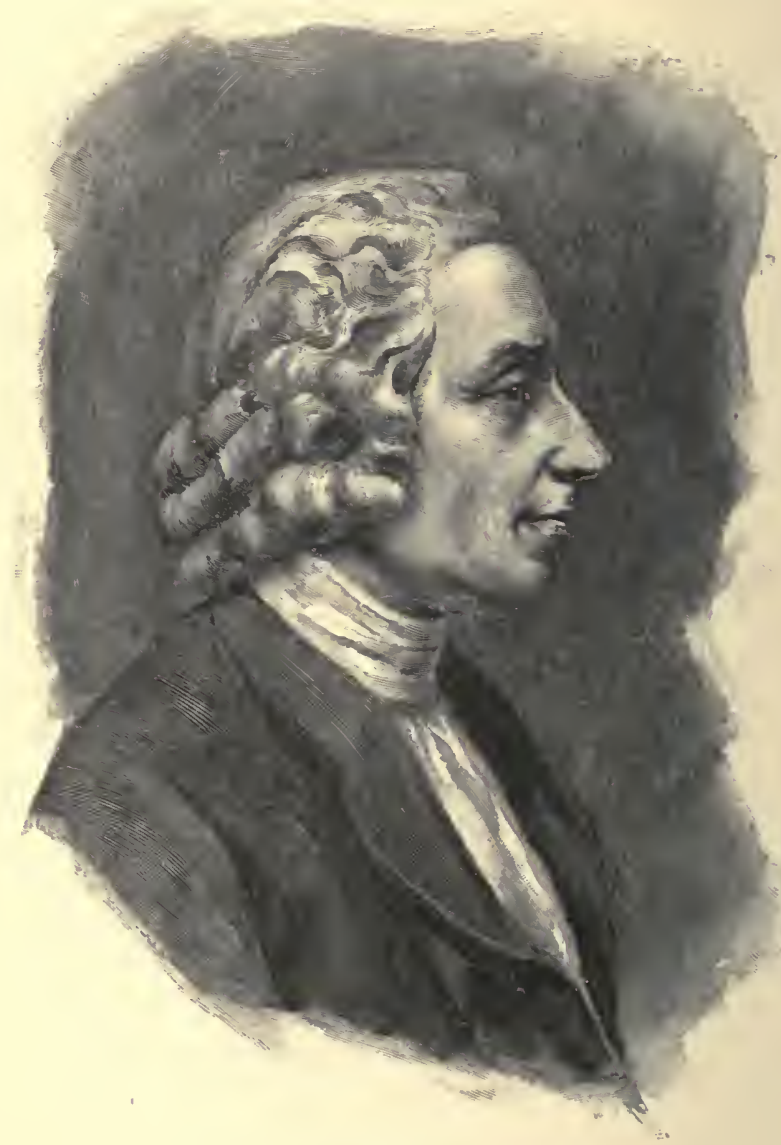

JOSEPII PIIESTLY

to harmonize with the phlogiston hypothesis; and so, later on, did the new phenomena which were discorered 
in such profusion during the third quarter of the eighteenth century - the epoch of pneumatic chemistry. Hydrogen gas, discovered by Cavendish in 1776 , and called inflammable air, was thought by some chemists to be the very principle of phlogiston itself. Other "airs" were adjudged "dephlogisticated" or "phlogisticated," in proportion as they supported or failed to support combustion. The familiar fact of a candle flame going out when kept in a confined space of ordinary air was said to be due to the saturation of this air with phlogiston. And all this seemed to tally beautifully with the prevailing theory.

But presently the new facts began, as new facts always will, to develop an iconoclastic tendency. The phlogiston theory had dethroned fire from its primacy as an element by alleging that flame is due to a union of the element heat with the element phlogiston. Now earths were decomposed, air and water were shown to be compound bodies, and at last the existence of phlogiston itself was to be called in question. The structure of the old chemical philosophy had been completely riddled; it was now to be orerthrown. The culminating observation which brought matters to a crisis was the discovery of oxygen, which was made by Priestley in England and Scheele in Sweden, working independently, in the year 177t. Priestley called the new element "dephlogisticated air"; Scheele called it "empyreal air."

But neither Priestley nor Scheele realized the full import of this discovery; nor, for that matter, did any one else at the moment. Very soon, however, one man at least had an inkling of it. This was the great French chemist Antoine Laurent Lavoisier. It has sometimes been claimed that he bimself discovered oxygen inde- 


\section{THE STORY OF NINETEENTH-CENTURY SCIENCE}

pendently of Priestley and Scheele. At all events, he at once began experimenting with it, and very soon it dawned upon him that this remarkable substance might furnish a key to the explanation of many of the puzzles of chemistry. He found that oxygen is consumed or transformed during the combustion of any substance in air. He reviewed the phenomena of combustion in the light of this new knowledge. It seemed to him that the new element explained them all without aid of the supposititious element phlogiston. What proof, then, have we that phlogiston exists? Very soon he is able to answer that there is no proof, no reason to believe that it exists. Then why not denounce phlogiston as a myth, and discard it from the realm of chemistry?

Precisely this is what Lavoisier purposes to do. He associates with him three other famous French chemists, Berthollet, Guyton de Morveau, and Fourcroy, and sets to work to develop a complete system of chemistry based on the new conception. In 1788 the work is completed and given to the world. It is not merely an epoch-making book; it is rerolutionary. It discards phlogiston altogether, alleging that the elements really concerned in combustion are oxygen and heat. It claims that acids are compounds of oxygen with a base, instead of mixtures of "earth" and water; that metals are simple elements, not compounds of "earth" and "phlogiston"; and that water itself, like air, is a compound of oxygen with another element.

In applying these ideas the new system proposes an altogether new nomenclature for chemical substances. Hitherto the terminology of the science has been a matter of whim and caprice. Such names as "liver of sulphur," "mercury of life," "horned moon," "the double 32 . 
secret," "the salt of many virtues," and the like, have been accepted without protest by the chemical world. With such a terminology continued progress was as impossible as human progress without speech. The new chemistry of Lavoisier and his confrères, following the model set by zoology half a century earlier, designates each substance by a name instead of a phrase, applies these names according to fixed rules, and, in short, classifies the chemical knowledge of the time and brings it into a system, lacking which no body of knowledge has full title to the name of science.

Though Lavoisier was not alone in dereloping this revolutionary scheme, posterity remembers him as its originator. His dazzling and comprehensive genius obscured the feebler lights of his confrères. Perhaps, too, his tragic fate was not without influence in augmenting his posthumous fame. In 1794 he fell by the guillotine, guiltless of any crime but patriotism-a victim of the "Reign of Terror." "The Republic has no need of savants," remarked the functionary who signed the death-warrant of the most famous chemist of the century.

The leader of the reform morement in chemistry thus died at the hands of bigotry and fanaticismrather, let us say, as the victim of a national frenzywhile the cause he championed was young, yet not too soon to see the victory as good as won. The main body of French chemists had accepted the new doctrines almost from the first, and elsewhere the opposition had been of that fierce, eager type which soon exhausts itself in the effort. At Berlin they began by burning Lovoisier in effigy, but they ended speedily by accepting the new theories. In Fngland the fight was more stubborn, 
but equally decisive. At first the new chemistry was opposed by such great men as Black, of "latent heat" fame ; Rutherford, the discorerer of nitrogen; and Cavendish, the inventor of the pneumatic trough and the discoverer of the composition of water, not to mention a caterie of lesser lights; but one by one they warered and went over to the enemy. Oddly enough, the doughtiest and most uncompromising of all the champions of the old "phlogistic" ideas was Dr. Priestley, the very man whose discorery of oxygen had pared the way for the "antiphlogistic" morement-a fact which gave rise to Curier's remark that Priestley was undoubtedly one of the fathers of modern chemistry, but a father who never wished to recognize his daughter.

A most extraordinary man was this Dr. Priestley. Dary said of him, a generation later, that no other person erer discovered so many new and curious substances as he; yet to the last he was only an amateur in science, his profession being the ministry. There is hardly another case in history of a man not a specialist in science accomplishing so much in original research as did Joseph Priestley, the chemist, physiologist, electrician; the mathematician, logician, and moralist; the theologian, mental philosopher, and political economist. He took all knowledge for his field; but how he found time for his numberless researches and multifarious trritings, along with his every-day duties, must ever remain a mystery to ordinary mortals.

That this marvellously receptive, flexible mind should have refused acceptance to the clearly logical doctrines of the new chemistry seems equally inexplicable. But so it was. To the very last, after all his friends had capitulated, Priestley kept up the fight. From America, 
whither he had gone to live in 1794, he sent out the last defy to the enemy in 1800 , in a brochure entitled "The Doctrine of Phlogiston Upheld," etc. In the mind of its author this was little less than a pæan of victory; but all the world besides knew that it was the swansong of the doctrine of phlogiston. Despite the defiance of this single warrior the battle was really lost and won, and as the century closed, "antiphlogistic" chemistry had practical possession of the field.

Several causes conspired to make exploration all the fashion during the closing epoch of the eighteenth cen. tury. New aid to the navigator had been furnished by the perfected compass and quadrant, and by the invention of the chronometer; medical science had banished scurvy, which hitherto had been a perpetual menace to the voyager; and, above all, the restless spirit of the age impelled the venturesome to seek novelty in fields altogether new. Some started for the pole, others tried for a northeast or northwest passage to India, yet others sought the great fictitious antarctic continent told of by tradition. All these of course failed of their immediate purpose, but they added much to the world's store of knowledge and its fund of travellers' tales.

Among all these tales none was more remarkable than those which told of strange living creatures found in antipodal lands. And here, as did not happen in every field, the narratives were often substantiated by the exhibition of specimens that admitted no question. Many a company of explorers returned more or less laden with such trophies from the animal and vegetable 


\section{THE STORY OF NINETEENTH-CENTURY SCIENCE}

kingdoms, to the mingled astonishment, delight, and bewilderment of the closet naturalists. The followers of Linnæus in the "golden age of natural history," a few decades before, had increased the number of known species of fishes to about 400 , of birds to 1000 , of insects to 3000 , and of plants to 10,000 . But now these sudden accessions from new territories doubled the figure for plants, tripled it for fish and birds, and brought the number of described insects above 20,000.

Naturally enough, this wealth of new material was sorely puzzling to the classifiers. The more discerning began to see that the artificial system of Linnæus, wonderful and useful as it had been, must be advanced upon before the new material could be satisfactorily disposed of. The way to a more natural system, based on less arbitrary signs, had been pointed out by Jussieu in botany, but the zoologists were not prepared to make headway towards such a system until they should gain a wider understanding of the organisms with which they had to deal through comprehensive studies of anatomy. Such studies of individual forms in their relations to the entire scale of organic beings were pursued in these last decades of the century, but though two or three most important generalizations were achieved (notably Kaspar Wolff's conception of the cell as the basis of organic life, and Goethe's all-important doctrine of metamorphosis of parts), yet, as a whole, the work of the anatomists of the period was germinative rather than fruit-bearing. Bichat's volumes, telling of the recognition of the fundamental tissues of the body, did not begin to appear till the last year of the century. The announcement by Cuvier of the doctrine of correlation of parts bears the same date, but in general the studies of this great nat- 


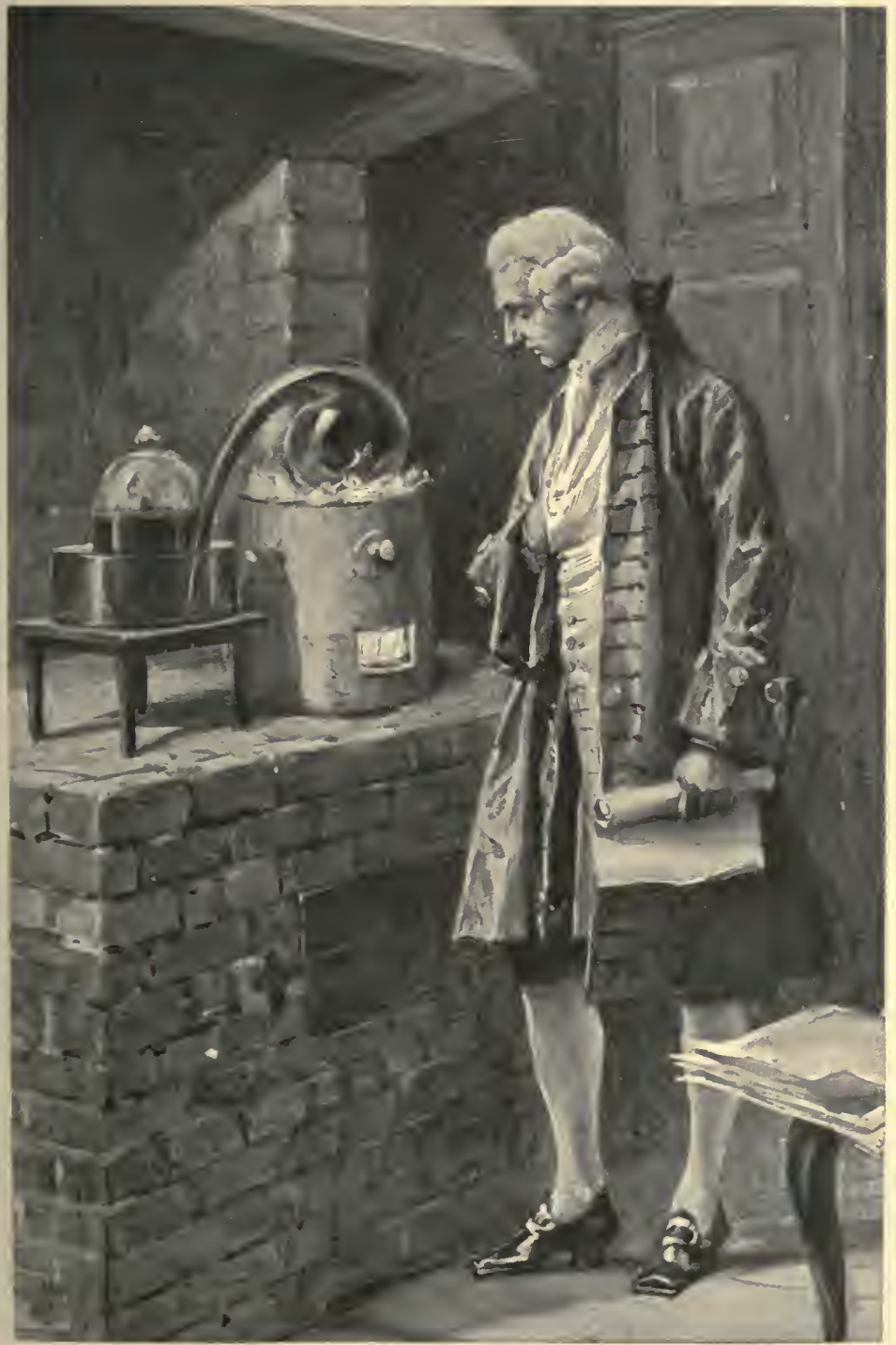

LAVOISIER IN HIS LABORATORY 

uralist, which in due time were to stamp him as the successor of Linnæus, were as yet only fairly begun.

In the field of physiology, on the other hand, two most important works were fairly consummated in this epoch-the long-standing problems of digestion and respiration were solved, almost coincidently. Two very distinguished physiologists share the main honors of discovery in regard to the function of digestion-the Abbe Spallanzani, of the University of Paria, Italy, and John Hunter, of England. Working independently, these investigators showed at about the same time that digestion is primarily a chemical rather than a mechanical process. It is a curious commentary on the crude notions of mechanics of previous generations that it should have been necessary to prove by experiment that the thin, almost membranous stomach of a mammal has not the power to pulverize, by mere attrition, the foods that are taken into it. However, the proof was now for the first time forthcoming, and the question of the general character of the function of digestion was forever set at rest.

To clear up the mysteries of respiration was a task that fell to the lot of chemistry. The solution of the problem followed almost as a matter of course upon the advances of that science in the latter part of the century. Hitherto no one since Mayow, of the previous century, whose flash of insight had been strangely overlooked and forgotten, had even vaguely surmised the true function of the lungs. The great Boerhaave had supposed that respiration is chiefly important as an aid to the circulation of the blood; his great pupil, Haller, had believed to the day of his death in 1777 that the main purpose of the function is to form the voice. No genius could hope to fathom the mystery of the lungs so long as air was supposed to 


\section{THE STORY OF NINETEENTH-CENTURY SCIENCE}

be a simple element, serving a mere mechanical purpose in the economy of the earth.

But the discorery of oxygen gave the clew, and very soon all the chemists were testing the air that came from the lungs-Dr. Priestley, as usual, being in the van. His initial experiments were made in 1777 , and from the outset the problem was as good as solved. Other experimenters confirmed his results in all their essentials-notably Scheele and Lavoisier and Spallanzani and Davy. It was clearly established that there is chemical action in the contact of the air with the tissue of the lungs; that some of the oxygen of the air disappears, and that carbonic acid gas is added to the inspired air. It was shown, too, that the blood, having come in contact with the air, is changed from black to red in color. These essentials were not in dispute from the first. But as to just what chemical changes caused these results was the subject of controversy. Whether, for example, oxygen is actually absorbed into the blood, or whether it merely unites with carbon given off from the blood, was long in dispute.

Each of the main disputants was biassed by his own particular views as to the moot points of chemistry. Lavoisier, for example, believed oxygen gas to be composed of a metal oxygen combined with the alleged element heat; Dr. Priestley thought it a compound of positive electricity and phlogiston; and Humplry Dary, when he entered the lists, a little later, supposed it to be a compound of oxygen and light. Such mistaken notions naturally complicated matters, and delayed a complete understanding of the chemical processes of respiration. It was some time, too, before the idea gained acceptance that the most important chemical changes 
do not occur in the lungs themselves, but in the ultimate tissues. Indeed, the matter was not clearly settled at the close of the century. Nevertheless, the problem of respiration had been solved in its essentials. Moreover, the vastly important fact had been established that a process essentially identical with respiration is necessary to the existence not only of all creatures supplied with lungs, but to fishes, insects, and eren vegetables - in short, to every kind of living organism.

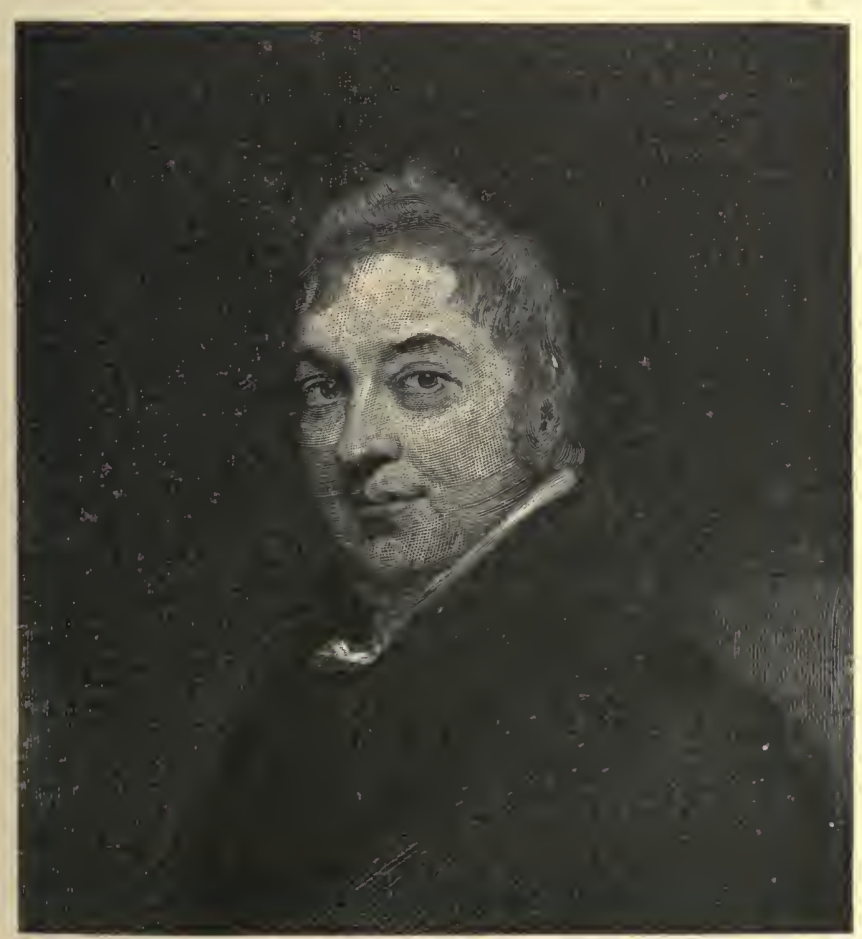

EDWARD JENNER

From the painting by Sir Thomas Jawrence 


\section{THE STORY OF NINETEENTH-CENT'URY SCIENCE}

All advances in science have a bearing, near or remote, on the welfare of our race; but it remains to credit to the closing decade of the eighteenth century a discovery which, in its power of direct and immediate benefit to humanity, surpasses any other discovery of this or any previous epoch. Needless to say I refer to Jenner's discovery of the method of preventing smallpox by inoculation with the virus of cow-pox. It detracts nothing from the merit of this discorery to say that the preventive power of accidental inoculation had long been rumored among the peasantry of England. Such vague, unavailing half-knowledge is often the forerunner of fruitful discovery. To all intents and purposes Jenner's discovery was original and unique. Neither, considered as a perfected method, was it in any sense an accident. It was a triumph of experimental science; how great a triumph it is difficult now to understand, for we of to-day can only vaguely realize what a ruthless and ever-present scourge small-pox had been to all previous generations of men since history began. Despite all efforts to check it by medication and by direct inoculation, it swept now and then over the earth as an alldevastating pestilence, and year by year it claimed onetenth of all the beings in Christendom by death as its average quota of victims. "From small-pox and love but few remain free," ran the old saw. A pitted face was almost as much a matter of course a hundred years ago as a smonth one is to-day.

Little wonder, then, that the world gave eager acceptance to Jenner's discovery. The first vaccination was made in 1796. Before the close of the century the method was practised everywhere in Christendom. No urging was needed to induce the majority to give it 


\section{SCIENCE AT THE BEGINNING OF THE CENTURY}

trial; passengers on a burning ship do not hold aloof from the life-boats. Rich and poor, high and low, sought succor in vaccination, and blessed the name of their deliverer. Of all the great names that were before the world in the closing days of the century, there was perhaps no other one at once so widely known and so uniformly reverenced as that of the English physician Edward Jenner. Surely there was no other one that should be recalled with greater gratitude by posterity. 


\section{CHAPTER II}

\section{THE CENTURY'S PROGRESS IN ASTRONOMY}

\section{I}

The first day of our century was fittingly signalized by the discovery of a new world. On the erening of January 1, 1801, an Italian astronomer, Piazzi, observed an apparent star of about the eighth magnitude (hence, of course, quite invisible to the unaided eye), which later on was seen to have moved, and was thus shown to be vastly nearer the earth than any true star. He at first supposed, as Herschel had done when he first saw Uranus, that the unfamiliar body was a comet; but later observation proved it a tiny planet, occupying a position in space between Mars and Jupiter. It was christened Ceres, after the tutelary goddess of Sicily.

Though unpremeditated, this discovery was not unexpected, for astronomers had long surmised the existence of a planet in the wide gap between Mars and Jupiter. Indeed, they were eren preparing to make concerted search for it, despite the protests of philosophers, who argued that the planets could not possibly exceed the magic number seven, when Piazzi forestalled their efforts. But a surprise came with the sequel; for the very next year Dr. Olbers, the wonderful physicianastronomer of Bremen, while following up the course of 


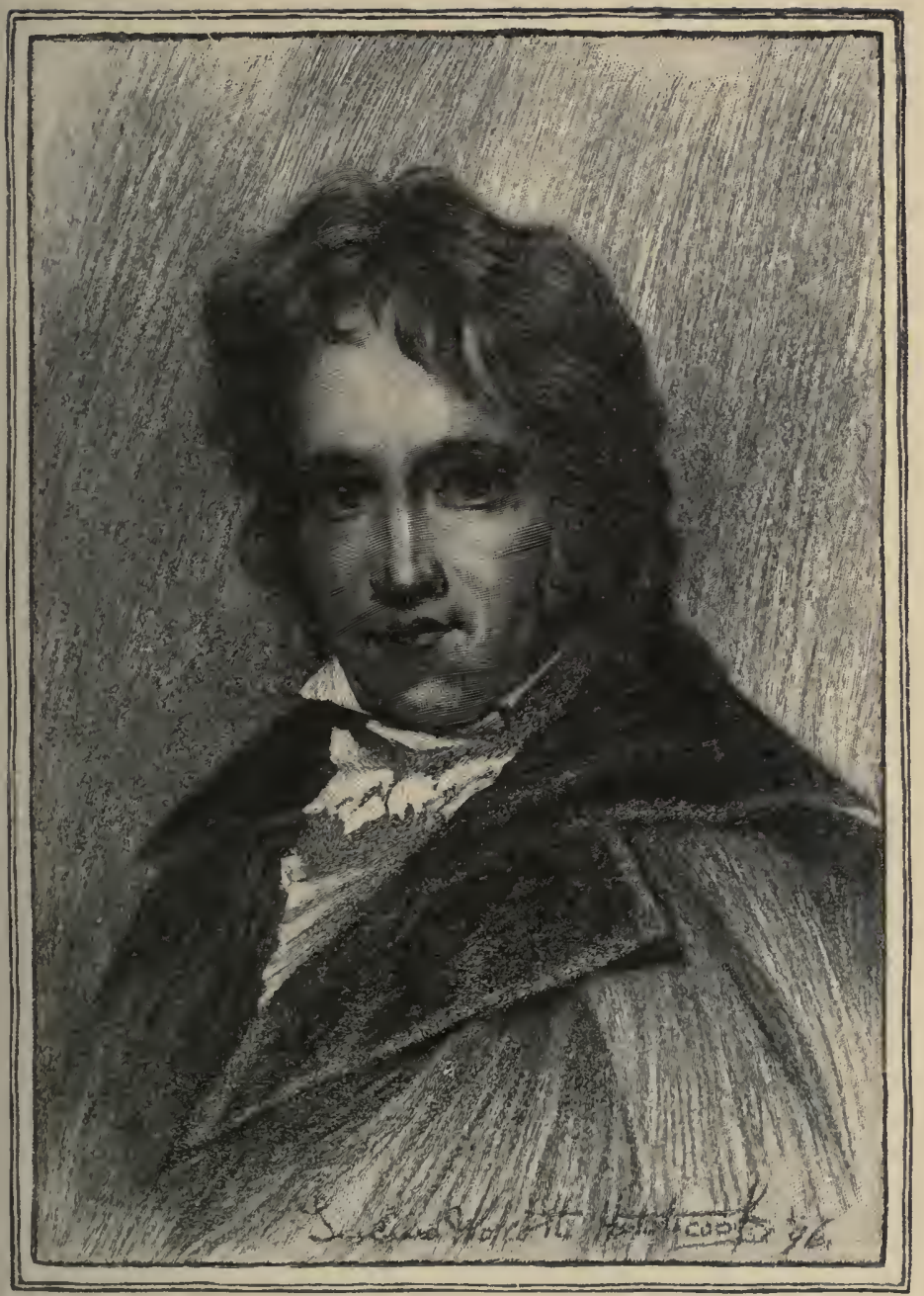

FRIEDRICH WILHELM BESSEL 

Ceres, happened on another tiny moving star, similarly located, which soon revealed itself as planetary. Thus two planets were found where only one was expected.

The existence of the supernumerary was a puzzle, but Olbers solved it for the moment by suggesting that Ceres and Pallas, as he called his captive, might be fragments of a quondam planet, shattered by internal explosion, or by the impact of a comet. Other similar fragments, he ventured to predict, would be found when searched for. William Herschel sanctioned this theory, and suggested the name asteroids for the tiny planets. The explosion theory was supported by the discovery of another asteroid, by Harding, of Lilienthal, in 1804, and it seemed clinched when Olbers himself found a fourth in 1807. The new-comers were named Juno and Vesta respectively.

There the case rested till 1845, when a Prussian amateur astronomer named Hencke found another asteroid, after long searching, and opened a new epoch of discovery. From then on the finding of asteroids became a commonplace. Latterly, with the aid of photography, the list has been extended to above four hundred, and as yet there seems no dearth in the supply, though doubtless all the larger members have been revealed. Even these are but a few hundreds of miles in diameter, while the smaller ones are too tiny for measurement. The combined bulk of these minor planets is believed to be but a fraction of that of the earth.

Olbers's explosion theory, long accepted by astronomers, has been proven open to fatal objections. The minor planets are now believed to represent a ring of cosmical matter, cast off from the solar nebula like the rings that went to form the major planets, but prevented 
from becoming aggregated into a single body by the perturbing mass of Jupiter.

As we have seen, the discovery of the first asteroid confirmed a conjecture; the other important planetary discovery of our century fulfilled a prediction. Neptune was found through scientific prophecy. No one suspected the existence of a trans-Uranian planet till Uranus itself, by hair-breadth departures from its predicted orbit, gave out the secret. No one saw the disturbing planet till the pencil of the mathematician, with almost occult divination, had pointed out its place in the heavens. The general predication of a transUranian planet was made by Bessel, the great Königsberg astronomer, in 1840; the analysis that revealed its exact location was undertaken, half a decade later, by two independent workers-John Couch Adanis, just graduated senior wrangler at Cambridge, England, and U. J. J. Leverrier, the leading French mathematician of his generation.

Adams's calculation was first begun and first completed. But it had one radical defect-it was the work of a young and untried man. So it found lodgment in a pigeon-hole of the desk of England's Astronomer Royal, and an opportunity was lost which English astronomers have never ceased to mourn. Had the search been made, an actual planet would have been seen shining there, close to the spot where the pencil of the mathematician had placed its hypothetical counterpart. But the search was not made, and while the prophecy of Adams gathered dust in that regrettable pigeon-hole, Leverrier's calculation was coming on, his tentative results meeting full encouragement from Arago and other French savants. At last the laborious calculations 
proved satisfactory, and, confident of the result, Leverrier sent to the Berlin observatory, requesting that search be made for the disturber of Uranus in a particular spot of the hearens. Dr. Galle received the request September $23,18+6$. That very night he turned his telescope to the inclicated region, and there, within a single degree of the suggested spot, he saw a seeming star, invisible to the unaided eye, which proved to be the long-sought planet, henceforth to be known as Neptune. To the average mind, which finds something altogether mystifying about abstract mathematics, this was a feat savoring of the miraculous.

Stimulated by this success, Leverrier calculated an orbit for an interior planet from perturbations of Mercury, but though prematurely christened Vulcan, this hypothetical nurseling of the sun still haunts the realm of the undiscovered, along with certain equally hypothetical trans-Neptunian planets whose existence has been suggested by "resiclual perturbations" of Uranus, and by the movements of comets. No other veritable additions to the sun's planetary family have been made in our century, beyond the finding of seven small moons, which chiefly attest the adrance in telescopic powers. Of these, the tiny attendants of our Martian neighbor, discovered by Professor Hall with the great Washington refractor, are of greatest interest, because of their small size and extremely rapid flight. One of them is poised only 6000 miles from Mars, and whirls about him almost four times as fast as he revolves, seeming thus, as viewed by the Martian, to rise in the west and set in the east, and making the month only one-fourth as long as the day.

The discovery of the inner or clape ring of Saturn, made simultaneously in 1850 by William C. Bond, at 


\section{THE STORY OF NINEIEENTH-CENTURY SCIENCE}

the Harvard observatory, in America, and the Rev. W. R. Dawes in England, was another interesting optical achievement; but our most important advances in knowledge of Saturn's unique system are due to the mathematician. Laplace, like his predecessors, supposed these rings to be solid, and explained their stability as due to certain irregularities of coritour which Herschel had pointed out. But about 1851 Professor Peirce of Harvard showed the untenability of this conclusion, proving that were the rings such as Laplace thought them, they must fall of their own weight. Then Professor J. Clerk Maxwell of Cambridge took the matter in hand, and his analysis reduced the puzzling rings to a cloud of meteoric particles-a "shower of brickbats" each fragment of which circulates exactly as if it were an independent planet, though of course perturbed and jostled more or less by its fellows. Mutual perturbations, and the disturbing pulls of Saturn's orthodox satellites, as investigated by Maxwell, explain nearly all the phenomena of the rings in a manner highly satisfactory.

But perhaps the most interesting accomplishments of mathematical astronomy-from a mundane stand-point, at any rate-are those that refer to the earth's own satellite. That seemingly staid body was long ago discovered to have a propensity to gain a little on the earth, appearing at eclipses an infinitesimal moment ahead of time. Astronomers were sorely puzzled by this act of insubordination; but at last Laplace and Lagrange explained it as due to an oscillatory change in the earth's orbit, thus fully exonerating the moon, and seeming to demonstrate the absolute stability and permanence of our planetary system, which the moon's misbehaviol had appeared to threaten. 
This highly satisfactory conclusion was an orthodox belief of celestial mechanics until 1853, when Professor Adams of Neptunian fame, with whom complex analyses were a pastime, reviewed Laplace's calculation, and discovered an error, which, when corrected, left about half the moon's acceleration unaccounted for. This was a momentous discrepancy, which at first no one could explain. But presently Professor Helmholtz, the great German physicist, suggested that a key might be found in tidal friction, which, acting as a perpetual brake on the earth's rotation, and affecting not merely the waters but the entire substance of our planet, must in the long sweep of time have changed its rate of rotation. Thus the seeming acceleration of the moon might be accounted for as actual retardation of the earth's rotation-a lengthening of the day instead of a shortening of the month.

Again the earth was shown to be at fault, but this time the moon could not be exonerated, while the estimated stability of our system, instead of being re-established, was quite upset. For the tidal retardation is not an oscillatory change which will presently correct itself, like the orbital wobble, but a perpetual change, acting always in one direction. Unless fully counteracted by some opposing reaction, therefore (as it seems not to be), the effect must be cumulative, the ultimate consequences disastrous. The exact character of these consequences was first estimated by Professor G. H. Darwin, in 1879. He showed that tidal friction in retarding the earth must also push the moon out from the parent planet on a spiral orbit. Plainly, then, the moon must formerly have been nearer the earth than at present. At some very remote period it must have actually touched the 


\section{THE STORY OF NINETEENTH-CENTURY SCIENCE}

earth; must, in other words, have been thrown off from the then plastic mass of the earth, as a polyp buds out from its parent polyp. At that time the earth was spinning about in a day of from two to four hours.

Now the day has been lengthened to twenty-four hours, and the moon has been thrust out to a distance of a quarter-million miles; but the end is not yet. The same progress of erents must continue, till, at some remote period in the future, the day has come to equal the month, lunar tidal action has ceased, and one face of the earth looks out always at the moon, with that same fixed stare which even now the moon has been brought to assume towards her parent orb. Should we choose to take even greater liberties with the future, it may be made to appear (though some astronomers dissent from this prediction) that, as solar tidal action still continues, the day must finally exceed the month, and lengthen out little by little towards coincidence with the year; and that the moon meantime must pause in its outwarl flight, and come swinging back on a descending spiral, until finally, after the lapse of untold reons, it ploughs and ricochets along the surface of the earth, and plunges to catastrophic destruction.

But even though imagination pause far short of this direful culmination, it still is clear that modern calculations, based on inexorable tidal friction, suffice to revoJutionize the views formerly current as to the stability of the planetary system. The eighteenth-century mathematician looked upon this system as a vast celestial machine which had been in existence about six thousand years, and which was destined to run on forever. The analyst of to-day computes both the past and the future of this system in millions instead of thousands of years, 


\section{THE CENTURY'S PROGRESS IN ASTRONOMY}

yet feels well assured that the solar system offers no contradiction to those laws of growth and decay which seem everywhere to represent the immutable order of nature.

\section{II}

Until the mathematician ferreted out the secret, it surely never could have been suspected by any one that the earth's serene attendant,

"That orbed maiden, with white fire laden, Whom mortals call the moon,"

could be plotting injury to her parent orb. But there is another inhabitant of the skies whose purposes have not been similarly free from popular' suspicion. Needless to say I refer to the black sheep of the sidereal family, 'that "celestial vagabond" the comet.

Time out of mind these wanderers have been supposed to presage war, famine, pestilence, perhaps the destruction of the world. And little wonder. Here is a body which comes flashing out of boundless space into our system, shooting out a pyrotechnic tail some hundreds of millions of miles in length; whirling perhaps through the very atmosphere of the sun at a speed of three or four hundred miles a second; then darting off on a hyperbolic orbit that forbids it ever to return, or an elliptical one that cannot be closed for hundreds or thousands of years; the tail meantime pointing always away from the sun, and fading to nothingness as the weird royager recedes into the spacial void whence it came. Not many times need the advent of such an apparition coincide with the outbreak of a pestilence, or the death of a Crsar, to stamp the race of comets as an 


\section{THE STURY OF NINETEENTH-CENTURY SCIENCE}

ominous clan in the minds of all snperstitious generations.

It is true a hard blow was struck at the prestige of these alleged supernatural agents when Newton proved that the great comet of 1650 obeyed Kepler's laws in its flight about the sun; and an even harder one when the - same visitant came back in 1758 , obedient to Halley's prediction, after its three-quarters of a century of voyaging out in the abyss of space. Prored thus to bow to natural law, the celestial messenger could no longer fully sustain its rôle. But long-standing notoriety cannot be lived down in a day, and the comet, though proved a "natural" object, was still regarded as a very menacing one for another hundred years or so. It remained for our own century to completely unmask the pretender, and show how egregiously our forebears had been deceived.

The unmasking began early in the century, when Dr. Olbers, then the highest authority on the subject, expressed the opinion that the spectacular tail, which had all along been the comet's chief stock in trade as an earth-threatener, is in reality composed of the most filmy of vapors, repelled from the cometary body by the sun, presumably through electrical action, with a relocity comparable to that of light. This luminous suggestion was held more or less in abeyance for half a century. Then it was elaborated by Zöllner, and particularly by Bredichin, of the Moscow observatory, into what has since been regarded as the most plausible of cometary theories. It is held that comets and the sun are similarly electrified, and hence mutually repulsive. Gravitation vastly outmatches this repulsion in the body of the comet, but yields to it in the case of gases, 


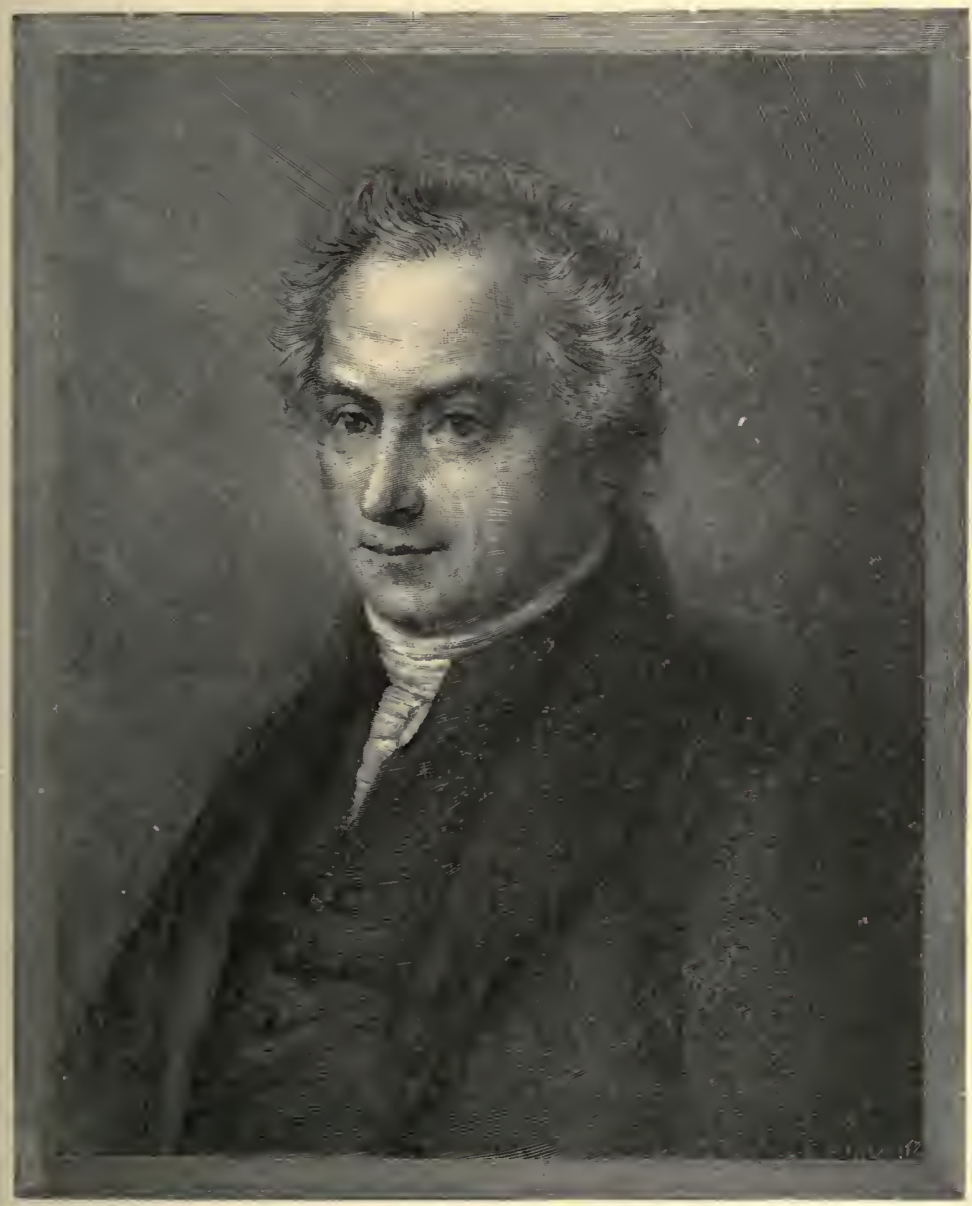

HEINRICH WILHELM MATTHIAS OLBERS 



\section{THE CENTURY'S PROGRESS IN ASTRONOMY}

because electrical force varies with the surface, while gravitation varies only with the mass. From study of atomic weights, and estimates of the velocity of thrust of cometary tails, Bredichin concluded that the chief components of the various kinds of tails are hydrogen, hydrocarbons, and the vapor of iron; and spectroscopic analysis goes far towards sustaining these assumptions.

But, theories aside, the unsubstantialness of the cornet's tail has been put to a conclusive test. Twice during our century the earth has actually plunged directly through one of these threatening appendages, in 1819, and again in 1861, once being immersed to a depth of some 300,000 miles in its substance. Yet nothing dreadful happened to us. There was a peculiar glow in the atmosphere, so the more imaginative observers thought, and that was all. After such fiascoes, the cometary train could never again pose as a world-destroyer.

But the full measure of the comet's humiliation is not yet told. The pyrotechnic tail, composed as it is of portions of the comet's actual substance, is tribute paid the sun, and can never be recovered. Should the obeisance to the sun be many times repeated, the train-forming material will be exhausted, and the comet's chiefest glory will have departed. Such a fate has actually befallen a multitude of comets, which Jupiter and the other outlying planets have dragged into our system, and helped the sun to hold captive here. Many of these tailless comets were known to the eighteenth-century astronomers, but no one at that time suspected the true meaning of their condition. It was not even known how closely some of them are enchained, until the German astronomer Encke, in 1822 , showed that one which he had rediscovered, and which has since borne his name, was moving in an orbit 


\section{THE STORY OF NINETEENTH-CENTURY SCIENCE}

so contracted that it must complete its circuit in about three and a half years. Shortly afterwards another comet, revolving in a period of about six years, was discovered by Biela, and given his name. Only two more of these short-period comets were discovered during our first half century, but latterly they have been shown to be a numerous family. Nearly twenty are known which the giant Jupiter holds so close that the utmost reach of their elliptical tether does not let them go beyond the orbit of Saturn. These aforetime wanderers have adapted themselves wonderfully to planetary customs, for all of them revolve in the same direction with the planets, and in planes not wide of the ecliptic.

Checked in their proud hyperbolic sweep, made captive in a planetary net, deprived of their trains, these quondam free lances of the heavens are now mere shadows of their former selves. Considered as to mere bulk, they are very substantial shadows, their extent being measured in hundreds of thousands of miles; but their actual mass is so slight that they are quite at the mercy of the gravitation pulls of their captors. And worse is in store for them. So persistently do sun and planets tug at them that they are doomed presently to be torn into shreds.

Such a fate has already orertaken one of them, under the very eyes of the astronomers, within the relatively short period during which these ill-fated comets have been observed. In 1832 Biela's comet passed quite near the earth, as astronomers measure distance, and in doing so created a panic on our planet. It did no greater harm than that, of course, and passed on its way as usual. The very next time it came within telescopic hail it was seen to have broken into two fragments. Six years later 
these fragments were separated by many millions of miles; and in 1852, when the comet was due again, as tronomers looked for it in vain. It had been completely shattered.

What had become of the fragments? At that time no one positively knew. But the question was to be answered presently. It chanced that just at this period astronomers were paying much attention to a class of bodies which they had hitherto somewhat neglected, the familiar shooting-stars or meteors. The studies of Professor Newton of Yale and Professor Adams of Cambridge with particular reference to the great meteorshower of November, 1866, which Professor Newton had predicted, and shown to be recurrent at intervals of thirty-three years, showed that meteors are not mere sporadic swarms of matter flying at random, but exist in isolated swarms, and sweep about the sun in regular elliptical orbits.

Presently it was shown by the Italian astronomer Schiaparelli that one of these meteor swarms moves in the orbit of a previously observed comet, and other coincidences of the kind were soon forthcoming. The conviction grew that meteor swarms are really the débris of comets ; and this conviction became a practical certainty when, in November, 1872, the earth crossed the orbit of the ill-starred Biela, and a shower of meteors came whizzing into our atmosphere in lieu of the lost comet.

And so at last the full secret was out. The awe-inspiring comet, instead of being the planetary body it had all along been regarded, is really nothing more nor less than a great aggregation of meteoric particles, which have become clustered together out in space somewhere, 
and which by jostling one another or through electrical action become luminous. So widely are the individual particles separated that the cometary body as a whole has been estimated to be thousands of times less dense than the earth's atmosphere at sea-level. Hence the ease with which the comet may be dismembered and its particles strung out into streaming sirarms.

So thickly is the space we traverse strewn with this cometary dust that the earth sweeps up, according to Professor Newcomb's estimate, a million tons of it each day. Each individual particle, perhaps no larger than a millet seed, becomes a shooting-star or meteor as it burns to rapor in the earth's upper atmosphere. And if one tiny planet sweeps up such masses of this cosmic matter, the amount of it in the entire stretch of our system must be beyond all estimate. What a story it tells of the myriads of cometary victims that have fallen prey to the sun since first he stretched his planetary net across the heavens.

\section{III}

When Biela's comet gave the inhabitants of the earth such a fright in 1832 , it really did not come within fifty millions of miles of us. Even the great comet through whose filmy tail the earth passed in 1561 was itself fourteen millions of miles away. The ordinary mind, schooled to measure space by the tiny stretches of a pygmy planet, cannot grasp the import of such distances; yet these are mere units of measure compared with the vast stretches of sidereal space. Were the comet which hurtles past us at a speed of, say, a hundred miles a second to continue its mad flight unchecked straight out into the void of space, it must fly 


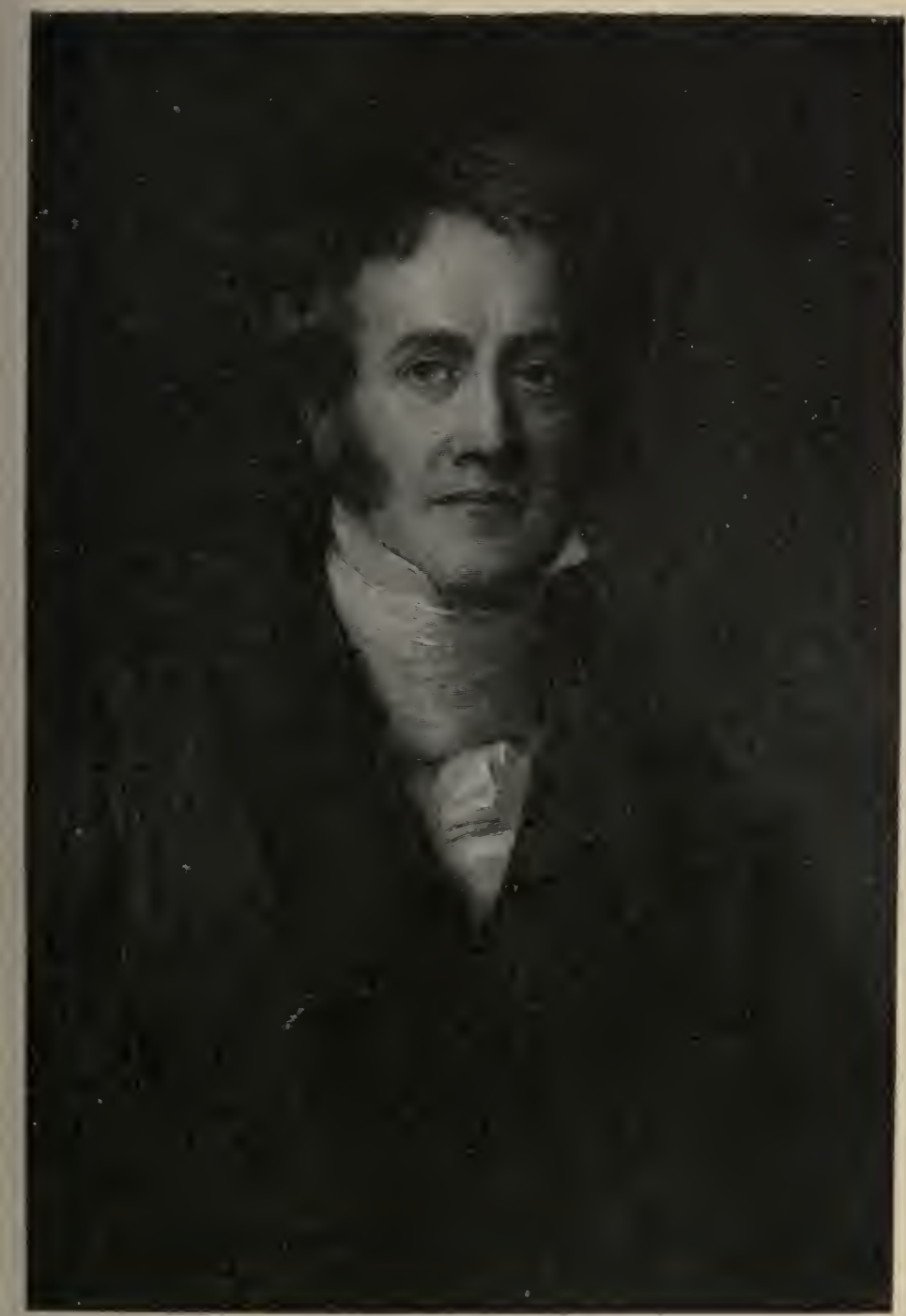

SIR JOIIN IIERSCIEL

From the painting by II. W. Pickersgill, R. A., in St. John's College, Cambridge 

on its frigid way eight thousand years before it could reach the very nearest of our neighbor stars; and even then it would have penetrated but a mere arm's-length into the vistas where lie the dozen or so of sidereal residents that are next beyond. Even to the trained mind such distances are only vaguely imaginable. Yet the astronomer of our century has reached out across this unthinkable roid and brought back many a secret which our predecessors thought forever beyond human grasp.

A tentative assault upon this stronghold of the stars was being made by Herschel at the beginning of the century. In 1802 that greatest of observing astronomers announced to the Royal Society his discovery that certain double stars had changed their relative positions towards one another since he first carefully charted them twenty years before. Hitherto it had been supposed that double stars were mere optical effects. Now it became clear that some of them, at any rate, are true "binary systems," linked together presumably by gravitation, and revolving about one another. Halley had shown, three-quarters of a century before, that the stars have an actual or "proper" motion in space; Herschel himself had proved that the sun shares this motion with the other stars. Here was another shift of place, hitherto quite unsuspected, to be reckoned with by the astronomer in fathoming sidereal secrets.

When John Herschel, the only son and the worthy successor of the great astronomer, began star-gazing in earnest, after graduating senior wrangler at Cambridge, and making two or three tentative professional starts in other directions to which his versatile genius impelled him, his first extended work was the observation of his 


\section{THE STORY OF NINETEENTH-CENTURY SCIENCE}

father's double stars. His studies, in which at first he bad the collaboration of Mr. James South, brought to light scores of hitherto unrecognized pairs, and gave fresh data for the calculation of the orbits of those longer known. So also did the independent researclies of $\mathrm{F}$. G. W. Struve, the enthusiastic observer of the famous Russian observatory at the university of Dorpat, and subsequently at Pulkowa. Utilizing data gathered by these observers, M. Sarary of Paris showed in 1527 that the observed elliptical orbits of the double stars are explicable by the ordinary laws of graritation, thus confirming the assumption that Newton's laws apply to these sidereal bodies. Henceforth there could be no reason to doubt that the same force which holds terrestrial objects on our globe pulls at each and every particle of matter throughout the visible universe.

The pioneer explorers of the double stars early found that the systems into which the stars are linked are by no means confined to single pairs. Often three or four stars are found thus closely connected into gravitation systems; indeed, there are all gradations between binary systems and great cluster's containing hundreds or eren thousands of members. It is known, for example, that the familiar cluster of the Pleiades is not merely an optical grouping, as was formerly supposed, but an actual federation of associated stars, some 2500 in number, only a few of which are visible to the unaided eye. And the more carefully the motions of the stars are studied, the more evident it becomes that widely separated stars are linked together into infinitely complex systems, as yet but little understood. At the same time all instrumental advances tend to resolve more and more seemingly single stars into close pairs and minor clus- 


\section{THE CENTURY'S PROGRESS IN AST'RONOMY}

ters. The two Herschels between them discovered some thousands of these close multiple systems; Struve and others increased the list to above ten thousand; and Mr. S. W. Burnham, of late years the most enthusiastic and successful of double-star pursuers, added a thousand new discoveries while he was still an amateur in astronomy, and by profession the stenographer of a Chicago court. Clearly the actual number of multiple stars is beyond all present estimate.

The elder Herschel's early studies of double stars were undertaken in the hope that these objects might aid him in ascertaining the actual distance of a star, through measurement of its annual parallax; that is to say, of the angle which the diameter of the earth's orbit would subtend as seen from the star. The expectation was not fulfilled. The apparent shift of position of a star as viewed from opposite sides of the earth's orbit, from which the parallax might be estimated, is so extremely minute that it proved utterly inappreciable, even to the almost preternaturally acute vision of Herschel, with the aid of any instrumental means then at command. So the problem of star distance allured and eluded him to the end, and he died in 1822 without seeing it even in prospect of solution. His estimate of the minimum distance of the nearest star, based though it was on the fallacious test of apparent brilliancy, was a singularly sagacious one, but it was at best a scientific guess, not a scientific measurement.

Just about this time, however, a great optician came to the aid of the astronomers. Joseph Fraunhofer perfected the refracting telescope, as Herschel had perfected the reflector, and invented a wonderfully accurate "heliometer," or sun-measurer. With the aid of these in- 


\section{THE STORY OF NINETEENTH-CENTURY SCIENCE}

struments the old and almost infinitely difficult problem of star distance was solved. In 1838 Bessel announced from the Königsberg observatory that he had succeeded, after months of effort, in detecting and measuring the parallax of a star. Similar claims had been made often enough before, always to prove fallacious when put to further test; but this time the announcement carried the authority of one of the greatest astronomers of the age, and scepticism was silenced.

Nor did Bessel's achievement long await corroboration. Indeed, as so often happens in fields of discorery, two other workers had almost simultaneously solved the same problem-Struve at Pulkowa, where the great Russian observatory, which so long held the palm over all others, had now been established; and Thomas Henderson, then working at the Cape of Gond Hope, butafterwards the Astronomer Royal of Scotland. Henderson's observations had actual precedence in point of time, but Bessel's measurements were so much more numerous and authoritative that he has been uniformly considered as deserving the chief credit of the discovery, which priority of publication secured him.

By an odd chance, the star on which Henderson's observations were made, and consequently the first star the parallax of which was ever measured, is our nearest neighbor in sidereal space, being, indeed, some ten billions of miles nearer than the one next beyond. Yet even this nearest star is more than 200,000 times as remote from us as the sun. The sun's light flashes to the earth in eight minutes, and to Neptune in about three and a half hours, but it requires three and a half years to signal Alpha Centauri. And as for the great majority of the stars, had they been blotted out of existence 


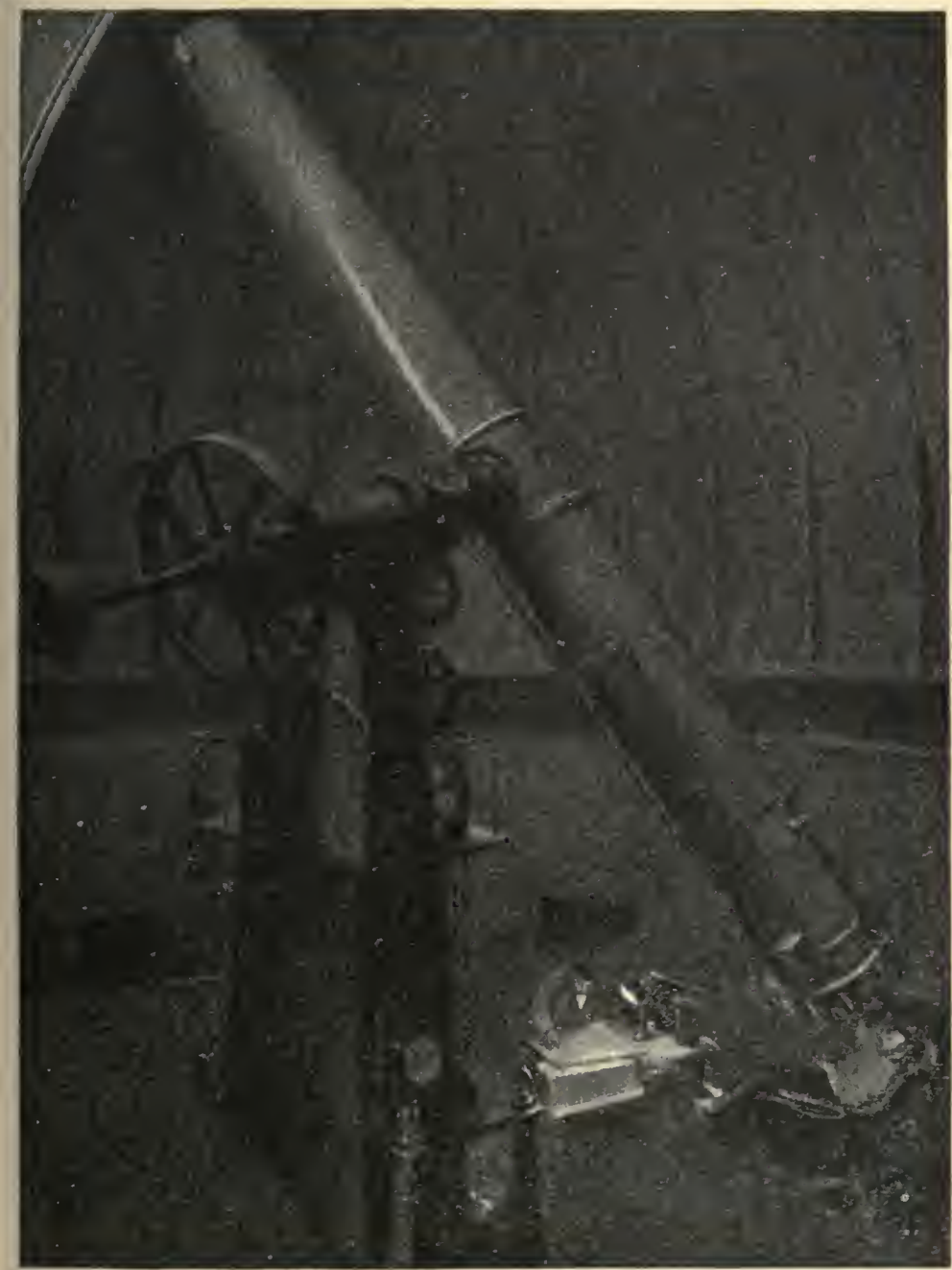

THE GREAT REFRACTOR OF THE NATIONAL, OBSERVATORY AT WASHINGTON 

before the Christian era, we of to-day should still receive their light and seem to see them just as we do. When we look up to the sky, we study ancient history; we do not see the stars as they are, but as they were years, centuries, even millennia ago.

The information derived from the parallax of a star by no means halts with the disclosure of the distance of that body. Distance known, the proper motion of the star, hitherto only to be reckoned as so many seconds of arc, may readily be translated into actual speed of progress ; relative brightness. becomes absolute lustre, as compared with the sun ; and in the case of the double stars the absolute mass of the components may be computed from the laws of gravitation. It is found that stars differ enormously among themselves in all these regards. As to speed, some, like our sun, barely creep through space-compassing ten or tiventy miles a second, it is true, yet even at that rate only passing through the equivalent of their own diameter in a day. At the other extreme, among measured stars, is one that moves two hundred miles a second; yet eren this " $\mathrm{fly}$ ing star," as seen from the earth, seems to changre its place by only about three and a half lunar diameters in a thousand years. In brightness, some stars yield to the sun, while others surpass him as the arc-light surpasses a candle. Arcturus, the brightest measured star, shines like two hundred suns; and even this giant orb is dim beside those other stars which are so distant that their parallax cannot be measured, yet which greet our eyes at first magnitude. As to actual bulk, of which apparent lustre furnishes no adequate test, some stars are smaller than the sun, while others exceed him hundreds or perhaps thousands of times. Yet one and all, 


\section{THE STORY OH NINETEENTH-CENTURY SCIENCE}

so distant are they, remain mere diskless points of light before the utmost powers of the modern telescope.

All this seems wonderful enough, but even greater things were in store. In 1859 the spectroscope came upon the scene, perfected by Kirchhoff and Bunsen, along lines pointed out by Fraunhofer almost half a century before. That marvellous instrument, by revealing the telltale lines sprinkled across a prismatic spectrum, discloses the chemical nature and physical condition of any substance whose light is submitted to it, telling its story equally well, provided the light be strong enough, whether the luminous substance be near or far-in the same room or at the confines of space. Clearly such an instrument must prove a veritable magic wand in the hands of the astronomer.

Very soon eager astronomers all over the world were putting the spectroscope to the test. Kirchhoff himself led the way, and Donati and Father Secchi in Italy, Huggins and Miller in England, and Rutherfurd in America, were the chief of his immediate followers. The results exceeded the dreams of the most visionary. At the very outset, in 1860 , it was shown that such common terrestrial substances as sodium, iron, calcium, magnesium, nickel, barium, copper, and zinc exist in the form of glowing vapors in the sun, and very soon the stars gave up a corresponding secret. Since then the work of solar and sidereal analysis has gone on steadily in the hands of a multitude of workers (prominent among whom, in this country, are Professor Young of Princeton, Professor Langley of Washington, and Professor Pickering of Harvard), and more than half the known terrestrial elements have been definitely located in the sun, while fresh discoveries are in prospect. 


\section{THE CENTURY'S PROGRESS IN ASTRONOMY}

It is true the sun also contains some seeming elements that are unknown on the earth, but this is no matter for surprise. The modern chemist makes no claim for his

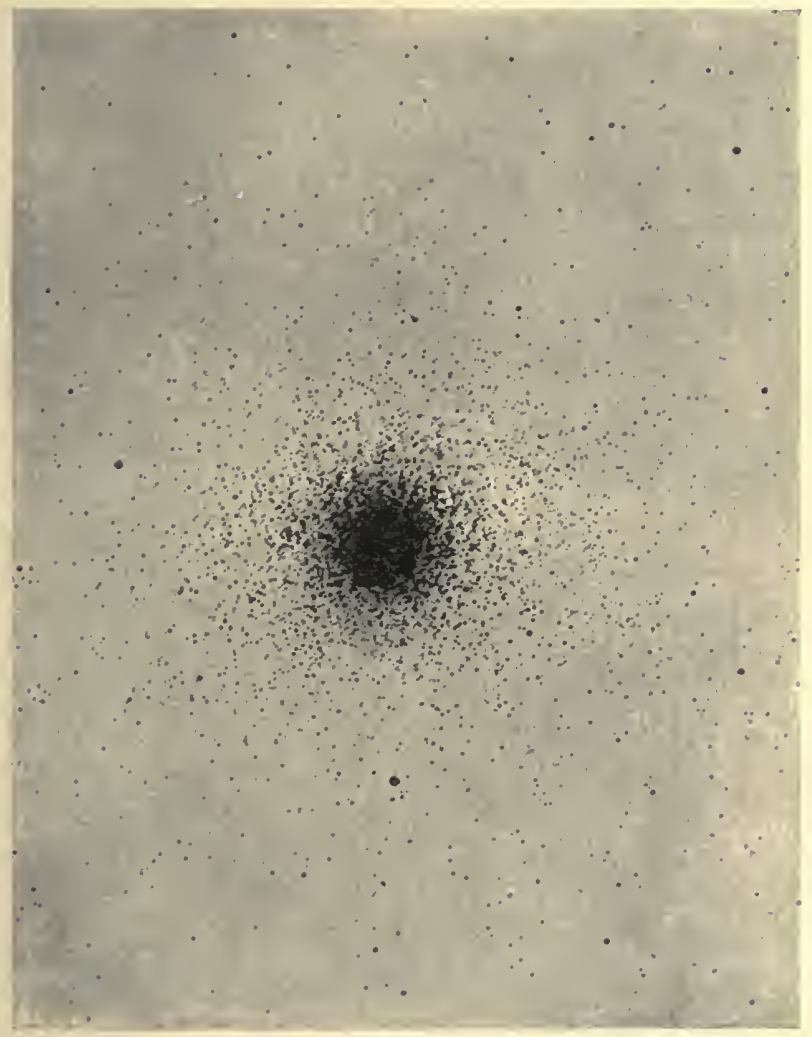

A TYPICAL STAR CLUSTER-CENTAURI

elements except that they have thus far resisted all human efforts to dissociate them; it would be nothing strange if some of them, when subjected to the crucible 


\section{THE STORY OF NINETEENTH-CEN'TURY SCIENCE}

of the sun, which is seen to vaporize iron, nickel, silicon, should fail to withstand the test. But again, chemistry has by no means exhausted the resources of the earth's supply of raw material, and the substance which sends its message from a star may exist undiscovered in the dust we tread or in the air we breathe. Only last year two new terrestrial elements were discovered; but one of these had for years been known to the astronomer as a solar and suspected as a stellar element, and named helium because of its abundance in the sun. The spectroscope had reached out millions of miles into space and brought back this new element, and it took the chemist a score of years to discover that he had all along had samples of the same substance unrecognized in his sublunary laboratory. There is hardly a more picturesque fact than that in the entire history of science.

But the identity in substance of earth and sun and stars was not more clearly shown than the diversity of their existing physical conditions. It was seen that sun and stars, far from being the cool, earthlike, habitable bodies that Herschel thought them (surrounded by glowing clouds, and protected from undue heat by other clouds), are in truth seething caldrons of fiery liquid, or gas made viscid by condensation, with lurid envelopes of belching flames. It was soon made clear, also, particularly by the studies of Rutherfurd and of Seccli, that stars differ among themselves in exact constitution or condition. There are white or Sirian stars, whose spectrum revels in the lines of hydrogen; yellow or solar stars (our sun being the type), showing various metallic vapors; and sundry red stars, with banded spectra indicative of carbon compounds; besides, the 


\section{THE CENTURY'S PROGRESS IN ASTRONOMY}

purely gaseous stars of more recent discovery, which Professor Pickering had specially studied. Zöllner's famous interpretation of these diversities, as indicative

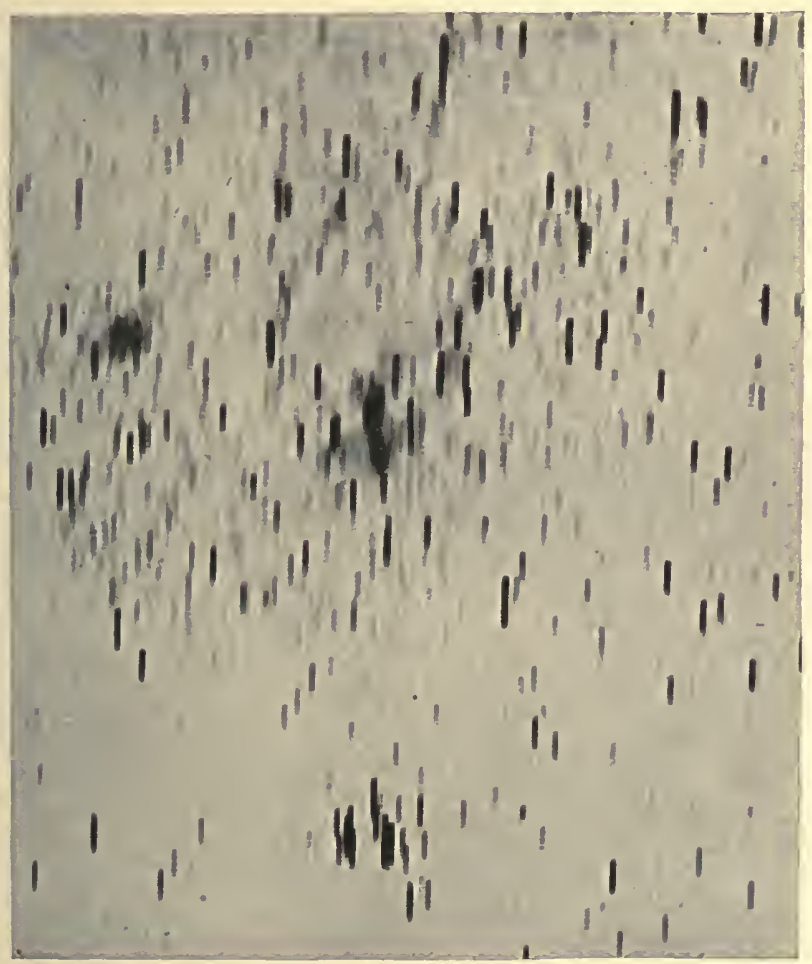

SPECTIA OF STARS IN CARINA

of varying stages of cooling, has been called in question as to the exact sequence it postulates, but the general proposition that stars exist under widely varying conditions of temperature is hardly in dispute. 
The assumption that different star types mark varying stages of cooling has the further support of modern physics, which has been unable to demonstrate any way in which the sun's radiated energy may be restored, or otherwise made perpetual, since meteoric impact has been shown to be-under existing conditions at any rate-inadequate. In accordance with the theory of Helmholtz, the chief supply of solar energy is held to be contraction of the solar mass itself, and plainly this must have its limits. Therefore, unless some means as yet unrecognized is restoring the lost energy to the stellar bodies, each of them must gradually lose its lustre, and come to a condition of solidification, seeming sterility, and frigid darkness. In the case of our own particular star, according to the estimate of Lord Kelvin, such a culmination appears likely to occur within a period of five or six million years.

But by far the strongest support of such a forecast as this is furnished by those stellar bodies which even now appear to have cooled to the final stage of star derelopment and ceased to shine. Of this class examples in miniature are furnished by the earth and the smaller of its companion planets. But there are larger bodies of the same type out in stellar space-veritable "dark stars"-invisible, of course, yet nowadays clearly recognized.

The opening up of this "astronomy of the invisible" is another of the great achievements of our century, and again it is Bessel to whom the honor of discovery is due. While testing his stars for parallax, that astute observer was led to infer, from certain unexplained aberrations of motion, that various stars, Sirius himself among the number, are accompanied by invisible companions, and 
THE CENTURY'S PROGRESS IN ASTRONOMY

in 1840 he definitely predicated the existence of such "dark stars." The correctness of the inference was shown twenty years later, when Alvan Clark, Jun., the American optician, while testing a new lens, discovered

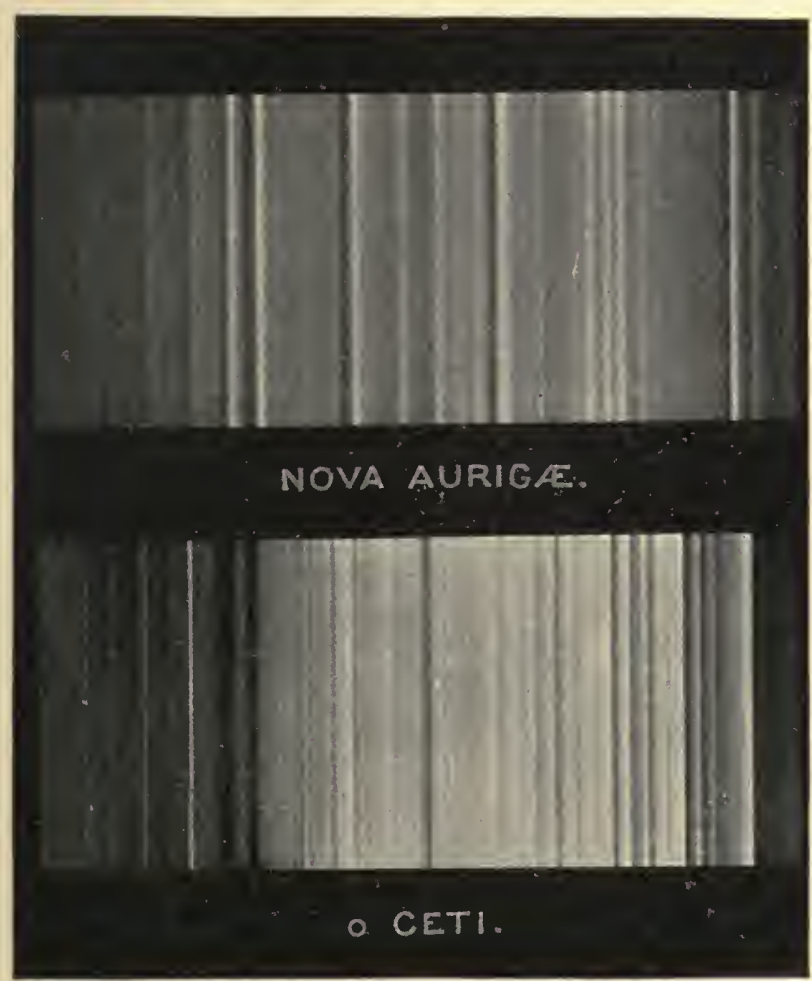

STAI SPECTRA

the companion of Sirius, which proved thus to be faintly luminous. Since then the existence of other and quite invisible star companions has been proved incontestably, 
not merely by renewed telescopic observations, but by the curious testimony of the ubiquitous spectroscope.

One of the most surprising accomplishments of that instrument is the power to record the flight of a luminous object directly in the line of vision. If the luminous body approaches swiftly, its Fraunhofer lines are shifted from their normal position towards the violet end of the spectrum; if it recedes, the lines shift in the opposite direction. The actual motion of stars whose distance is unknown may be measured in this way. But in certain cases the light lines are seen to oscillate on the spectrum at regular intervals. Obviously the star sending such light is alternately approaching and receding, and the inference that it is revolving about a companion is unavoidable. From this extraordinary test the orbital distance, relative mass, and actual speed of revolution of the absolutely invisible body may be determined. Thus the spectroscope, which deals only with light, makes paradoxical excursions into the realm of the invisible. What secrets may the stars hope to conceal when questioned by an instrument of such necromantic power?

IV

But the spectroscope is not alone in this audacious assault upon the strongholds of nature. It has a worthy companion and assistant in the photographic film, whose efficient aid has been involied by the astronomer even more recently. Pioneer work in celestial photography was, indeed, done by Arago in France and by the elder Draper in America in 1839, but the results then achieved were only tentative, and it was not till forty years later that the method assumed really important proportions. 


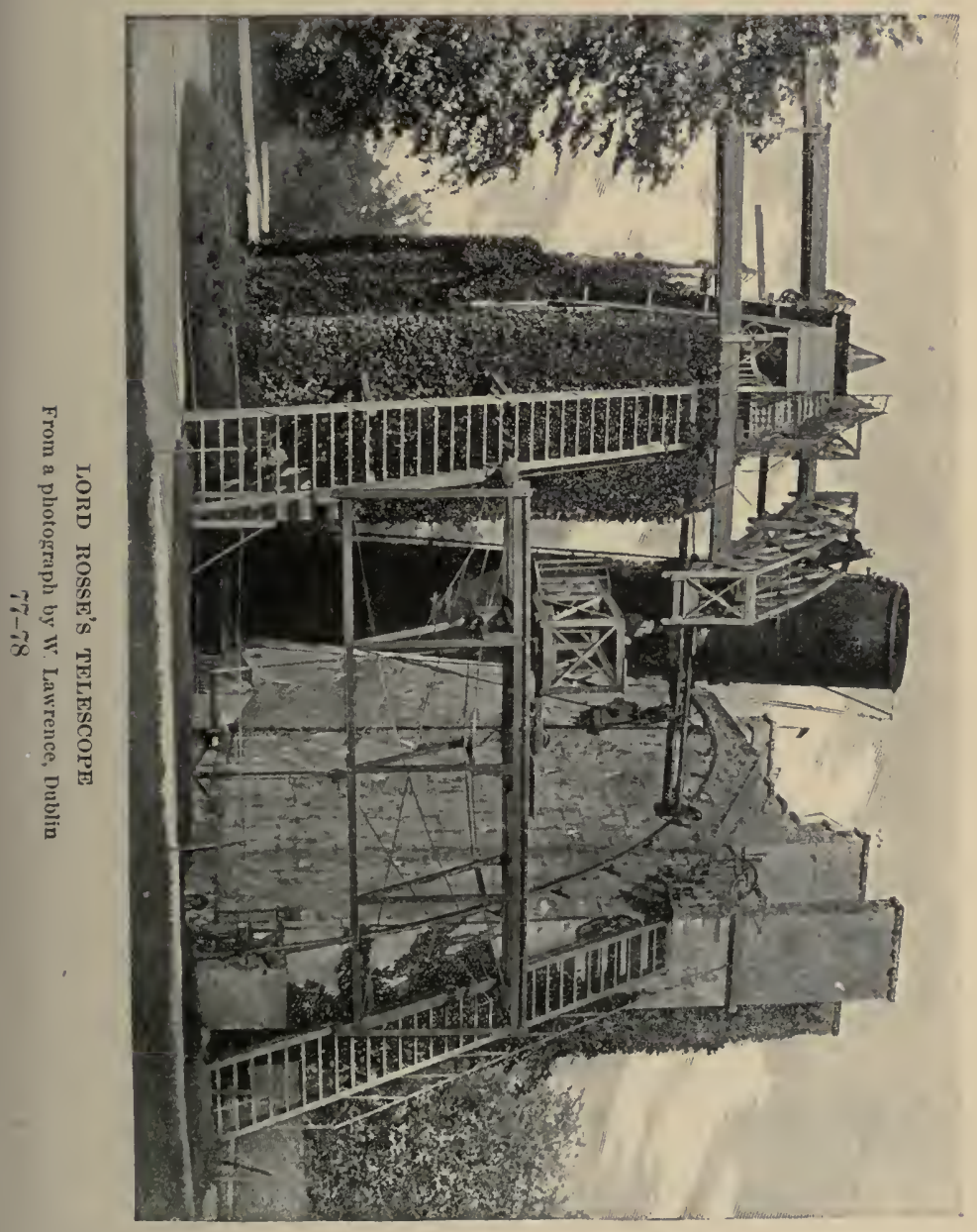





\section{THE CENIURY'S PROGRESS IN ASTRONOMY}

In 1880 Dr. Henry Draper, at Hastings-on-the-Hudson, made the first successful photograph of a nebula. Soon after, Dr. David Gill, at the Cape observatory, made fine photographs of a comet, and the flecks of starlight on his plates first suggested the possibilities of this method in charting the heavens.

Since then star-charting with the film has come to virtually supersede the old method. A concerted effort is being made by astronomers in various parts of the world to make a complete chart of the heavens, and before the close of our century this work will be accomplished, some fifty or sixty millions of risible stars being placed on record with a degree of accuracy hitherto unapproachable. Moreover, other millions of stars are brought to light by the negative which are too distant or dim to be visible with any telescopic powers yet attained-a fact which wholly discredits all previous inferences as to the limits of our sidereal system. Hence, notwithstanding the wonderful instrumental advances of our century, knowledge of the exact form and extent of our unirerse seems more unattainable than it seemed a century ago.

Yet the new instruments, while leaving so much untold, have revealed some vastly important secrets of cosmic structure. In particular, they have set at rest the long-standing doubts as to the real structure and position of the mysterious nebulæ--those hazy masses, only two or three of them visible to the unaided eye, which the telescope reveals in almost limitless abundance, scattered everywhere among the stars, but grouped in particular about the poles of the stellar stream or disk which we call the Milky Way.

Herschel's later view, which held that some at least of the nebulæ are composed of a "shining fluid," in 
process of condensation to form stars, was generally accepted for almost half a century. But in 1814, when Lord Rosse's great six-foot reflector-the largest telescope ever yet constructed-was turned on the nebula, it made this hypothesis seem very doubtful. Just as Galileo's first lens had resolved the Milky Way into stars, just as Herschel had resolved nebulæ that resisted all instruments but his own, so Lord Rosse's even greater reflector resolved others that would not yield to Herschel's largest mirror. It seemed a fair inference that with sufficient power, perhaps some day to be attained, all nebulæ would yield, hence that all are in reality what Herschel had at first thought them-vastly distant "island universes," composed of aggregations of stars, comparable to our own galactic system.

But the inference was wrong; for when the spectroscope was first applied to a nebula in 1864 , by Dr. Huggins, it clearly showed the spectrum not of discrete stars, but of a great mass of glowing gases, hydrogen among others. More extended studies showed, it is true, that some nebulæ give the continuous spectrum of solids or liquids, but the different types intermingle and grade into one another. Also, the closest affinity is shown between nebulæ and stars. Some nebulæe are found to contain stars, singly or in groups, in their actual midst; certain condensed "planetary" nebula are scarcely to be distinguished from stars of the gaseous type; and recently the photographic film has shown the presence of nebulous matter about stars that to telescopic vision differ in no respect from the generality of their fellows in the galaxy. The familiar stars of the Pleiades chuster, for example, appear on the negative immersed in a hazy blur of light. All in all, the accumulated impressions of 



\section{THE CENTURY'S PROGRESS IN ASTRONOMY}

the photographic film reveal a prodigality of nebulous matter in the stellar system not hitherto even conjectured.

And so, of course, all question of "island universes" vanishes, and the nebulæ are relegated to their true position as component parts of the one stellar system-the one universe-that is open to present human inspection. And these vast clouds of world-stuff have been found by Professor Keeler, of the Lick Observatory, to be floating through space at the starlike speed of from ten to thirty-eight miles per second.

The linking of nebulæ with stars, so clearly evidenced by all these modern observations, is, after all, only the scientific corroboration of what the elder Herschel's later theories affirmed. But the nebulæ have other affinities not until recently suspected; for the spectra of some of them are practically identical with the spectra of certain comets. The conclusion seems warranted that comets are in point of fact minor nebulæ that are drawn into our system ; or, putting it otherwise, that the telescopic nebulæ are simply gigantic distant comets.

Following up the suprising clews thus suggested, Mr. J. Norman Lockyer, of London, has in recent years elaborated what is perphaps the most comprehensive cosmogonic guess that has ever been attempted. His theory, known as the "meteoric hypothesis," probably bears the same relation to the speculative thought of our time that the nebular hypothesis of Laplace bore to that of the eighteenth century. Outlined in a few words, it is an attempt to explain all the major phenomena of the universe as due, directly or indirectly, to the gravitational impact of such meteoric particles, or 
specks of cosmic dust, as comets are composed of. Nebulæ are vast cometary clouds, with particles more or less widely separated, giving off gases through meteoric collisions, internal or external, and perhaps glowing also with electrical or phosphorescent light. Gravity eventually brings the nebular particles into closer aggregations, and increased collisions finally vaporize the entire mass, forming planetary nebulæ and gaseous stars. Continued condensation may make the stellar mass hotter and more luminous for a time, but eventually leads to its liquefaction, and ultimate consolidation-the aforetime nebulæ becoming in the end a dark or planetary star.

The exact correlation which Mr. Lockyer attempts to point out between successive stages of meteoric condensation and the various types of observed stellar bodies does not meet with unanimous acceptance. Mr. Ranyard, for example, suggests that the visible nebulæ may not be nascent stars, but emanations from stars, and that the true pre-stellar nebula are invisible until condensed to stellar proportions. But such details aside, the broad general hypothesis that all the bodies of the universe are, so to speak, of a single species-that nebulæ (including comets), stars of all types, and planets, are but varying stages in the life history of a single race or type of cosmic organisms-is accepted by the dominant thought of our time as having the highest warrant of scientific probability.

All this, clearly, is but an amplification of that nebular hypothesis which, long before the spectroscope gave us warrant to accurately judge our sidereal neighbors, had boldly imagined the development of stars out of nebular and of planets out of stars. But Mr. Lockyer's hypothesis does not stop with this. Having traced the 


\section{THE CENTURY'S PROGRESS IN ASTRONOMY}

developmental process from the nebula to the dark star, it sees no cause to abandon this dark star to its fate by assuming, as the original speculation assumed, that this is a culminating and final stage of cosmic existence. For the dark star, though its molecular activities have come to relative stability and impotence, still retains the enormous potentialities of molar motion; and clearly,

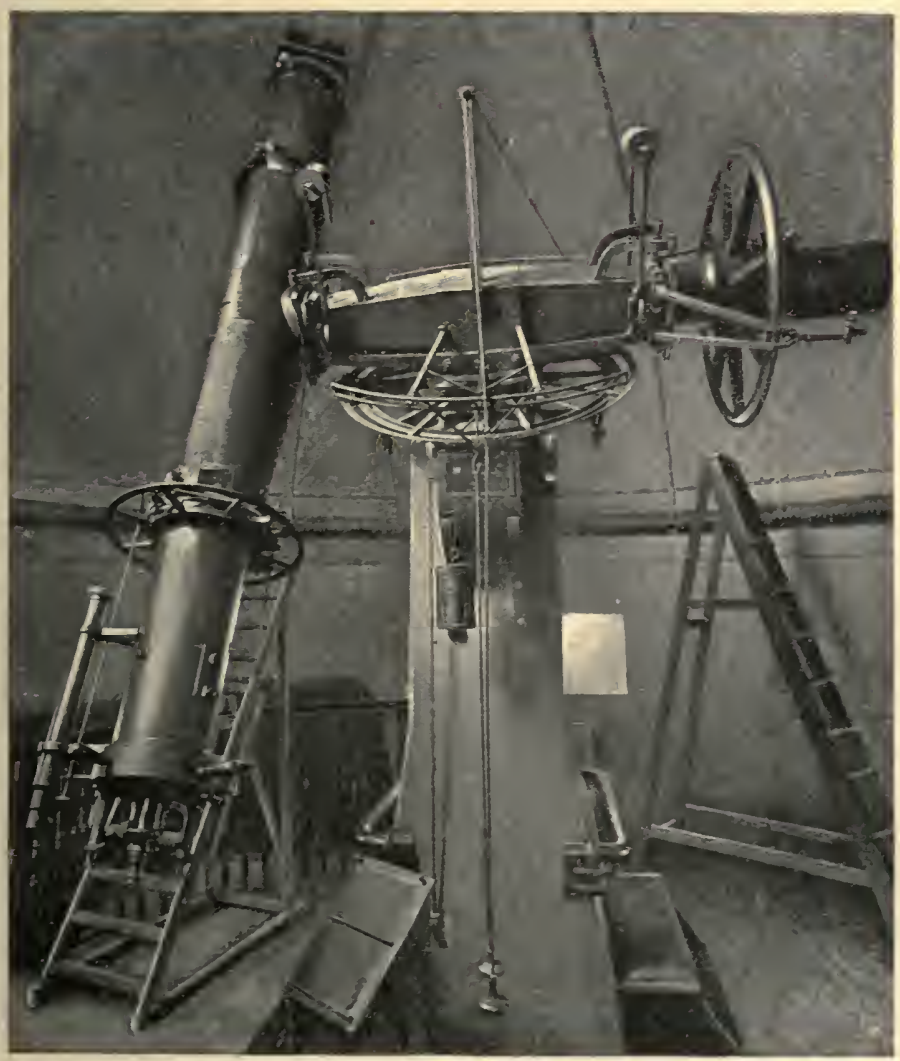

THE OXFORD HELIOMETER 


\section{THE STORY OF NINETEENTH-CENTURY SCIENCF}

where motion is, stasis is not. Sooner or later, in its ceaseless flight through space, the dark star must collide with some other stellar body, as Dr. Croll imagines of the dark bodies which his "pre-nebular theory" postulates. Such collision may be long delayed; the dark star may be drawn in cometlike circuit about thousands of other stellar masses, and be hurtled on thousands of diverse parabolic or elliptical orbits, before it chances to collide-but that matters not: "billions are the units in the arithmetic of eternity," and sooner or later, we can hardly doubt, a collision must occur. Then without question the mutual impact must shatter both colliding bodies into vapor, or vapor combined with meteoric fragments; in short, into a veritable nebula, the matrix of future worlds. Thus the dark star, which is the last term of one series of cosmic changes, becomes the first term of another series-at once a post-nebular and a prenebular condition; and the nebular hypothesis, thus anplified, ceases to be a mere linear scale, and is rounded out to connote an unending series of cosmic cycles, more nearly satisfying the imagination.

In this extended view, nebula and luminous stars are but the infantile and adolescent stages of the life history of the cosmic individual; the dark star, its adult stage, or time of true virility. Or we may think of the shrunken dark star as the germ-cell, the pollen-grain, of the cosmic organism. Reduced in size, as becomes a germ-cell, to a mere fraction of the nebular body from which it sprang, it yet retains within its seemingly nonvital body all the potentialities of the original organism, and requires only to blend with a fellow-cell to bring a new generation into being. Thus may the cosmic race, whose aggregate census makes up the stellar universe, 


\section{THE CENTURY'S PROGRESS IN ASTRONOMY}

be perpetuated-individual solar systems, such as ours, being born, and growing old, and dying to live again in their descendants, while the universe as a whole maintains its unified integrity throughout all these internal mutations-passing on, it may be, by infinitesimal stages, to a culmination hopelessly beyond human comprehension. 


\section{CHAPTER III}

\section{THE CENTURY'S PROGRESS IN PALEONTOLOGY}

I

Ever since Leonardo da Vinci first recognized the true character of fossils, there had been here and there a man who realized that the earth's rocky crust is one gigantic mausoleum. Here and there a dilettante had filled his cabinets with relics from this monster crypt; here and there a philosopher had pondered over themquestioning whether perchance they had once been alive, or whether they were not mere abortive souvenirs of that time when the fertile matrix of the earth was supposed to have

$$
\text { "teemed at a birth }
$$

Innumerous living creatures, perfect forms, Limbed and full-grown."

Some few of these philosophers-as Robert Hooke and Steno in the seventeenth century, and Moro, Leibnitz, Buffon, Whitehurst, Werner, Hutton, and others in the eighteenth-had vaguely conceived the importance of fossils as records of the earth's ancient history, but the wisest of them no more suspected the full import of the story written in the rocks than the average stroller in a modern museum suspects the meaning of the hieroglyphs on the case of a mummy. 


\section{THE CENTURY'S PROGRESS IN PALEONTOLOGY}

It was not that the rudiments of this story are so very hard to decipher-though in truth they are hard enough -but rather that the men who made the attempt had all along viewed the subject through an atmosphere of preconception, which gave a distorted image. Before this image could be corrected it was necessary that a man should appear who could see without prejudice, and apply sound common-sense to what he saw. And such a man did appear towards the close of the century in the person of William Smith, the English surveyor. He was a self-taught man, and perhaps the more independent for that, and he had the gift, besides his sharp eyes and receptive mind, of a most tenacious memory. By exercising these faculties, rare as they are homely, he led the way to a science which was destined, in its later developments, to shake the structure of established thought to its foundations.

Little enough did William Smith suspect, however, that any such dire consequences were to come of his act when he first began noticing the fossil shells that here and there are to be found in the stratified rocks and soils of the regions over which his surveyor's duties led him. Nor, indeed, was there anything of such apparent rerolutionary character in the facts which he unearthed; yet in their implications these facts were the most disconcerting of any that had been revealed since the day of Copernicus and Galileo. In its bald essence Smith's - discovery was simply this: that the fossils in the rocks, instead of being scattered haphazard, are arranged in regular systems, so that any given stratum of rock is labelled by its fossil population; and that the order of succession of such groups of fossils is always the same in any vertical series of strata in which they occur. That 


\section{THE STORY OF NINETEENTH-CENTURY SCIENCE}

is to say, if fossil A underlies fossil B in any given region, it never overlies it in any other series; though a kind of fossils found in one set of strata may be quite omitted in another. Moreover, a fossil once having disappeared never reappears in any later stratum.

From these novel facts Smith drew the common-sense inference that the earth had had successive populations of creatures, each of which in its turn had become extinct. He partially verified this inference by comparing the fossil shells with existing species of similar orders, and found that such as occur in older strata of the rocks had no counterparts among living species. But on the whole, being eminently a practical man, Smith troubled limself but little about the inferences that might be drawn from his facts. He was chiefly concerned in using the key he had discovered as an aid to the construction of the first geological map of England ever attempted, and he left to others the untangling of any snarls of thought that might seem to arise from his discovery of the succession of varying forms of life on the globe.

He disseminated his views far and wide, howerer, in the course of his journeyings-quite disregarding the fact that peripatetics went out of fashion when the printing-press came in-and by the beginning of our century he had begun to have a following among the geologists of England. It must not for a moment be supposed, however, that his contention regarding the succession of strata met with immediate or general ac- . ceptance. On the contrary, it was most bitterly antagonized. For a long generation after the discovery was made, the generality of men, prone as always to strain at gnats and swallow camels, preferred to believe that the fossils, instead of being deposited in successire 
ages, had been sivept all at once into their present positions by the current of a mighty flood-and that flood, needless to say, the Noachian deluge. Just how the numberless successive strata could have been laid down in orderly sequence to the depth of several miles in one such fell cataclysm was indeed puzzling, especially after it came to be admitted that the heaviest fossils were not found always at the bottom ; but to doubt that this had been done in some way was rank heresy in the early days of our century.

But once discovered, William Smith's unique facts as to the succession of forms in the rocks would not down. There was one most vital point, however, regarding which the inferences that seem to follow from these facts needed verification - the question, namely, whether the disappearance of a fauna from the register in the rocks really implies the extinction of that fauna. Everything really depended upon the answer to that question, and none but an accomplished naturalist could ansiver it with authority. Fortunately the most authoritative naturalist of the time, Georges Curier, took the question in hand-not, incleed, with the idea of verifying any suggestion of Smith's, but in the course of his own original studies-at the very beginning of the century, when Smith's views were attracting general attention.

Cuvier and Smith were exact contemporaries, both men having been born in 1759 , that "fertile year" which gare the world also Châteaubriand, Von Humboldt, Wellington, and Napoleon. But the French naturalist was of very different antecedents from the Eng- 


\section{THE S'TORY OF NINETEENTH-CENTURY SCIENCE}

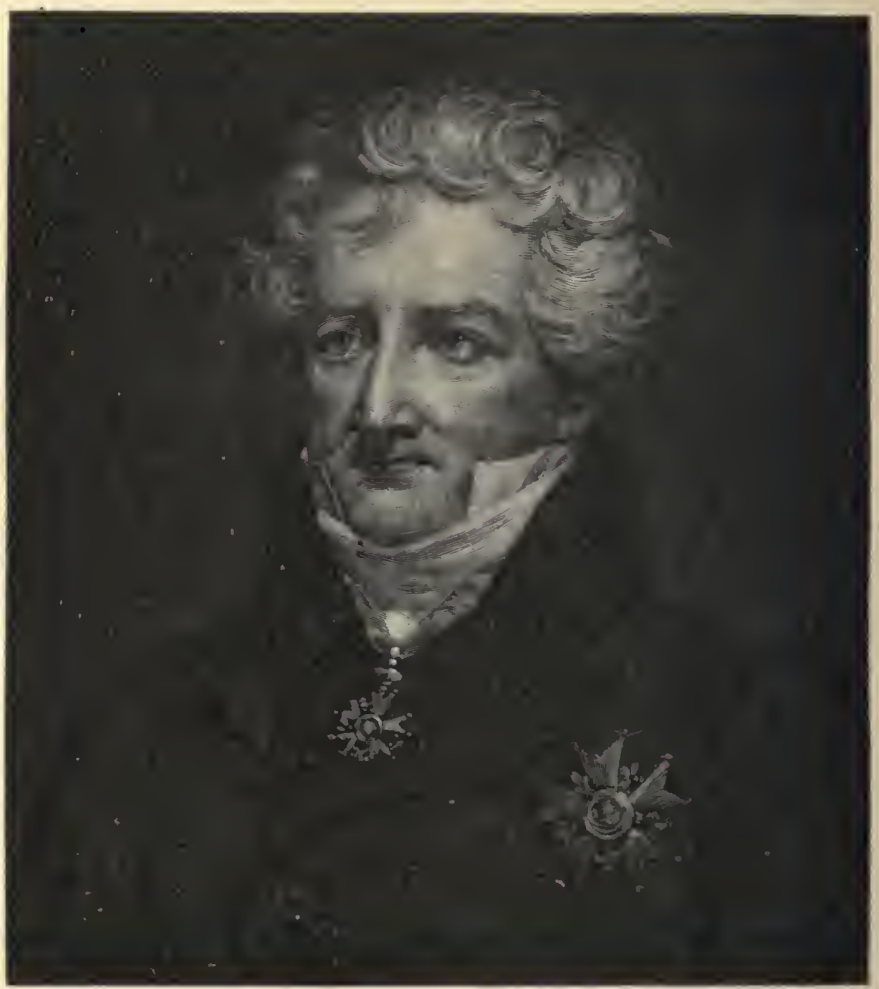

GEORGES CUVIER

lish surveyor. He was brilliantly educated, had early gained recognition as a scientist, and while yet a young man had come to be known as the foremost comparative anatomist of his time. It was the anatomical studies that led him into the realm of fossils. Some bones dug out of the rocks by workmen in a quarry were brought to his notice, and at once his trained eye told him that they were different from anything he had seen before. 


\section{THE CENTURY'S PROGRESS IN PALEONTOLOGY}

Hitherto such bones, when not entirely ignored, had been for the most part ascribed to giants of former days, or even to fallen angels. Cuvier soon showed that neither giants nor angels were in question, but elephants of an unrecognized species. Continuing his studies, particularly with material gathered from gypsum beds near Paris, he had accumulated, by the beginning of our century, bones of about twenty-five species of animals that he believed to be different from any now living on the globe.

The fame of these studies went abroad, and presently fossil bones poured in from all sides, and Cuvier's convictions that extinct forms of animals are represented among the fossils was sustained by the evidence of many strange and anomalous forms, some of them of gigantic size. In 1816 the famous Ossements Fossiles, describing these novel objects, was published, and vertebrate paleontology became a science. Among other things of great popular interest the book contained the first authoritative description of the hairy elephant, named by Cuvier the mammoth, the remains of which had been found embedded in a mass of ice in Siberia in 1802, so wonderfully preserved that the dogs of the Tungusian fishermen actually ate its flesh. Bones of the same species had been found in Siberia sereral years before by the naturalist Pallas, who had also found the carcass of a rhinoceros there, frozen in a mud bank; but no one then suspected that these were members of an extinct population-they were supposed to be merely transported relics of the flood.

Cuvier, on the other hand, asserted that these and the other creatures he described had lived and died in the region where their remains were found, and that most 


\section{THE STORY OF NINETEENTH-CLN'TURY SCIENCE}

of them have no living representatives upon the globe. This, to be sure, was nothing more than William Smith had tried all along to establish regarding lower forms of life; but great monsters appeal to the imagination in a

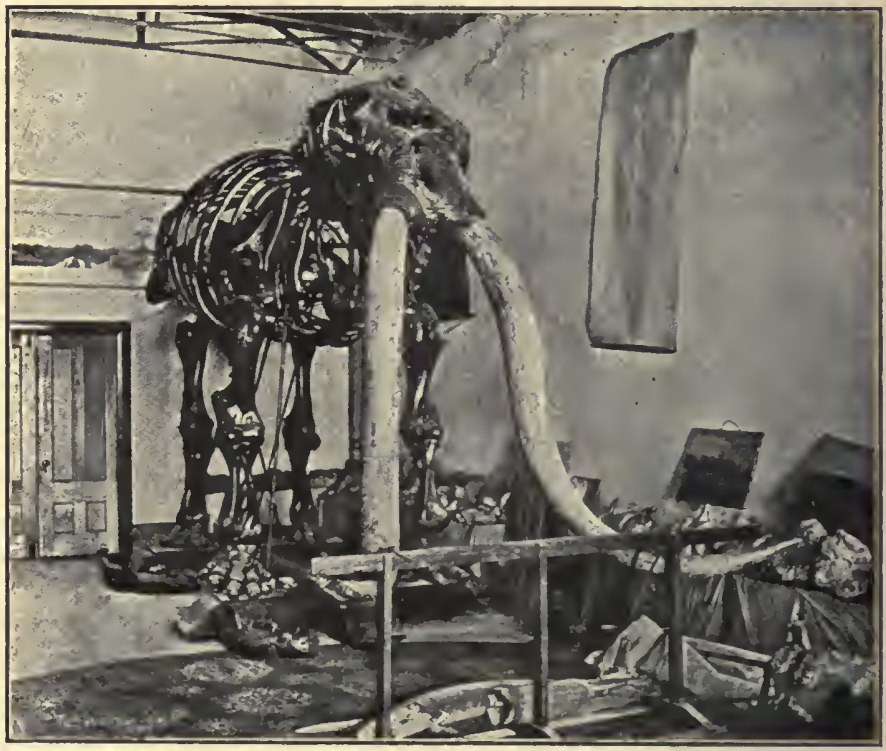

THE WAIREN MASTODON, FOUND NEAR NEWBURG, ON THE HUDSON

way quite beyond the power of mere shells; so the announcement of Cuvier's discoveries aroused the interest of the entire world, and the Ossements Fossiles was accorded a popular reception seldom given a work of technical science-a reception in which the enthusiastic approval of progressive geologists was mingled with the bitter protests of the conservatives. 


\section{TIIE CENTURY'S PROGRESS IN PALEONTOLOGY}

In England the interest thus aroused was sent to feverheat in 1821 by the discovery of abundant beds of fossil bones in the stalagmite-covered floor of a cave at Kirkdale, Yorkshire, which went to show that England too had once had her share of gigantic beasts. Dr. Buckland, the incumbent of the recently established chair of geology at Oxford, and the most authoritative English geologist of the day, took these finds in hand and showed that the bones belonged to a number of species, including such alien forms as elephants, rhinoceroses, hippopotami, and hyenas. He maintained that all of these creatures had actually lived in Britain, and that the caves in which their bones were found had been the dens of hyenas.

The claim was hotly disputed as a inatter of course. As late as 1827 books were published denouncing Buckland, Doctor of Divinity though he was, as one who had joined in an " unhallowed cause," and reiterating the old cry that the fossils were only remains of tropical species washed thither by the deluge. That they were found in solid rocks or in caves offered no difficulty, at least not to the fertile imagination of Granville Penn, the leader of the conservatives, who clung to the old idea of Woodward and Cattcut that the deluged ha dissolved the entire crust of the earth to a paste, into which the relics now called fossils had settled. The cares, said Mr. Penn, are merely the result of gases given off by the carcasses during decomposition-great air-bubbles, so to speak, in the pasty mass becoming caverns when the waters receded and the paste hardened to rocky consistency.

But these and such like fanciful views were doomed even in the day of their utterance. Already in 1823 other gigantic creatures, christened ichthyosaurus and plesio- 
THE STORY OF NINETEENTH-CENTURY SCIENCE

saurus by Conybeare, had been found in deeper strata of British rocks; and these, as well as other monsters whose remains were unearthed in various parts of the world, bore such strange forms that eren the most sceptical could scarcely hope to find their counterparts among living creatures. Cuvier's contention that all the larger

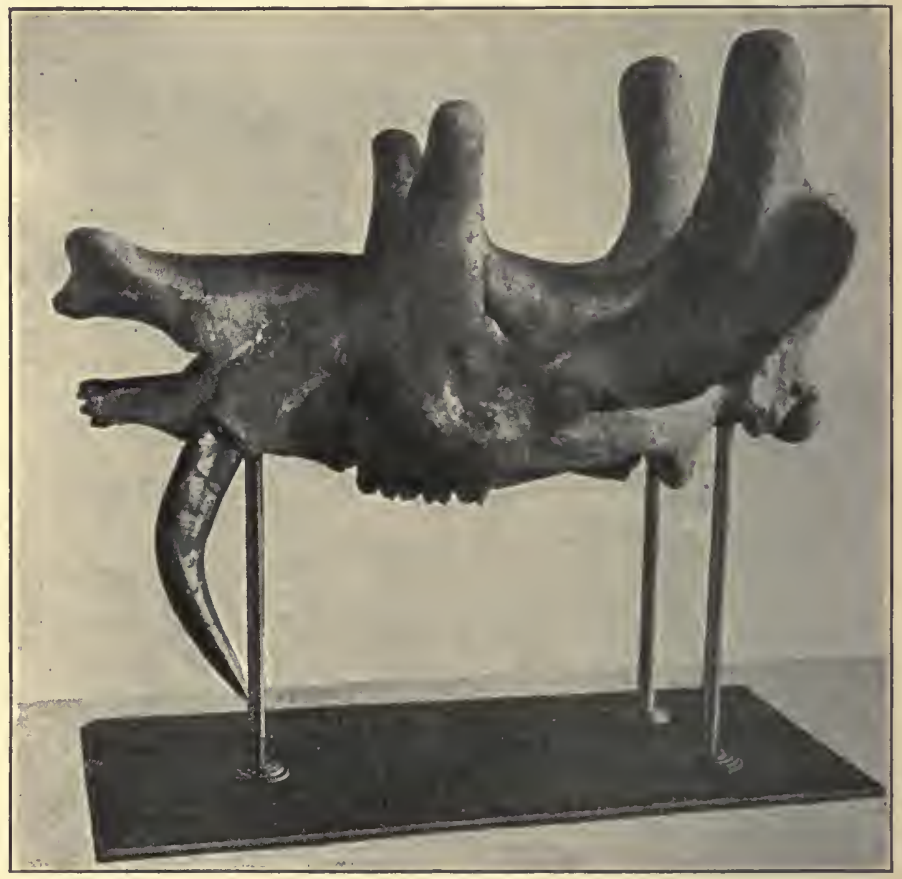

SKULL, IACKING JAW, OF EOBASILEUS CURNUTUS, COPE

vertebrates of the existing age are known to naturalists was borne out by recent explorations, and there seemed no refuge from the conclusion that the fossil records tell of populations actually extinct. But if this were 
admitted, then Smith's view that there have been successive rotations of population could no longer be denied. Nor could it be in doubt that the successive faunas, whose individual remains have been preserved in myriads, representing extinct species by thousands and tens of thousands, must have required vast periods of time for the production and growth of their countless generations.

As these facts came to be generally known, and as it came to be understood in addition that the very matrix of the rock in which fossils are embedded is in many cases itself one gigantic fossil, composed of the remains of microscopic forms of life, common-sense, which, after all, is the final tribunal, came to the aid of belabored science. It was conceded that the only tenable interpretation of the record in the rocks is that numerous populations of creatures, distinct from one another and from present forms, have risen and passed away; and that the geologic ages in which these creatures lived were of inconceivable length. The rank and file came thus, with the aid of fossil records, to realize the import of an idea which James Hutton, and here and there another thinker, had conceired with the swift intuition of genius long before the science of paleontology came into existence. The Huttonian proposition that time is long had been abundantly established, and by about the close of the first third of our century geologists had begun to speak of "ages" and "untold æons of time" with a familiarity which their predecessors had reserved for days and decades.

III

And now a new question pressed for solution. If the earth has been inhabited by successive populations of 


\section{THE S'TORY OF NINETEENTH-CENTURY SCIENCE}

beings now extinct, how have all these creatures been destroyed? That question, however, seemed to present no difficulties. It was answered out of hand by the application of an old idea. All down the centuries, whatever their varying phases of cosmogonic thought, there had been ever present the idea that past times were not as recent times; that in remote epochs the earth had been the scene of awful catastrophes that have no parallel in "these degenerate days." Naturally enough this thought, embalmed in every cosmogonic speculation of whatever origin, was appealed to in explanation of the destruction of these hitherto unimagined hosts, which now, thanks to science, rose from their abysmal slumber as incontestable, but alśo as silent and as thought-provocative as Sphinx or pyramid. These ancient hosts, it was said, have been exterminated at intervals of odd millions of years by the recurrence of catastrophes of whicl the Mosaic deluge is the latest, but perhaps not the last.

This explanation had fullest warrant of scientific authority. Cuvier had prefaced his classical work with a speculative disquisition whose very title (Discours sur les Révolutions du Globe) is ominous of catastrophism, and whose text fully sustains the augury. And Buckland, Cuvier's foremost follower across the Channel, had gone even beyond the master, naming the work in which he described the Kirkdale fossils, Reliquice Diluviana, or Proofs of a Universal Deluge.

Both these authorities supposed the creatures whose remains they studied to have perished suddenly in the mighty flood whose awful current, as they supposed, gouged out the modern valleys, and hurled great blocks of granite broadcast over the land. And they involied 


\section{THE CENTURY'S PROGRESS IN PALEONTOLOGY}

similar floods for the extermination of previous populations.

It is true these scientific citations had met with only qualified approval at the time of their utterance, because then the conservative majority of mankind did not concede that there had been a plurality of populations or revolutions; but now that the belief in past geologic ages had ceased to be a heresy, the recurring catastrophes of the great paleontologists were accepted with acclaim. For the moment science and tradition were at one, and there was a truce to controversy, except indeed in those outlying skirmish-lines of thought whither news from headquarters does not permeate till it has become ancient history at its source.

The truce, however, was not for long. Hardly had contemporary thought begun to adjust itself to the conception of past ages of incomprehensible extent, each terminated by a catastrophe of the Noachian type, when a man appeared who made the utterly bewiidering assertion that the geological record, instead of proving numerous catastrophic revolutions in the earth's past history, gives no warrant to the pretensions of any universal catastrophe whatever, near or remote.

This iconoclast was Charles Lyell, the Scotchman, who was soon to be famous as the greatest geologist of his time. As a young man he had become imbued with the force of the Huttonian proposition, that present causes are one with those that produced the past changes of the globe, and he carried that idea to what he conceived to be its logical conclusion. To his mind this excluded the thought of catastrophic changes in either inorganic or organic worlds. 
But to deny catastrophism was to suggest a revolution in current thought. Needless to say such revolution could not be effected without a long contest. For a score of years the matter was argued pro and con, often with most unscientific ardor. A mere outline of the controversy would fill a volume; yet the essential facts with which Lyell at last established his proposition, in its bearings on the organic world, may be epitomized in few words. The evidence which seems to tell of past revolutions is the apparently sudden change of fossils from one stratum to another of the rocks. But Lyell showed that this change is not always complete. Some species live on from one alleged epoch into the next. By no means all the contemporaries of the mammoth are extinct, and numerous marine forms vastly more ancient still have living representatives.

Moreover, the blanks between strata in any particular vertical series are amply filled in with records in the form of thick strata in some geographically distant series. For example, in some regions Silurian rocks are directly overlaid by the coal measures; but elsewhere this sudden break is filled in with the Devonian rocks that tell of a great "age of fishes." So commonly are breaks in the strata in one region filled up in another, that we are forced to conclude that the record shown by any single vertical series is of but local significancetelling, perhaps, of a time when that particular sea-bed oscillated above the water-line, and so ceased to receive sediment until some future age when it had oscillater back again. But if this be the real significance of the seemingly sudden change from stratum to stratum, then the whole case for catastrophism is hopelessly lost ; for 


\section{THE CENTURY'S PROGRESS IN PALEONTOLOGY}

such breaks in the strata furnish the only suggestion geology can offer of sudden and catastrophic changes of wide extent.

When evidence from widely separated regions is gathered, said Lyell, it becomes clear that the numberless species that have been exterminated in the past

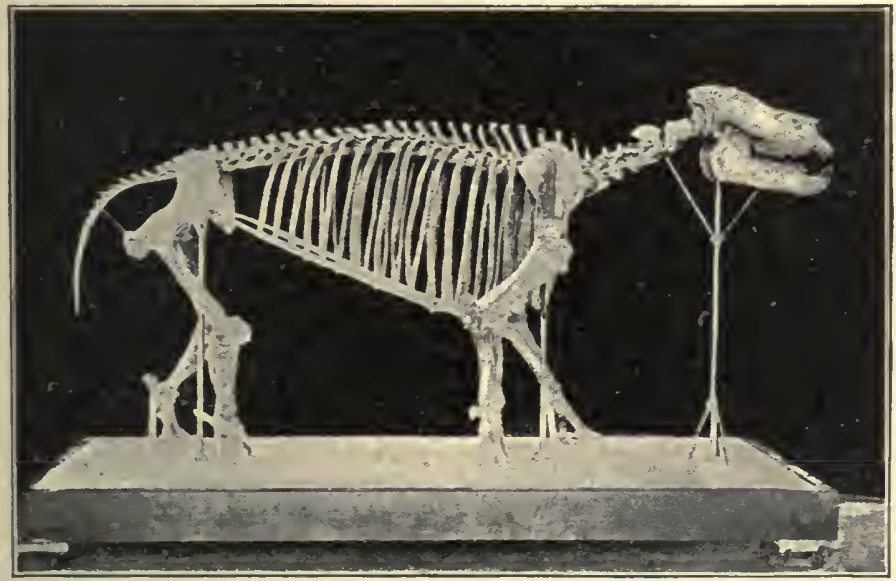

METAMYNODON, OR SWIMMING RHINOCEROS, FROM SOUTH DAKOTA

have died out one by one, just as individuals of a species die, not in vast shoals; if whole populations have passed away, it has been not by instantaneous extermination, but by the elimination of a species now here, now there, much as one generation succeeds another in the life history of any single species. The causes which have brought about such gradual exterminations, and in the long lapse of ages have resulted in rotations of population, are the same natural causes that are still in operation. Species have died out in the past as they are dying out in the present, under influence of changed 


\section{THE STORY OF NINETEENTH-CEN'TURY SCIENCE}

surroundings, such as altered climate, or the migration into their territory of more masterful species. Past and present causes are one-natural law is changeless and eternal.

Such was the essence of the Huttonian doctrine, which Lyell adopted and extended, and with which his name will always be associated. Largely through his efforts, though of course not without the aid of many other workers after a time, this idea - the doctrine of uniformitarianism, it came to be called-became the accepted dogma of the geologic world not long after the middle of our century. The catastrophists, after clinging madly to their phantom for a generation, at last capitulated without terms: the old heresy became the new orthodoxy, and the way was paved for a fresh controversy.

\section{IV}

The fresh controversy followed quite as a matter of course. For the idea of catastrophism had not concerned the destruction of species merely, but their introduction as well. If whole faunas had been extirpated suddenly, new faunas had presumably been introduced with equal suddenness by special creation; but if species die out gradually, the introduction of new species may be presumed to be correspondingly gradual. Then may not the new species of a later geological epoch be the modified lineal descendants of the extinct population of an earlier epoch?

The idea that such might be the case was not new. It had been suggested when fossils first began to attract conspicuous attention; and such sagacious thinkers as Buffon and Kant and Goethe and Erasmus Darwin had 
been disposed to accept it in the closing days of the eighteenth century. Then, in 1809, it had been contended for by one of the early worker's in systematic paleontology, Jean Baptiste Lamarck, who had studied the fossil shells about Paris while Cuvier studied the vertebrates, and who had been led by these studies to conclude that there had been not merely a rotation but a progression of life on the globe. He found the fossil shells--the fossils of invertebrates, as he himself had christened them-in deeper strata than Cuvier's vertebrates; and he believed that there had been long ages

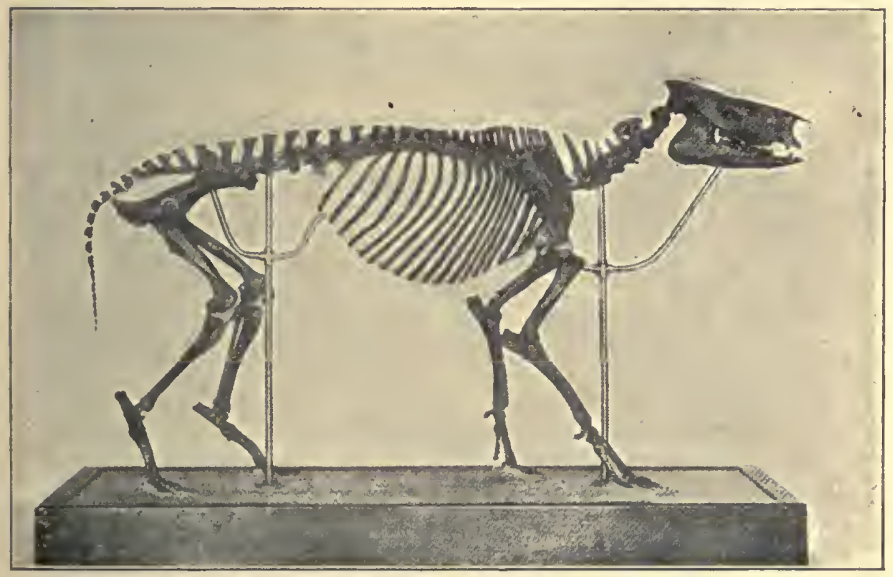

ITYACHYUS, OR RUNNING RHINOCEROS, FROM SOUTHERN WYOMING

when no higher forms than these were in existence, and that in successive ages fishes, and then reptiles, had been the highest of animate creatures, before mammals, including man, appeared. Looking beyond the pale of his bare facts, as genius sometimes will, he had insisted that these progressive populations had developed one from 
another, under influence of changed surroundings, in unbroken series.

Of course such a thought as this was hopelessly misplaced in a generation that doubted the existence of extinct species, and hardly less so in the generation that accepted catastrophism; but it had been lept alive by here and there an advocate like Geoffrey St.-Hilaire, and now the banishment of catastrophism opened the way for its more respectful consideration. Respectful consideration was given it by Lyell in each recurring edition of his Principles, but such consideration led to its unqualified rejection. In its place Lyell put forward a modified hypothesis of special creation. He assumed that from time to time, as the extirpation of a species had left room, so to speak, for a new species, such new species had been created de novo; and he supposed that such intermittent, spasmodic impulses of creation manifest themselves nowadays quite as frequently as at any time in the past. He did not say in so many words that no one need be surprised to-day were he to see a new species of deer, for example, come up out of the ground before him, "pawing to get free," like Milton's lion, but his theory implied as much. And that theory, let it be noted, was not the theory of Lyell alone, but of nearly all his associates in the geologic world. There is perhaps no other fact that will bring home to one so vividly the advance in thought of our own generation as the recollection that so clude, so almost unthinkable a conception could have been the current doctrine of science less than half a century ago.

This theory of special creation, moreover, excluded the current doctrine of uniformitarianism as night excludes day, though most thinkers of the time did not 


\section{THE CENTURY'S PROGRESS IN PALEONTOLOGY}

seem to be awrare of the incompatibility of the two ideas. It may be doubted whether even Lyell himself fully realized it. If he did, he saw no escape from the dilemma, for it seemed to him that the record in the rocks clearly disproved the alternative Lamarckian hypothesis. And almost with one accord the paleontologists of the time sustained the verdict. Owen, Agassiz, Falconer, Barrande, Pictet, Forbes, repudiated the idea as unqualifiedly as their great predecessor Cuvier had done in the earlier generation. Some of them did, indeed, come to believe that there is evidence of a progressive development of life in the successive ages, but no such graded series of fossils had been discovered as would give countenance to the idea that one species had ever been transformed into another. And to nearly every one this objection seemed insuperable.

But now in 1859 appeared a book which, though not dealing primarily with paleontology, yet contained a chapter that revealed the geological record in an altogether new light. The book was Charles Darwin's Origin of Species, the chapter that wonderful citation of the "Imperfections of the Geological Record." In this epoch-making chapter Darwin shows what conditions must prevail in any given place in order that fossils shall be formed, how unusual such conditions are, and how probable it is that fossils once embedded in sediment of a sea-bed will be destroyed by metamorphosis of the rocks, or by denudation when the strata are raised above the water-level. Add to this the fact that only small territories of the earth have been explored geologically, he says, and it becomes clear that the paleontological record as we now possess it shows but a mere fragment of the past history of organisms on the 


\section{THE STURY OF NINETEENTH-CENTURY SCIENCE}

earth. It is a history "imperfectly kept and written in a changing dialect. Of this history we possess the last volume alone, relating only to two or three countries. Of this volume only here and there a short chapter has

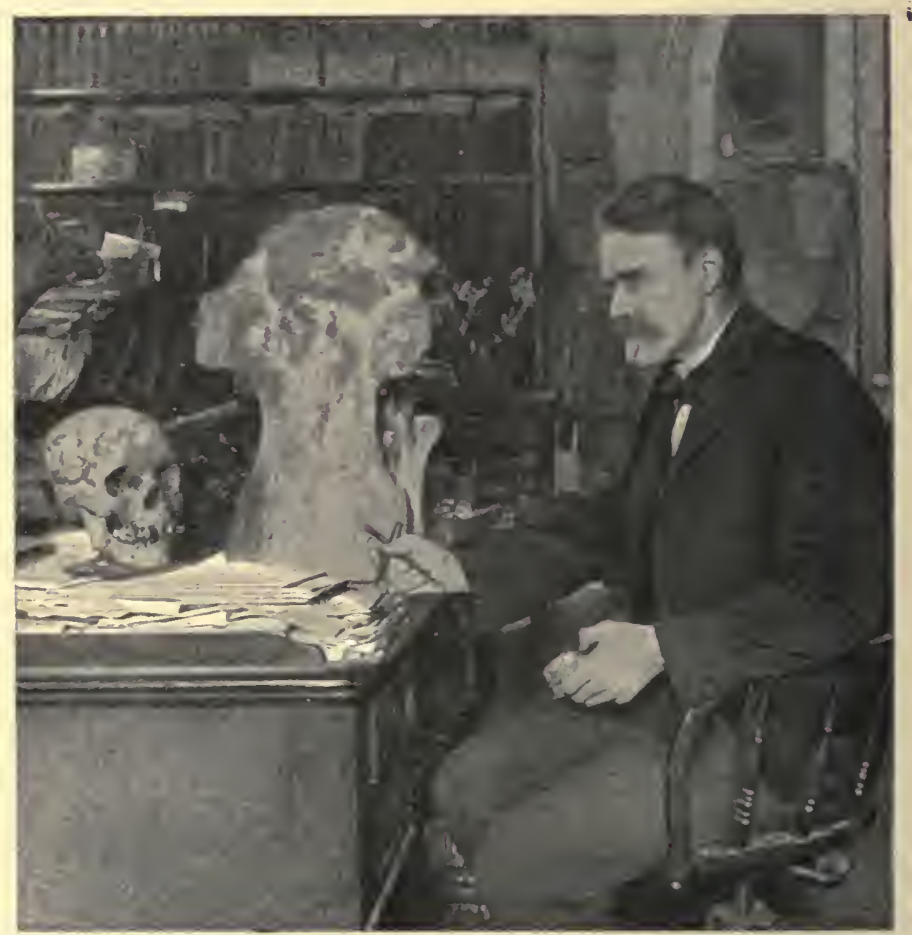

PROFESSOR E. D. COPE

been preserved, and of each page only here and there a few lines." For a paleontologist to dogmatize from such a record would be as rash, he thinks, as "for a naturalist to land for five minutes on a barren point of 


\section{THE CENTURY'S PROGRESS IN PALEUNTOLOGY}

Australia and then discuss the number and range of its productions."

This citation of observations, which when once pointed out seemed almost self-evident, came as a revelation to the geological world. In the clarified view now possible old facts took on a new meaning. It was recalled that Cuvier had been obliged to establish a new order for some of the first fossil creatures he examined, and that Buckland had noted that the nondescript forms were intermediate in structure between allied existing orders. More recently such intermediate forms had been discovered over and over; so that, to name but one example, Owen had been able, with the aid of extinct species, to "dissolve by gradations the apparently wide interval between the pig and the camel." Owen, moreover, had been led to speak repeatedly of the "generalized forms" of extinct animals, and Agassiz had called them "synthetic or prophetic types," these terms clearly implying "that such forms are in fact intermediate or connecting links." Darwin himself had shown some years before that the fossil animals of any continent are closely related to the existing animals of that continent-edentates predominating, for example, in South America, and marsupials in Australia. Many observers had noted that recent strata everywhere show a fossil fauna more nearly like the existing one than do more ancient strata; and that fossils from any two consecutive strata are far more closely related to each other than are the fossils of two remote formations, the fauna of each geological formation being, indeed, in a wide view, intermediate between preceding and succeeding faunas.

So suggestive were all these observations that Lyell, the admitted leader of the geological world, after read- 
ing Darwin's citations, felt able to drop his own crass explanation of the introduction of species, and adopt the transmutation bypothesis, thus rounding out the doctrine of uniformitarianism to the full proportions in which Lamarck had conceived it half a century before. Not all paleontologists could follow him at once, of course; the proof was not yet sufficiently demonstative for that; but all were shaken in the seeming security of their former position, which is always a necessary stage in the progress of thought. And popular interest in the matter was raised to white heat in a twinkling.

So, for the third time in this first century of its existence, paleontology was called upon to play a leading rôle in a controversy whose interest extended far beyond the bounds of staid truth-seeking science. And the controversy waged over the age of the earth had not been more bitter, that over catastrophism not more acrimonious, than that which now raged over the question of the transmutation of species. The question had implications far beyond the bounds of paleontology, of course. The main evidence yet presented had been drawn from quite other fields, but by common consent the record in the rocks might furnish a crucial test of the truth or falsity of the hypothesis. "He who rejects this view of the imperfections of the geological record," said Darwin, "will rightly reject the whole theory."

With something more than mere scientific zeal, therefore, paleontologists turned anew to the records in the rocks, to inquire what evidence in proof or refutation might be found in unread pages of the "great stone book." And as might have been expected, many minds 
being thus prepared to receive new evidence, such evidence was not long withheld.

Indeed, at the moment of Darwin's writing a new and very instructive chapter of the geologic record was being presented to the public-a chapter which for the first time brought man into the story. In $1859 \mathrm{Dr}$. Falconer, the distinguished British paleontologist, made a visit to Abberille, in the valley of the Somme, incited by reports that for a decade before had been sent out from there by M. Boucher des Perthes. These reports had to do with the alleged finding of flint implements, clearly the work of man, in undisturbed gravel beds, in the midst of fossil remains of the mammoth and other extinct animals. Dr. Falconer was so much impressed with what he saw that he urged his countrymen Professor Prestwich to go to Abbeville and thoroughly investigate the subject. Professor Prestwich complied, with the collaboration of Mr. John Evans, and the report which these paleontologists made of their investigation brought the subject of the very significant human fossils at Abbeville prominently before the public; whereas the publications of the original discoverer, Boucher des Perthes, bearing date of $18+7$, had been altogether ignored. A new aspect was thus given to the current controversy.

As Dr. Falconer remarked, geology was now passing through the same ordeal that astronomy passed in the age of Galileo. But the times were changed since the day when the author of the Dialogues was humbled before the Congregation of the Index, and now no Index 


\section{THE STORY OF NINETEENTH-CENTURY SCIENCE}

Prohibitorum could avail to hide from eager human eyes such pages of the geologic story as Nature herself had spared. Eager searchers were turning the leaves with renewed zeal everywhere, and with no small measure of success. In particular, interest attached just at this time to a buman skull which Dr. Fuhlrott had dis-

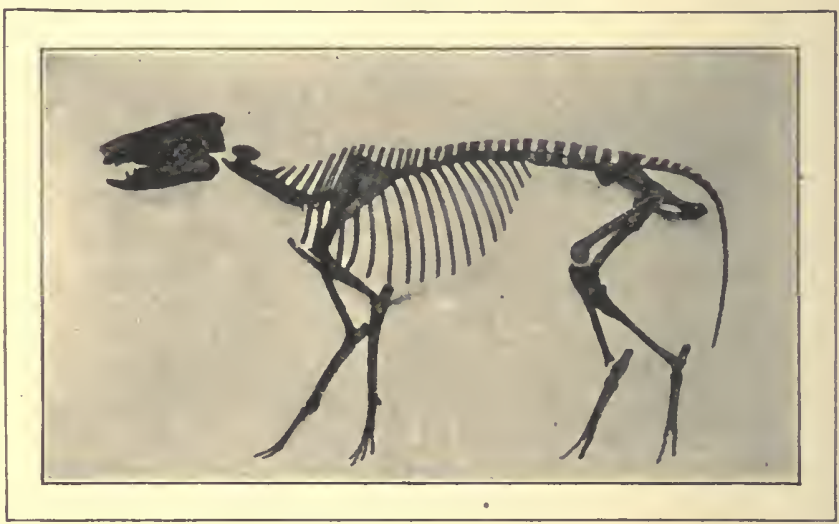

PROTOROHIPPUS, TUE ANCESTRAL FOUR-TOED HOTSE

Height at shoulder, 16 inches. From the Big Horn Jountains

covered in a cave at Neanderthal two or three years before-a cranium which has ever since been famous as the Neanderthal skull, the type specimen of what modern zoologists are disposed to regard as a distinct species of man, Homoneanderthalensis. Like others of the same type since discovered at Spy, it is singularly Simian in character-low-arched, with receding forehead and enormous protuberant eyebrows. When it was first exhibited to the scientists at Berlin by Dr. Fuhlrott, in 1857 , its human character was doubted by some of the witnesses; of that, however, there is no present question. 


\section{THE CENTURY'S PROGRESS IN PALEONTOLOGY}

This interesting find served to recall with fresh significance some observations that had been made in France and Belgium a long generation earlier, but whose bearings had hitherto been ignored. In 1826 MM. Tournal and Christol had made independent discoveries of what they believed to be human fossils in the caves of the south of France; and in 1827 Dr. Schmerling had found in the care of Engis; in Westphalia, fossil bones jof even greater significance. Schmerling's explorations had been made with the utmost care and patience. At Engis he had found human bones, including skulls, intermingled with those of extinct manmals of the mammoth period in a way that left no doubt in his mind that all dated from the same geological epoch. He had published a full account of his discoveries in an elaborate monograph issued in 1833 .

But at that time, as it chanced, human fossils were under a ban as effectual as any ever pronounced by canonical index, though of far different origin. The oracular voice of Cuvier had declared against the authenticity of all human fossils. Some of the bones brought him for examination the great anatomist had pettishly pitched out of the window, declaring them fit only for a cemetery, and that had settled the matter for a generation: the evidence gathered by lesser workers could avail nothing against the decision rendered at the Delphi of Science. But no ban, scientific or canonical, can long resist the germinative power of a fact, and so now, after three decades of suppression, the truth which Curier had buried beneath the weight of his ridicule burst its bonds, and fossil man stood revealed, if not as a flesh and blood, at least as a skeletal entity.

The reception now accorded our prehistoric ancestor 


\section{THE STORY OF NINETEENTH-CENTURY SCIENCE}

by the progressive portion of the scientific world amounted to an ovation; but the unscientific masses, on the other hand, notwithstanding their usual fondness for tracing remote genealogies, still gave the men of Engis and

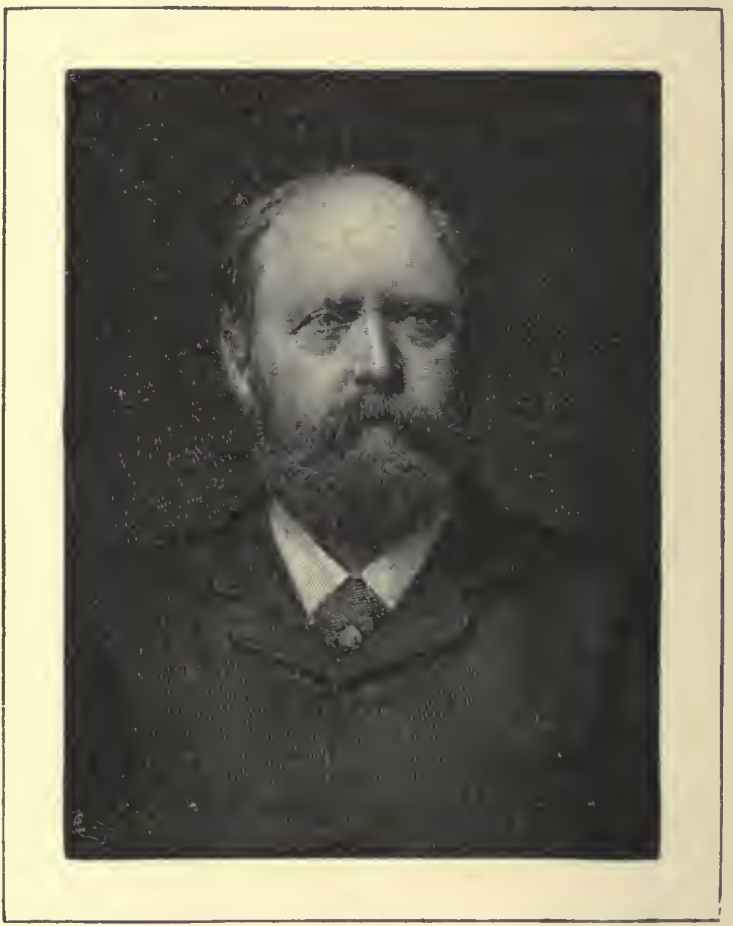

PROFESSOR O. C. MARSH

Neanderthal the cold shoulder. Nor were all of the geologists quite agreed that the contemporaneity of these human fossils with the animals whose remains had been mingled with them had been fully established. The bare possibility that the bones of man and of animals 
that long preceded him had been swept together into the cares in successive ages, and in some mysterious way intermingled there, was clung to by the conservatives as a last refuge. But even this small measure of security was soon to be denied them, for in 1865 two associated workers, M. Edouard Lartet and Mr. Henry Christy, in exploring the caves of Dordogne, unearthed a bit of evidence against which no such objection could be urged. This momentous exhibit was a bit of ivory, a fragment of the tusk of a mammoth, on which was scratched a rude but unmistakable outline portrait of the mammoth itself. If all the evidence as to man's antiquity before presented was suggestive merely, here at last was demonstration; for the cave-dwelling man could not well have drawn the picture of the mammoth unless he had seen that animal, and to almit that man and the mammoth had been contemporaries was to concede the entire case. So soon, therefore, as the full import of this most instructive work of art came to be realized, scepticism as to man's antiquity was silenced for all time to come.

In the generation that has elapsed since the first drawing of the cave-dweller artist was discovered, evidences of the wide-spread existence of man in an early epoch have multiplied indefinitely, and to-day the paleontologist traces the history of our race back beyond the iron and bronze ages, through a neolithic or polished-stone age, to a paleolithic or rough-stone age, with confidence born of unequirocal knowledge. And he looks confidently to the future explorer of the earth's fossil records to extend the history back into vastly more remote epochs, for it is little doubted that paleolithic man, the most ancient of our recognized progenitors, is a modern 


\section{THE STORY OF NINETEENTH-CENTURY SCIENCE}

compared to those generations that represented the real childhood of our race.

\section{VI}

Coincidently with the discovery of these highly suggestive pages of the geologic story, other still more instructive chapters were being brought to light in America. It was found that in the Rocky Mountain region, in strata found in ancient lake beds, records of the tertiary period, or age of mammals, had been made and preserved with fulness not approached in any other region hitherto geologically explored. These records were made known mainly by Professor's Joseph Leidy, O. C. Marsh, and E. D. Cope, working independently, and more recently by numerous younger paleontologists.

The profusion of vertebrate remains thus brought to light quite beggars all previous exhibits in point of mere numbers. Professor Marsh, for example, who was first in the field, found 300 new tertiary species between the years 1870 and 1S76. Meanwhile, in cretaceous strata, he unearthed remains of about 200 birds with teeth, 600 pterodactyls, or flying dragons, some with a spread of wings of twenty-five feet, and 1500 mosasaurs of the sea-serpent type; some of them sixty feet or more in length. In a single bed of Jurassic rock, not larger than a good-sized lecture-room, he found the remains of 160 individuals of mammals, representing twenty species and nine genera; while beds of the same age have yielded 300 reptiles, varying from the size of a rabbit to sixty or eighty feet in length.

But the chief interest of these fossils from the West is 


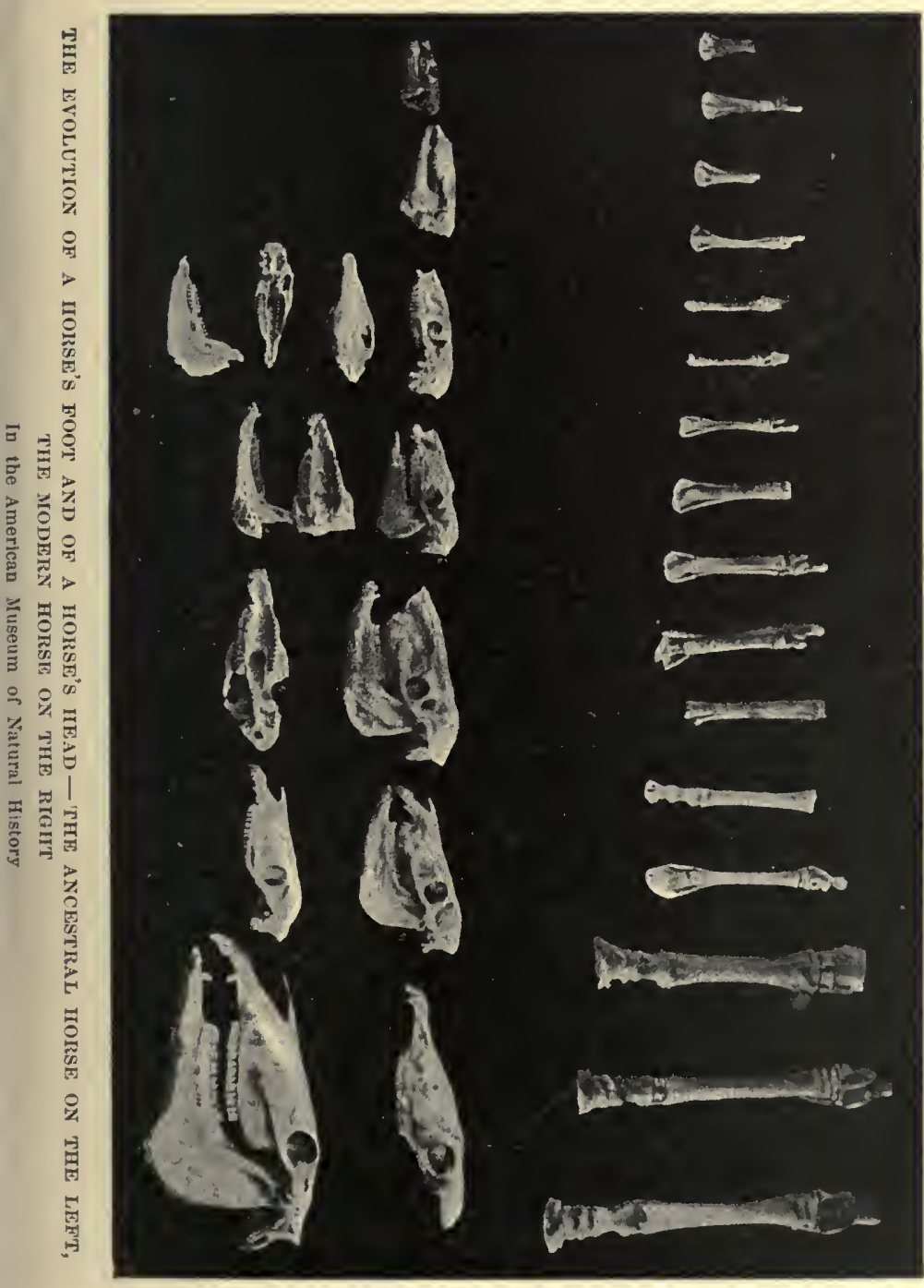



not their number but their nature; for among them are numerous illustrations of just such intermediate types of organisms as must have existed in the past if the succession of life on the globe has been an unbroken lineal succession. Here are reptiles with bat-like wings, and others with bird-like pelves and legs adapted for bipedal locomotion. Here are birds with teeth and other reptilian characters. In short, what with reptilian birds and bird-like reptiles, the gap between modern reptiles and birds is quite bridged over. In a similar way, various diverse mammalian forms, as the tapir, the rhinoceros, and the horse, are linked together by fossil progenitors. And most important of all, Professor Marsh has discovered a series of mammalian remains, occurring in successive geological epochs, which are held to represent beyond cavil the actual line of descent of the modern horse; tracing the lineage of our one-toed species back through two and three toed forms, to an ancestor in the encene or early tertiary that had four functional toes and the rudiment of a fifth.

These and such like revelations have come to light in our own time; are, incleed, still being disclosed. Needless to say, no Index of any sort now attempts to conceal them; yet something has been accomplished towards the same end by the publication of the discoveries in Smithsonian bulletins, and in technical memoirs of government surveys. Fortunately, however, the results have been rescued from that partial oblivion by such interpreters as Professors Huxley and Cope, so the unscientific public has been allowed to gain at least an inkling of the wonderful progress of paleontology in our generation.

The writings of Huxley in particular epitomize the 
record. In 1862 he admitted candidly that the paleontological record as then known, so far as it bears on the doctrine of progressive development, negatives that doctrine. In 1870 he was able to "soften somewhat the Brutus-like severity" of his former verdict, and to assert that the results of recent researches seem "to leave a clear balance in favor of the doctrine of the evolution of living forms one from another." Six years later, when reviewing the work of Marsh in America and of Gaudry in Pikermi, he declared that, "on the evidence of paleontology, the evolution of many existing forms of animal life from their predecessors is no longer an hypothesis,

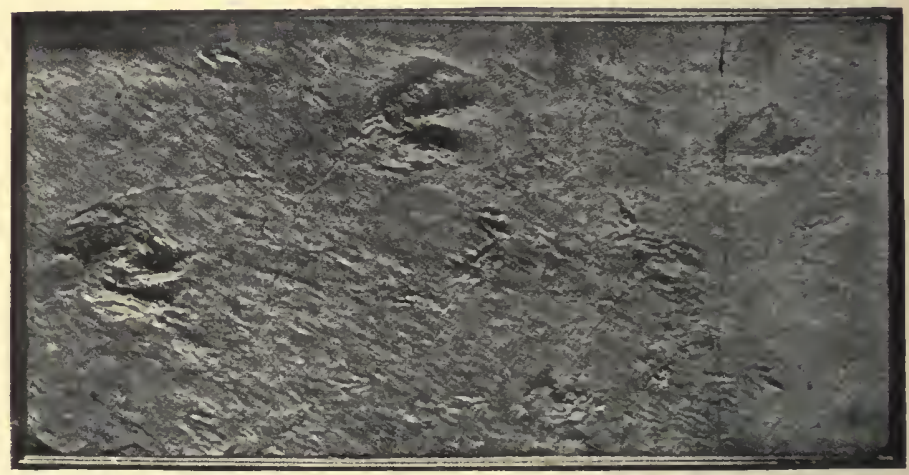

FOOTPRINTS OF REPTILES FOUND IN CONNECTICUT SANDSTONE In the American Suseum of Natural History

but an historical fact." In $18 s 1$ he asserted that the evidence gathered in the previous decade had been so unequivocal that, had the transmutation hypothesis not existed, "the paleontologist would have had to in vent it."

Since then the delvers after fossils have piled proof on proof in bewildering profusion. The fossil beds in 


\section{TILE CENTURY'S PROGRESS IN PALEONTOLOGY}

the "bad lands" of western America seem inexhaustible. And in the Connecticut River Valley near relatives of the great reptiles which Professor Marsh and others have found in such profusion in the West left their tracks on the mud flats-since turned to sandstone; and a few skeletons also have been found. The bodies of a race of great reptiles that were the lords of creation of their day have been dissipated to their elements, while the chance indentations of their feet as they raced along the shores, mere footprints on the sands, have been preserved among the most imperishable of the memorytablets of the world.

Of the other vertebrate fossils that have been found in the eastern portions of America, among the inost abundant and interesting are the skeletons of mastodons. Of these one of the largest and most complete is that which was unearthed in the bed of a drained lake near Newburg, New York, in 1St5. This specimen was larger than the existing elephants, and had tusks eleven feet in length. It was mounted and described by Dr. John C. Warren, of Boston, and has been famous for half a century as the "Warren mastodon."

But to the student of racial development as recorded by the fossils, all these sporadic finds have but incidental interest as compared with the rich Western fossil beds to which we have already referred. From records here unearthed the racial evolution of many mammals has in the past few years been made out in greater or less detail. Professor Cope lias traced the ancestry of the camels (which, like the rhinoceroses, hippopotami, and sundry other forms now spoken of as "Old World," seem to have had their origin here) with much completeness. 
A lemuroid form of mammal, believed to be of the type from which man has descended, has also been found in these beds. It is thought that the descendants of this creature, and of the other "Old-World" forms above referred to, found their way to Asia, probably, as sug-

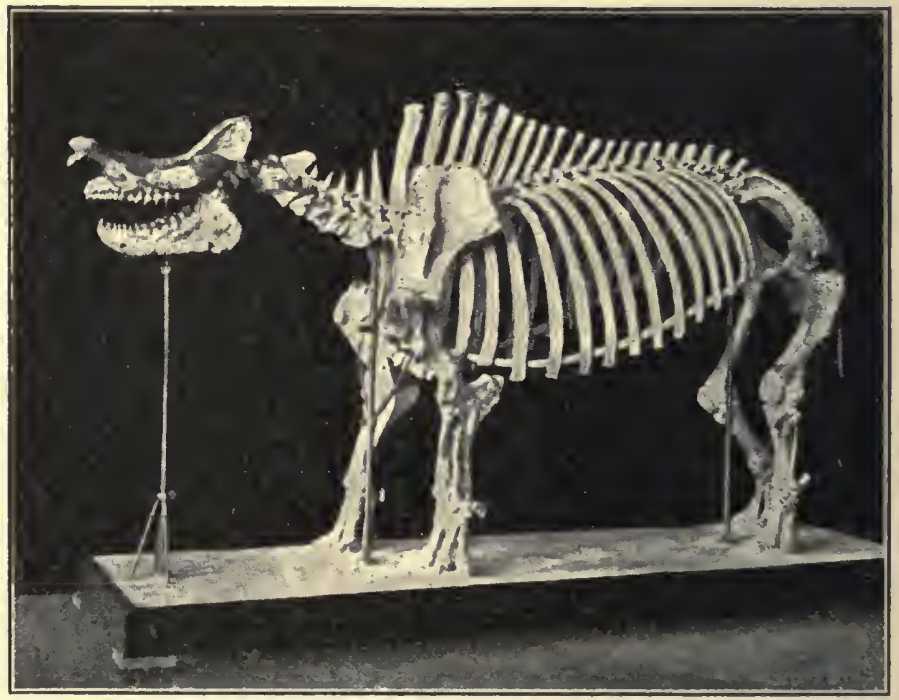

TITANOTHERE FROM SOUTH DAKO'TA

In the American Museum of Natural History

gested by Professor Marsh, across a briclge at Bering Strait, to continue their evolution on the other hemisphere, becoming extinct in the land of their nativity. The ape-man fossil found in the tertiary strata of the island of Java two years ago by the Dutch surgeon Dr. Engène Dubois, and named Pithecanthropus erectus, may have been a direct descendant of the American tribe of primitive lemurs, though this is only a conjecture. 


\section{THE CENTURY'S PROGRESS IN PALEONTOLOGY}

Not all the strange beasts which have left their remains in our "bad lands" are represented by living descendants. The titanotheres, or brontotheridæ, for example, a gigantic tribe, offshoots of the same stock which produced the horse and rhinoceros, represented the culmination of a line of descent. They dereloped rapidly in a geological sense, and flourished about the middle of the tertiary period; then, to use Agassiz's phrase, "time fought against them." The story of their erolution has been worked out by Professors Leidy, Marsh, Cope, and H. F. Osborne.

The very latest bit of paleontological evidence bearing on the question of the introduction of species is that presented by Dr. J. L. Wortman in connection with the fossil lineage of the edentates. It was suggested by Marsh, in 1877, that these creatures, whose modern representatives are all South American, originated in North America long before the two continents had any land connection. The stages of degeneration by which these animals gradually lost the enamel from their teeth, coming finally to the unique condition of their modern descendants of the sloth tribe, are illustrated by strikingly graded specimens now preserved in the American Museum of Natural History, as shown by Dr. Wortman.

All these and a multitule of other recent observations that cannot be even outlined here tell the same story With one accord paleontologists of our time regard the question of the introduction of new species as solved. As Professor Marsh has sail, "to doubt evolution today is to doubt science; and science is only another name for truth."

Thus the third great battle over the meaning of the fossil records has come to a conclusion. Again there 


\section{THE STORY OF NINETEENTH-CENTURY SCIENCE}

is a truce to controversy, and it may seem to the casual observer that the present stand of the science of fossils is final and impregnable. But does this really mean that a full synopsis of the story of paleontology has been told? Or do we only await the coming of the twentieth-century Lamarck or Darwin, who shall attack the fortified knowledge of to-day with the batteries of a new generalization? 
CHAPTER IV

\section{THE CENTURY'S PROGRESS IN GEOLOGY}

JAMES HutTov's theory that continents wear away and are replaced by volcanic upheaval had gained comparatively few adherents at the beginning of our century. Even the lucid Illustrations of the IIuttonian Theory, which Playfair, the pupil and friend of the great Scotchman, published in 1502, did not at once prove convincing. The world had become enamoured of the rival theory of Hutton's famous contemporary, Werner of Saxony-the theory which taught that "in the beginning" all the solids of the earth's present crust were dissolved in the heated waters of a universal sea. Werner affirmed that all rocks, of whatever character, had been formed by precipitation from this sea, as the waters cooled; that even veins have originated in this way; and that mountains are gigantic crystals, not upheaved masses. In a word, he practically ignored volcanic action, and denied in toto the theory of metamorphosis of rocks through the agency of heat.

The followers of Werner came to be known as Neptunists; the Huttonians as Plutonists. The history of geology during our first quarter-century is mainly a recital of the intemperate controversy between these op- 


\section{THE STORY OF NINETEENTH-CEN'TURY SCIENCE}

posing schools; though it should not be forgotten that, meantime, the members of the Geological Society of London were making an effort to hunt for facts and avoid compromising theories. Fact and theory, however, were too closely linked to be thus dirorced.

The brunt of the controversy settled about the unstratified rocks-granites and their allies-which the Plutonists claimed as of igneous origin. This contention had the theoretical support of the nebular hypothesis, then gaining ground, which supposed the earth to be a cooling globe. The Plutonists laid great stress, too, on the observed fact that the temperature of the earth increases at a pretty constant ratio as descent towards its centre is made in mines. But in particular they appealed to the phenomena of volcanoes.

The evidence from this source was gathered and elaborated by Mr. G. Poulett Scrope, secretary of the Geological Society of England, who, in 1823, published a classical work on rolcanoes, in which he claimed that volcanic mountains, including some of the lighest known peaks, are merely accumulated masses of lava belched forth from a crevice in the earth's crust. The Neptunists stoutly contended for the aqueous origin of volcanic as of other mountains.

But the facts were with Scrope, and as time went on it came to be admitted that not merely volcanoes, but many "trap" formations not taking the form of craters had been made by the obtrusion of molten rock through fissures in overlying strata. Such, for example, to cite familiar illustrations, are Mount Holyoke, in Massachusetts, and the well-known formation of the Palisades along the Hudson.

But to admit the "Plutonic" origin of such wide- 
spread formations was practically to abandon the Neptunian hypothesis. So gradually the Huttonian explanation of the origin of granites and other "igneous" rocks, whether massed or in veins, came to be accepted. Most geologists then came to think of the earth as a molten mass, on which the crust rests as a mere film. Some, indeed, with Lyell, preferred to believe that the molten areas exist only as lakes in a solid crust, heated to melting, perhaps, by electrical or chemical action, as Davy suggested. More recently a popular theory attempts to reconcile geological facts with the claim of the physicists, that the earth's entire mass is at least as rigid as steel, by supposing that a molten film rests between the observed solid crust and the alleged solid nucleus. But be that as it may, the theory that subterranean heat has been instrumental in determining the condition of "primary" rocks, and in producing many other phenomena of the earth's crust, has never been in dispute since the long controversy between the Neptunists and the Plutonists led to its establishment.

If molten matter exists beneath the crust of the earth, it must contract an cooling, and in so doing it must disturb the level of the portion of the crust already solidified. So a plausible explanation of the upheaval of continents and mountains was supplied by the Plutonian theory, as Hutton had from the first alleged. But now an important difference of opinion arose as to the exact rationale of such upheavals. Hutton himself, and practically every one else who accepted his theory, had supposed that there are long periods of relative repose, 
during which the level of the crust is undisturbed, followed by short periods of active stress, when continents are thrown up with volcanic suddenness, as by the throes of a gigantic earthquake. But now came Charles Lyell with his famous extension of the "uniformitarian" doctrine, claiming that past changes of the earth's surface have been like present changes in degree as well as in kind. The making of continents and mountains, he said, is going on as rapidly to-day as at any time in the past. There have been no gigantic cataclysmic uphearals at any time, but all changes in level of the strata as a whole have been gradual, by slow oscillation, or at most by repeated earthquake shocks such as are still often experienced.

In support of this very startling contention Lyell gathered a mass of evidence of the recent changes in level of continental areas. He corroborated by personal inspection the claim which had been made by Playfair in 1802, and by ron Buch in 1807 , that the coast-line of Sweden is rising at the rate of from a few inches to sereral feet in a century. He cited Daririn's observations going to prove that Patagonia is similarly rising, and Pingel's claim that Greenland is slowly sinking. I'roof as to sudden changes of level of several feet, over large areas, due to earthquakes, was brought forward in abundance. Cumulative evidence left it no longer open to question that such oscillatory changes of level, either upward or downward, are quite the rule, and it could not be denied that these observed changes, if continued long enough in one direction, would produce the highest elevations. The possibility that the making of even the highest ranges of mountains had been accomplished without exaggerated catastrophic action came to be freely admitted. 


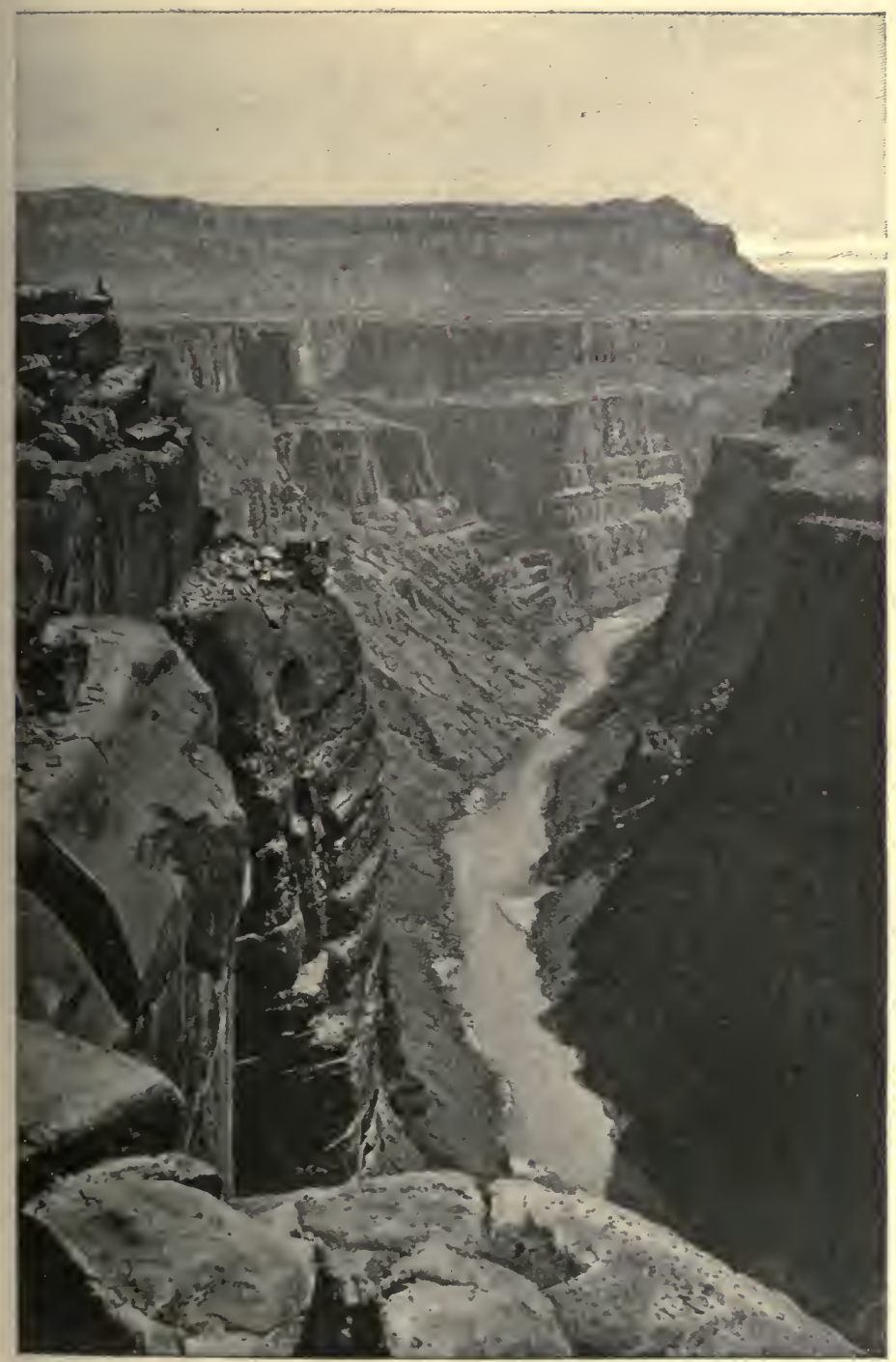

THF RESULTS OF EROSION BY RUNNING WATER 

It became clear that the supposedly stable land surfaces are in reality much more variable than the surface of the "shifting sea"; that continental masses, seemingly so fixed, are really rising and falling in billows thousands of feet in height, ages instead of moments being consumed in the sweep between crest and hollow.

These slow oscillations of land surfaces being understood, many geological enigmas were made clear-such as the alternation of marine and fresh-water formations in a vertical series, which Cuvier and Brongniart had observed near Paris; or the sandwiching of layers of coal, of subaerial formation, between layers of subaqueous clay or sandstone, which may be observed everywhere in the coal measures. In particular, the extreme thickness of the sedimentary strata as a whole, many times exceeding the depth of the deepest known sea, was for the first time explicable when it was understool that such strata had formed in slowly sinking ocein-beds.

All doubt as to the mode of origin of stratified rocks being thus removed, the way was opened for a more favorable cousideration of that other IIuttonian doctrine of the extremely slow denudation of land surfaces. The enormous amount of land erosion will be patent to any one who uses his eyes intelligently in a mountain district. It will be evident in any region where the strata are tilted-as, for example, the Alleghaniesthat great folds of strata which must once have risen miles in lieight have in many cases been worn entirely away, so that now a valley marks the location of the former eminence. Where the strata are level, as in the case of the mountains of Sicily, the Scotch Highlands, and the familiar Catskills, the evidence of denudation is, 


\section{TIIE STORY OF NINETEENTH-CEN'ULY SCIENCE}

if possible, even more marked; for here it is clear that elevation and valley have been carved by the elements out of land that rose from the sea as level plateaus.

But that this herculean labor of land-sculpturing could have been accomplished by the slow action of wind and frost and shower was an idea few men could grasp within the first half-century after Hutton propounded it; nor did it begin to gain general currency until Lyell's crusade against catastrophism, begun about 1830, had for a quarter of a century accustomed geologists to the thought of slow continuous changes producing final results of colossal proportions. And eren long after that, it was combated by such men as Murchison, Director-General of the Geological Survey of Great Britain, then accounted the foremost field-geologist of his time, who continued to believe that the existing valleys owe their main features to subterranean forces of upheaval. Even Murchison, however, made some recession from the belief of the Continental authorities, Elie de Beaumont and Leopold von Buch, who contended that the mountains had sprung up like veritable jacks-in-thebox. Von Buch, whom his friend and fellow-pupil von Humboldt considered the foremost geologist of the time, died in 1853 , still firm in his early faith that the erratic bowlders found high on the Jura had been hurled there, like cannon-balls, across the ralley of Genera by the sudden upheaval of a neighboring mountain range.

III

The bowlders whose presence on the crags of the Jura the old German accounted for in a manner so theatrical had long been a source of contention among geologists. 
They are found not merely on the Jura, but on numberless other mountains in all north temperate latitudes, and often far out in the open country, as many a farmer who has broken his plough against them might testify. The early geologists accounted for them, as for nearly every thing else, with their supposititious Deluge. Brong-

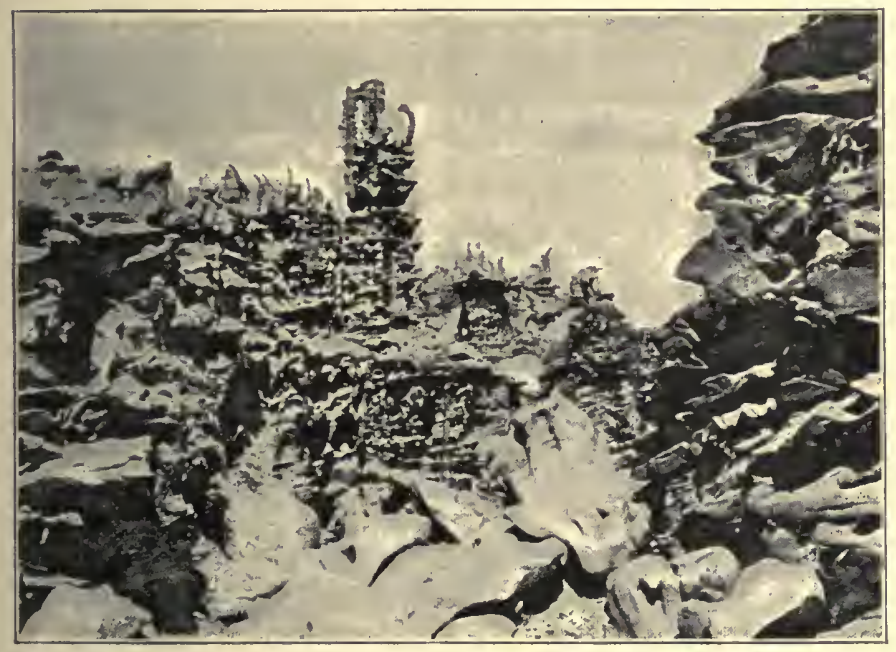

THE RESULTS OF EROSION BY WIND

niart and Cuvier and Buckland and their contemporaries appeared to have no difficulty in conceiving that masses of granite weighing hundreds of tons had been swept by this current scores or hundreds of miles from their source. But of course the uniformitarian faith permitted no such explanation, nor could it countenance the projection idea; so Lyell was bound to find some other means of transportation for the puzzling erratics.

The only available medium was ice, but fortunately 131 
this one seemed quite sufficient. Icebergs, said Lyell, are observed to carry all manner of débris, and deposit it in the sea-bottoms. Present land surfaces have often been submerged beneath the sea. During the latest of these submergences icebergs deposited the bowlders now scattered here and there over the land. Nothing could be simpler or more clearly uniformitarian. And even the catastrophists, though they met Lyell amicably on almost no other theoretical ground, were inclined to admit the plausibility of his theory of erratics. Indeed, of all Lyell's non-conformist doctrines, this seemed the one most likely' to meet with general acceptance.

Yet, even as this iceber'g theory loomed large and larger before the geological world, observations were making in a different field that were destined to show its fallacy. As early as 1815 a sharp-eyed chamois-hunter of the Alps, Perraudin by name, had noted the existence of the erratics, and, unlike most of his companion hunters, had puzzled his head as to how the bowlders got where he saw them. He knew nothing of submerged continents or of icebergs, still less of upheaving mountains; and though he doubtless had heard of the Flood, he had no experience of heary rocks lloating like corks in water. Moreover, he had never observed stones rolling up hill and perching themselves on mountaintops, and he was a good enough uniformitarian (though he would have been puzzled indeed had any one told him so) to disbelieve that stones in past times had disported themselves differently in this regard from stones of the present. Yet there the stones are. How did they get there?

The mountaineer thought that he coulil answer that question. He saw about him those gigantic serpent-like 132 


\section{THE CENTURY'S PROGRESS IN GEOLOGY}

streams of ice called glaciers, "from their far fountains slow rolling on," carrying with them blocks of granite and other débris to form moraine deposits. If these glaciers had once been much' more extensive than they now are, they might have carried the bowlders and left them where we find them. On the other hand, no other natural agency within the sphere of the chamois-hunt-

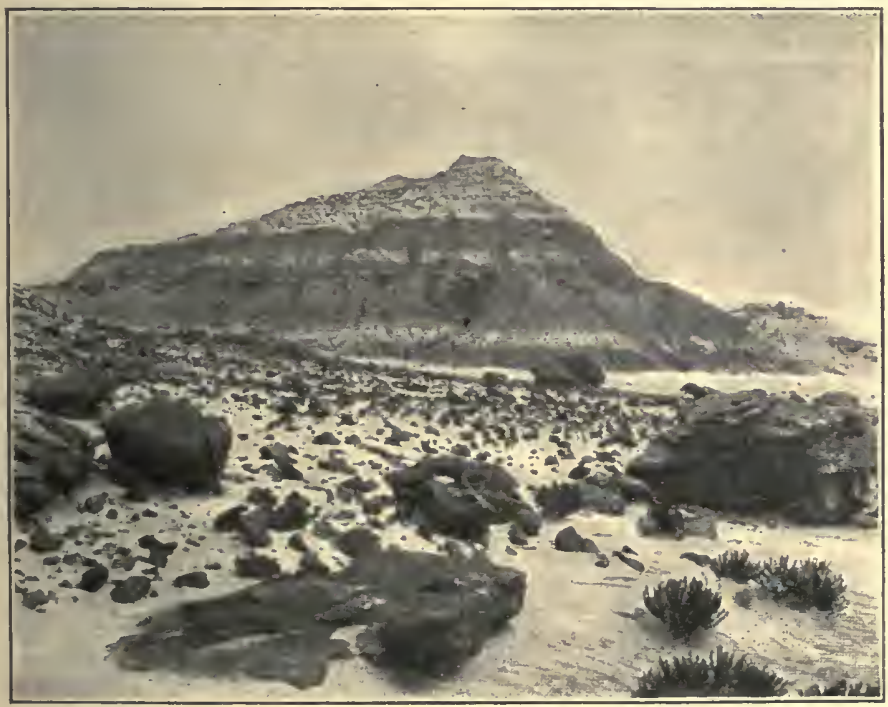

A MOUNTAIN CAIRVD FIROM IORIZONTAL STRATA

er's linowledge could have accomplished this, ergo the glaciers must once have been more extensive. Perraudin would probably have said that common-sense drove him to this conclusion; but be that as it may, he luad conceived one of the few truly original and novel ideas of which our century can boast. 


\section{THE STORY OF NINETEENTH-CENTURY SCIENCE}

Perraudin announced his idea to the greatest scientist in his little world-Jean de Charpentier, director of the mines at Bex, a skilled geologist who had been a fellowpupil of von Buch and von Humboldt under Werner at the Freiberg School of Mines. Charpentier laughed at the mountaineer's grotesque idea, and thought no more about it. And ten years elapsed before Perraudin could find any one who treated his notion with greater respect. 'Then he found a listener in M. Venetz, a civil engineer, who read a paper on the novel glacial theory before a local society in 1823 . This brought the matter once more to the attention of de Charpentier, who now felt that there might be something in it worth investigation.

A survey of the field in the light of the new theory soon convinced Charpentier that the chamois-hunter had all along been right. He became an enthusiastic supporter of the idea that the Alps had once been embedded in a mass of ice, and in 1836 he brought the notion to the attention of Louis Agassiz, who was spending the summer in the Alps. Agassiz was sceptical at first, but soon became a convert. Then he saw that the implications of the theory extended far beyond the Alps. If the Alps had been covered with an ice sheet, so had many other regions of the northern hemisphere. Casting abroad for evidences of glacial action, Agassiz found them everywhere, in the form of transported erratics, scratched and polished outcropping rocks, and morainelike deposits. Presently he became convinced that the ice sheet which covered the Alps had spread orer the whole of the higher latitudes of the northern hemisphere, forming an ice cap over the giobe. Thus the common-sense induction of the chamois-hunter blos- 


\section{TIIE CENTURY'S I'ROGRESS IN GEOLOGY}

somed in the mind of Agassiz into the conception of a universal Ice Age.

In 1857 Agassiz introduced his theory to the world, in a paper read at Neuchâtel, and three years later he published his famous Etudes sur les Glaciers. Never did idea make a more profound disturbance in the scientific world. Von Buch treated it with alternate ridicule, contempt, and

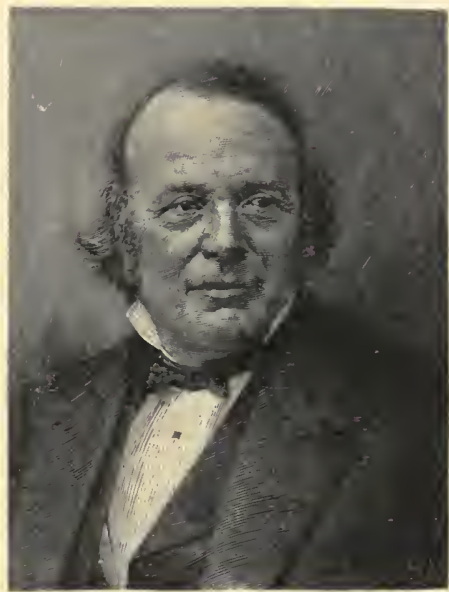

LOUIS JEAX RODOLPI AGASSIZ rage; Murchison opposed it with customary vigor; even Lyell, whose most remarkable mental endowment was an unfailing receptiveness to new truths, could not at

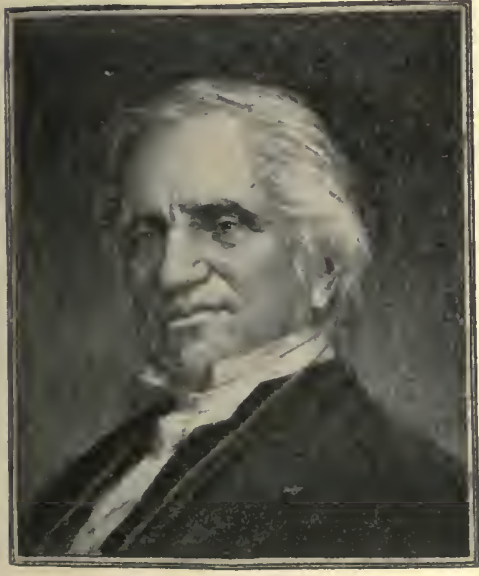

ADAM SEDGWICK, F.R.S. once discard his iceberg theory in favor of the new claimant. Dr. Buckland, however, after Agassiz had shown him evidence of former glacial action in his own Scotland, became a convert - the more readily, perhaps, as it seemed to him to oppose the uniformitarian idea. Gradually others fell in line, and after the usual embit- 


\section{THE STORY OF NINETEENTH-CENTURY SCIENCE}

tered controversy and the inevitable full generation of probation, the idea of an Ice Age took its place among the accepted tenets of geology. All manner of moot points still clemanded attention - the cause of the Ice Age, the exact extent of the ice sheet, the precise manner in which it produced its effects, and the exact nature of these effects ; and not all of these have even yet been determined. But, details aside, the Ice Age now has full recognition from geologists as an historical period. There may have been many Ice Ages, as Dr. Croll contends; there was surely one; and the conception of such a period is one of the very few ideas of our century that no previous century had eren so much as faintly adumbrated.

IV

But, for that matter, the entire subject of historical geology is one that had but the barest beginning before our century. Until the paleontologist found out the key to the earth's chronology, no one-not even Hutton - could have any definite idea as to the true story of the earth's past. The only conspicuous attempt to classify the strata was that made by Werner, who divided the rocks into three systems, based on their supposed order of deposition, and called primary, transition, and secondary.

Though Werner's observations were confined to the small province of Saxony, he did not hesitate to affirm that all over the world the succession of strata would be found the same as there, the concentric layers, according to this conception, being arranged about the earth with the regularity of layers on an onion. But in this Werner was as mistaken as in his theoretical explana- 


\section{THE CENTURY'S PROGRESS IN GEOLOGY}

tion of the origin of the "primary" rocks. It required but little observation to show that the exact succession of strata is never precisely the same in any widely separated regions. Nevertheless, there was a germ of truth in Werner's system. It contained the idea, however faultily interpreted, of a chronological succession of strata; and it furnished a work-

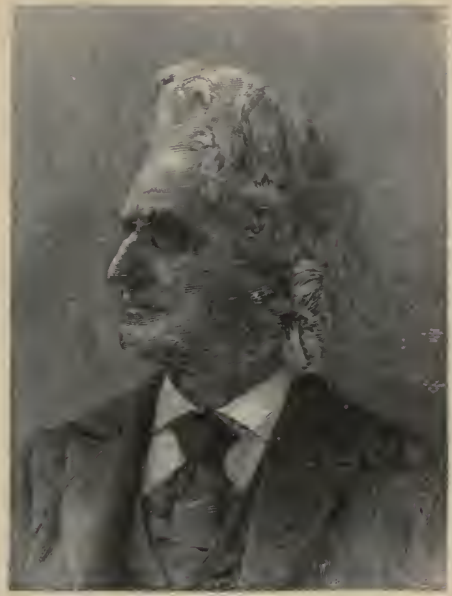

JAMES DWTGHT DAXA ing outline for the observers who were to make out the true story of geological development. But the correct interpretation of the observed facts could only be made

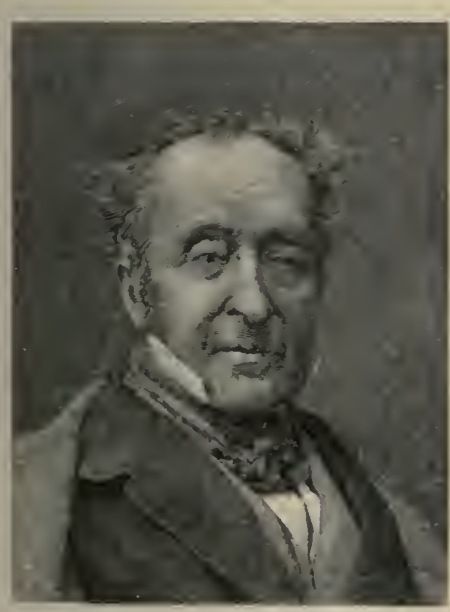

SIR RODERICK IMPEY MCRCIHSON after the Huttonian view as to the origin of strata had gained complete acceptance.

When William Smith, having found the true key to this story, attempted to apply it, the territory with which he lad to deal chanced to be one where the surface rocks are of that later series which Werner termed secondary. He made numerrous subdivisions within 


\section{THE STORY OF NINETEENTII-CENTURY SCIENCE}

this system, based mainly on the fossils. Meantime it was found that, judged by the fossils, the strata that Brongniart and Cuvier studied near Paris were of a still more recent period (presumed at first to be due to the latest deluge), which came to be spoken of as tertiary. It was in these beds, some of which seemed to have been formed in fresh-water lakes, that many of the strange mammals which Cuvier first described were found.

But the "transition" rocks, underlying the "secondary" system that Smith studied, were still practically unexplored when, along in the thirties, they were taken in hand by Roderick Impey Murchison, the reformed fox-hunter and ex-captain who had turned geologist to such notable advantage, and Adam Sedgivick, the brilliant Woodwardian professor at Cambridge.

Working together, these two friends classified the transition rocks into chronological groups, since familiar to every one in the larger outlines as the Silurian system (age of invertebrates) and the Devonian system (age of fishes)-names derived respectively from the country of the ancient Silures, in Wales, and Devonshire, England. It was subsequently discovered that these systems of strata, which crop out from beneath newer rocks in restricted areas in Britain, are spread out into broad undisturbed sheets over thousands of miles in continental Europe and in America. Later on Murchison studied them in Russia, and described them, conjointly with Verneuil and von Kerserling, in a ponderous and classical work. In America they were studied by Hall, Newberry, Whitney, Dana, Whitfield, and other pioneer geologists, who all but anticipated their English contemporaries.

The rocks that are of still older formation than those 
THE CENTURY'S PROGRESS IN GEOLOGY

studied by Murchison and Sedgwick (corresponding in location to the "primary" rocks of Werner's conception) are the surface feature of vast areas in Canada, and were first prominently studied there by William I.

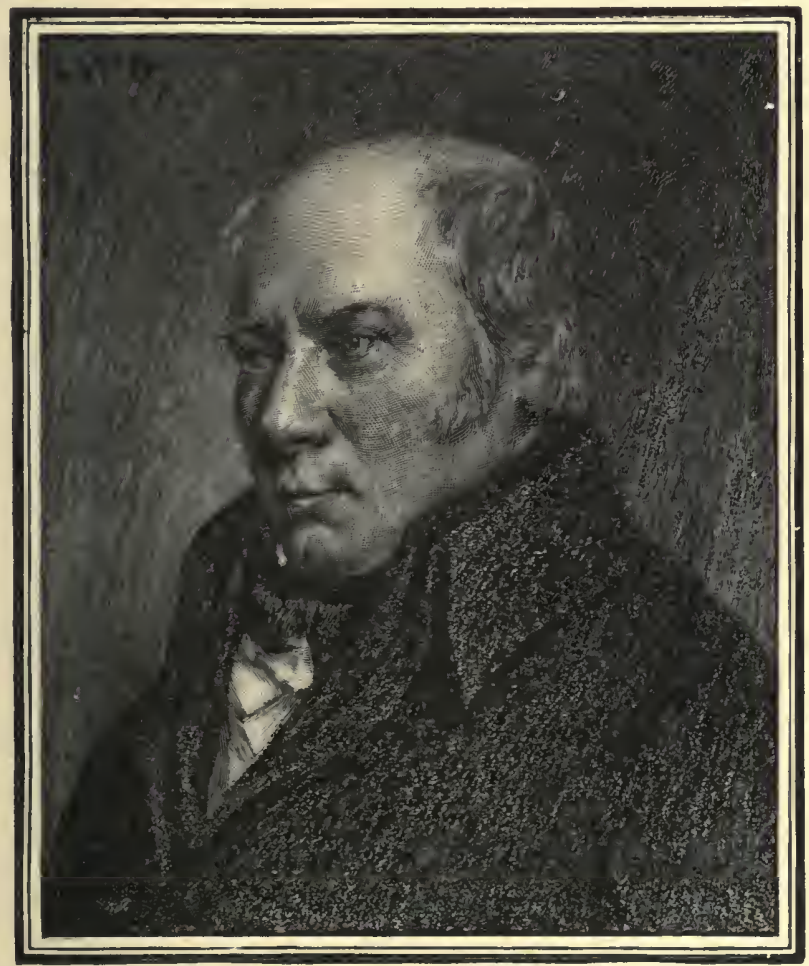

WILLIAM SMITH, LL.D.

Logan, of the Canadian Government Survey, as early as 1846, and later on by Sir William Dawson. These rocks -comprising the Laurentian system-were formerly supposed to represent parts of the original crust of the earth, 


\section{'THE STORY OF NINETEENTH-CENTURY SCIENCE}

formed on first cooling from a molten state; but they are now more generally regarded as once-stratified deposits metamorphosed by the action of heat.

Whether " primitive" or metamorphic, however, these Canadian rocks, and analogous ones beneath the fossiliferous strata of other countries, are the oldest portions of the earth's crust of which geology has any present knowledge. Mountains of this formation, as the Adirondacks, and the Storm King range overlooking the Hudson near West Point, are the patriarchs of their kind, beside which Alleghanies and Sierra Nevadas are recent upstarts, and Rockies, Alps, and Andes are mere parvenus of yesterday.

The Laurentian rocks were at first spoken of as representing "Azoic" time; but in 1846 Dawson found a formation deep in their midst which was believed to be the fossil relic of a very low form of life, and after that it became customary to speak of the system as "Eozoic." Still more recently the title of Dawson's supposed fossil to rank as such has been questioned, and Dana's suggestion that the early rocks be termed merely Archæan has met with general favor. Murchison and Sedgwick's Silurian, Devonian, and Carboniferous groups (the ages of invertebrates, of fishes, and of coal plants respectively) are together spoken of as representing Paleozoic time. William Smith's sy'stem of strata, next above these, once called "secondary," represents Mesozoic time, or the age of reptiles. Still higher, or more recent, are Curier and Brongniart's Tertiary rocks, representing the age of mammals. Lastly, the most recent formations, dating back, however, to a period far enough from recent in any but a geological sense, are classed as Quaternary, representing the age of man. 
THE CENTURY'S PROGRESS IN GEOLOGY

It must not be supposed, however, that the successive "ages" of the geologist are shut off from one another in any such arbitrary way as this verbal classification might seem to suggest. In point of fact, these "ages" have no better warrant for existence than have the "centuries" and the "weeks" of every-day computa-

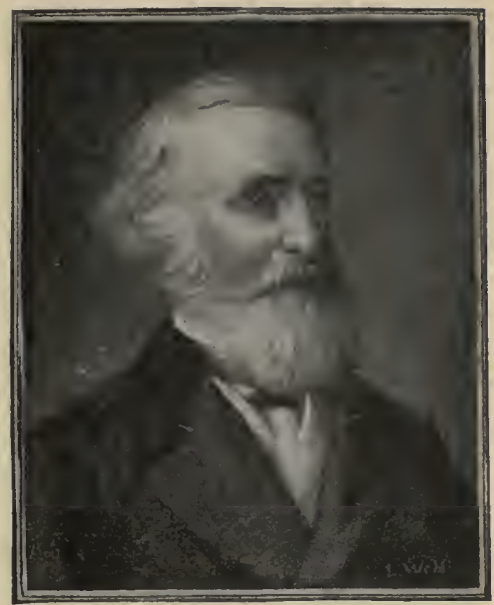

GEORGE POULETTE SCROPE, F.R.S. tion. They are convenient, and they may even stand for local divisions in the strata, but they are bounded by no actual gaps in the sweep of terrestrial events.

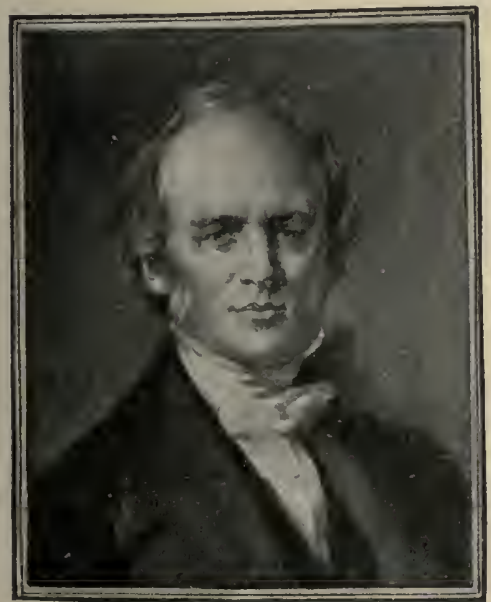

SIR CRARLES LYELL, BART, F.R.S.

Moreover, it must be understood that the "ages" of different continents, though described under the same name, are not necessarily of exact contemporaneity. There is no sure test available by which it could be shown that the Devonian age, for instance, as outlined in the strata of Europe, did not begin millions of 


\section{THE STORY OF NINETEENTII-CENTURY SCIENCE}

years earlier or later than the period whose records are said to represent the Devonian age in America. In attempting to decide such details as this, mineralogical data fail us utterly. Even in rocks of adjoining regions identity of structure is no proof of contemporaneous origin; for the veritable substance of the rock of one age is ground up to build the rocks of subsequent ages. Furthermore, in seas where conditions change but little the same form of rock may be made age after age. It is believed that chalk beds still forming in some of our present seas may form one continuous mass dating back to earliest geologic ages. On the other hand, rocks different in character may be formed at the same time in regions not far apart-say a sandstone along shore, a coral limestone farther seaward, and a chalk bed beyond. This continuous stratum, broken in the process of upheaval, might seem the record of three different epochs.

Paleontology, of course, supplies far better chronological tests, but even these have their limitations. There has been no time since rocks now in existence were formed, if ever, when the earth had a uniform climate and a single undiversified fauna over its entire land surface, as the early paleontologists supposed. Speaking broadly, the same general stages have attended the evolution of organic forms every where, but there is nothing to show that equal periods of time witnessed corresponding changes in diverse regions, but quite the contrary. To cite but a single illustration, the marsupial order, which is the dominant mammalian type of the living fauna of Australia to-day, existed in Europe and died out there in the Tertiary age. Hence a future geologist might think the Australia of to-day contempo- 


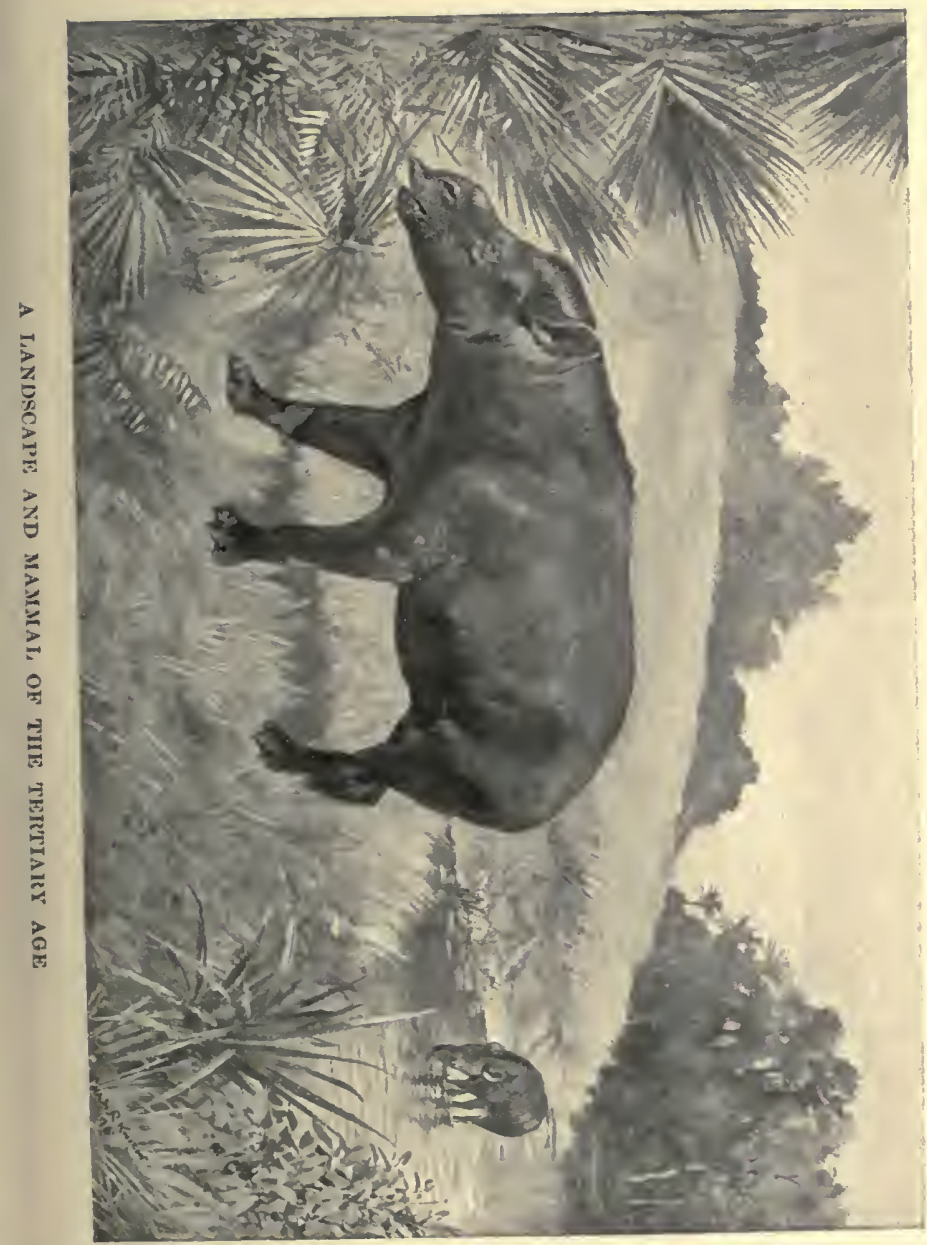





\section{THE CENTURY'S PlOGRESS IN GEOLOGY}

raneous with a period in Europe which in reality antedated it by perhaps millions of year

\section{$\nabla$}

All these puzzling features unite to render the subject of historical geology anything but the simple matter the fathers of the science esteemed it. No one would now attempt to trace the exact sequence of formation of all the mountains of the globe, as Elie de Beaumont did a half-century ago. Even within the limits of a single continent, the geologist must proceed with much caution in attempting to chronicle the order in which its various parts rose from the matrix of the sea. The key to this story is found in the identification of the strata that are the surface feature in each territory. If Deronian rocks are at the surface in any given region, for example, it would appear that this region became a land surface in the Deronian age, or just afterwards. But a moment's consideration shows that there is an element of uncertainty about this, due to the steady denudation that all land surfaces undergo. The Devonian rocks may lie at the surface simply because the thousands of feet of carboniferous strata that once lay above them have been worn away. All that the cautious geologist dare assert, therefore, is that the region in question did not become permanent land surface earlier than the Devonian age.

But to know even this is much-sufficient, indeed, to establish the chronological order of elevation, if not its exact period, for all parts of any continent that have been geologically explored-understanding always that there must be no scrupling about a latitnde of a few millions or perhaps tens of millions of years here and there. 


\section{THE STORY OF NINETEENTH-CENTURY SCIENCE}

Regarding our own continent, for example, we learn through the researches of a multitude of workers that in the early day it was a mere archipelago. Its chief island-the backbone of the future continent-was a great $\mathrm{V}$-shaped area surrounding what is now Hudson Bay, an area built up, perhaps, through denudation of a yet more ancient polar continent, whose existence is only conjectured. To the southeast an island that is now the Adirondack Mountains, and another that is now the Jersey Highlands, rose above the waste of waters; and far to the south stretched probably a line of islands now represented by the Blue Ridge Mountains. Far off to the westward another line of islands foreshadowed our present Pacific border. A few minor islands in the interior completed the archipelago.

From this bare. skeleton the continent grew, partly by the deposit of sediment from the denudation of the original islands (which once towered miles, perhaps, where now they rise thousands of feet), but largely also by the deposit of organic remains, especially in the interior sea, which teemed with life. In the Silurian ages, invertebrates-brachiopods and crinoids, and cephalopods-were the dominant types. But very early - no one knows just when-there came fishes of many strange forms, some of the early ones enclosed in turtlelike shells. Later yet, large spaces within the interior sea having risen to the surface, great marshes or forests of strange types of vegetation grew and deposited their remains to form coal beds. Many times orer such forests were formed, only to be destroyed by the oscillations of the land surface. All told, the strata of this Paleozoic period aggregate several miles in thickness, and the time consumed in their formation stands to all later time up to the 


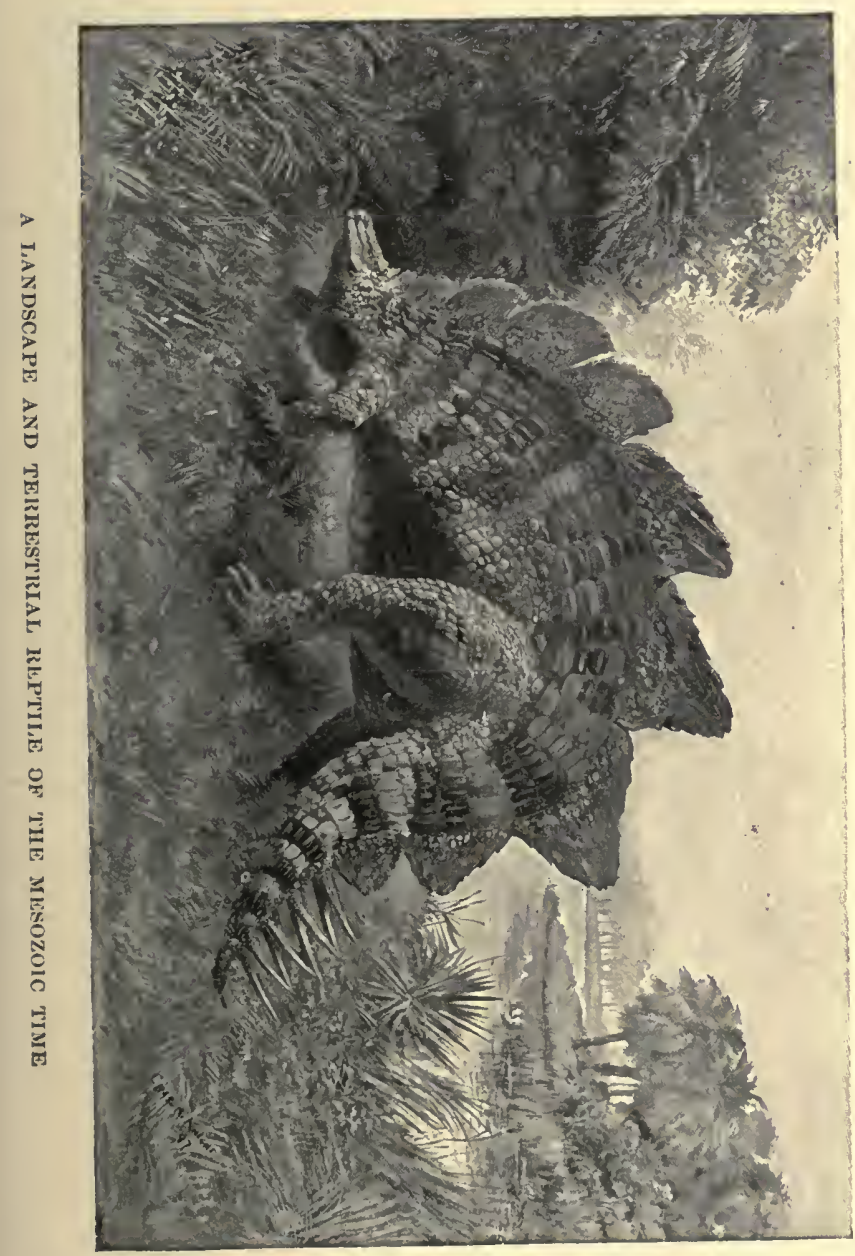



present, according to Professor Dana's estimate, as three to one.

Towards the close of this Paleozoic era the Appalachian Mountains were slowly upheaved in great convoluted folds, some of them probably reaching three or four miles above the sea-level, though the tooth of time has since gnawed them down to comparatively puny limits. The continental areas thus enlarged were peopled during the ensuing Mesozoic time with multitudes of strange reptiles, many of them gigantic in size. The waters, too, still teeming with invertebrates and fishes, had their quota of reptilian monsters; and in the air were flying reptiles, some of which measured twenty-five feet from tip to tip of their bat-like wings. During this era the Sierra Nevada Mountains rose. Near the eastern border of the forming continent the strata were perhaps now too thick and stiff to bend into mountain folds, for they were rent into great fissures, letting out floods of molten lava, remnants of which are still in evidence after ages of denudation, as the Palisades along the Hudson, and such elevations as Mount Holyoke in western Massachusetts.

Still there remained a vast interior sea, which, later on, in the Tertiary age, was to be divided by the slow uprising of the land, which only yesterday - that is to say, a million, or three or five or ten million years agobecame the Rocky Mountains. High and erect these young mountains stand to this day, their sharp angles and rocky contours vouching for their youth, in strange contrast with the shrunken forms of the old Adirondacks, Green Mountains, and Appalachians, whose lowered heads and rounded shoulders attest the weight of ages. In the vast lakes which still remained on either 
side of the Rocky range, Tertiary strata were slowly formed to the ultimate depth of two or three iniles, enclosing here and there those vertebrate remains which were to be exposed again to view by denudation when the land rose still higher, and then, in our own time, to tell so wonderful a story to the paleontologist.

Finally the interior seas were filled, and the shore lines of the continent assumed nearly their present outline.

Then came the long winter of the glacial epoch-perhaps of a succession of glacial epochs. The ice sheet extended southward to about the fortieth parallel, driving some animals before it, and destroying those that were unable to migrate. At its fulness, the great ice mass lay almost a mile in depth over New Englind, as attested by the scratched and polished rock surfaces and deposited erratics in the White Mountains. Such a mass presses down with a weight of about one hundred and tiventy-five tons to the square foot, according to Dr. Croll's estimate. It crushed and ground everything beneath it more or less, and in some regions planed off hilly surfaces into prairies. Creeping slowly forward, it carried all manner of débris with it. When it melted away its terminal moraine built up the nucleus of the land masses now known as Long Island and Staten Island ; other of its deposits formed the "drumlins" about Boston famous as Bunker and Breeds hills; and it left a long irregular line of ridges of "till" or bowlder clay and scattered erratics clear across the country at about the latitude of New York City.

As the ice sheet slowly receded it left minor moraines all along its course. Sometimes its deposits dammed up river courses or inequalities in the surface, to form the 


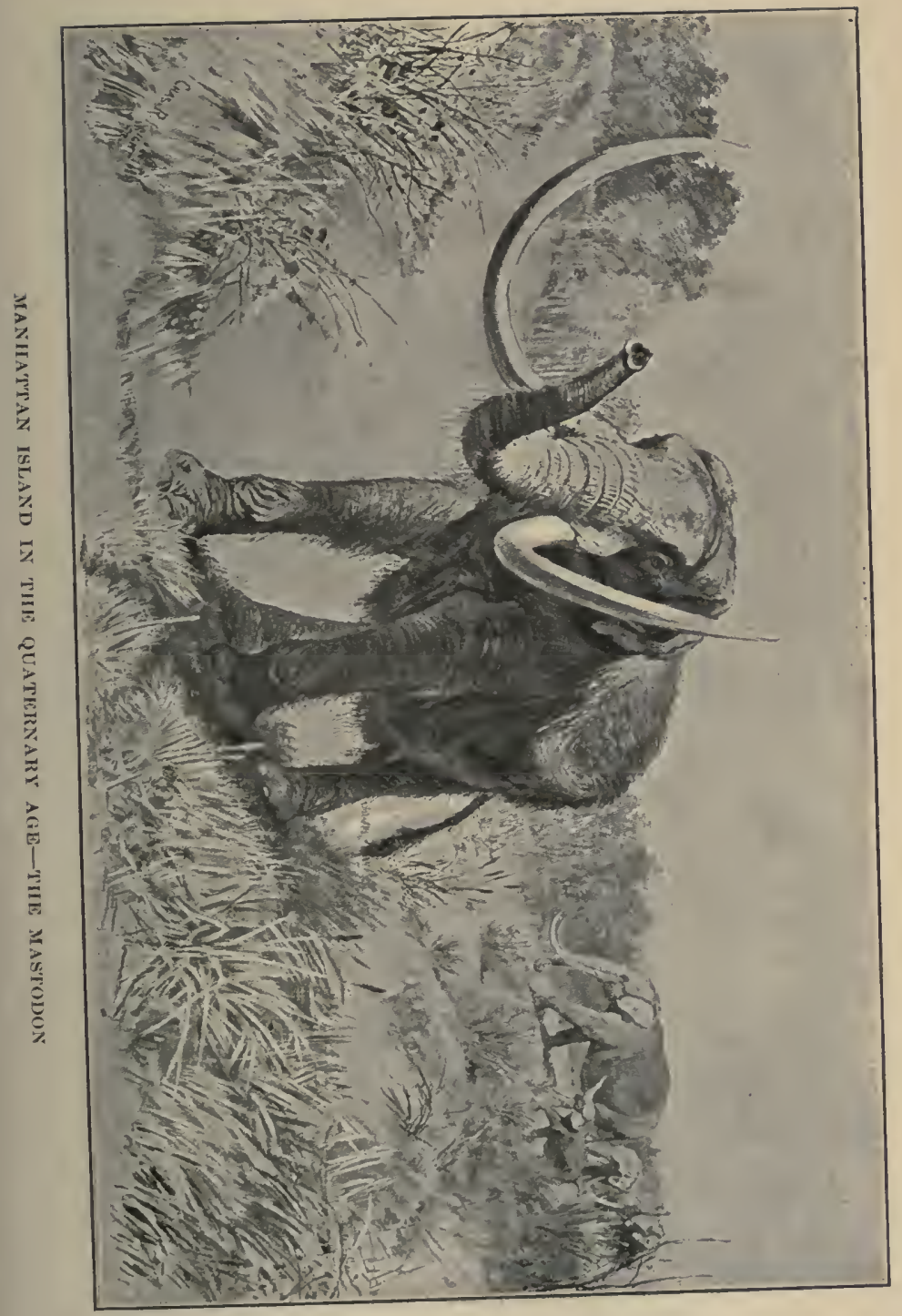





\section{'THE CENTURY'S PROGRESS IN GEOLOGY}

lakes which every where abound over Northern territories. Some glacialists even hold the view first suggested by Ramsey, of the British Geological Survey, that the great glacial sheet scooped out the basins of many lakes, including the system that feeds the Saint Lawrence. At all events, it left traces of its presence all along the line of its retreat, and its remnants exist to this day as mountain glaciers and the polar ice cap. Indeed, we live on the border of the last glacial epoch, for with the closing of this period the long geologic past merges into the present.

VI

And the present, no less than the past, is a time of change. That is the thought which James Hutton conceived more than a century ago, but which his contemporaries and successors were so very slow. to appreciate. Now, however, it has become axiomatic-one can hardly realize that it was ever doubted. Every new scientific truth, says Agassiz, must pass through three stagesfirst, men say it is not true; then they declare it hostile to religion; finally, they assert that every one has known it always. Hutton's truth that natural law is changeless and eternal has reached this final stage. Nowhere now could you find a scientist who would dispute the truth of that text which Lyell, quoting from Playfair's Illustrations of the IHuttonian Theory, printed on the title-page of his Principles: "Amid all the revolutions of the globe the economy of Nature has been uniform, and her laws are the only things that have resisted the general movement. The rivers and the rocks, the seas and the continents, have been changed in all their parts; but the laws which direct those changes, and the 
rules to which they are subject, have remained invariably the same."

But, on the other hand, Hutton and Playfair, and in particular Lyell, drew inferences from this principle which the modern physicist can by no means admit. To them it implied that the changes on the surface of the earth have always been the same in degree as well as in kind, and must so continue while present forces hold their sway. In other words, they thought of the world as a great perpetual-motion machine. But the modern physicist, given truer mechanical insight by the doctrines of the conservation and the dissipation of energy, will have none of that. Lord Kelvin, in particular, has urged that in the periods of our earth:s infancy and adolescence its developmental changes must have been, like those of any other infant organism, vastly more rapid and pronounced than those of a later day; and to every clear thinker this truth also must now seem axiomatic.

Whoever thinks of the earth as a cooling globe can hardly doubt that its crust, when thinner, may have heaved under strain of the moon's tidal pull-whether or not that body was nearer-into great billows, daily rising and falling, like waves of the present seas vastly magnified.

Under stress of that same lateral pressure from contraction which now produces the slow depression of the Jersey coast, the slow rise of Siveden, the occasional belching of an insignificant volcano, the jetting of a geyser, or the trembling of an earthquake, once large areas were rent in twain, and vast floods of lava flowed over thousands of square miles of the earth's surface perhaps at a single jet; and, for aught we linow to the 


\section{'THE CEN'URY'S PROGRESS IN GEOLOGY}

contrary, gigantic mountains may have heaped up their contorted heads in cataclysms as spasmodic as even the most ardent catastrophist of the elder day of geology could have imagined.

The atmosphere of that early day, filled with vast volumes of carbon, oxygen, and other chemicals that have since been stored in beds of coal, limestone, and

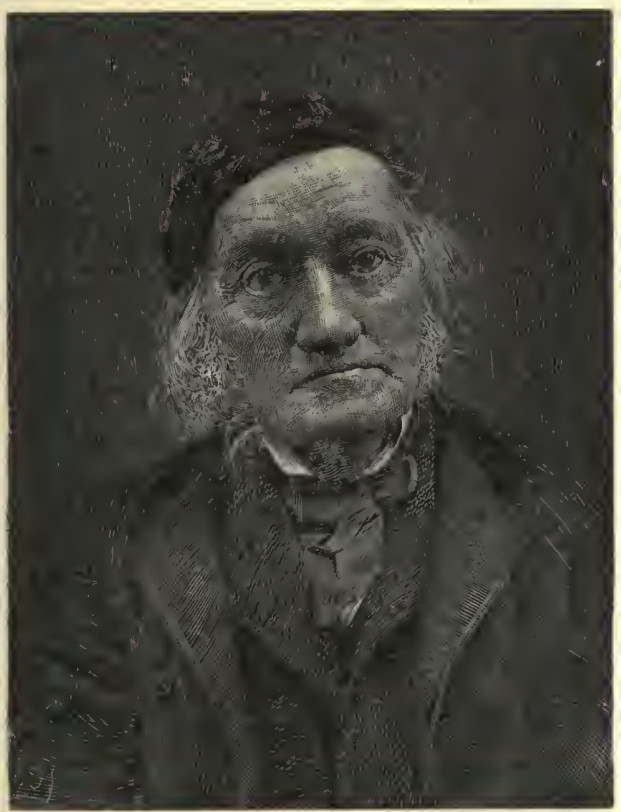

SIIR RICHARD OWEN

granites, may have worn down the rocks, on the one liand, and built up organic forms on the other, with a rapidity that would now seem hardly conceivable.

And yet while all these anomalous things went on, 


\section{THE STORY OF NINETEENTH-CENTURY SCIENCE}

the same laws held that now are operative; and a true doctrine of uniformitarianism would make no unwonted concession in conceding them all-though most of the embittered geological controrersies of the middle of our century were due to the failure of both parties to realize that simple fact.

And as of the past and present, so of the future. The same forces will continue to operate; and under operation of these unchanging forces each day will differ from every one that has preceded it. If it be true, as every physicist believes, that the earth is a cooling globe, then, whatever its present stage of refrigeration, the time must come when its surface contour will assume a rigidity of level not yet attained. Then, just as surely, the slow action of the elements will continue to wear away the land surfaces, particle by particle, and transport them to the ocean, as it does to-day, until, compensation no longer being afforded by the upheaval of the continents, the last foot of dry land will sink for the last time beneath the water, the last mountain-peak melting array, and our globe, lapsing like any other organism into its second childhood, will be on the surface-as presumably it was before the first continent rose-one vast "waste of waters." As puny man conceires time and things, an awful cycle will have lapsed; in the sweep of the cosmic life, a pulse-beat will have throbbed. 


\section{CHAPTER V}

\section{THE CENTURY'S PROGRESS IN METEOROLOGY}

"Av astonishing miracle has just occurred in our district," wrote M. Marais, a worthy if undistinguished citizen of France, from his home at L'Aigle, under date of "the 13th Floreal, year 11"-a date which outside of France would be interpreted as meaning May 3, 1803. This "miracle" was the appearance of a "fireball" in broad daylight_- perhaps it was wildfire," says the naïre chronicle - which "hung over the meadow," being seen by many people, and then explorled with a loud sound, scattering thousands of stony fragments over the surface of a territory some miles in extent.

Such a "miracle" could not have been announced at a more opportune time. For some years the scientific world had been agog over the question whether such a form of lightning as that reported-appearing in a clear sky, and hurling literal thunder-bolts-had real existence. Such cases had been reported often enough, it is true. The "thunder-bolts" themselves were exhibited as sacred relics before many an altar, and those who doubted their authenticity had been chided as having "an evil heart of unbelief." But scientific scepticism had ques- 


\section{THE STORY OF NINETEENTH-CENTURY SCLENCE}

tioned the evidence, and late in the eighteenth century a consensus of opinion in the French Academy had declined to admit that such stones had been "conveyed to the earth by lightning," let alone any more miraculous agency.

In 1802, however, Edward Howard had read a paper before the Royal Society in which, after reviewing the eridence recently put forward, he had reached the conclusion that the fall of stones from the sky, sometimes or always accompanied by lightning, must be admitted as an actual phenomenon, however inexplicable. So now, when the great stone-fall at I'Aigle was announced, the French Academy made haste to send the brilliant young physicist Jean Baptiste Biot to investigate it, that the matter might, if possible, be set finally at rest. The investigation was in all respects successful, and Biot's report transferred the stony or metallic lightning-bolt-the aerolite or meteorite-from the realm of tradition and conjecture to that of accepted science.

But how explain this strange phenomenon? At once speculation was rife. One theory contended that the stony masses had not actually fallen, but had been formed from the earth by the action of the lightning; but this contention was early abandoned. The chemists were disposed to believe that the aerolites had been formed by the combination of elements floating in the upper atmosphere. Geologists, on the other hand, thought them of terrestrial origin, urging that they might have been thrown up by volcanoes. The astronomers, as represented by Olbers and Laplace, modified this theory by suggesting that the stones might, indeed, have been cast out by rolcanoes, but by volcanoes situated not on the earth, but on the moon. 
THE CENTURY'S PROGRESS IN METEOROLOGY

And one speculator of the time took a step even more daring, urging that the aerolites were neither of telluric nor selenic origin, nor yet children of the sun, as the old

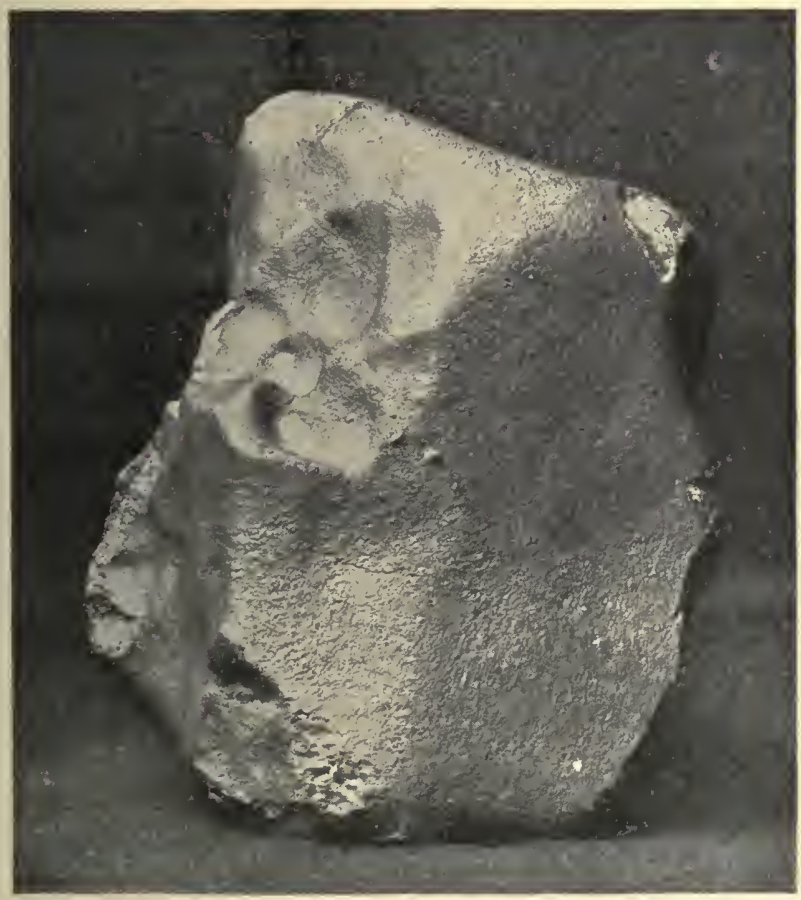

A METEORIC STONE

Greeks had, many of them, contended, but that they are visitants from the depths of cosmic space. This bold speculator was the distinguished German physicist Ernst F. F. Chladni, a man of no small repute in his day. As early as 1794 he urged his cosmical theory of meteorites, when the rery existence of meteorites was denied by most scientists. And he did more: he 


\section{TIIE STORY OF NINE'IEENTH-CENTURY SCIENCE}

declared his belief that these falling stones were really one in origin and kind with those flashing meteors of the upper atmosphere which are familiar everywhere as "shooting-stars."

Each of these coruscating meteors, he affirmed, must tell of the ignition of a bit of cosmic matter entering the earth's atmosphere. 'Such wandering bits of matter might be the fragments of shattered worlds, or, as Chladni thought more probable, merely aggregations of "world stuff" never hitherto connected with any large planetary mass.

Naturally enough, so unique a view met with very scant favor. Astronomers at that time saw little to justify it; and the non-scientific world rejected it with fervor as being "atheistic and leretical," because its acceptance would seem to imply that the unirerse is not a perfect mechanism.

Some light was thrown on the moot point presently by the observations of Brandes and Benzenberg, which tended to show that falling-stars travel at an actual speed of from fifteen to ninety miles a second. This observation tended to discredit the selenic theory, since an object, in order to acquire such speed in falling merely from the moon, must have been projected with an initial relocity not conceivably to be given by any lunar volcanic impulse. Moreover, there was a growing conviction that there are no active volcanoes on the moon, and other considerations of the same tenor led to the complete abandonment of the selenic theory.

But the theory of telluric origin of aerolites was by no means so easily disposed of. This was an epoch when electrical phenomena were exciting unbounded and universal interest, and there was a not unnatural 
tendency to appeal to electricity in explanation of every obscure phenomenon; and in this case the seeming similarity between a lightning-flash and the flash of an aerolite lent color to the explanation. So we find Thomas Forster, a meteorologist of repute, still adhering to the atmospheric theory of formation of aerolites in his book published in 1823 ; and, indeed, the prevailing opinion of the time seemed divided between various telluric theories, to the neglect of any cosmical theory whaterer.

But in 1833 occurred a phenomenon which set the matter finally at rest. A great meteoric shower occurred in Norember of that year, and in observing it Professor Denison Olmsted, of Yale, noted that all the stars of the shower appeared to come from a single centre or vanishing-point in the hearens, and that this centre shifted its position with the stars, and hence was not telluric. The full significance of this obserration was at once recognized by astronomers; it demonstrated beyond all caril the cosmical origin of the shooting-stars. Some conservative meteorologists kept up the argument for the telluric origin for some decades to come as a matter of course-such a band trails always in the rear of progress. But even these doubters were silenced when the great shower of shooting-stars appeared again in 1866 , as predicted by Olbers and Newton, radiating from the same point of the hearens as before.

Since then the spectroscope has added its confirmatory evidence as to the identity of meteorite and shootingstal, and, moreover, has linked these atmospheric meteors with such distant cosmic residents as comets and nebulæ. Thus it appears that Chladni's daring hypothesis of 1794 
has been more than verified, and that the fragments of matter dissociated from planetary connection-which he postulated and was declared atheistic for postulatinghave been shown to be billions of times more numerous than any larger cosmic bodies of which we have cognizance-so willely does the existing universe differ from man's preconceived notions as to what it should be.

Thus also the " miracle" of the falling stone, against which the scientific scepticism of yesterday presented "an evil heart of unbelief," turns out to be the most natural of plenomena, inasmuch as it is repeated in our atmosphere some millions of times each day.

If fire-balls were thought miraculous and portentous in days of yore, what interpretation must needs have been put upon that vastly more picturesque plienomenon, the aurora? "Through all the city," says the Book of Maccabees, "for the space of almost forty days, there were seen horsemen running in the air, in cloth of gold, armed with lances, like a band of soldiers: and troops of horsemen in array encountering and running one against another, with shaking of shields and multitude of pilies, and drawing of swords, and casting of darts, and glittering of golden ornaments and lrarness." Dire omens these; and hardly less ominous the aurora seemed to all succeeding generations that observed it down till well into the eighteenth century - as witness the popular excitement in England in 1716 over the brilliant aurora of that year, which became famous through Halley's description.

But after 1752, when Franklin dethroned the light162 


\section{THE CENTURY'S YROGRESS IN METEOROLOGI'}

ning, all spectacular meteors came to be regarded as natural phenomena, the aurora among the rest. Franklin explained the aurora-which was seen commonly enough in the eighteenth century, though only recorded

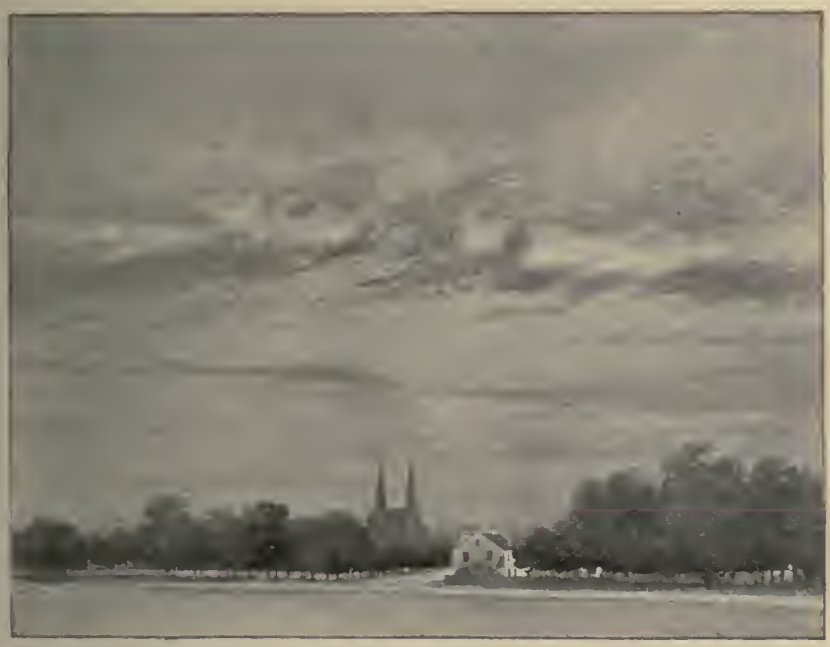

CIRRUS CI,OUDS

once in the serenteenth-as due to the accumulation of electricity on the surface of polar snows, and its discharge to the equator through the upper atmosphere. Erasmus Dirwin suggested that the luminosity might be due to the ignition of hydrogen, which was supposed by many philosophers to form the upper atmosphere. Dalton, who first measured the height of the aurora, estimating it at about one hundred miles, thought the phenomenon due to magnetism acting on ferruginous particles in the air, and his explanation was perhaps the most popular one at the beginning of the century. 


\section{THE STORY OF NINEIEENTH-CENTURI SCIENCE}

Since then a multitude of observers have studied the aurora, but the scientific grasp has found it as elusire in fact as it seems to casual observation, and its exact nature is as undetermined to day as it was a hundred years ago. There has been no dearth of theories concerning it, however. Biot, who studied it in the Shetland Islands in 1817 , thought it due to electrified ferruginous dust, the origin of which he ascribed to Icelandic rolcanoes. Much more recently the idea of ferruginous particles has been revired, their presence being ascribed not to volcanoes, but to the meteorites constantly being dissipated in the upper atmosphere. Ferruginous dust, presumably of such origin, has been found on the polar snows, as well as on the snows of mountain-tops, but whether it could produce the phenomena of auroras is at least an open question.

Other theorists have explained the aurora as due to the accumulation of electricity on clouds or on spicules of ice in the upper air. Tet others think it due merely to the passage of electricity through rarefied air itself. Humboldt considered the matter settlerl in yet another way when Faraday showed. in 1831, that magnetism may produce lnminous effects. But perhaps the prevailing theory of to-lay assumes that the aurora is due to a current of electricity generated at the equator, ancl passing through upper regions of space, to enter the earth at the magnetic poles-simply reversing the course which Franklin assumed.

The similarity of the auroral light to that generaterl in a vacuum bulb by the passage of electricity lends support to the long-standing supposition that the aurora is of electrical origin, but the subject still awaits complete elucidation. For once even that mystery-solver 


\section{THE CENTURY'S PROGRESS IN METEOROLOGY}

the spectroscope lias been baffled, for the line it sifts from the aurora is not matched by that of any recognized substance. A like line is found in the zodiacal light, it is true, but this is of little aid, for the zodiacal light, though thought by some astroilomers to be due to meteor swarms about the sun, is held to be, on the whole, as inysterious as the aurora itself.

Whatever the exact nature of the aurora, it has long been known to be intimately associated with the phenomena of terrestrial magnetism. Whenerer a brilliant

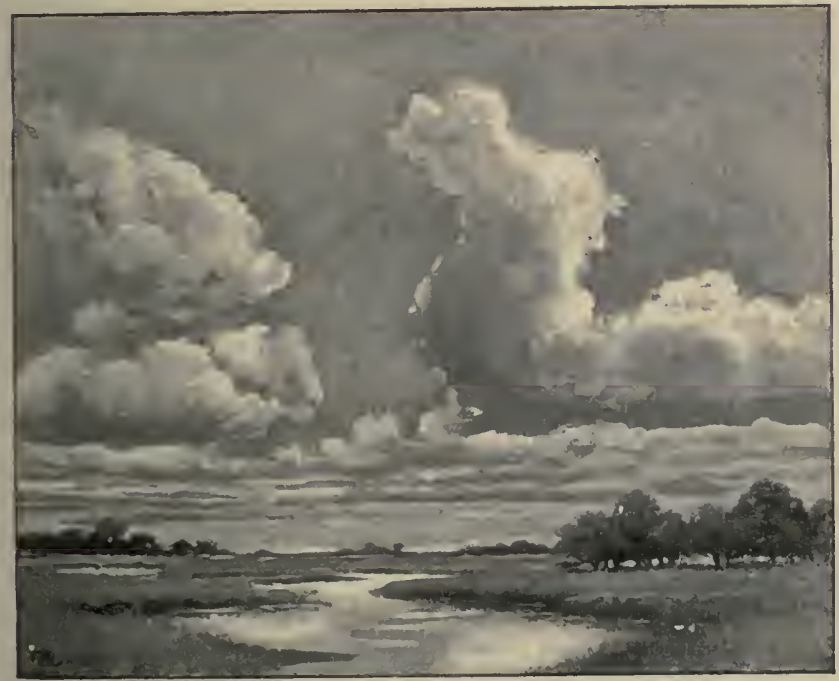

CUMULUS CLOUDS

aurora is visible, the world is sure to be visited with what Humboldt called a magnetic storm-a "storm" which manifests itself to human senses in no way whatsoever except by deflecting the magnetic needle and 


\section{THE STORY OF NINETEENTH-CENTURY SCIENCE}

conjuring with the electric wire. Such magnetic storms are curiously associated also with spots on the sun-just how no one has explained, though the fact itself is unquestioned. Sun-spots, too, seem directly linlied with auroras, each of these phenomena passing through periods of greatest and least frequency in corresponding cycles of about eleven years' duration.

It was suspected a full century ago by Herschel that the variations in the number of sun-spots had a direct effect upon terrestrial weather, and he attempted to demonstrate it by using the price of wheat as a criterion of climatic conditions, meantime making careful observation of the sun-spots. Nothing very definite came of his efforts in this direction, the subject being far too complex to be determined without long periods of observation. Latterly, however, meteorologists, particularly in the tropics, are disposed to think they find evidence of some such connection between sun-spots and the weather as Herschel suspected. Indeed, Mr. Meldrum declares that there is a positive coincidence between periods of numerous sun-spots and seasons of excessive rain in India.

That some such connection does exist seems intrinsically probable. But the modern moteorologist, learning wisdom of the past, is extremely cautious about ascribing casual effects to astronomical phenomena. He finds it hard to forget that until recently all manner of climatic conditions were associated with phases of the moon; that not so very long ago showers of falling-stars were considered "prognostic" of certain kinds of weather; and that the "equinoctial storm" had been accepted as a verity by every one, until the unfeeling hand of statistics banished it from the earth.

Yet, on the other hand, it is easily within the possi- 


\section{THE CENTURY'S PROGRESS IN METEOROLOGY}

bilities that the science of the future may reveal associations between the weather and sun-spots, auroras, and terrestrial magnetism that as yet are hardly dreamed of. Until such time, however, these phenomena must feel themselves very grudgingly admitted to the inner circle of meteorology. More and more this science concerns itself, in our age of concentration and specialization, with weather and climate. Its votaries no longer concern themselves with star's or planets or comets or sliooting-stars-once thought the very essence of guides to weather wisdoin; and they are even looking askance at the moon, and asking her to show cause why she also should not be excluded from their domain. Equally little do they care for the interior of the earth, since they have learned that the central emanations of heat which Mairan imagined as a main source of aerial warmth can claim no such distinction. Even such problems as why the magnetic pole does not coincide with the geographical, and why the force of terrestrial magnetism decreases from the magnetic poles to the magnetic equator, as Humboldt first discovered that it does, excite them only to lukewarm interest; for magnetism, they say, is not known to have any connection whatever with climate or weather.

\section{III}

There is at least one form of meteor, however, of those that interested our forebears, whose meteorological importance they did not overestimate. This is the vapor of water. How great was the interest in this familiar meteor at the beginning of the century is attested by the number of theories then extant regarding it; and these conflicting theories bear witness also to the difficulty 
THE STORY OF NINETEENTH-CEN'TURY SCIENCE with which the familiar phenomenon of the evapuration of water was explained.

Franklin had suggested that air dissolves water much as water dissolves salt, and this theory was still popular,

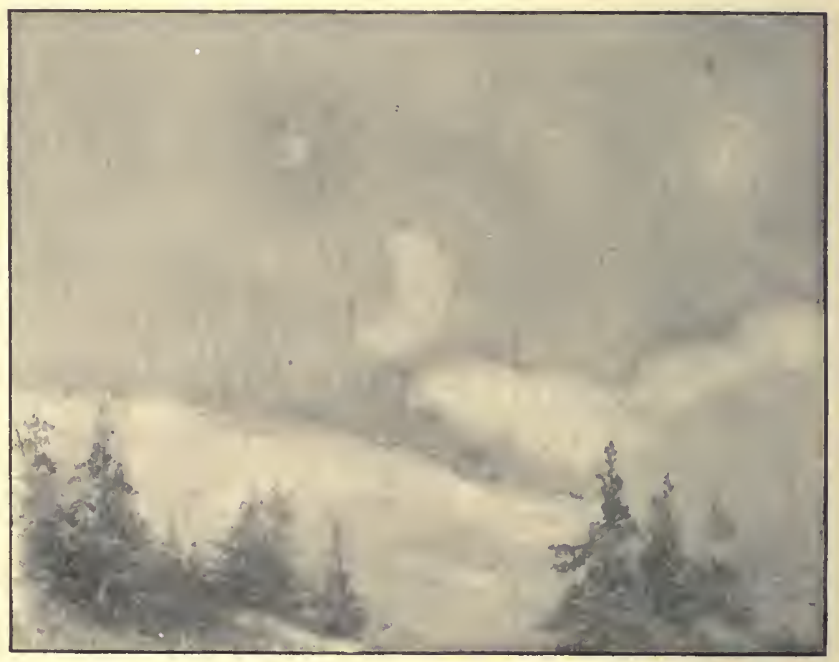

STRATUS CLOUDS

though Deluc had disprored it by showing that water evaporates even more rapidly in a vacuum than in air. Deluc's own theory, borrowed from earlier chemists, was that evaporation is the chemical union of particles of water with particles of the supposititious element heat. Erasmus Darwin combined the two theories, suggesting that the air might hold a variable quantity of vapor in mere solution, and in addition a permanent moiety in chemical combination with caloric.

Undisturbed by these conflicting views, that strangely original genius, John Dalton, afterwards to be known as 


\section{THE CENTURY'S PROGRESS IN ME'TEOROLOGY}

perhaps the greatest of theoretical chemists, took the question in hand, and solved it by showing that water exists in the air as an utterly independent gas. He reached a partial insight into the matter in 1793, when his first volume of meteorological essays was published; but the full elucidation of the problem came to him in 1S01. The merit of his studies was at once recognized, but the tenability of his hypothesis was long and ardently disputed.

While the nature of evaporation was in dispute, as a matter of course the question of precipitation must be equally undetermined. The most famous theory of the period was that formulated by Dr. Hutton in a paper read before the Royal Society of Edinburgh, and published in the volume of transactions which contained also the same author's epoch-making paper on geology. This "theory of rain" explained precipitation as due to the cooling of a current of saturated air by contact with a colder current, the assumption being that the surplusage of moisture was precipitated in a chemical sense, just as the excess of salt dissolved in hot water is precipitated when the water cools. The idea that the cool. ing of the saturated air causes the precipitation of its moisture is the germ of truth that renders this paper of IIutton's important. All correct later theories build on this foundation.

The next ambitious attempt to explain the phenomena of aqueous meteors was made by Luke Howard, in his remarkable paper on clouds, published in the Philosophical Magazine in 1S03-the paper in which the names cirrus, cumulus, stratus, etc., afterwards so universally alopted, were first proposed. In this paper IIoward acknowledges his indebtedness to Dalton for the theory 


\section{THE STORY OF NINETEENTH-CENTURY SCIENCE}

of evaporation, yet he still clings to the idea that the vapor, though independent of the air, is combined with particles of caloric. He holds that clouds are composed of vapor that has previously risen from the earth, combating the opinions of those who believe that they are formed by the union of hydrogen and oxygen existing independently in the air; though he agrees with these theorists that electricity has entered largely into the modus operandi of cloud formation. He opposes the opinion of Deluc and de Saussure that clouds are composed of particles of water in the form of hollow vesicles (miniature balloons, in short, perhaps filled with hydrogen), which untenable opinion was a revival of the theory as to the formation of all vapor which Dr. Halley had advocated early in the eighteenth century.

Of particular interest are Howard's views as to the formation of dew, which he explains as caused by the particles of caloric forsaking the vapor to enter the cool body, leaving the water on the surface. This comes as near the truth perhaps as could be expected while the old idea as to the materiality of heat held sway. Howard believed, however, that dew is usually formed in the air at some height, and that it settles to the surface, opposing the opinion, which had gained vogue in France and in America (where Noah Webster prominently advocated it), that dew ascends from the earth.

The complete solution of the problem of dew formation-which really involved also the entire question of precipitation of watery vapor in any form-was made by Dr. C. W. Wells, a man of American birth, whose life, howerer, after boyhood, was spent in Scotland (where as a young man he enjoyed the friendship of Darid Hume) and in London. Inspired no doubt by the re- 


\section{'IHE CENTURY'S PROGRESS IN METEOROLOGY}

searches of Black, Hutton, and their confrères of that Edinburgh school, Wells made observations on evaporation and precipitation as early as 1784 , but other things claimed his attention; and though he asserts that the subject was often in his mind, he did not take it up again in earnest until about 1812 .

Meantime the observations on heat of Rumford and Dary and Leslie had cleared the way for a proper interpretation of the facts-about the facts themselves there had long been practical unanimity of opinion. Dr. Black, with his latent-heat observations, had really given the clew to all subsequent discussions of the subject of precipitation of vapor; and from his time on it liad been known that heat is taken up when water evaporates, and given out again when it condenses. Dr. Darwin had shown in 1788 , in a paper before the Royal Society, that air gives off heat on contracting; and takes it up on expanding; and Dalton in his essay of 1793 had explained this phenomenon as due to the condensation and vaporization of the water contained in the air.

But some curious and puzzling observations which Professor Patrick Wilson, Professor of Astronomy in the University of Glasgow, had communicated to the Royal Society of Edinburgh in 1784, and some similar ones made by Mr. Six of Canterbury a few years later, had remained unexplained. Both these gentlemen observed that the air is cooler where dew is forming than the air a few feet higher, and they inferred that the dew in forming had taken up heat, in apparent violation of established physical principles.

It remained for Wells, in his memorable paper of 1816 , to show that these observers lad simply gotten the cart before the liorse. He made it clear that the 


\section{THE STORY OF NINETEENTH-CENTURY SCIENCE}

air is not cooler because the dew is formed, but that the dew is formed because the air is cooler-laving become so through radiation of heat from the solids on which the dew forms. The dew itself, in forming, gives out its latent heat, and so tends to equalize the temperature. This explanation made it plain why dew forms on a clear night, when there are no clouds to reflect the radiant heat. Combined with Dalton's theory that vapor is an independent gas, limited in quantity in any given space by the temperature of that space, it solved the problem of the formation of clouds, rain, snow, and hoar-frost. Thus this paper of IVeils's closed the epoch of speculation regarding this field of meteorology, as Hutton's paper of $178 t$ had opened it. The fact that the volume containing Hutton's paper contained also his epoch-making paper on Geology, finds curiously a duplication in the fact that Wells's volume contained also his essay on Albinism, in which the doctrine of natural selection was for the first time formulated, as Charles Darwin freely admitted after his own efforts had made the doctrine famous.

\section{IV}

The very next year after Dr. Wells's paper was pub. lished, there appeared in France the third volume of the Mémoires de Physique et de Chimie de la Société d'Arcueil, and a new epoch in meteorology was inaugurated. The society in question was numerically an inconsequential band, listing only a dozen members. But erery name was a famous one: Arago, Bérard, Berthollet, Biot, Chaptal, de Candolle, Dulong, Gay-Lussac, II umboldt, Laplace, Poisson, and Thénard-rare spirits every 


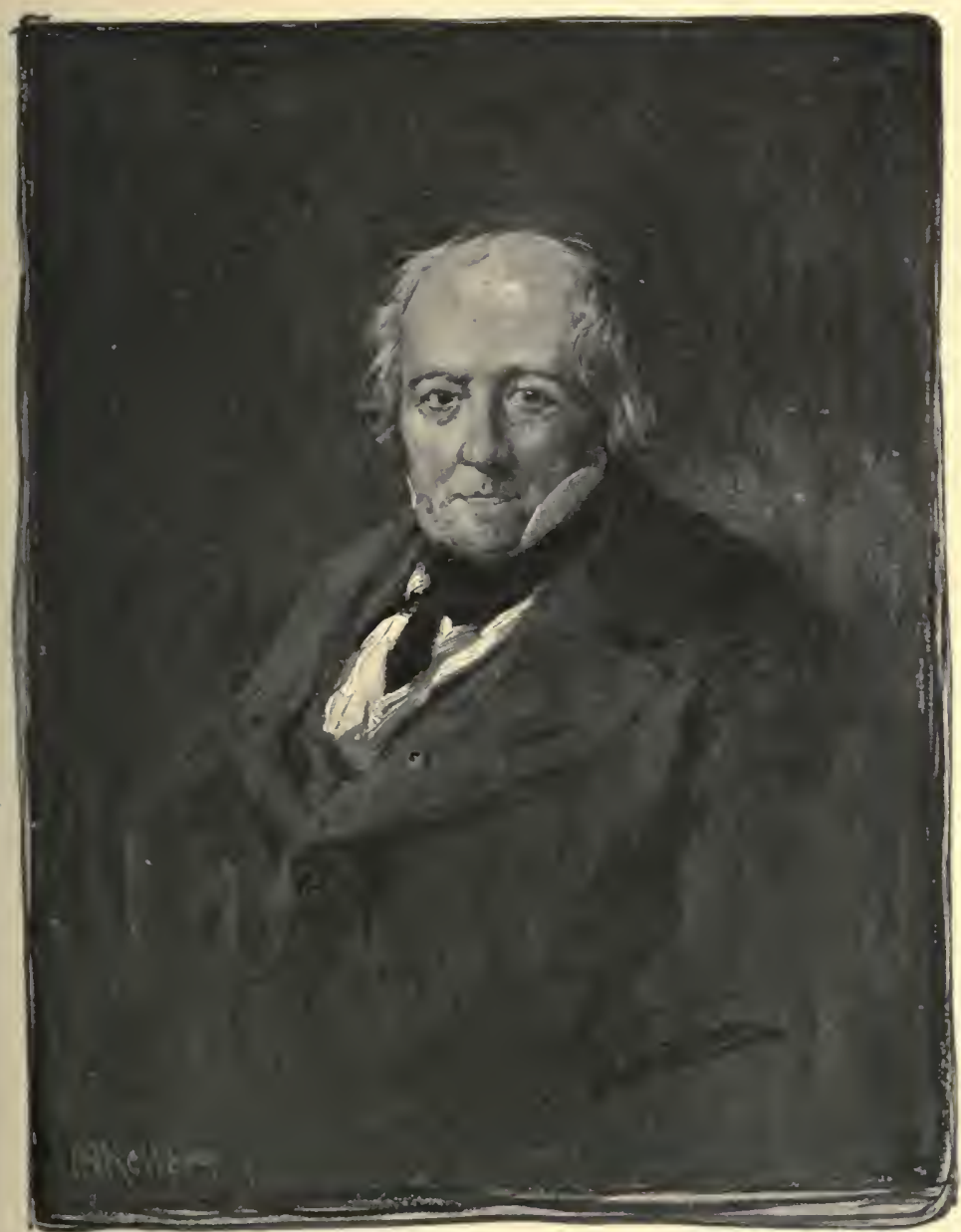

JEAN BAPTISTE BIOT 

one. Little danger that the memoirs of such a band would be relegated to the dusty shelves where most proceedings of societies belong-no milk-for-babes fare would be served to such a company.

The particular paper which here interests us closes this third and last volume of memoirs. It is entitled Des lignes isothermes et de la distribution de la chaleur sur le globe. The author is Alexander Humboldt. Needless to say, the topic is handled in a masterly manner. The distribution of heat on the surface of the globe, on the mountain-sides, in the interior of the earth; the causes that regulate such distribution; the climatic resultsthese are the topics discussed. But what gives epochal character to the paper is the introduction of those isothermal lines, circling the earth in irregular course, joining together places having the same mean annual temperature, and thu's laying the foundation for a science of comparative climatology.

It is true the attempt to study climates comparatively was not new. Mairan had attempted it in those papers in which he developed his bizarre ideas as to central emanations of heat. Euler had brought his profound mathematical genius to bear on the topic, evolving the "extraordinary conclusion that under the equator at midnight the cold ought to be more rigorous than at the poles in winter." And in particular Richard Kirwan, the English chemist, had combined the mathematical and the empirical methods, and calculated temperatures for all latitudes. But Humboldt differs from all these predecessors in that he grasps the idea that the basis of all such computations should be not theory, but fact. He drew his isothermal lines not where some occult calculation would locate them on an ideal globe, 
but where practical tests with the thermometer locate them on our globe as it is. London, for example, lies in the same latitude as the southern extremity of Hudson Bay; but the isotherm of London, as Humboldt outlines it, passes through Cincinnati.

Of course such deriations of climatic conditions between places in the same latitude had long been known. As Humboldt himself observes, the earliest settlers of America were astonished to find themselves subjected to rigors of climate for which their European experience had not at all prepared them. Moreover, sagacious travellers, in particular Cook's companion on his second voyage, young George Forster, had noted as a general principle that the western borders of continents in temperate regions are always warmer than corresponding - latitudes of their eastern borders; and of course the general truth of temperatures being milder in the vicinity of the sea than in the interior of continents had long been familiar. But Humboldt's isothermal lines for the first time gave tangibility to these ideas, and made practicable a truly scientific study of comparative climatology.

In studying these lines, particularly as elaborated by further observations, it became clear that they are by no means haphazard in arrangement, but are dependent upon geographical conditions which in most cases are not difficult to determine. Irumboldt himself pointed ont very clearly the main causes that tend to produce deviations from the arerage-or, as Dove later on callel it, the normal-temperature of any given latitule. For example, the mean annual temperature of a region (referring mainly to the northern hemisphere) is raised by the proximity of a western coast; by a divided config- 
uration of the continent into peninsulas ; by the existence of open seas to the north or of radiating continental surfaces to the south; by mountain ranges to shield from cold winds; by the infrequency of swamps to become congealed; by the absence of woods in a dry, sandy soil ; and by the serenity of sky in the summer months, and the vicinity of an ocean current bringing water which is of a higher temperature than that of the surrounding sea.

Conditions opposite to these tend, of course, correspondingly to lower the temperature. In a word, Humboldt says the climatic distribution of heat depends on the relative distribution of land and sea, and on the "hypsometrical configuration of the continents"; and he urges that "great meteorological phenomena cannot be comprehended when considered independently of geognostic relations"-a truth which, like most other general principles, seems simple enough once it is pointed out.

With that broad sweep of imagination which characterized him, Humboldt speaks of the atmosphere as the "aerial ccean, in the lower strata and on the shoals of which we live," and he studies the atmospheric phenomena always in relation to those of that other ocean of water. In each of these oceans there are vast permanent currents, flowing always in determinate directions, which enormously modify the climatic conditions of erery zone. The ocean of air is a vast maelstrom, boiling up always under the influence of the sun's heat at the equator, and flowing as an upper current towards either pole, whlle an under current from the poles, which becomes the trade-winds, flows towards the equator to supply its place. 
But the superheated equatorial air, becoming chilled, descends to the surface in temperate latitudes, and continues its poleward journey as the anti-trade-winds. The trade-winds are deflected towards the west, because in approaching the equator they constantly pass over surfaces of the earth having a greater and greater velocity of rotation, and so, as it were, tend to lag behindan explanation which Hadley pointed out in 1735 , but which was not accepted until Dalton independently worked it out and promulgated it in 1793. For the opposite reason, the anti-trades are deflected towards the east; hence it is that the western borders of continents in temperate zones are bathed in moist seabreezes, while their eastern borders lack this cold-dispelling influence.

In the ocean of water the main currents run as more sharply circumscribed streams-veritable rivers in the sea. Of these the best known and most sharply circumscribed is the familiar Gulf Stream, which has its origin in an equatorial current, impelled westward by trade-winds, which is deflected northward in the main at Cape St. Roque, entering the Caribbean Sea and Gulf of Mexico, to emerge finally through the Strait of Florida, and journey off across the Atlantic to warm the shores of Europe.

Such, at least, is the Gulf Stream as Humboldt understood it. Since his time, however, ocean currents in general, and this one in particular, have been the subject of no end of controversy, it being hotly disputed whether either causes or effects of the Gulf Stream are just what Humboldt, in common with others of his time, conceived them to be. About the mildle of the century, Lieutenant M. F. Maury, the distinguished American 
THE CENTURY'S PROGRESS IN ME'LOROLOGY

hydrographer and meteorologist, adrocated a theory of gravitation as the chief cause of the currents, claiming that difference in density, due to difference in temperature and saltness, would sufficiently account for the

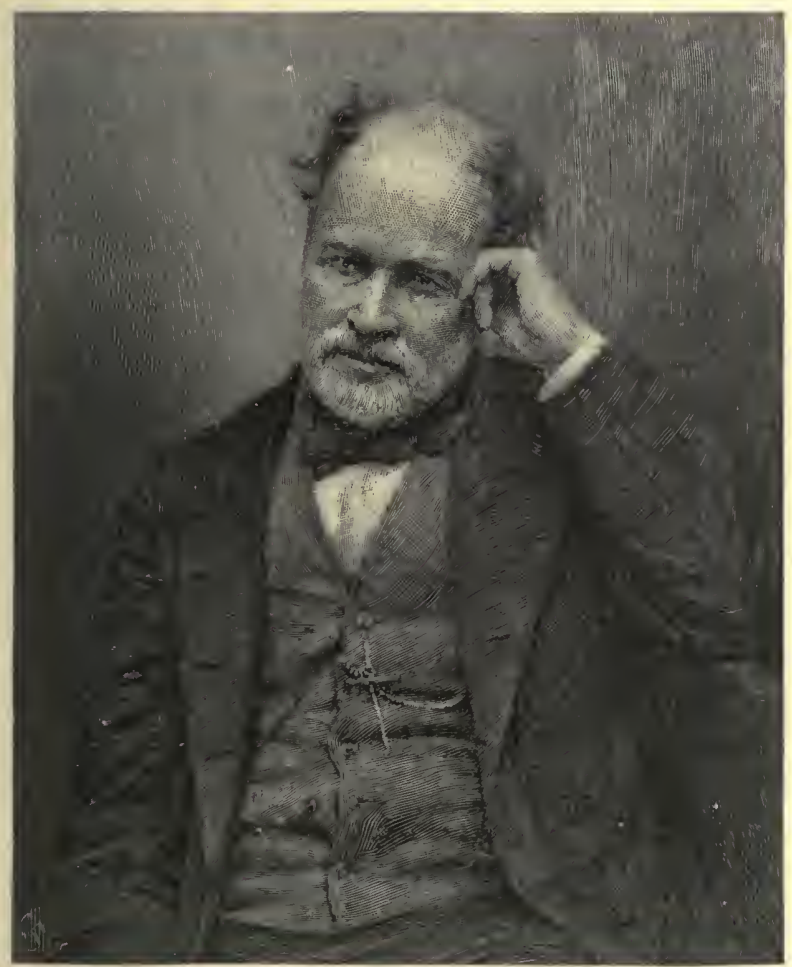

LIEUTENANT MATTHEW FONTAINE MAURY

oceanic circulation. This theory gained great popularity through the wide circulation of Maury's Physical Geography of the Sea, which is said to have passed through more editions than any other scientific book of the 179 
period; but it was ably and vigorously combated by Dr. James Croll, the Scottish geologist, in his Climate and Time, and latterly the old theory that ocean currents are due to the trade-winds has again come into favor. Indeed, very recently a model has been constructed, with the aid of which it is said to have been demonstrated that prevailing winds in the direction of the actual tradewinds would produce such a current as the Gulf Stream.

Meantime, however, it is by no means sure that gravitation does not enter into the case to the extent of producing an insensible general oceanic circulation, independent of the Gulf Stream and similar marked currents, and similar in its larger outlines to the polar-equatorial circulation of the air. The idea of such oceanic circulation was first suggested in detail by Professor Lenz of St. Petersburg, in 1845 , but it was not generally recognized until Dr. Carpenter independently hit upon the idea more than twenty years later. The plausibility of the conception is obvious; yet the alleged fact of such circulation has been hotly disputed, and the question is still sub judice.

But whether or not such general circulation of ocean water takes place, it is beyond dispute that the recognized currents carry an enormous quantity of heat from the tropics towards the poles. Dr. Croll, who has perhaps given more attention to the physics of the subject than almost any other person, computes that the Gulf Stream conveys to the North Atlantic one-fourth as much heat as that body receives directly from the sun, and he argues that were it not for the transportation of heat by this and similar Pacific currents, only a narrow tropical region of the globe would be warm enough for habitation by the existing faunas. Dr. Croll argues that 


\section{THE CEN'TURY'S PROGRESS IN ME'TEOROLOGY}

a slight change in the relative values of northern and southern trade-winds (such as he believes has taken place at various periods in the past) would suffice to so alter the equatorial current which now feeds the Gulf Stream that its main bulk would be deflected southward instead of northward, by the angle of Cape St. Roque. Thus the Gulf Stream would be nipped in the bud, and, according to Dr. Croll's estimates, the results would be disastrous for the northern hemisphere. The anti-trades, which now are warmed by the Gulf Stream, would then blow as cold winds across the shores of western Europe, and in all probability a glacial epoch would supervene throughout the northern hemisphere.

The same consequences, so far as Europe is concerned at least, would apparently ensue were the Isthmus of Panama to settle into the sea, allowing the Caribbean current to pass into the Pacific. But the geologist tells us that this isthmus rose at a comparatively recent geological period, though it is hinted that there had been some time previously a temporary land connection between the two continents. Are we to infer, then, that the two Americas in their unions and disunions have juggled with the climate of the other hem. isphere? Apparently so, if the estimates made of the influence of the Gulf Stream be tenable. It is a far cry from Panama to Russia. Yet it seems within the possibilities that the meteorologist may learn from the geologist of Central America something that will enable him to explain to the paleontologist of Europe how it chanced that at one time the mammoth and rhinoceros roamed across northern Siberia, while at another time the reindeer and musk-ox browsed along the shores of the Mediterranean. 


\section{THE STORY OF NINETEENTH-CENTURY SCIENCE}

Possibilities, I said, not probabilities. Yet even the faint glimmer of so alluring a possibility brings home to one with vividness the truth of Humboldt's perspicuous observation that meteorology can be properly comprehended only when studied in connection with the companion sciences. There are no isolated phenomena in nature.

V

Yet, after all, it is not to be denied that the chief concern of the meteorologist must be with that other medium, the "ocean of air, on the shoals of which we live." For whatever may be accomplished by water currents in the way of conveying heat, it is the wind currents that effect the final distribution of that heat. As Dr. Croll has urged, the waters of the Gulf Stream do not warm the shores of Europe by direct contact, but by warming the anti-trade-winds, which subsequently blow across the continent. And everywhere the heat accumulated by water becomes effectual in modifying climate, not so much by direct radiation as by diffusion through the medium of the air.

This very obvious importance of aerial currents led to their practical study long before meteorology had any title to the rank of science, and Dalton's explanation of the trade-winds had laid the foundation for a science of wind dynamics before our century began. But no substantial further advance in this direction was effected until about 1827, when Heinrich W. Dore, of Königsberg, afterwards to be known as perhaps the foremost meteorologist of his generation, included the winds among the subjects of his elaborate statistical studies in climatology. 


\section{THE CENT'URY'S PROGRESS IN METEOROLOGY}

Dove classified the winds as permanent, periodical, and variable. His great discovery was that all winds, of whatever character, and not merely the permanent winds, come under the influence of the earth's rotation in such a way as to be deflected from their course, and hence to take on a gyratory motion-that, in short, all

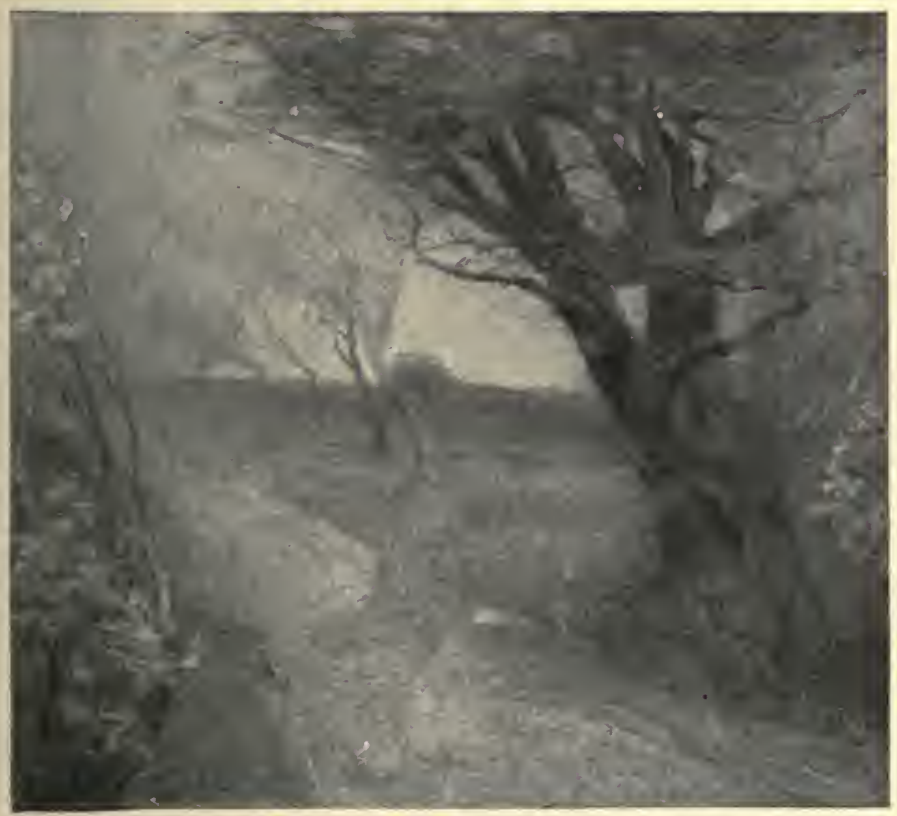

A WHIRLWIND IN A DUSTY ROAD

local winds are minor eddies in the great polar-equatorial whirl, and tend to reproduce in miniature the character of that vast maelstrom. For the first time, then, temporary or variable winds were seen to lie within the province of law.

A generation later, Professor William Ferrel, the 183 
American meteorologist, who had been led to take up the subject by a perusal of Maury's discourse on ocean winds, formulated a general mathematical law, to the effect that any body moving in a right line along the surface of the earth in any direction tends to have its course deflected, owing to the earth's rotation, to the right hand in the northern and to the left hand in the southern hemispheres. This law had indeed been stated as early as 1835 by the French physicist Poisson, but no one then thought of it as other than a mathematical curiosity ; its true significance was only understood after Professor Ferrel had independently rediscovered it (just as Dalton rediscovered Hadley's forgotten law of the tradewinds) and applied it to the motion of wind currents.

Then it became clear that liere is a key to the phenomena of atmospheric circulation, from the great polarequatorial maelstrom which manifests itself in the tradewinds, to the most circumscribed riffle which is announced as a local storm. And the more the phenomena were studied, the more striking seemed the parallel between the greater maelstrom and these lesser eddies. Just as the entire atmospheric mass of each hemisphere is seen, when viewed as a whole, to be carried in a great whirl about the pole of that hemisphere, so the local disturbances within this great tide are found always to take the form of whirls about a local storm-centrewhich storm-centre, meantime, is carried along in the major current, as one often sees a little whirlpool in the water swept along with the main current of the stream. Sometimes, indeed, the local eddy, caught as it were in an ancillary current of the great polar stream, is deflected from its normal course and may seem to travel against the stream; but such deviations are departures 


\section{TILE CENTURY'S PROGRESS IN METEOROLOGY}

from the rule. In the great majority of cases, for ex. ample, in the north-temperate zone, a storm-centre (with

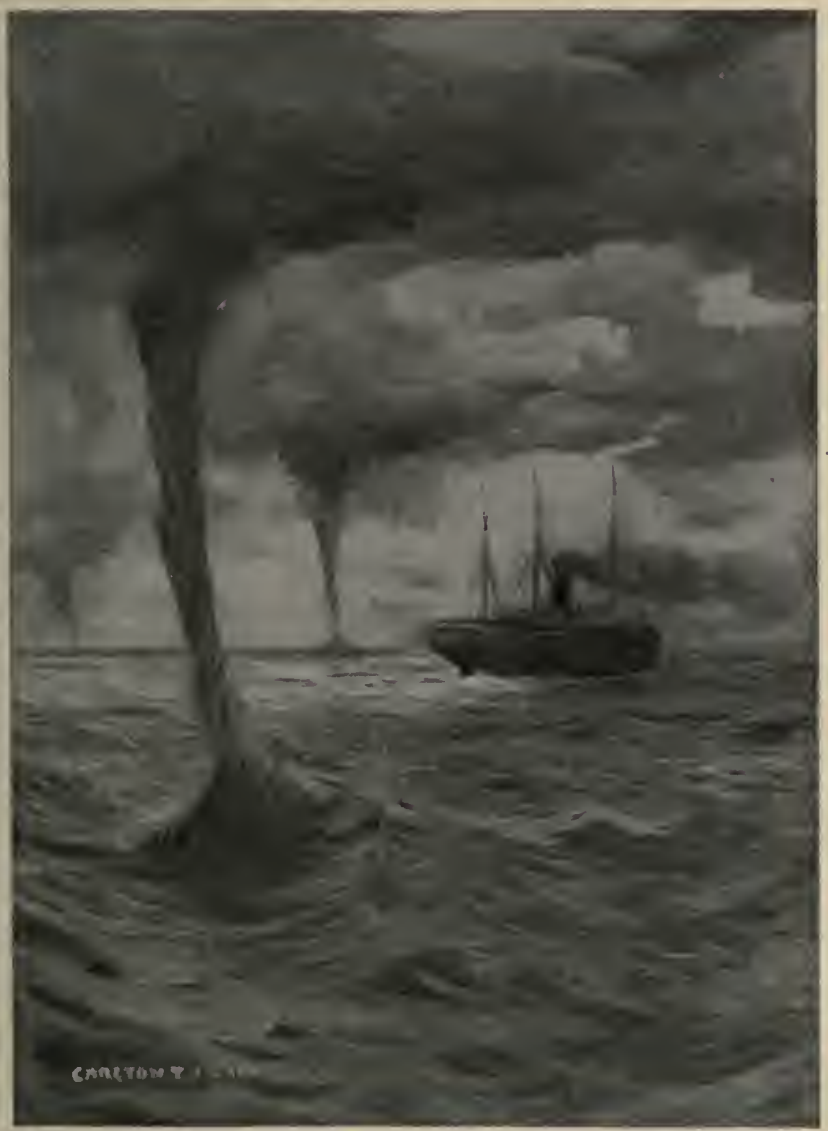

WATERSPOUTS IN MID-ATLANTIC

its attendant local whirl) travels to the northeast, along the main current of the anti-trade-wind, of which it is a 


\section{THE STORY OF NINETEENTH-CENTURY SCIENCE}

part; and though exceptionally its course may be to the southeast instead, it almost never departs so widely from the main channel as to progress to the westward. Thus it is that storms sweeping over the United States can be announced, as a rule, at the seaboard in advance of their coming by telegraphic communication from the interior, while similar storms come to Europe off the ocean unannounced. Hence the more practical arailability of the forecasts of weather bureaus in the former country.

But these local whirls, it must be understood, are local only in a very general sense of the word, inasmuch as a single one may be more than a thousand miles in diameter, and a small one is two or three liundred miles across. But quite without regard to the size of the whirl, the air composing it conducts itself always in one of two ways. It never whirls in concentric circles; it always either rushes in towards the centre in a descending spiral, in which case it is called a cyclone, or it spreads out from the centre in a widening spiral, in which case it is called an anti-cyclone. The word cyclone is associated in popular phraseology with a terrific storm, but it has no such restriction in technical usage. A gentle zephyr flowing towards a "stormcentre" is just as much a cyclone to the meteorologist as is the whirl constituting a West-Indian hurricane. Indeed, it is not properly the wind itself that is called the cyclone in either case, but the entire system of whirls - inclucling the storm-centre itself, where there may be no wind at all.

What, then, is this storm-centre? Merely an area of low barometric pressure-an area where the air has become lighter than the air of surrounding regions. Under 


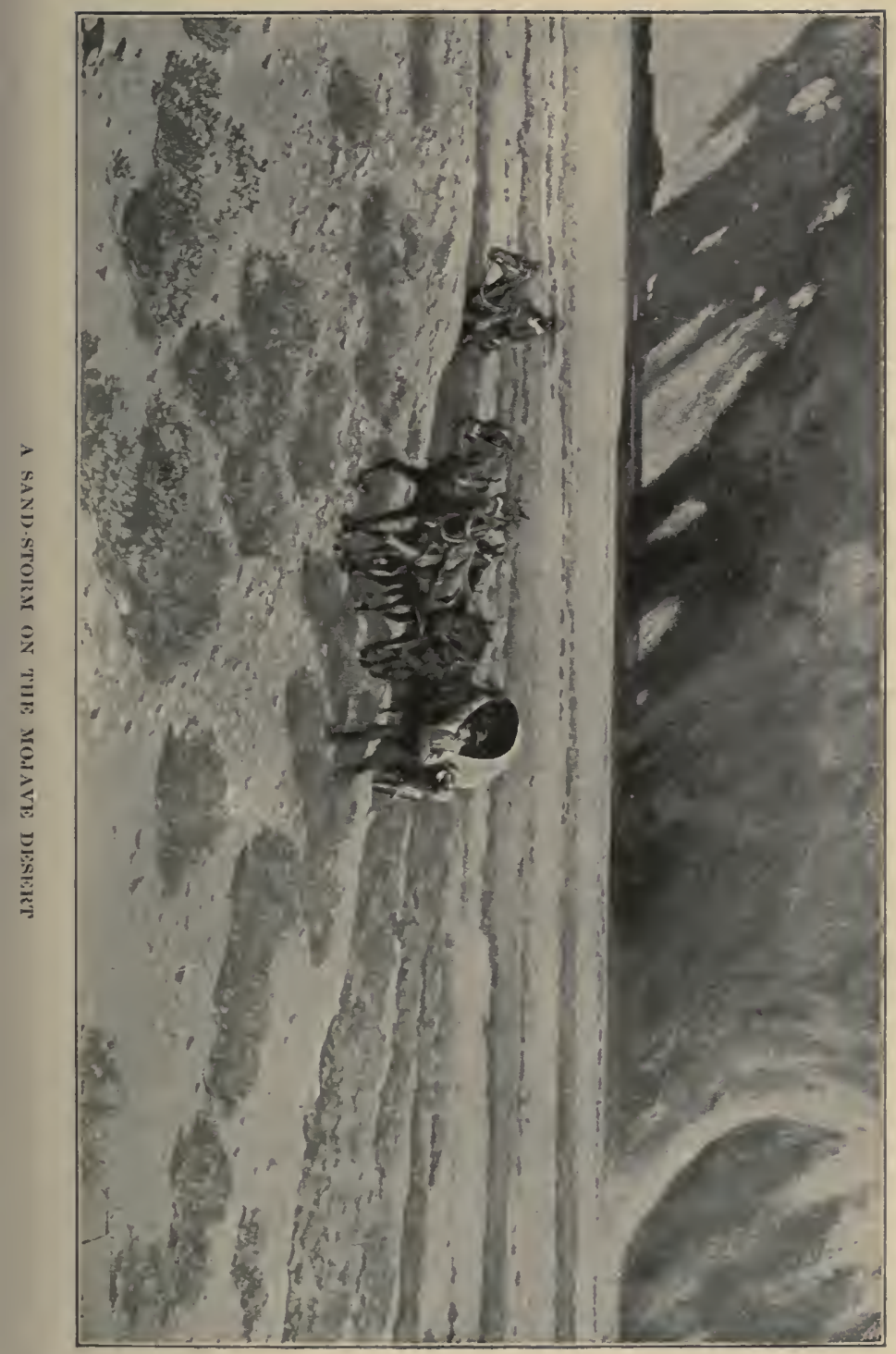



influence of gravitation the air seeks its level just as water does; so the heavy air comes flowing in from all sides towards the low-pressure area, which thus becomes a "storm-centre." But the inrushing currents never come straight to their mark. In accordance with Ferrel's law, they are deflected to the right, and the result, as will readily be seen, must be a rortex current, which whirls always in one direction - namely, from left to right, or in the direction opposite to that of the hands of a watch held with its face upward. The velocity of the cyclonic currents will depend largely upon the difference in barometric pressure between the storm-centre and the confines of the cyclone system. And the relocity of the currents will determine to some extent the degree of deflection, and hence the exact path of the descending spiral in which the wind approaches the centre. But in every case and in every part of the cyclone system it is true, as Buys Ballot's famous rule first pointed out, that a person standing with his back to the wind has the storm-centre at his left.

The primary cause of the low barometric pressure which marks the storm-centre and establishes the cyclone is expansion of the air through excess of tem. perature. The heated air, rising into cold upper regions, has a portion of its vapor condensed into clouds, and now a new dynamic factor is added, for each particle of vapor, in condensing, gires up its modicum of latent heat. Each pound of vapor thus liberates, according to Professor Tyndall's estimate, enough heat to melt five pounds of cast iron; so the amount given out where large masses of cloud are forming must enormously add to the convection currents of the air, and hence to the storm-developing power of the forming cyclone. In189 
deed, one school of meteorologists, of whom Professor Espy was the leader, has held that without such added increment of energy constantly augmenting the dynamic effects, no storm could long continue in violent action. And it is doubted whether any storm could ever attain, much less continue, the terrific force of that most dreaded of winds of temperate zones, the tornado - a storm which obeys all the laws of cyclones, but dffers from ordinary cyclones in having a vortex cole only a few feet or yards in diameter - without the aid of those great masses of condensing vapor which always accompany it in the form of storm-clouds.

The anti-cyclone simply reverses the conditions of the cyclone. Its centre is an area of high pressure, and the air rushes out from it in all directions towards surrounding regions of low pressure. As before, all parts of the current will be deflected towards the right, and the result, clearly, is a whirl opposite in direction to that of the cyclone. But here there is a tendency to dissipation rather than to concentration of energy, hence, considered as a storm-generator, the anti-cyclone is of relative insignificance.

In particular the professional meteorologist who conducts a "weather bureau"-as, for example, Sergeant Dunn, of the United States signal-service station in New York - is so preoccupied with the observation of this phenomenon that cyclone-liunting might be said to be his chief pursuit. It is for this purpose, in the main, that government weather bureaus or signal-service departments have been established all over the world. Their chief work is to follow up cyclones, with the aid of telegraphic reports, mapping their course, and recording the attendant meteorological conditions. Their so- 
called predictions or forecasts are essentially predications, gaining locally the effect of predictions because the telegraph outstrips the wind.

At only one place on the globe has it been possible as yet for the meteorologist to make long-time forecasts meriting the title of predictions. This is in the middle Ganges Valley of northern India. In this country the climatic conditions are largely dependent upon the periodical winds called monsoons, which blow steadily landward from April to October, and seaward from October to April. The summer monsoons bring the all-essential rains ; if they are delayed or restricted in extent, there will be drought and consequent famine. And such restriction of the monsoon is likely to result when there has been an unusually deep or very late snowfall on the IIimalayas, because of the lowering of spring temperature by the melting snow. Thus here it is possible, by observing the snowfall in the mountains, to predict with some measure of success the average rainfall of the following summer. The drought of 1896 , with the consequent famine and plague that devastated India last winter, was thus predicted some months in advance.

This is the greatest present triumph of practical meteorology. Nothing like it is yet possible anywhere in temperate zones. But no one can say what may not be possible in times to come, when the data now being gathered all over the world shall at last be co-ordinated, classified, and made the basis of broad inductions. Meteorology is pre-eminently a science of the future. 


\title{
CHAPTER VI
}

\section{THE CENTURY'S PROGRESS IN PHYSICS}

\author{
THE "IMPONDERABLES"
}

THERE were giants abroad in the world of science in the early days of our century. Herschel, Lagrange, and Laplace; Cuvier, Brongniart, and Lamarck; Humboldt, Goethe, Priestley-what need to extend the list? - the names crowd upon us. But among them all there was no taller intellectual figure than that of a young Quaker who came to settle in London and practise the profession of medicine in the year 1801. The name of this young aspirant to medical honors and emoluments was Thomas Young. He came fresh from professional studies at Edinburgh and on the Continent, and he had the theory of medicine at his tongue's end; yet his medical knowledge, compared with the mental treasures of his capacious intellect as a whole, was but as a drop of water in the ocean.

For it chanced that this young Quaker physician was one of those prodigies who come but few times in a century, and the full list of whom in the records of history could be told on one's thumbs and fingers. His biographers tell us things about him that read like the most patent fairy-tales. As a mere infant in arms he had 192 
been able to read fluently. Before his fourth birthday came he had read the Bible twice through, as well as Watts's Hymns-poor child!-and when seren or eight he had shown a propensity to absorb languages much as other children absorb nursery tattle and Mother Goose rhymes. When he was fourteen, a young lady visiting the household of his tutor patronized the pretty boy by asking to see a specimen of his penmanship. The pretty boy complied readily enough, and mildly rebuked his interrogator by rapidly writing some sentences for her in fourteen languages, including such as Arabian, Persian, and Ethiopic.

Meantime languages had been but an incident in the education of the lad. He seems to have entered every available field of thought-mathematics, physics, botany, literature, music, painting, languages, philosophy, archæology, and so on to tiresome lengths--and once he had entered any field he seldom turned aside until he had reached the confines of the subject as then known, and added something new from the recesses of his own genius. He was as versatile as Priestley, as profound as Newton himself. He had the range of a mere dilettante, but every where the full grasp of the master. He took early for his motto the saying that what one man has done, another man may do. Granting that the other man has the brain of a Thomas Young, it is a true motto.

Such then was the young Quaker who came to London to follow out the humdrum life of a practitioner of medicine in the year 1801. But incidentally the young physician was prevailed upon to occupy the interims of early practice by fulfilling the duties of the chair of Natural Philosophy at the Royal Institution, which Count Rumford 
had founded, and of which Davy was then Professor of Chemistry-the institution whose glories have been perpetuated by such names as Faraday and Tyndall, and which the Briton of to-day speaks of as the "Pantheon of Science." Here it was that Thomas Young made those studies which have insured him a niche in the temple of fame not far removed from that of Isaac Newton.

As early as 1793, when he was only twenty, Young had begun to communicate papers to the Royal Society of London, which were adjudged worthy to be printed in full in the Philosophical Transactions; so it is not strange that he should have been asked to deliver the Bakerian lecture before that learned body the very first year after he came to London. The lecture was delivered November 12,1801. Its subject was "The Theory of Light and Colors," and its reading marks an epoch in physical science; for here was brought forward for the first time convincing proof of that undulatory theory of light with which every student of modern physics is familiar-the theory which holds that light is not a corporeal entity, but a mere pulsation in the substance of an all-pervading ether, just as sound is a pulsation in the air, or in liquids or solids.

Young had, indeed, adrocated this theory at an earlier date, but it was not until 1801 that he hit upon the idea which enabled him to bring it to anything approaching a demonstration. It was while pondering over the familiar but puzzling phenomena of colored rings into which white light is broken when reflected from thin films-Nerwton's rings, so called-that an explanation occurred to him which at once put the entire undulatory theory on a new footing. With that sagac- 


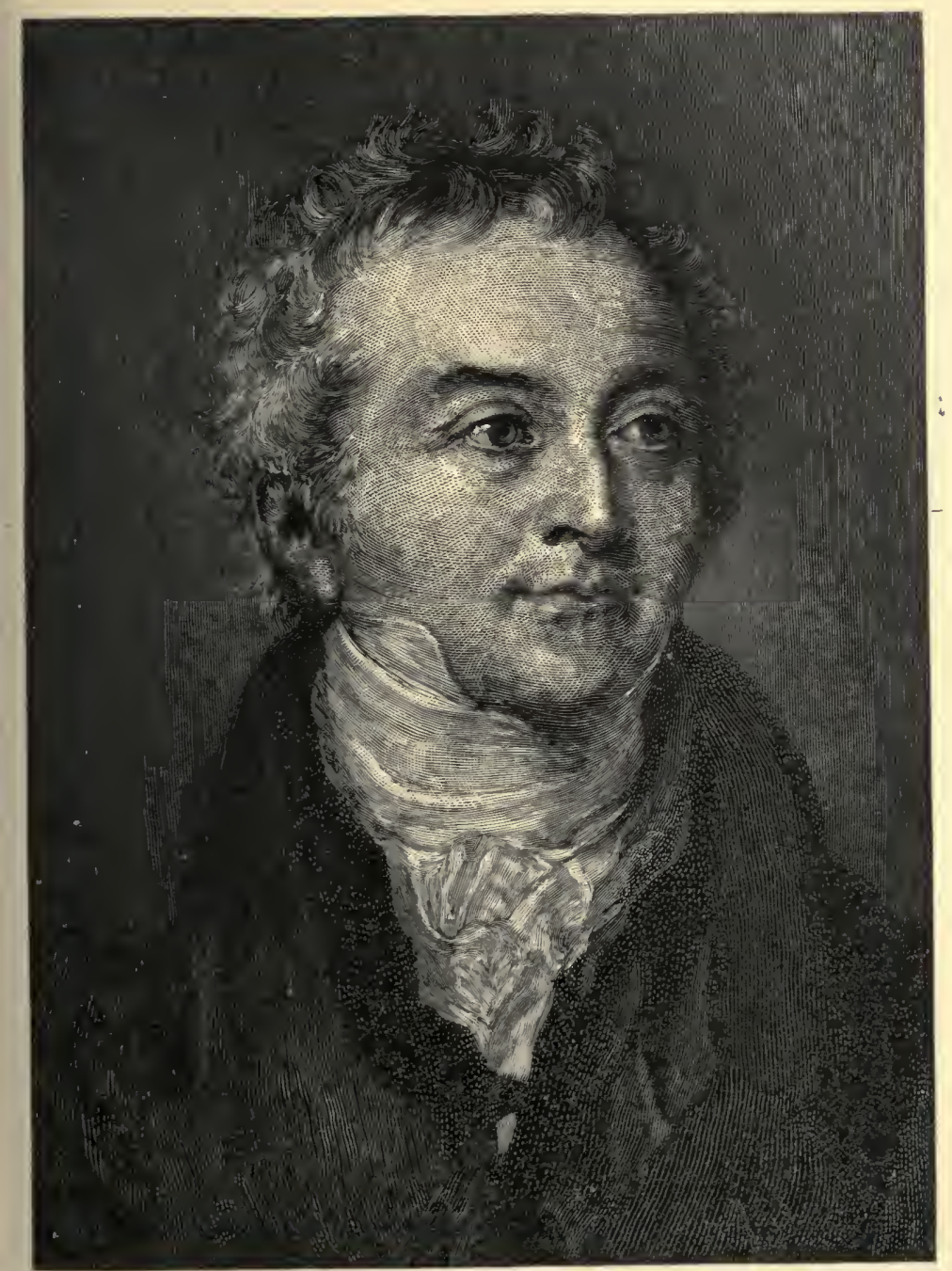

\section{THOMAS YOUNG}

From Peacock's Life of Young, by permission of John Mturray, Publisher, London 



\section{THE CENTURY'S PROGRESS IN PHYSICS}

ity of insight which we call genius, he saw of a sudden that the phenomena could be explained by supposing that when rays of light fall on a thin glass, part of the rays being reflected from the upper surface, other rays, reflected from the lower surface, might be so retarded in their course through the glass that the two sets would interfere with one another, the forward pulsation of one ray corresponding to the backward pulsation of another, thus quite neutralizing the effect. Some of the component pulsations of the light being thus effaced by mutual interference, the remaining rays would no longer give the optical effect of white light; hence the puzzling colors.

By following up this clew with mathematical precision, measuring the exact thickness of the plate and the space between the different rings of color, Young was able to show mathematically what must be the length of pulsation for each of the different colors of the spectrum. He estimated that the undulations of red light, at the extreme lower end of the visible spectrum, must number about 37,640 to the inch, and pass any given spot at a rate of 463 millions of millions of undulations in a second, while the extreme violet numbers 59,750 undulations to the inch, or 735 millions of millions to the second.

Young similarly examined the colors that are produced by scratches on a smooth surface, in particular testing the light from "Mr. Coventry's exquisite micrometers," which consist of lines scratched on glass at measured intervals. These microscopic tests brought the same results as the other experiments. The colors were produced at certain definite and measurable angles, and the theory of interference of undulations explained 
them perfectly, while, as Young affirmed with confidence, no other theory hitherto advanced could explain them at all. Taking all the eridence together, Young declared that he considered the argument he had set forth in favor of the undulatory theory of light to be "sufficient and decisive."

This doctrine of interference of undulations was the absolutely novel part of Young's theory. The allcompassing genius of Robert Hooke had, indeed, very nearly apprehended it more than a century before, as Young himself points out, but no one else had so much as vaguely conceived it; and even with the sagacious Hooke it was only a happy guess, never distinctly outlined in his own mind, and utterly ignored by all others. Young did not know of Hooke's guess until he himself had fully formulated the theory, but he hastened then to give his predecessor all the credit that could possibly be adjudged his due by the most disinterested observer. To Hooke's contemporary, Huyghens, who was the originator of the general doctrine of undulation as the explanation of light, Young renders full justice also. For himself he claims only the merit of having demonstrated the theory which these and a few others of his predecessors had adrocated without full proof.

The following year Dr. Young detailed before the Royal Society other experiments, which threw additional light on the doctrine of interference; and in 1803 he cited still others, which, he affirmed, brought the doctrine to complete demonstration. In applying this demonstration to the general theory of light, he made the striking suggestion that "the luminiferous ether pervades the substance of all material bodies with little or no resistance, as freely, perhaps, as the wind passes 
through a grove of trees." He asserted his belief also that the chemical rays which Ritter had discovered beyond the violet end of the visible spectrum are but still more rapid undulations of the same character as those which produce light. In his earlier lecture he had affirmed a like affinity between the light rays and the rays of radiant heat which Herschel detected below the red end of the spectrum, suggesting that "light differs from heat only in the frequency of its undulations or vibrations - those undulations which are within certain limits with respect to frequency affecting the optic nerve and constituting light, and those which are slower and probably stronger constituting heat only." From the very outset he had recognized the affinity between sound and light; indeed, it had been this affinity that led him on to an appreciation of the undulatory theory of light.

But while all these affinities seemed so clear to the great co-ordinating brain of Young, they made no such impression on the minds of his contemporaries. The immateriality of light had been substantially demonstrated, but practically no one save its author accepted 'the demonstration. Newton's doctrine of the emission of corpuscles was too firmly rooted to be readily dislodged, and Dr. Young had too many other interests to continue the assault unceasingly. He occasionally wrote something touching on his theory, mostly papers contributed to the Quarterly Review and similar periodicals, anonymously or under a pseudonym, for he had conceived the notion that too great conspicuousness in fields outside of medicine would injure his practice as a physician. His views regarding light (including the original papers from the Philosophical Transactions of 
the Royal Society) were again given publicity in full in his celebrated volume on natural philosophy, consisting in part of his lectures before the Royal Institution, published in 1807; but even then they failed to bring conviction to the philosophic world. Indeed, they did not even arouse a controversial spirit, as his first papel's had done.

So it chanced that when, in 1815, a young French military engineer, named Augustin Jean Fresnel, returning from the Napoleonic wars, became interested in the phenomena of light, and made some experiments concerning diffraction, which seemed to him to controvert the accepted notions of the materiality of light, he was quite unaware that his experiments had been anticipated by a philosopher across the Channel. He communicated his experiments and results to the French Institute, supposing them to be absolutely novel. That body referred them to a committee, of which, as good fortune would have it, the dominating member was Dominique François Arago, a man as rersatile as Young himself, and hardly less profound, if perhaps not quite so original. Arago at once rccognized the merit of Fresnel's work, and soon became a convert to the theory. He told Fresnel that Young had anticipated him as legards the general theory, but that much remained to be done, and he offered to associate himself with Fresnel in prosecuting the investigation. Fresnel was not a little dashed to learn that his original ideas had been worked out by another while he was a lad, but he bowed gracefully to the situation, and went ahead with unabated zeal.

The championship of Arago insured the undulatory theory a hearing before the French Institute, but by no 200 


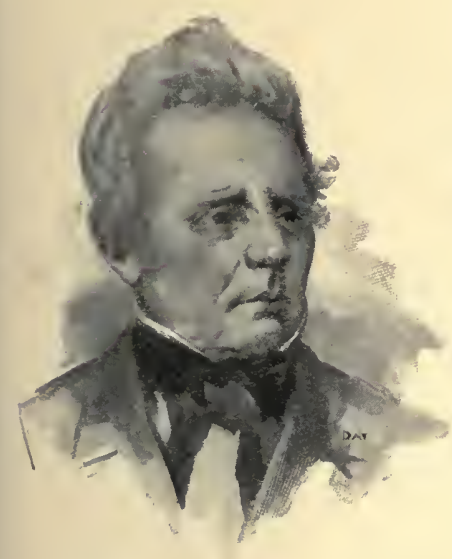

HANS CHRISTIAN OERSTED

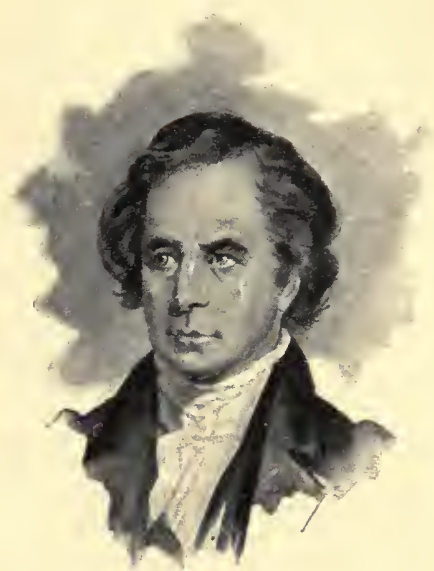

DOMINIQUE FRANGOIS ARAGO

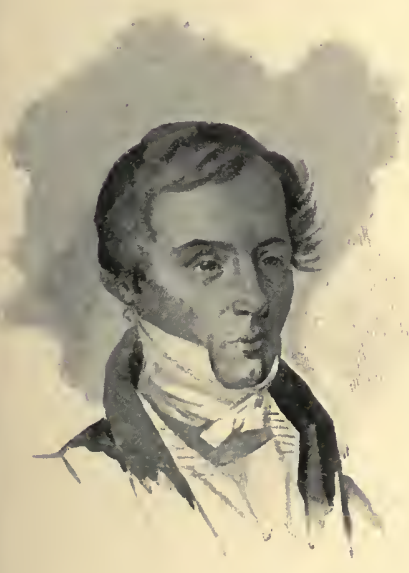

AOGCSTIN JEAYN FRESNEL

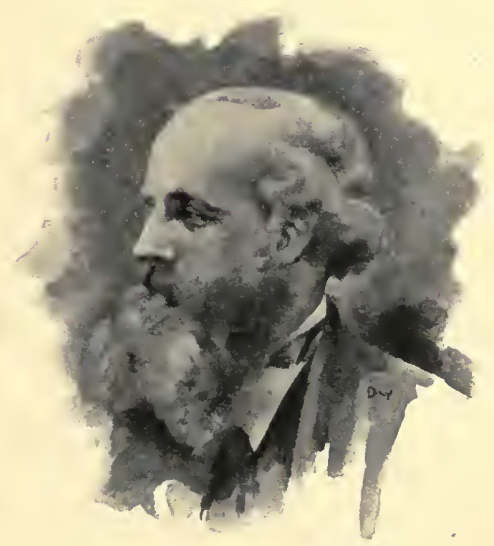

JAMES CLERK MAXTELLL 

means sufficed to bring about its general acceptance. On the contrary, a bitter feud ensued, in which Arago was opposed by the "Jupiter Olympius of the Academy," Laplace, by the only less famous Poisson, and by the younger but hardly less able Biot. So bitterly raged the feud that a life-long friendship between Arago and Biot was ruptured forever. The opposition managed to delay the publication of Fresnel's papers, but Arago continued to fight with his customary enthusiasm and pertinacity, and at last, in 1823, the Academy yielded, and voted Fresnel into its ranks, thus implicitly admitting the value of his work.

It is a humiliating thought that such controversies as this must mar the progress of scientific truth ; but fortunately the story of the introduction of the undulatory theory has a more pleasant side. Three men, great both in character and in intellect, were concerned in pressing its claims - Young, Fresnel and Arago - and the relations of these men form a picture unmarred by any of those petty jealousies that so often dim the lustre of great names. Fresnel freely acknowledged Young's priority so soon as his attention was called to it; and Young applauded the work of the Frenchman, and aided with his counsel in the application of the undulatory theory to the problems of polarization of light, which still demanded explanation, and which Fresnel's fertility of experimental resource and profundity of mathematical insight sufficed in the end to conquer.

After Fresnel's admission to the Institute in 1823 the opposition weakened, and gradually the philosophers came to realize the merits of a theory which Young had vainly called to their attention a full quartercentury before. Now, thanks largely to Arago, both 
Young and Fresnel received their full meed of appreciation. Fresnel was given the Rumford medal of the Royal Society of England in 1825, and chosen one of the foreign members of the Society two years later, while Young in turn was elected one of the eight foreign members of the French Academy. As a fitting culmination of the chapter of felicities between the three friends, it fell to the lot of Young, as Foreign Secretary of the Royal Society, to notify Fresnel of the honors shown him by England's representative body of scientists; while Arago, as Perpetual Secretary of the French Institute, conveyed to Young in the same year the notification that he had been similarly honored by the savants of France.

A few months later Fresnel was dead, and Young survived him only two years. Both died prematurely; but their great work was done, and the world will remember always and link together these two names in connection with a theory which in its implications and importance ranks little below the theory of universal gravitation.

The full importance of Young's studies of light might perhaps have gained earlier recognition had it not chanced that, at the time when they were made, the attention of the philosophic world was turned with the fixity and fascination of a hypnotic stare upon another field, which for a time brooked no rival. How could the old familiar phenomenon light interest any one when the new agent galvanism was in view? As well ask one to fix attention on a star while a meteorite blazes across the sky. 
The question of the hour was whether in galvanism the world had to do with a new force, or whether it is identical with electricity, masking under a new form. Very early in the century the profound, if rather captious, Dr. Wollaston made experiments which seemed to show that the two are identical; and by 1807 Dr. Young could write in his published lectures: "The identity of the general causes of electrical and of galvanic effects is now doubted by few." To be entirely accurate, he should have added, "by few of the leaders of scientific thought," for the lesser lights were by no means so fully agreed as the sentence cited might seem to imply.

But meantime an even more striking affinity had been found for the new agent galvanism. From the first it had been the chemists rather than the natural philosophers-the word physicist was not then in vogue-who had chiefly experimented with Volta's battery; and the acute mind of Humphry Davy at once recognized the close relationship between chemical decomposition and the appearance of the new "imponderable." The great Siredish chemist Berzelius also had an inkling of the same thing. But it was Davy who first gave the thought full expression, in a Bakerian lecture before the Royal Society in 1806-the lecture which gained him not only the plaudits of his own countrymen, but the Napoleonic prize of the French Academy at a time when the political bodies of the two countries were in the midst of a sanguinary wal. "Science knows no country," said the young Englishman, in accepting the French testimonial, against the wishes of some of the more narrow-minded of his friends. "If the two countries or governments are at war, the men of science are not. That would, indeed, be a civil war of the worst 
description. We should rather, through the instrumentality of men of science, soften the asperities of national hostility."

Here it was that Davy explicitly" stated his belief that "chemical and electrical attraction are produced by the same cause, acting in one case on particles, in the other on masses," and that "the same property, under different modifications, is the cause of all the phenomena exhibited by different voltaic combinations." The phenomena of galvanism were thus linked with chemical action on the one hand, and with frictional electricity on the other, in the first decade of the century, showing that electricity is by no means the isolated "fluid" that it had been thought. But there the matter rested for another decade. The imaginative Dary, whose penetrative genius must hare carried him further had it not been diverted, became more and more absorbed in the chemical side of the problem; and Young, having serered his connection with the Royal Institution, was devoting himself to developing his medical practice, and in intervals of duty to deciphering Egyptian hieroglyphics. Parenthetically it may be added that Young was far too much in advance of his time to make a great success as a practitioner (people demand sophistry rather than philosophy of their family physician), but that his success with the hieroglyphics was no less novel and epoch-making than his work in philosophy.

For a time no master-generalizer came to take the place of these men in the study of the "imponderables" as such, and the phenomena of electricity occupied an isolated corner in the realm of science, linked, as has been said rather to chemistry than to the field we now term physics. 
But in the year 1819 there flashed before the philosophic world, like lightning from a clear sky, the report that Hans Christian Oersted, the Danish philosopher, had discovered that the magnetic needle may be deflected by the passage near it of a current of electricity. The experiment was repeated every where. Its validity was beyond question, its importance beyond estimate. Many men had vaguely dreamed that there might be some connection between electricity and magnetismchiefly because each shows phenomena of seeming attraction and repulsion-but here was the first experimental evidence that any such connection actually exists. The wandering eye of science was recalled to electricity as suddenly and as irresistibly as it had been in 1500 by the discovery of the roltaic pile. But now it was the physical rather than the chemical side of the subject that chiefly demanded attention.

At once André Marie Ampère, whom the French love to call the Nerton of electricity, appreciated the farreaching importance of the newly disclosed relationship, and, combining mathematical and experimental studies, showed how close is the link between electricity and magnetism, and suggesterl the possibility of signalling at a distance by means of electric wires associated with magnetic needles. Gauss, the great mathematician, and Weber, the physicist, put this idea to a practical test by communicating with one another at a distance of several roods, in Göttingen, long before "practical" telegraphy grew out of Oersted's discovery.

A new impetus thus being giren to the inrestigators, an epoch of electrical discovery naturally followed. For a time interest centred on the French investigators, in particular upon the experiments of the ever-receptive 207 
A rago, who discorered in 1825 that magnets may be produced at will by electrical induction. But about 1830 the scene shifted to London; for then the protégé of Davy, and his successor in the Royal Institution, Michael Faraday, the "man who added to the powers of his intellect all the graces of the human heart," began that series of electrical experiments at the Royal Institution which were destined to attract the dazed attention of the philosophic world, and stamp their originator as "the greatest experimental philosopher the world has ever seen." Nor does the rank of prince of experimenters do Faraday full justice, for he was far more than a mere experimenter. He had not, perhaps, quite the intuitive insight of Davy, and he utterly lacked the profound mathematical training of Young. None the less was he a man who could dream dreams on occasion, and, as Maxwell has insisted, think in mathematical channels if not with technical symbols. Only his wagon must always traverse earth though hitched to a star. His dreams guided him onward, but ever the hand of experiment kept check over the dreams.

It was in 1831 that Faraday opened up the field of magneto-electricity. Reversing the experiments of his predecessors, who had found that electric currents may generate magnetism, he showed that magnets have power under certain circumstances to generate electricity; le proved, indeed, the interconvertibility of electricity and magnetism. Then he showed that all bodies are more or less subject to the influence of magnetism, and that even light may be affected by magnetism as to its phenomena of polarization. He satisfied himself completely of the true identity of all the rarious forms of electricity, and of the convertibility of electricity and 
chemical action. Thus he linked together light, chemical affinity, magnetism, and electricity. And, moreover, he knew full well that no one of these can be produced in indefinite supply from another. Nowhere, he says, "is there a pure creation or production of power without a corresponding exhaustion of something to supply it."

When Faraday wrote those words in 1840 he was treading on the very heels of a greater generalization than any which he actually formulated; nay, he had it fairly within his reach. He saw a great truth without fully realizing its import; it was left for others, approaching the same truth along another path, to point out its full significance.

\section{III}

The great generalization which Faraday so narrowly missed is the truth which since then has become familiar as the doctrine of the conservation of energy-the law that in transforming energy from one condition to anether we can never secure more than an equivalent quantity; that, ill short, "to create or annihilate energy is as impossible as to create or annihilate matter; and that all the phenomena of the material universe consist in transformations of energy alone." Some philosophers think this the greatest generalization ever conceived by the mind of man. Be that as it may, it is surely one of the great intellectual landmarks of our century. It stands apart, so stupendous and so farreaching in its implications that the generation which first saw the law developed could little appreciate it; only now, through the vista of half a century, do we begin to see it in its true proportions. 
A vast generalization such as this is never a mushroom growth, nor does it usually spring full grown from the mind of any single man. Always a number of minds are very near a truth before any one mind fully grasps it. Pre-eminently true is this of the doctrine of conservation of energy. Not Faraday alone, but half a dozen different men had an inkling of it before it gained full expression; indeed, every man who advocated the undulatory theory of light and heat was verging towards the goal. The doctrine of Young and Fresnel was as a highway leading surely on to the wide plain of conservation. The phenomena of electro-magnetism furnished another such highway. But there was yet another road which led just as surely and even more readily to the same goal. This was the road furnished by the phenomena of heat, and the men who travelled it were destined to outstrip their fellow-workers; though, as we have seen, wayfarers on other roads were within hailing distance when the leaders passed the mark.

In order to do even approximate justice to the men who entered into the great achievement, we niust recall that just at the close of the last century Count Rumford and Humphry Davy independently showed that labor may be transformed into heat; and correctly interpreted this fact as meaning the transformation of molar into molecular motion. We can hardly doubt that each of these men of genius realized, vaguely, at any rate, that there must be a close correspondence between the amount of the molar and the molecular motions; hence that each of them was in sight of the law of the mechanical equiralent of heat. But neither of them quite grasped or explicitly stated what each must ragruely have seen; and for just a quarter of a century no one 


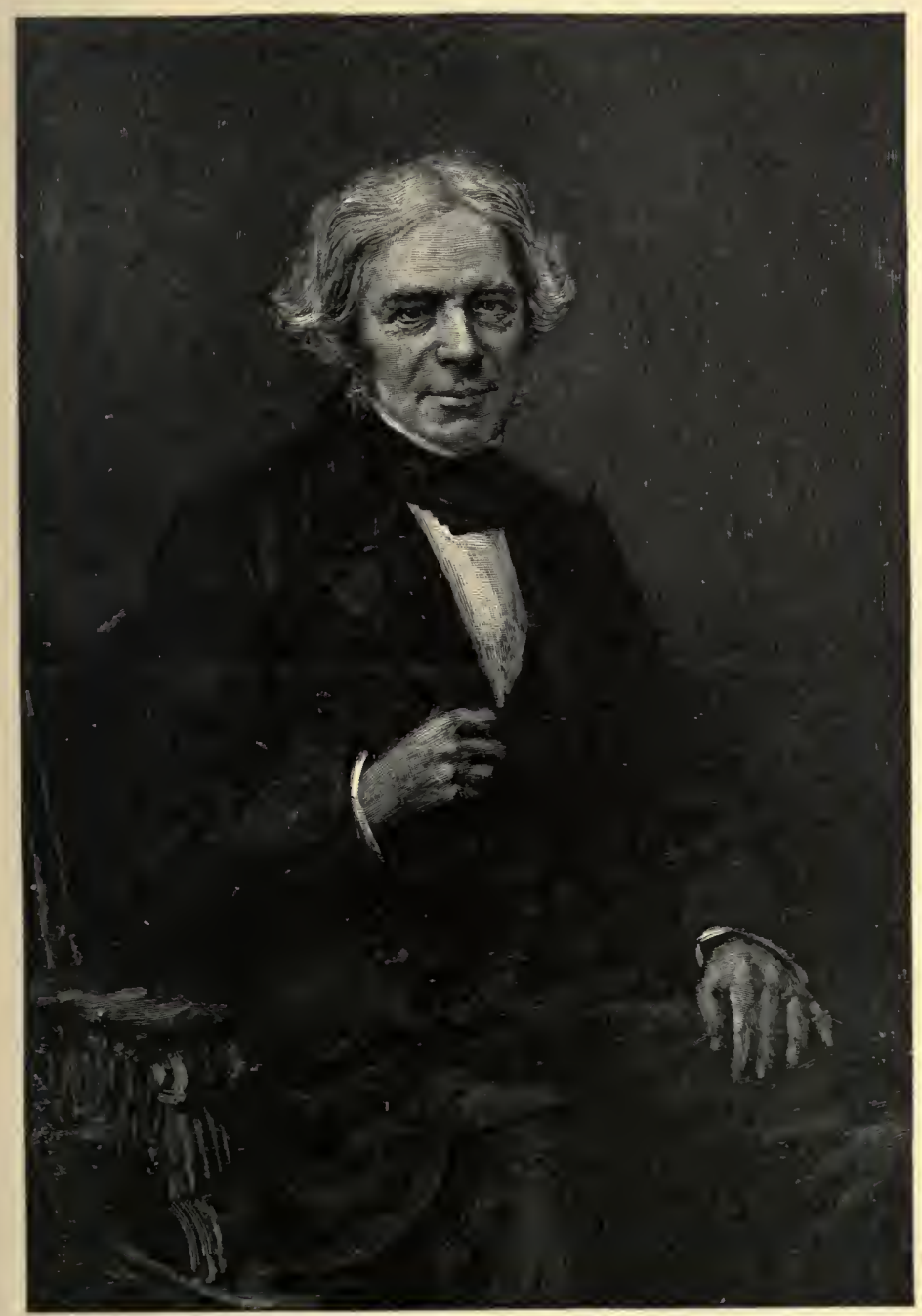

MICHAEL FARADAY 

else even came abreast their line of thought, let alone passing it.

But then, in 1824, a French philosopher, Sadi Carnot, caught step with the great Englishmen, and took a long leap ahead by explicitly stating his belief that a definite quantity of work could be transformed into a definite quantity of heat, no more, no less. Carnot did not, indeed, reach the clear view of his predecessors as to the nature of heat, for he still thought it a form of "imponderable" fluid; but he reasoned none the less clearly as to its mutual convertibility with mechanical work. But important as his conclusions seem now that we look back upon them with clearer vision, they made no impression whatever upon his contemporaries. Carnot's work in this line was an isolated phenomenon of historical interest, but it did not enter into the scheme of the completed narrative in any such way as did the work of Rumford and Davy.

The man who really took up the broken thread where Rumford and Davy had dropped it, and wove it into a completed texture, came upon the scene in 1840. His home was in Manchester, England; his occupation that of a manufacturer. He was a friend and pupil of the great Dr. Dalton. His name was James Prescott Joule. When posterity has done its final juggling with the names of our century, it is not unlikely that the name of this Manchester philosopher will be a household word like the names of Aristotle, Copernicus, and Newton.

For Joule's work it was, done in the fifth decade of our century, which demonstrated beyond all cavil that there is a precise and absolute equivalence between mechanical work and heat; that whatever the form of manifestation of molar motion, it can generate a definite and 
measurable amount of heat, and no more. Joule found, for example, that at the sea-level in Manchester a pound weight falling through seven hundred and seventy-two feet could generate enough heat to raise the temperature of a pound of water one degree Fahrenheit. There was nothing haphazard, nothing accidental, about this; it bore the stamp of unalterable law. And Joule himself saw, what others in time were made to see, that this truth is merely a particular case within a more general law. If heat cannot be in any sense created, but only made manifest as a transformation of another kind of motion, then must not the same thing be true of all those other forms of "force"-light, electricity, magnetism-which had been shown to be so closely associated, so mutually convertible, with heat? All analogy seemed to urge the truth of this inference; all experiment tended to confirm it. The law of the mechanical equivalent of heat then became the main corner-stone of the greater law of the conservation of energy.

But while this citation is fresh in mind, we must turn our attention with all haste to a country across the Channel-to Denmark, in short-and learn that eren as Joule experimented with the transformation of heat, a philosopher of Copenhagen, Colding by name, had hit upon the same idea, and carried it far towards a demonstration. And then, without pausing, we must shift yet again, this time to Germany, and consider the work of three other men, who independently were on the track of the same truth, and two of whom, it must be admitted, reached it earlier than either Joule or Colding, if neither brought it to quite so clear a demonstration. The names of these three Germans are Mohr, Mayer, and Helmholtz. Their share in establishing 
the great doctrine of conservation must now claim our attention.

As to Karl Friedrich Mohr, it may be said that his statement of the doctrine preceded that of any of his fellows, yet that otherwise it was perhaps least important. In 1837 this thoughtful German had grasped the main truth, and given it expression in an article published in the Zeitschrift für Physik, etc. But the article attracted no attention whatever, even from Mohr's own countrymen. Still, Mohr's title to rank as one who independently conceived the great truth, and perhaps first conceived it before any other man in the world saw it as clearly, even though he did not demonstrate its validity, is not to be disputed.

It was just five years later, in 1842 , that Dr. Julius Robert Mayer, practising physician in the little German town of Heilbronn, published a paper in Liebig's Annalen on "The Forces of Inorganic Nature," in which not merely the mechanical theory of heat, but the entire doctrine of the conservation of energy, is explicitly if briefly stated. Two years earlier Dr. Mayer, while surgeon to a Dutch India ressel cruising in the tropics, had observed that the venous blood of a patient seemed redder than venous blood usually is observed to be in temperate climates. He pondered over this seemingly insignificant fact, and at last reached the conclusion that the cause must be the lesser amount of oxidation required to keep up the body temperature in the tropics. Led by this reflection to consider the body as a machine dependent on outside forces for its capacity to act, he passed on into a novel realm of thought, which brought him at last to independent discovery of the mechanical theory of heat, and to the first full and comprehensive 


\section{THE STORY OF NINETEENTH-CENTURY SCIENCE}

appreciation of the great law of conservation. Bloodletting, the modern physician holds, was a practice of very doubtful benefit, as a rule, to the subject; but once, at least, it led to marvellous results. No straw is so small that it may not point the receptive mind of genius to new and wonderful truths.

Here, then, was this obscure German physician, leading the humdrum life of a village practitioner, yet seeing such visions as no human being in the world had ever seen before.

The great principle he had discovered became the dominating thought of his life, and filled all his leisure hours. He applied it far and wide, amidst all the phenomena of the inorganic and organic worlds. It taught him that both vegetables and animals are machines, bound by the same laws that hold sway over inorganic matter, transforming energy, but creating nothing. Then his mind reached out into space and met a universe made up of questions. Each star that blinked down at him as he rode in answer to a night call seemed an interrogation-point asking, How do I exist? Why have I not long since burned out if your theory of conservation be true? No one hitherto had even tried to answer that question; few had so much as realized that it demanded an answer. But the Heilbronn physician understood the question and found an answer. His meteoric hypothesis, published in $18+8$, gave for the first time a tenable explanation of the persistent light and heat of our sun and the myriad other suns-an explanation to which we shall recur in another connection.

All this time our isolated philosopher, his brain aflame with the glow of creative thought, was quite unaware that any one else in the world was working along the 
same lines. And the outside world was equally heedless of the work of the Heilbronn physician. There was no friend to inspire enthusiasm and give courage, no kindred spirit to react on this masterful but lonely mind. And this is the more remarkable because there are few other cases where a master-originator in science has come upon the scene except as the pupil or friend of some other master-originator. Of the men we have noticed in the present connection, Young was the friend and confrère of Davy ; Davy, the protégé of Rumford ; Farraday, the pupil of Davy; Fresnel, the co-worker with Arago; Colding, the confrère of Oersted; Joule, the pupil of Dalton. But Mayer is an isolated phenomenon -one of the lone mountain-peak intellects of the century. That estimate may be exaggerated which has called him the Galileo of the nineteenth century, but surely no lukewarm praise can do him justice.

Yet for a long time his work attracted no attention whatever. In 1847, when another German physician, Hermann von Helmboltz, one of the most massive and towering intellects of any age, had been independently led to comprehension of the doctrine of conservation of energy, and published his treatise on the subject, he had hardly heard of his countryman Mayer. When he did hear of him, however, he hastened to renounce all claim to the doctrine of conservation, though the world at large gives him credit of independent even though subsequent discovery.

Meantime in England Joule was going on from one experimental demonstration to another, oblivious of his German competitors and almost as little noticed by his own countrymen. He read his first paper before the chemical section of the British Association for the 
Adrancement of Science in 1843 , and no one heeded it in the least. Two years later he wished to read another paper, but the chairman hinted that time was limited, and asked him to confine himself to a brief verbal synopsis of the results of his experiments. Had the chairman but known it, he was curtailing a paper vastly more important than all the other papers of the meeting put together. However, the synopsis was given, and one man was there to hear it who had the genius to appreciate its importance. This was William Thomson, the present Lord Kelvin, now known to all the world as among the greatest of natural philosophers, but then only a novitiate in science. He came to Joule's aid, started rolling the ball of controversy, and subsequently associated himself with the Manchester experimenter in pursuing his in restigations.

But meantime the acknowledged leaders of British science viewed the new doctrine askance. Faraday, Brewster, Herschel-those were the grèat names in physics at that day, and no one of them could quite accept the new views regarding energy. For several years no older physicist, speaking with recognized authority, came forward in support of the doctrine of conservation. This culminating thought of our first half-century came silently into the world, unheralded and unopposed. The fifth decade of the century had seen it elaborated and substantially demonstrated in at least three different countries, yet even the leaders of thought did not so much as know of its existence. In 1853 Whe well, the historian of the inductive sciences, published a second edition of his history, and, as Huxley has pointed out, he did not so much as refer to the revolutionizing thought which even then was a full decade old. 


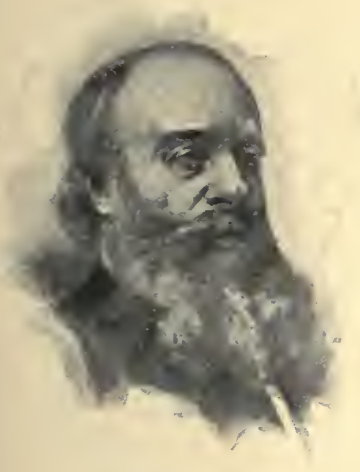

JAMES PRESCOTT JOULE

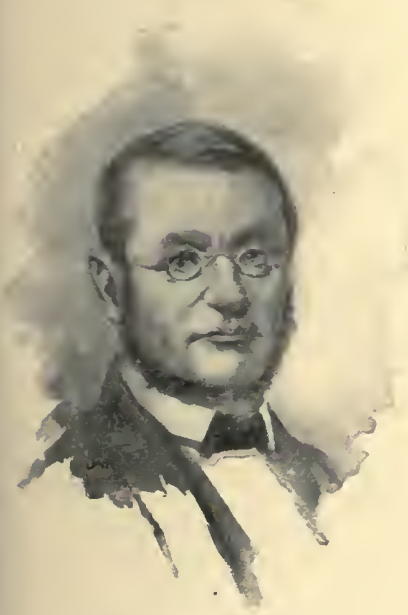

JULIUS ROHERT MAYKR

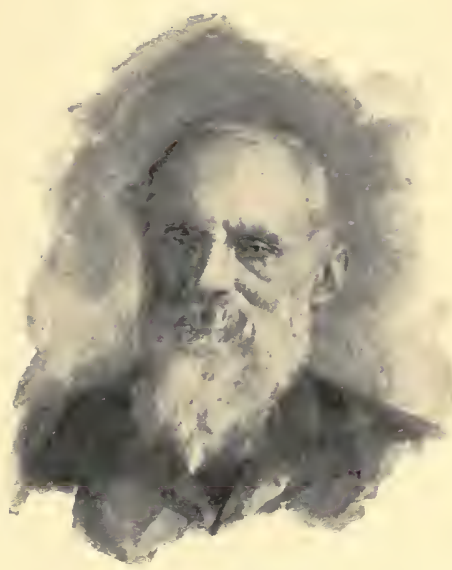

WILLIAM THOMSON (LORD KELVIN)

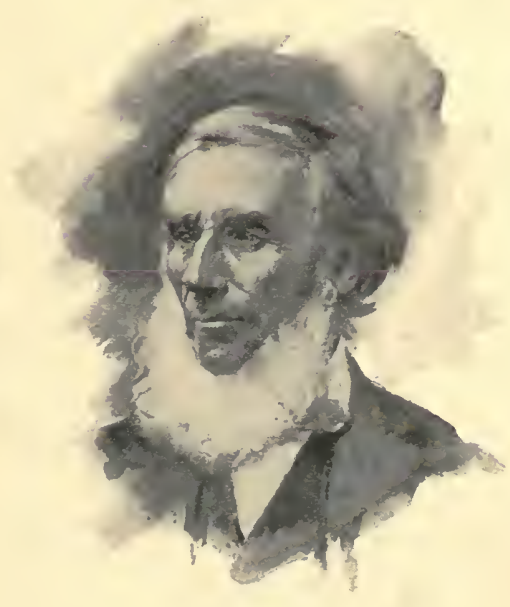

JOIIN TYNDALI. 



\section{THE CENTURY'S PROGRESS IN PHYSICS}

By this time, however, the battle was brewing. The rising generation saw the importance of a law which their elders could not appreciate, and soon it was noised abroad that there were more than one claimant to the honor of discovery. Chiefly through the efforts of Professor Tyndall, the work of Mayer became known to the British public, and a most regrettable controversy ensued between the partisans of Mayer and those of Joule-a bitter controversy, in which Davy's contention that science knows no country was not always regarded, and which left its scars upon the hearts and minds of the great men whose personal interests were involved.

And so to this day the question who is the chief discoverer of the law of conservation of energy is not susceptible of a categorical answer that would satisfy all philosopheis. It is generally held that the first choice lies between Joule and Mayer. Professor Tyndall has expressed the belief that in future each of these men will be equally remembered in connection with this work. But history gires us no warrant for such a hope. Posterity in the long-run demands always that its heroes shall stand alone. Who remembers now that Robert Hooke contested with Newton the discovery of the doctrine of universal gravitation? The judgment of posterity is unjust, but it is inexorable. And so we can little doubt that a century from now one name will be mentioned as that of the originator of the great doctrine of conservation of energy. The man whose name is thus remembered will perhaps be spoken of as the Galileo, the Newton, of the nineteenth century; but whether the name thus dignified by the final verdict of history will be that of Colding, Mohr, Mayer, Helmholtz, or Joule, it is not for our century to decide. 


\section{IV}

The gradual permeation of the field by the great doctrine of conservation simply repeated the history of the introduction of every novel and revolutionary thought. Necessarily the elder generation, to whom all forms of energy were imponderable fluids, must pass away before the new conception could claim the field. Even the word energy, though Young had introduced it in 1807 , did not come into general use till some time after the middle of the century. To the generality of philosophers (the word physicist was even less in favor at this time) the various forms of energy were still subtle fluids, and never was idea relinquished with greater unwillingness than this. The experiments of Young and Fresnel had convinced a large number of philosophers that light is a vibration and not a substance; but so great an authority as Biot clung to the old emission idea to the end of his life, in 1862, and held a following.

Meantime, however, the company of brilliant young men who had just served their apprenticeship when the doctrine of conservation came upon the scene had grown into authoritative positions, and were battling actively for the new ideas. Confirmatory evidence that energy is a molecular motion and not an "imponderable" form of matter accumulated day by day. The experiments of two Frenchmen, Hippolyte L. Fizeau and Léon Foucault, served finally to convince the last lingering sceptics that light is an undulation; and by implication brought heat into the same category, since James David Forbes, the Scotch physicist, had shown in 1837 that radiant heat conforms to the same laws of polarization and double 
refraction that govern light. But, for that matter, the experiments that had established the mechanical equivalent of heat hardly left room for doubt as to the immateriality of this "imponderable." Doubters had, indeed, expressed scepticism as to the validity of Joule's experiments, but the further researches, experimental and mathematical, of such workers as Thomson (Lord Kelvin), Rankine, and Tyndall in Great Britain, of Helmholtz and Clausius in Germany, and of Regnault in France, dealing with various manifestations of heat, placed the evidence beyond the reach of criticism.

Out of these studies, just at the middle of the century, to which the experiments of Mayer and Joule had led, grew the new science of thermo-dynamics. Out of them also grew in the mind of one of the investigators a new generalization, only second in importance to the doctrine of conservation itself. Professor William Thomson (Lord Kelvin) in his studies in thermo-dynamics was early impressed with the fact that whereas all the molar motion developed through labor or gravity could be converted into heat, the process is not fully reversible. Heat can, indeed, be conrerted into molar motion or work, but in the process a certain amount of the heat is radiated into space and lost. The same thing liappens whenever any other form of energy is converted into molar motion. Indeed, every transmutation of energy, of whatever character, seems complicated by a tendency to develop heat, part of which is lost. This observation led Professor Thomson to his doctrine of the dissipation of energy, which he formulated before the Royal Society of Edinburgh in 1852, and published also in the Philosophical Mugazine the same year, the title borne being, "On a Universal Ten- 


\section{THE STORY OF NINETEENIH-CENTURY SCIENCE}

dency in Nature to the Dissipation of Mechanical Energy."

From the principle here expressed Professor Thomson drew the startling conclusion that, "since any restoration of this mechanical energy without more than an equivalent dissipation is impossible," the universe, as known to us, must be in the condition of a machine gradually running down; and in particular that the world we live on has been within a finite time unfit for human habitation, and must again become so within a finite future. This thought seems such a commonplace to-day that it is difficult to realize how startling it appeared half a century ago. A generation trained, as ours has been, in the doctrines of conservation and dissipation of energy as the very alphabet of physical science can but ill appreciate the mental attitude of a generation which for the most part had not even thought it problematical whether the sun could continue to give out heat and light forever. But those advance thinkers who had grasped the import of the doctrine of conservation could at once appreciate the force of Thomson's doctrine of dissipation, and realize the complementary character of the two conceptions.

Here and there a thinker like Rankine did, indeed, attempt to fancy conditions under which the energy lost through dissipation might be restored to availability, but no such effort has met with success, and in time Professor Thomson's generalization and his conclusions as to the consequences of the law involred came to be universally accepted.

The introduction of the new views regarding the nature of energy followed, as I have said, the course of every other growth of new ideas. Young and imagina- 


\section{TIE CENTURY'S PROGRESS IN PHYSICS}

tive men could accept the new point of view ; older philosophers, their minds channelled by preconceptions, could not get into the new groove. So strikingly true is this in the particular case now before us that it is worth while to note the ages at the time of the revolutionary experiments of the men whose work has been mentioned as entering into the scheme of evolution of the idea that energy is merely a manifestation of matter in motion. Such a list will tell the story better than a rolume of commentary.

Observe, then, that Davy made his epochal experiment of melting ice by friction when he was a youth of twenty. Young was no older when he made his first communication to the Royal Society, and was in his twenty-seventh year when he first actively espoused the undulatory theory. Fresnel was twenty-six when he made his first important discoveries in the same field; and Arago, who at once became his champion, was then but two years his senior, though for a decade he had been so famous that one involuntarily thinks of him as belonging to an elder generation.

Forbes was under thirty when he discovered the polarization of heat, which pointed the way to Mohr, then thirty-one, to the mechanical equivalent. Joule was twenty-two in 1840, when his great work was begun; and Mayer, whose discoveries date from the same year, was then twenty-six, which was also the age of Helmholtz when he published his independent discovery of the same law. William Thomson was a youth just past his majority when he came to the aid of Joule before the British Society, and but seven years older when he formulated his own doctrine of dissipation of energy. And Clausius and Rankine, who are usually mentioned 
with Thomson as the great developers of thermo-dynamics, were both far advanced with their novel studies before they were thirty. We may well agree with the father of inductive science that " the man who is young in years may be old in hours."

Yet we must not forget that the shield has a reverse side. For was not the greatest of observing astronomers, Herschel, past thirty-five before he ever saw a telescope, and past fifty before he discovered the heat rays of the spectrum? And had not Faraday reached middle life before he turned his attention especially to electricity? Clearly, then, to make his phrase complete, "Bacon must have added that "the man who is old in years may be young in imagination." Here, howerer, even more appropriate than in the other case-more's the pity - would have been the application of his qualifying clause: "but that happeneth rarely."

\section{$\nabla$}

There are only a few great generalizations as yet thought out in any single field of science. Naturally, . then, after a great generalization has found definitive expression, there is a period of lull before another forward move. In the case of the doctrines of energy, the lull has lasted half a century. Throughout this period, it is true, a multitude of workers have been delsing in the field, and to the casual observer it might seem as if their activity had been boundless, while the practical applications of their ideas-as exemplified, for example, in the telephone, phonograph, electric light, and so onhave been little less than revolutionary. Yet the most competent of living authorities, Lord Kelvin, could as- 
sert in 1895 that in fifty years he had learned nothing new regarding the nature of energy.

This, however, must not be interpreted as meaning that the world has stood still during these two generations. It means rather that the rank and file have been moving forward along the road the leaders had already travelled. Only a few men in the world bad the range of thought regarding the new doctrine of energy that Lord Kelvin had at the middle of the century. The few leaders then saw clearly enough that if one form of energy is in reality merely an undulation or vibration among the particles of "ponderable" matter or of ether, all other manifestations of energy must be of the same nature. But the rank and file were not even within sight of this truth for a long time after they had partly grasped the meaning of the doctrine of conservation. When, late in the fifties, that marvellous young Scotchman, James Clerk Maxwell, formulating in other words an idea of Faraday's, expressed his belief that electricity and magnetism are but manifestations of various conditions of stress and motion in the ethereal medium (electricity a displacement of strain, magnetism a whirl in the ether), the idea met with no immediate popularity. And even less cordial was the reception given the same thinker's theory, put forward in 1863 , that the ethereal undulations producing the phenomenon we call light differ in no respect except in their wave-length from the pulsations of electro-magnetism.

At about the same time Helmholtz formulated a somewhat similar electro-magnetic theory of light; but even the weight of this combined authority could not give the doctrine vogue until very recently, when the experiments of Heinrich Hertz, the pupil of Helmholtz, 
have shown that a condition of electrical strain may be developed into a wave system by recurrent interruptions of the electric state in the generator, and that such waves travel through the ether with the rapidity of light. Since then the electro-magnetic theory of light has been enthusiastically referred to as the greatest generalization of the century; but the sober thinker must see that it is really only what Hertz himself called itone pier beneath the great arch of conservation. It is an interesting detail of the architecture, but the part cannot equal the size of the whole.

More than that, this particular pier is as yet by no means a very firm one. It has, indeed, been demonstrated that wares of electro-magnetism pass through space with the speed of light, but as yet no one has dereloped electric waves even remotely approximating the shortness of the visual rays. The most that can positively be asserted, therefore, is that all the known forms of radiant energy - heat, light, electro-magnetismtravel through space at the same rate of speed, and consist of traverse vibrations - "lateral quirers," as Fresnel said of light-known to differ in length, and not positively known to differ otherwise. 'It has, indeed, been suggested that the newest form of radiant energy, the famous X ray of Professor Röntgen's discovery, is a longitudinal vibration, but this is a mere surmise. Be that as it may, there is no one now to question that all forms of radiant energy, whatever their exact affinities, consist essentially of undulatory motions of one uniform medium.

A full century of experiment, calculation, and controversy has thus sufficed to correlate the "imponderable fluids" of our forebears, and reduce them all to man- 


\section{THE CENTURY'S PROGRESS IN PHYSICS}

ifestations of motion among particles of matter. At first glimpse that seems an enormous change of view. And yet, when closely considered, that change in thought is not so radical as the change in phrase might seem to imply. For the nineteenth-century physicist, in displacing the "imponderable fluids" of many kindsone each for light, heat, electricity, magnetism-las been obliged to substitute for them one all-pervading Huid, whose various quivers, waves, ripples, whirls, or strains produce the manifestations which in popular parlance are termed forms of force. This all-pervading fluid the physicist terms the ether, and he thinks of it as having no weight. In effect, then, the physicist has dispossessed the many imponderables in favor of a single imponderable-though the word imponderable has been banished from his vocabulary. In this view the etherwhich, considered as a recognized scientific verity, is essentially a nineteenth-century discovery-is about the most interesting thing in the universe. Something more as to its properties, real or assumed, we shall have occasion to examine as we turn to the obverse side of physics, which demands our attention in the next chapter. 
CHAPTER VII

THE ETHER AND PONDERABLE MATTER

I

"Whatever difficulties we may have in forming a consistent idea of the constitution of the ether, there can be no doubt that the interplanetary and interstellar spaces are not empty, but are occupied by a material substance or body which is certainly the largest and probably the most uniform body of which we have any knowledge."

Such was the verdict pronounced some twenty years ago by James Clerk Maxwell, one of the very greatest of nineteenth-century physicists, regarding tlie existence of an all-perrading plenum in the universe, in which every particle of tangible matter is immersed. And this verdict may be said to express the attitude of the entire philosophical world of our day. Without exception, the authoritative physicists of our time accept this plenum as a verity, and reason about it with something of the same confidence they manifest in speaking of "ponderable" matter or of energy. It is true there are those among them who are disposed to deny that this all-pervading plenum merits the name of matter. But that it is a something, and a vastly important something at that, all are agreed. Without it, they allege, we should know 230 
nothing of light, of radiant heat, of electricity, or magnetism; without it there would probably be no such thing as gravitation; nay, they even hint that without this strange something, ether, there would be no such thing as matter in the universe. If these contentions of the modern physicist are justified, then this intangible ether is incomparably the most important as well as the "largest and most uniform substance or body" in the universe. Its discovery may well be looked upon as the most important feat of our century.

For a discovery of our century it surely is, in the sense that all the known evidences of its existence have been gathered in this epoch. True, dreamers of all ages have, for metaphysical reasons, imagined the existence of intangible fluids in space-they had, indeed, peopled space several times over with different kinds of ethers, as Maxivell remarks - but such rague dreamings no more constituted the discovery of the modern ether than the dream of some pre-Columbian visionary that land might lie beyond the unknown waters constituted the discovery of America. In justice it must be admitted that Huyghens, the seventeenth-century originator of the undulatory theory of light, caught a glimpse of the true ether; but his contemporaries and some eight generations of his successors were utterly deaf to his claims; so he bears practically the same relation to the nineteenth-century discoverers of ether that the Norseman bears to Columbus.

The true Columbus of the ether was Thomas Young. His discovery was consummated in the early days of the present century, when he brought forward the first conclusive proofs of the undulatory theory of light. To say that light consists of undulations is to postulate 
something which undulates; and this something could not be air, for air exists only in infinitesimal quantity, if at all, in the intersteliar spaces, through which light freely penetrates. But if not air, what then? Why, clearly, something more intangible than air; something supersensible, evading all direct efforts to detect it, yet existing every where in seemingly vacant space, and also interpenetrating the substance of all transparent liquids and solids, if not, indeed, of all tangible substances. This intangible something Young rechristened the Luminiferous Ether.

In the early days of his discovery Young thought of the undulations which produce light and radiant lieat as being longitudinal $-a$ forward and backward pulsation, corresponding to the pulsations of sound-and as such pulsations can be transmitted by a fluid medium with the properties of ordinary fluids, he was justified in thinking of the ether as being like a fluid in its properties, except for its extreme intangibility. But about 1818 the experiments of Fresnel and Arago with polarization of light made it seem very doubtful whether the theory of longitudinal vibrations is sufficient, and it was suggested by Young, and independently conceived and demonstrated by Fresnel, that the luminiferous undulations are not longitudinal, but transverse; and all the more recent experiments have tended to confirm this view. But it happens that ordinary fluids-gases and liquids-cannot transmit lateral vibrations; only rigid bodies are capable of such a vibration. So it became necessary to assume that the luminiferous ether is a body possessing elastic rigidity - a familiar property of tangible solids, but one quite unknown among fluids.

The idea of transverse vibrations carried with it an- 
other puzzle. Why does not the ether, when set aquiver with the vibration which gives us the sensation we call light, have produced in its substance subordinate quivers, setting out at right angles from the path of the original quiver? Such perpendicular vibrations seem not to exist, else we might see around a corner; how explain their absence? The physicists could think of but one way: they must assume that the ether is incompressible. It must fill all space-at any rate, all space with which human knowledge deals-perfectly full.

These properties of the ether, incompressibility and elastic rigidity, are quite conceivable by themselves; but difficulties of thought appear when we reflect upon another quality which the ether clearly must possess-namely, frictionlessness. Per hypothesis this rigid, incompressible body pervades all space, imbedding every - particle of tangible matter; yet it seems not to retard the movements of this matter in the slightest degree. This is undoubtedly the most difficult to comprehend of the alleged properties of the ether. The physicist explains it as due to the perfect elasticity of the ether, in virtue of which it closes in behind a moving particle with a push exactly counterbalancing the stress required to penetrate it in front.

To a person unaccustomed to think of seemingly solid matter as really composed of particles relatively wide apart, it is hard to understand the claim that ether penetrates the substance of solids-of glass, for example-and, to use Young's expression, which we have previously quoted, moves among them as freely as the wind moves through a grove of trees. This thought, howerer, presents few difficulties to the mind 


\section{THE STORY OF NINETEENTH-CENTURY SCIENCE}

accustomed to philosophical speculation. But the question early arose in the mind of Fresnel whether the ether is not considerably affected by contact with the particles of solids. Some of his experiments led him to believe that a portion of the ether which penetrates among the molecules of tangible matter is held captive, so to speak, and made to move along with these particles. He spoke of such portions of the ether as "bound" ether, in contradistinction to the great mass of "free" ether. Half a century after Fresnel's death, when the ether hypothesis had become an accepted tenet of science, experiments were undertaken by Fizeau in France, and by Maxwell in England, to ascertain whether any portion of ether is really thus bound to particles of matter; but the results of the experiments were negative, and the question is still undetermined.

While the undulatory theory of light was still fighting its way, another kind of evidence favoring the existence. of an ether was put forward by Michael Faraday, who, in the course of his experiments in electrical and magnetic induction, was led more and more to perceive definite lines or channels of force in the medium subject to electro-magnetic influence. Faraday's mind, like that of Newton and many other philosophers, rejected the idea of action at a distance, and he felt convinced that the phenomena of magnetism and of electric induction told strongly for the existence of an invisible plenum everywhere in space, which might very probably be the same plenum that carried the undulations of light and radiant heat.

Then, about the middle of the century, came that final revolution of thought regarding the nature of energy which we have already outlined in the preceding chap- 
ter, and with that the case for ether was considered to be fully established. The idea that energy is merely a "mode of motion" (to adopt Tyndall's familiar phrase), combined with the universal rejection of the notion of action at a distance, made the acceptance of a plenum throughout space a necessity of thought-so, at any rate, it has seemed to most physicists of recent decades. The proof that all known forms of radiant energy move through space at the same rate of speed is regarded as practically a demonstration that but one plenum-one ether-is concerned in their transmission. It has, indeed, been tentatively suggested, by Professor J. Oliver Lodge, that there may be two ethers, representing the two opposite kinds of electricity, but even the author of this hypothesis would hardly claim for it a high degree of probability.

The most recent speculations regarding the properties of the ether have departed but little from the early ideas of Young and Fresnel. It is assunied on all sides that the ether is a continuous, incompressible body, possessing rigidity and elasticity. Lord Kelvin has even calculated the probable density of this ether, and its coefficient of rigidity. As might be supposed, it is all but infinitely tenuous as compared with any tangible solid, and its rigidity is but infinitesimal as compared with that of steel. In a word, it combines properties of tangible matter in a way not known in any tangible substance. Therefore we cannot possibly conceive its true condition correctly. The nearest approximation, according to Lord Kelvin, is furnished by a mould of transparent jelly. It is a crude, inaccurate analogy, of course, the density and resistance of jelly in particular being utterly different from those of the ether; but the 


\section{TIIE STORY OF NINETEENTH-CENTURY SCIENCE}

quivers that run through the jelly when it is shaken, and the elastic tension under which it is placed when its mass is twisted about, furnish some analogy to the quirers and strains in the ether, which are held to constitute radiant energy, magnetism, and electricity.

The great physicists of the day being at one regarding the existence of this all-pervading ether, it would be a manifest presumption for any one standing without the pale to challenge so firmly rooted a belief. And, indeed, in any event, there seems little ground on which to base such a challenge. Yet it may not be altogether amiss to reflect that the physicist of to-day is no more certain of his ether than was his predecessor of the eighteenth century of the existence of certain alleged substances which he called phlogiston, caloric, corpuscles of light, and magnetic and electric fluids. It would be but the repetition of history should it chance that before the close of another century the ether should have taken its place along with these discarded creations of the scientific imagination of earlier generations. The philosopher of to-day feels very sure that an ether exists ; but. when he says there is "no doubt" of its existence he speaks incautiously, and steps beyond the bounds of demonstration. He does not know that action cannot take place at a distance; he does not know that empty space itself may not perform the functions which he ascribes to his space-filling ether.

\section{II}

Meantime, however, the ether, be it substance or be it only dream-stuff, is serving an admirable purpose in furnishing a fulcrum for modern physics. Not alone 236 
THE E'THER ANI) PONDERABLE MA'T'TER

to the student of energy has it proved invaluable, but to the student of matter itself as well. Out of its hypo-

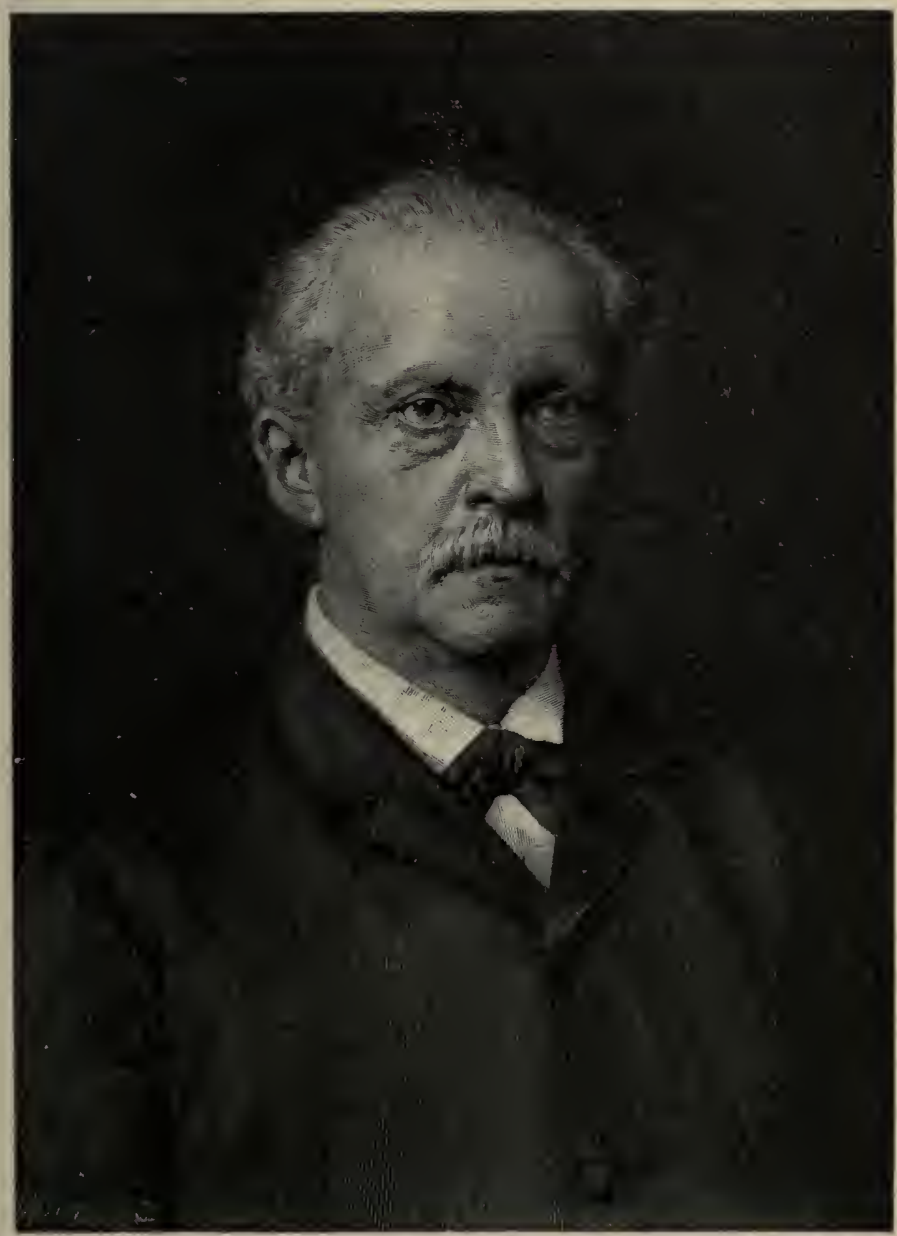

HERMANN I,UDWIG FERDINAND IIELMHOTTZ

From a photograph by Loescher and Petsch, Berlin 


\section{'THE STORY OF NINETEENTH-CENTURY SCIENCE}

thetical mistiness has been reared the most tenable theory of the constitution of ponderable matter which has yet been suggested-or, at any rate, the one that will stand as the definitive nineteenth-century guess at this " riddle of the ages." I mean, of course, the vortex theory of atoms - that profound and fascinating doctrine which suggests that matter, in all its multiforn phases, is nothing more or less than ether in motion.

The author of this wonderful conception is Lord Kelvin. The idea was born in his mind of a happy union of mathematical calculations with concrete experiments. The mathematical calculations were largely the work of Hermann von Helmholtz, who, about the year 1858, had undertaken to solve some unique problems in rortex motions. Helmholtz found that a vortex whirl, once established in a frictionless medium, must go on, theoretically, unchanged forever. In a limited medium such a whirl may be $\mathrm{V}$-shaped, with its ends at the surface of the medium. We may imitate such a rortex by drawing the bowl of a spoon quickly through a cup of water. But in a limitless medium the vortex whirl must always be a closed ring, which may take the simple form of a hoop or circle, or which may be indefinitely contorted, looped, or, so to speak, knotted. Whether simple or contorted, this endless chain of whirling matter (the particles revolving about the axis of the loop as the particles of a string revolve when the string is rolled between the fingers) must, in a frictionless medium, retain its form, and whirl on with undiminished speed forever.

While these theoretical calculations of Helmholtz were fresh in his mind, Lord Kelvin (then Sir William Thomson) was shown by Professor P. G. Tait, of Edinburgh, an apparatus constructed for the purpose of creating 238 


\section{THE ETHER AND PONDERABLE MATTER}

vortex rings in air. The apparatus, which any one may duplicate, consisterl simply of a box with a hole bored in one side, and a piece of canvas stretched across the opposite side in lieu of boards. Fumes of chloride of ammonia are generated within the box, merely to render the air visible. By tapping with the hand on the canvas side of the box, vortex rings of the clouded air are driven out, precisely similar in appearance to those smoke-rings which some expert tobacco-smokers can produce by tapping on their cheeks, or to those larger ones which we sometimes see blown out from the funnel of a locomotive.

The adrantage of Professor Tait's apparatus is its manageableness, and the certainty with which the desired result can be produced. Before Lord Kelvin's interested observation it threw out rings of various sizes, which moved straight across the room at varying rates of speed, according to the initial impulse, and which behaved rery strangely when coming in contact with one another. If, for example, a rapidly moving ring overtook another moving in the same path, the one in advance seemed to pause, and to spread out its periphery like an elastic band, while the pursuer seemed to contract, till it actually slid through the orifice of the other, after which each ring resumed its original size, and continued its course as if nothing had happened. When, on the other hand, two rings moving in slightly different directions came near each other, they seemed to have an attraction for each other; yet if they impinged, they boundled away, quivering like elastic solids. If an effort were made to grasp or to cut one of these rings, the subtle thing shrunk from the contact, and slipped away as if it were alire. 


\section{THE STORY OF NINETEENTII-CENTURY SCIENCE}

And all the while the body which thus conducted itself consisted simply of a whirl in the air, made visible, but not otherwise influencel, by smoky fumes. Presently the friction of the surrounding air wore the ring away, and it faded into the general atmosphereoften, however, not until it had persisted for many seconds, and passed clear across a large room. Clearly, if there were no friction, the ring's inertia must make it a permanent structure. Only the frictionless medium was lacking to fulfil all the conditions of Helmholtzs indestructible vortices. And at once Lord Kelvin bethought him of the frictionless medium which physicists had now begun to accept-the all-pervading ether. What if vortex rings were started in this ether, must they not have the properties which the vortex rings in air had exhibited-inertia, attraction, elasticity? And are not these the properties of ordinary tangible matter? Is it not probable, then, that what we call matter consists merely of aggregations of infinitesimal vortex rings in the ether?

Thus the vortex theory of atoms took form in Lord Kelvin's mind, and its expression gave the world what many philosophers of our time regard as the plausible conception of the constitution of matter hitherto formulated. It is only a theory, to be sure; its author would be the last person to claim finality for it. "It is only a dream," Lord Kelvin said to me, in referring to it not long ago. But it has a basis in mathematical calculation and in analogical experiment such as no other theory of mat. ter can lay claim to, and it has a unifying or monistic tendency that makes it, for the philosophical mind, little less than fascinating. True or false, it is the definitive theory of matter of the nineteenth century. 


\section{THE ETHER AND PONDERABLE MATTER}

\section{III}

Quite aside from the question of the exact constitution of the ultimate particles of matter, questions as to the distribution of such particles, their mutual relations, properties, and actions, have come in for a full share of attention during our century, though the foundations for the modern speculations were furnished in a previous epoch. The most popular eighteenth-century speculation as to the ultimate constitution of matter was that of the learned Italian priest, Roger Joseph Boscovich, published in 1758, in his Theoria Philosophice Naturalis. "In this theory," according to an early commentator, "the whole mass of which the bodies of the universe are composed is supposed to consist of an exceedingly great yet finite number of simple, indivisible, inextended atoms. These atoms are endued by the Creator with repulsive and attractive forces, which vary according to the distance. At very small distances the particles of matter repel each other; and this repulsive force increases beyond all limits as the distances are diminished, and will consequently forever prevent actual contact. When the particles of matter are removed to sensible distances, the repulsive is exchanged for an attractive force, which decreases in inverse ratio with the squares of the distances, and extends beyond the spheres of the most remote comets."

This conception of the atom as a mere centre of force was hardly such as could satisfy any mind other than the metaphysical. No one made a conspicuous attempt to improve upon the idea, however, till just at the close of the century, when Humphry Dary was led, in the course of his studies of heat, to speculate as to the 


\section{THE STORY OF NINETEENTH-CENTURY SCIENCE}

changes that occur in the intimate substance of matter under altered conditions of temperature. Davy, as we have seen, regarded heat as a manifestation of motion among the particles of matter. As all bodies with which we come in contact have some temperature, Davy inferred that the intimate particles of every substance must be perpetually in a state of ribration. Such vibrations, he believed, produced the "repulsive force" which (in common with Boscovich) he adınitted as holding the particles of matter at a distance from one another. To heat a substance means merely to increase the rate of vibration of its particles; thus also, plainly, increasing the repulsive forces, and expanding the bulk of the mass as a whole. If the degree of heat applied be sufficient, the repulsive force may become strong enough quite to overcome the attractive force, and the particles will separate and tend to fly away from one another, the solid then becoming a gas.

Not much attention was paid to these very suggestive illeas of Davy, because they were founded on the idea that heat is merely a motion, which the scientific world then repudiated; but half a century later, when the new theories of energy had made their way, there came a revival of practically the same ideas of the particles of matter (molecules they were now called) which Dary had adrocated. Then it was that Clausius in Germany and Clerk Maxwell in England took up the investigation of what came to be known as the kinetic theory of gases - the now familiar conception that all the phenomena of gases are due to the helter-skelter flight of the showers of widely separated molecules of which they are composed. The specific idlea that the pressure or "spring" of gases is due to such molecular impacts was 


\section{TIE ETHER AND PONDERABLE MATTER}

due to Daniel Bournelli, who adranced it early in the eighteenth century. The idea, then little noticed, had been revised about a century later by William Herapath, and again with some success by J. J. Waterston, of Bombay, about 1846 ; but it gained no distinct footing until taken in hand by Clausius in 1857 and by Maxwell in 1859.

The in vestigations of these great physicists not only served fully to substantiate the doctriné, but threw a flood of light upon the entire subject of molecular dynamics. Soon the physicists came to feel as certain of the existence of these showers of flying molecules making up a gas as if they could actually see and watch their individual actions. Through study of the viscosity of gases - that is to say, of the degree of frictional opposition they show to an object moving through them or to another current of gas - an idea was gained, with the aid of mathematics, of the rate of speed at which the particles of the gas are moving, and the number of collisions which each particle must experience in a given time, and of the length of the average free path traversed by the molecule between collisions. These measurements were confirmed by study of the rate of diffusion at which different gases mix together, and also by the rate of diffusion of heat through a gas, both these phenomena being chiefly due to the helter-skelter flight of the molecules.

It is sufficiently astonishing to be told that such measurements as these have been made at all, but the astonishment grows when one hears the results. It appears from Maxwell's calculations that the mean free path, or distance traversed by the molecules between collisions in ordinary air, is about one half-millionth of 
an inch; while the speed of the molecules is such that each one experiences about eight billions of collisions per second! It would be hard, perhaps, to cite an illustration showing the refinements of modern physics better than this; unless, indeed, one other result that followed directly from these calculations be considered such - the feat, namely, of measuring the size of the molecules themselves. Clausius was the first to point out how this might be done from a knowledge of the length of free path; and the calculations were made by Loschmidt in Germany, and by Lord Kelvin in England, independently.

The work is purely mathematical, of course, but the results are regarded as unassailable; indeed, Lord Kelvin speaks of them as being absolutely demonstrative within certain limits of accuracy. This does not mean, however, that they show the exact dimensions of the molecule; it means an estimate of the limits of size within which the actual size of the molecule may lie. These limits, Lord Kelvin estimates, are about the one tenmillionth of a centimetre for the maximum, and the one one-hundred-millionth of a centimetre for the minimum. Such figures convey no particular meaning to our blunt senses, but Lord Kelvin has given a tangible illustration that aids the imagination to at least a vague comprehension of the unthinkable smallness of the molecule. He estimates that if a ball, say of water or glass, about "as large as a football, were to be magnified up to the size of the earth, each constituent molecule being magnified in the same proportion, the magnified structure would be more coarse-grained than a heap of shot, but probably less coarse-grained than a heap of footballs."

Several other methods have been employed to estimate 
the size of molecules. One of these is based upon the phenomena of contact electricity; another upon the wave-theory of light; and another upon capillary attraction, as shown in the tense film of a soap-bubble! No one of these methods gives results more definite than that due to the kinetic theory of gases, just outlined; but the important thing is that the results obtained by these different methods (all of them due to Lord Kelvin) agree with one another in fixing the dimensions of the molecule at somerwhere about the limits already mentioned. We may feel very sure indeed, therefore, that the ultimate particles of matter are not the unextended, formless points which Boscovich and his followers of the last century thought them.

\section{IV}

Whatever the exact form of the molecule, its outline is subject to incessant variation; for nothing in molecular science is regarded as more firmly established than that the molecule, under all ordinary circumstances, is in a state of intense but variable vibration. The entire energy of a molecule of gas, for example, is not measured by its momentum, but by this plus its energy of vibration and rotation, due to the collisions already referred to. Clausius has even estimated the relative importance of these two quantities, showing that the translational motion of a molecule of gas accounts for only threefifths of its kinetic energy. The total energy of the molecule (which we call "heat") includes also another factor, namely, potential energy, or energy of position, due to the work that has been done on expanding, in overcoming external pressure, and internal attraction 


\section{THE STORY OF NINETEENTH-CENTURY SCIENCE}

between the molecules themselves. This potential energy (which will be recovered when the gas contracts) is the "latent heat" of Black, which so long puzzled the philosophers. It is latent in the same sense that the energy of a ball thrown into the air is latent at the moment when the ball poises at its greatest height before beginning to fall.

It thus appears that a variety of motions, real and potential, enter into the production of the condition we term heat. It is, however, chiefly the translational motion which is measurable as temperature; and this, too, which most obviously determines the physical state of the substance that the molecules collectively compose-whether, that is to say, it shall appear to our blunt perceptions as a gas, a liquid, or a solid. In the gaseous state, as we have seen, the translational motion of the molecules is relatively enormous, the molecules being widely separated. It does not follow, as we formerly supposed, that this is evidence of a repulsive power acting between the molecules. The physicists of to-day, headed by Lord Kielvin, decline to recognize any such power. They lold that the molecules of a gas fly in straight lines in virtue of their inertia, quite independently of one another, except at times of collision, from which they rebound in virtue of their elasticity; or an approach to collision, in which latter case, coming within the range of mutual attraction, two molecules may circle about one another, as a comet circles about the sun, then rush apart again, as the comet rushes from the sun.

It is obvious that the length of the mean free path of the molecules of a gas may be increased indefinitely by decreasing the number of the molecules themselves in a 
circumscribed space. It has been shown by Professors Tait and Dewar that a vacuum may be produced artificially of such a degree of rarefaction that the mean free path of the remaining molecules is measurable in inches. The calculation is based on experiments made with the radiometer of Professor Crookes, an instrument which in itself is held to demonstrate the truth of the kinetic theory of gases. Such an attenuated gas as this is considered by Professor Crookes as constituting a fourth state of matter, which he terms ultra-gaseous.

If, on the other hand, a gas is subjected to pressure, its molecules are crowded closer together, and the length of their mean free path is thus lessened. Ultimately, the pressure being sufficient, the molecules are practically in continuous contact. Meantime the enormously increased number of collisions has set the nolecules more and more actively vibrating, and the temperature of the gas has increased, as, indeed, necessarily results in accordance with the law of the conservation of energy. No amount of pressure, therefore, can suffice by itself to reduce the gas to a liquid state. It is believed that even at the centre of the sun, where the pressure is almost inconceivably great, all matter is to be regarded as really gaseous, though the molecules must be so packed together that the consistency is probably more like that of a solid.

If, however, coincidently with the application of pressure, opportunity be given for the excess of heat to be dissipated to a colder surrounding medium, the molecules, giving off their excess of energy, become relatively quiescent, and at a certain stage the gas becomes a liquid. The exact point at which this transformation occurs, however, differs enormously for different sub- 
stances. In the case of water, for example, it is a temperature more than four hundred degrees above zero, Centigrade; while for atmospheric air it is $194^{\circ}$ Centigrade below zero, or more than a hundred and fifty degrees below the point at which mercury freezes.

Be it high or low, the temperature above which any substance is always a gas, regardless of pressure, is called the critical temperature, or absolute boiling-point, of that substance. It does not follow, however, that below this point the substance is necessarily a liquid. This is a matter that will be determined by external conditions of pressure. Even far below the critical temperature the molecules have an enormous degree of activity, and tend to fly asunder, maintaining what appears to be a gaseous, but what technically is called a vaporous, condition-the distinction being that pressure alone suffices to reduce the vapor to the liquid state. Thus water may change from the gaseous to the liquid state at four hundred degrees above zero, but under conditions of ordinary atmospheric pressure it does not do so until the temperature is lowered three hundred degrees further. Below four hundred degrees, however, it is technically a vapor, not a gas; but the sole difference, it will be understood, is in the degree of molecular activity.

It thus appears that the prevalence of water in a vaporous and liquid rather than in a "permanently" gaseous condition here on the globe is a mere incident of telluric evolution. Equally incidental is the fact that the air we breathe is "permanently" gaseous and not liquid or solid, as it might be were the eartl's surface temperature to be lowered to a degree which, in the larger view, may be regarded as trifling. Between the 
atmospheric temperature in tropical and in arctic regions there is often a variation of more than one hundred degrees; were the temperature reduced another hundred, the point would be reached at which oxygen gas becomes a vapor, and under increased pressure would be a liquid. Thirty-seven degrees more would bring us to the critical temperature of nitrogen.

Nor is this a mere theoretical assumption; it is a determination of experimental science, quite independent of theory. The physicist in the laboratory has produced artificial conditions of temperature enabling him to change the state of the most persistent gases. Some fifty years since, when the kinetic theory was in its infancy, Faraday liquefied carbonic acid gas, among others, and the experiments thus inaugurated have been extended by numerous more recent investigators, notably by Cailletet in Switzerland, by Pictet in France, and by Dr. Thomas Andrews and Professor James Dewar in England. In the course of these experiments not only has air been liquefied, but hydrogen also, the most subtle of gases; and it has been made more and more apparent that gas and liquid are, as Andrews long ago asserted, "only distant stages of a long series of continuous physical changes." Of course if the temperature be lowered still further, the liquid becomes a solid; and this change also has been effected in the case of some of the most "permanent" gases, including air.

The degree of cold-that is, of absence of heat-thus produced is enormous, relatively to anything of which we have experience in nature here at the earth now, yet the molecules of solidified air, for example, are not absolutely quiescent. In other words, they still have a temperature, though so very low. But it is clearly con- 
ceivable that a stage might be reached at which the molecules became absolutely quiescent, as regards either translational or vibratory motion. Such a heatless condition has been approached, but as yet not quite attained, in laboratory experiments. It is called the absolute zero of temperature, and is estimated to be equivalent to $273^{\circ}$ Centigrade below the freezing-point of water, or ordinary zero.

A temperature (or absence of temperature) closely approximating this is believed to obtain in the ethereal ocean of interplanetary and interstellar space, which transmits, but is thought not to absorb, radiant energy. We here on the earth's surface are protected from exposure to this cold, which would deprive every organic thing of life almost instantaneously, solely by the thin blanket of atmosphere with which the globe is coated. It would seem as if this atmosphere, exposed to such a temperature at its surface, must there be incessantly liquefied, and thus fall back like rain to be dissolred into gas again while it still is many miles above the earth's surface. This may be the reason why its scurrying molecules have not long ago wandered off into space, and left the world without protection.

But whether or not such liquefaction of the air now occurs in our outer atmosphere, there can be no question as to what must occur in its entire depth were we permanently shut off from the heating influence of the sun, as the astronomers threaten that we may be in a future age. Each molecule, not alone of the atmosphere, but of the entire earth's substance, is kept aquiver by the energy which it receives, or has received, directly or indirectly, from the sun. Left to itself, each molecule would wear out its energy and fritter it off into the space about it, 


\section{THE E'TIER AND PONDERABLE MATTER}

ultimately running completely down, as surely as any human-made machine whose power is not from time to time restored. If then it shall come to pass in some future age that the sun's rays fail us, the temperature of the globe must gradually sink towards the absolute zero. That is to say, the molecules of gas which now fly about at such inconceivable speed must drop helpless to the earth; liquids must in turn become solids; and solids themselves, their molecular quivers utterly stilled, may perhaps take on properties the nature of which we cannot surmise.

Yet even then, according to the current hypothesis, the heatless molecule will still be a thing instinct with life. Its vortex whirl will still go on, uninfluenced by the dying out of those subordinate quivers that produced the transitory effect which we call temperature. For those transitory thrills, though determining the physical state of matter as measured by our crude organs of sense, were no more than non-essential incidents; but the vortex whirl is the essence of matter itself. 


\section{CHAPTER VIII}

THE CENTURY'S PROGRESS IN CHEMISTRY

Syall beginnings have great endings-sometimes. As a case in point, note what came of the small original effort of a self-trained back-country Quaker youth named John Dalton, who along towards the close of the last century became interested in the weather, and was led to construct and use a crude rain-gauge to test the amount of the waterfall. The simple experiments thus inaugurated led to no fewer than two hundred thousand recorded observations regarding the weather, which formed the basis for some of the most epochal discoveries in meteorology, as we have seen. But this was only a beginning. The simple rain-gauge pointed the way to the most important generalization of our century in a field of science with which, to the casual observer, it might seem to have no alliance whatever. The wonderful theory of atoms, on which the whole gigantic structure of modern chemistry is founded, was the lngical outgrowth, in the mind of John Dalton, of those early studies in meteorology.

The way it happened was this: From studying the rainfall, Dalton turned naturally to the complementary process of evaporation. He was soon led to believe that 


\section{THE CENTURY'S PROGRESS IN CHEMISTRY}

rapor exists in the atmosphere as an independent gas. But since two bodies cannot occupy the same space at the same time, this implies that the various atmospheric gases are really composed of discrete particles. These ultimate particles are so small that we cannot see them -cannot, indeed, more than vaguely imagine themyet each particle of vapor, for example, is just as much a portion of water as if it were a drop out of the ocean, or, for that matter, the ocean itself. But again, water is a compound substance, for it may be separated, as Cavendish had shown, into the two elementary substances hydrogen and oxygen. Hence the atom of water must be composed of two lesser atoms joined together. Imagine an atom of hydrogen and one of oxygen. Unite them, and we have an atom of water; sever them, and the water no longer exists; but whether united or separate the atoms of hydrogen and of oxygen remain hydrogen and oxygen and nothing else. Differently mixed together or united, atoms produce different gross substances; but the elementary atoms never change their chemical nature-their distinct personality.

It was about the year 1803 that Dalton first gained a full grasp of the conception of the chemical atom. At once he saw that the hypothesis, if true, furnished a marrellous key to secrets of matter hitherto insolublequestions relating to the relative proportions of the atoms themselves. It is known, for example, that a certain bulk of hydrogen gas unites with a certain bulk of oxygen gas to form water. If it be true that this combination consists essentially of the union of atoms one with another (each single atom of hydrogen united to a single atom of oxygen), then the relative weights of the original masses of hydrogen and of oxygen must 


\section{THE STORY OF NINETEENTH-CENTURY SCIENCF}

be also the relative weights of each of their respective atoms. If one pound of hydrogen unites with fire and one-half pounds of oxygen (as, according to Dalton's experiments, it did), then the weight of the oxygen

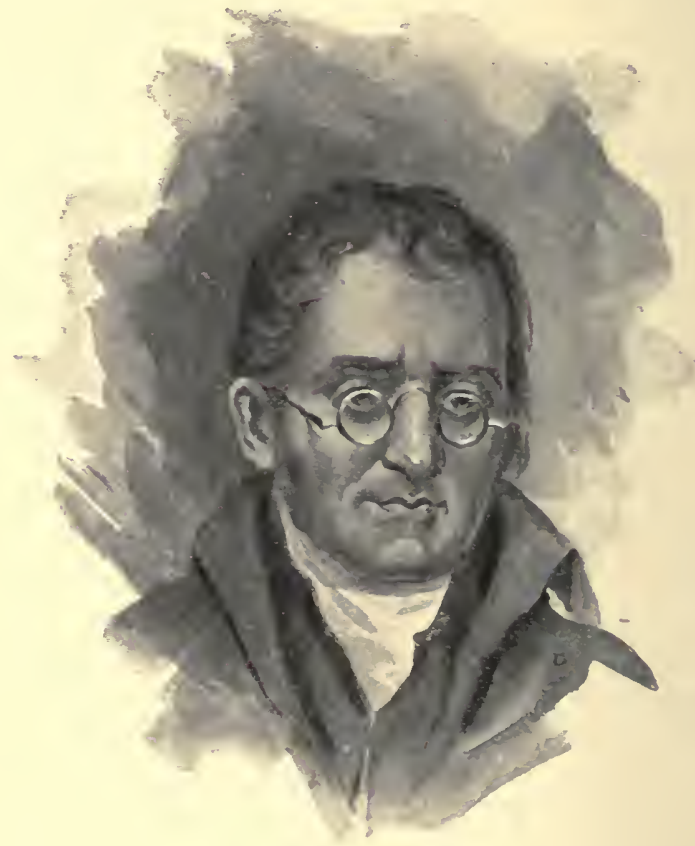

JOIN DALTON

atom must be five and one-half tmes that of the hydrogen atom. Other compounds may plainly be tested in the same way. Dalton made numerous tests before ho published his theory. He found that hydrogen enters into compounds in smaller proportions than any other element known to him, and so, for convenience, determined to take the weight of the hydrogen atom as unity. 
The atomic weight of oxygen then becomes (as given in Dalton's first table of 1803) 5.5; that of water (hydrogen plus oxygen) being of course 6.5. The atomic weights of about a score of substances are given in Dalton's first paper, which was read before the Literary and Philosophical Society of Manchester, October 21, 1803. I wonder if Dalton himself, great and acute intellect. though he had, suspected, when he read that paper, that he was inaugurating one of the most fertile movements ever entered on in the whole history of science?

\section{II}

Be that as it may, it is certain enough that Dalton's contemporaries were at first little impressed with the novel atomic theory. Just at this time, as it chanced, a dispute was waging in the field of chemistry regarding a matter of empirical fact which must necessarily be settled before such a theory as that of Dalton could even liope for a hearing. This was the question whether or not chemical elements unite with one another always in definite proportions. Berthollet, the great co-worlier with Lavoisier, and now the most authoritative of living chemists, contended that substances combine in almost indefinitely graded proportions between fixed extremes. Ie held that solution is really a form of chemical combination-a position which, if accepted, left no room for argument.

But this contention of the master was most actively disputed, in particular by Louis Joseph Proust, and all chemists of repute were obliged to take sides with one or the other. For a time the authority of Berthollet held out against the facts, but at last accumulated evi- 
dence told for Proust and his followers, and towards the close of the first decade of our century it came to be generally conceded that chemical elements combine with one another in fixed and definite proportions.

More than that. As the analysts were led to weigh carefully the quantities of combining elements, it was observed that the proportions are not only definite, but that they bear a very curious relation to one another. It element $A$ combines with two different proportions of element $\mathrm{B}$ to form two compounds, it appeared that the weight of the larger quantity of $B$ is an exact multiple of that of the smaller quantity. This curious relation was noticed by Dr. Wollaston, one of the most accurate of observers, and a little later it was confirmed by Johan Jakob Berzelius, the great Swedish chemist, who was to be a dominating influence in the chemical world for a generation to come. But this combination of elements in numerical proportions was exactly what Dalton had noticed as early as 1802, and what had led him directly to the atomic weights. So the confirmation of this essential point by chemists of such authority gave the strongest confirmation to the atomic theory.

During these same years the rising authority of the French chemical world, Joseph Louis Gay-Lussac, was conducting experiments with gases, which he had undertaken at first in conjunction with Humboldt, but which later on were conducted independently. In 1809, the next year after the publication of the first volume of Dalton's New System of Chemical Philosophy, GayLussac published the results of his observations, and among other things brought out the remarkable fact that gases, under the same conditions as to temperature and pressure, combine always in definite numerical 


\section{THE CENTURY'S PROGRESS IN CIIEMISTRY}

proportions as to volume. Exactly two volumes of hydrogen, for example, combine with one volume of oxygen to form water. Moreover, the resulting compound gas always bears a simple relation to the combining volumes. In the case just cited the union of two

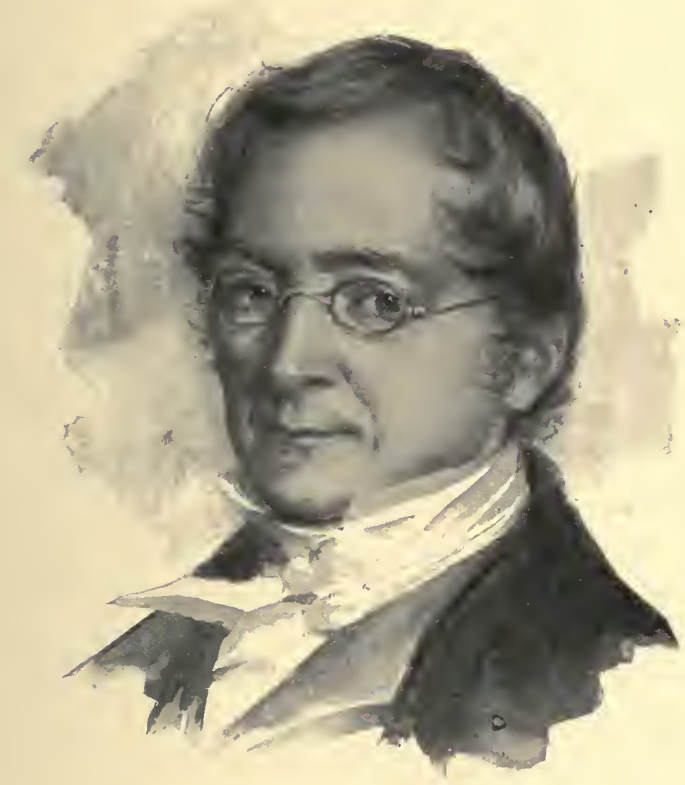

JOSEPII LOUIS GAY-IUUSAC

volumes of hydrogen and one of oxygen results in precisely two volumes of water vapor.

Naturally enough the champions of the atomic theory seized upon these observations of Gay-Lussac as lending strong support to their hypothesis-all of them, that is, but the curiously self-reliant and self-sufficient author of the atomic theory himself, who declined to accept the 


\section{THE STORY OF NINETEENTH-CENTURY SCIENCE}

observations of the French chemist as valid. Yet the observations of Gay-Lussac were correct, as countless chemists since then have demonstrated anew, and his theory of combination by volumes became one of the foundation-stones of the atomic theory, despite the opposition of the author of that theory.

The true explanation of Gay-Lussac's law of combination by volumes was thought out almost immediately by an Italian savant, Amadeo Avogadro, and expressed in terms of the atomic theory. The fact must be, said Arogadro, that under similar physical conditions every form of gas contains exactly the same number of ultimate particles in a given volume. Each of these ultimate physical particles may be composed of two or more atoms (as in the case of water vapor), but such a compound atom conducts itself as if it were a simple and indivisible atom, as regards the amount of space that separates it from its fellows under given conditions of pressure and temperature. The compound atom, composed of two or more elementary atoms, Avogadro proposed to distinguish, for purposes of convenience, by the name molecule. It is to the molecule, considered as the unit of physical structure, that A rogadro's law applies.

This vastly important distinction between atoms and molecules, implied in the law just expressed, was published in 1811. Four years later, the famous French physicist Ampère outlined a similar theory, and utilized the law in his mathematical calculations. And with that the law of Avogadro dropped out of sight for a full generation. Little suspecting that it was the very key to the inner mysteries of the atoms for which they were seeking, the chemists of the time cast it aside, and let it fade from the memory of their science. 
This, however, was not strange, for of course the law of Arogadro is based on the atomic theory, and in 1811 the atomic theory was itself still being weighed in the balance. The law of multiple proportions found general acceptance as an empirical fact; but many of the leading lights of chemistry still looked askance at Dalton's explanation of this law. Thus Wollaston, though from the first he inclined to acceptance of the Daltonian view, cautiously suggested that it would be well to use the non-committal word "equivalent" instead of "atom"; and Davy, for a similar reason, in his book of 1812, speaks only of "proportions," binding himself to no theory as to what might be the nature of these proportions.

At least two great chemists of the time, however, adopted the atomic view with less reserration. One of these was Thomas Thomson, professor at Edinburgh, who in 1807 had given an outline of Dalton's theory in a widely circulated book, which first brought the theory to the general attention of the chemical world. The other, and eren more noted adrocate of the atomic theory, was Johan Jakob Berzelius. This great Swedish chemist at once set to work to put the atomic theory to such tests as might be applied in the laboratory. He was an analyst of the utmost skill, and for years he devoted himself to the determination of the combining weights, "equivalents," or "proportions" of the different elements. These determinations, in so far as they were accurately made, were simple expressions of empirical facts, independent of any theory ; but gradually it became more and more plain that these facts all harmonize with the atomic theory of Dalton. So by common consent the proportionate combining weights of 
the elements came to be linown as atomic weightsthe name Dalton had given them from the first-and the tangible conception of the chemical atom as a body of definite constitution and weight gained steadily in favor.

From the outset the idea had had the utmost tangibility in the mind of Dalton. He had all along represented the different atoms by geometrical symbols - as a circle for oxygen, a circle enclosing a dot for lyydrogen, and the like-and had represented compounds by placing these symbols of the elements in juxtaposition. Berzelius proposed to improve upon this method by substituting for the geometrical symbol the initial of the Latin name of the element represented-O for oxygen, $\mathrm{H}$ for hydrogen, and so on - a numerical coefficient to follow the letter as an indication of the number of atoms present in any given compound. This simple system soon gained general acceptance, and with slight modifications it is still universally employed. Every schoolboy now is aware that $\mathrm{H}_{2} \mathrm{O}$ is the chemical way of expressing the union of two atoms of hydrogen with one of oxygen to form a molecule of water. But such a formula would have had no meaning for the wisest chemist before the day of Berzelius.

The universal fame of the great Swedish anthority served to give general currency to his symbols and atomic weights, and the new point of view thus developed led presently to two important discoveries which removed the last lingering doubts as to the validity of the atomic theory. In 1819 two French plyysicists, Dulong and Petit, while experimenting with heat, discovered that the specific heats of solids (that is to say, the amount of heat requirerl to raise the temperature of 


\section{THE CENTURY'S PROGRESS IN CHEMISTRY}

a given mass to a given degree) vary inversely as their atomic weights. In the same year Eilhard Mitscherlich, a German investigator, observed that compounds having the same number of atoms to the molecule are disposed to form the same angles of crystallization-a property which he called isomorphism.

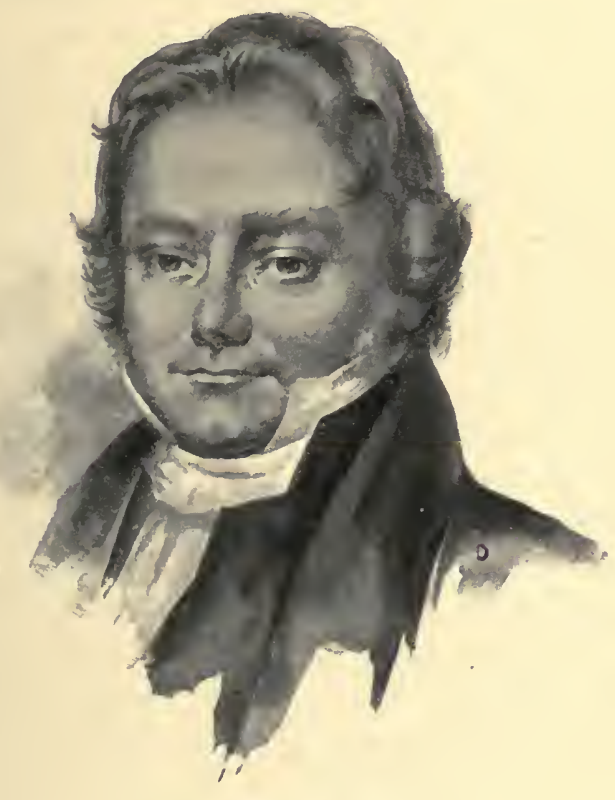

JOHAN JAKOB BERZELIUS

Here, then, were two utterly novel and independent sets of empirical facts which harmonize strangely with the supposition that substances are composed of chemical atoms of a determinate weight. This surely could not be coincidence-it tells of law. And so as soon as the claims of Dulong and Petit and of Mitscherlich had been substantiated by other observers, the laws of the 
specific heat of atoms, and of isomorphism, took their place as new levers of chemical science. With the aid of these new tools an impregnable breastwork of facts was soon piled about the atomic theory. And John Dalton, the author of that theory, plain, provincial Quaker, working on to the end in semi-retirement, became known to all the world and for all time as a master of masters.

III

During those early years of our century, when Dalton was grinding away at chemical fact and theory in his obscure Manchester laboratory, another Englishman held the attention of the chemical world with a series of the most brilliant and widely heralded researches. Humphry Davy had come to London in 1801, at the instance of Count Rumford, to assume the chair of chemical philosophy in the Royal Institution, which the famous American had just founded.

Here, under Davy's direction, the largest voltaic battery yet constructed had been put in operation, and with its aid the brilliant young experimenter was expected almost to perform miracles. And indeed he scarcely disappointed the expectation, for with the aid of his battery he transformed so familiar a substance as common potash into a metal which was not only so light that it floated on water, but possessed the seemingly miraculous property of bursting into flames as soon as it came in contact with that fire-quenching liquid. If this were not a miracle, it had for the popular eye all the appearance of the miraculous.

What Davy really had done was to decompose the potash, which hitherto had been supposed to be elemen- 


\section{THE CEN'TURY'S PROGRESS IN CHEMISTRY}

tary, liberating its oxygen, and thus isolating its metallic base, which he named potassium. The same thing was done with soda, and the closely similar metal sodium was discuvered-metals of a unique type, possessed of a strange avidity for oxygen, and capable of seizing on it even when it is bound up in the molecules of water. Considered as mere curiosities, these discoveries were interesting, but aside from that they were of great theoretical importance, because they showed the compound nature of some familiar chemicals that had been regarded as elements. Several other elementary earths met the same fate when subjected to the electrical influence, the metals barium, calcium, and strontium being thus discovered. Thereafter Davy alivays referred to the supposed elementary substances (including oxygen, hydrogen, and the rest) as "undecompounded" bodies. These resist all present efforts to decompose them, but how can one know what might not happen were they subjected to an influence, perhaps some day to be discovered, which exceeds the battery in power as the battery exceeds the blow-pipe?

Another and even more important theoretical result that flowed from Davy's experiments during this first decade of the century was the proof that no elementary substances other than hydrogen and oxygen are produced when pure water is decomposed by the electric current. It was early noticed by Davy and others that when a strong current is passed through water, alkalies appear at one pole of the battery and acids at the other, and this though the water used were absolutely pure. This seemingly told of the creation of elements-a transmutation but one step removed from the creation of matter itself-under the influence of the new "force." It was 


\section{THE STORY OF NINETEENTH-CENTURY SCIENCE}

one of Dary's greatest triumphs to prove, in the series of experiments recorded in his famous Bakerian lecture of $1 S 06$, that the alleged creation of elements did not take place, the substances found at the poles of the battery having been dissolved from the walls of the vessels in which the water experimented upon had been placed. Thus the same implement which had served to give a certain philosophical warrant to the fading dreams of alchemy banished those dreams peremptorily from the domain of present science.

Though the presence of the allialies and acids in the water was explained, however, their respective migrations to the negative and positive poles of the battery remained to be accounted for. Davy's classical explanation assumed that different elements differ among themselves as to their electrical properties, some being positively, others negatively, electrified. Electricity and "chemical affinity," he said, apparently are manifestations of the same force, acting in the one case on masses, in the other on particles. Electro-positive particles unite with electro-negative particles to form chemical compounds, in virtue of the familiar principle that opposite electricities attract one another. When compounds are decomposed by the battery, this mutual attraction is orercome by the stronger attraction of the poles of the battery itself.

This theory of binary composition of all chemical compounds, through the union of electro-positive and electro-negative atoms or molecules, was extended by Berzelius, and made the basis of his famous system of theoretical chemistry. This theory held that all inorganic compounds, howerer complex their composition, are essentially composed of such binary combinations. 
For many years this view enjoyed almost undisputed sway. It received what seemed strong confirmation when Faraday showed the definite connection between the amount of electricity employed and the amount of decomposition produced in the so-called electrolyte. But its claims were really much too comprehensive, as subsequent discoveries proved.

\section{IV}

When Berzelius first promulgated his binary theory he was careful to restrict its unmodified application to the compounds of the inorganic world. At that time, and for a long time thereafter, it was supposed that substances of organic nature had some properties that kept them aloof from the domain of inorganic chemistry. It was little doubted that a so-called "vital force" operated here, replacing or modifying the action of ordinary "chemical affinity." It was, indeed, admitted that organic compounds are composed of familiar elementschiefly carbon, oxygen, hydrogen, and nitrogen--but these elements were supposed to be united in ways that could not be imitated in the domain of the non-living. It was regarded almost as an axiom of chemistry that no organic compound whatever could be put together from its elements-synthesized-in the laboratory. To effect the synthesis of even the simplest organic compound it was thought that the "vital force" must be in operation.

Therefore a veritable sensation was created in the chemical world when, in the year 1828, it was announced that the young German chemist Friedrich Wöhler, formerly pupil of Berzelius, and already known 265 
as a coming master, had actually synthesized the wellknown organic product urea in his laboratory at Sacrow. The "exception which proves the rule" is something never heard of in the domain of logical science. Natural law knows no exceptions. So the synthesis of a single organic compound sufficed at a blow to break down the chemical barrier which the imagination of the fathers of the science had erected between animate and inanimate nature. Thenceforth the philosophical chemist would regard the plant and animal organisins as chemical laboratories in which conditions are peculiarly favorable for building up complex compounds of a few familiar elements, under the operation of universal chemical laws. The chimera "vital force" could no longer gain recognition in the domain of chemistry.

Now a wave of interest in organic chemistry sivept over the chemical world, and soon the study of carbon compounds became as much the fashion as electro-chemistry had been in the preceding generation.

Foremost among the workers who rendered this epoch of organic chemistry memorable were Justus Liebig in Germany and Jean Baptiste André Dumas in France, and their respective pupils, Charles Frédéric Gerhardt and Augustus Laurent. Wöhler, too, must be named in the same breath, as also must Louis Pasteur, who, though somewhat younger than the others, came upon the scene in time to take chief part in the most important of the controversies that grew out of their labors.

Several years earlier than this the way had been paved for the study of organic substances by Gay-Lussac's discovery, made in 1815 , that a certain compound of carbon and nitrogen, which he naned cyanogen, has a peculiar degree of stability which enables it to retain 


\section{THE CENTURY'S PROGRESS IN CHEMISTRY}

its identity, and enter into chemical relations after the manner of a simple body. A year later Ampère discovered that nitrogen and hydrogen, when combined in certain proportions to form what he called ammonium,

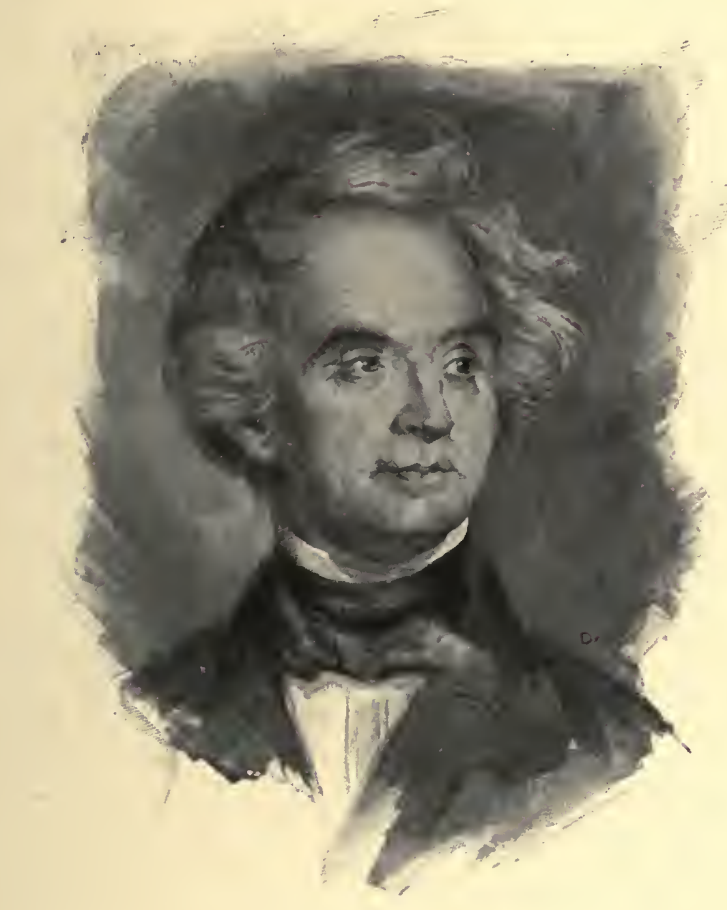

JUSTUS VON LIFBIG

have the same property. Berzelius had seized upon this discovery of the compound radical, as it was called, because it seemed to lend aid to his dualistic theory. $\mathrm{He}$ conceived the idea that all organic compounds are binary unions of various compound radicals with an atom of oxygen, announcing this theory in 1818. Ten years 


\section{THE STORY OF NINETEENTH-CENTURY SCIENCE}

later, Liebig and Wöhler undertook a joint investigation which resulted in proving that compound radicals are indeed rery abundant among organic substances. Thus the theory of Berzelius seemed to be substantiated, and organic chemistry came to be defined as the chemistry of compound radicals.

But even in the day of its seeming triumph the dualistic theory was destined to receive a rude shock. This came about through the investigations of Dumas, who proved that in a certain organic substance an atom of hydrogen may be removed, and an atom of chlorine substituted in its place without destroying the integrity of the original compound-much as a child might substitute one block for another in its play-house. Such a substitution would be quite consistent with the clualistic theory, were it not for the very essential fact that hydrogen is a powerfully electro-positive element, while chlorine is as strongly electro-llegative. Hence the compound radical which united successively with these two elements must itself be at one time electro-positive, at another electro-negative- $\mathbf{a}$ seeming inconsistency which threw the entire Berzelian theory into disfavor.

In its place there was elaborated, chiefly through the efforts of Laurent and Gerhardt, a conception of the molecule as a unitary structure, built up through the aggregation of various atoms, in accordance with " elective affinities" whose nature is not yet understood. A doctrine of "nuclei" and a doctrine of " types" of molecmar structure were much exploited, and, like the doctrine of compound radicals, became useful as aids to inemory and guides for the analyst, indicating some of the plans of molecular construction, though by no means penetrating the mysteries of chemical affinity. They 
are classifications rather than explanations of chemical unions. But at least they served an important purpose in giving definiteness to the idea of a molecular structure built of atoms as the basis of all substances. Now at last the word molecule came to have a distinct meaning, as distinct from "atom," in the minds of the generality of chemists, as it had had for Avogadro a third of a century before. Avogadro's hypothesis that there are equal numbers of these molecules in equal volumes of gases, under fixed conditions, was revived by Gerhardt, and a little later, under the championship of Cannizzaro, was exalted to the plane of a fixed law. Thenceforth the conception of the molecule was to be as dominant a thought in chemistry as the idea of the atom had become in a previous epoch.

\section{V}

Of course the atom itself was in no sense displaced, but A vogadro's law soon made it plain that the atom had often usurped territory that did not really belong to it. In many cases the chemists had supposed themselves dealing with atoms as units where the true unit was the molecule. In the case of elementary gases, such as hydrogen and oxygen, for example, the law of equal numbers of molecules in equal spaces made it clear that the atoms do not exist isolated, as had been supposed. Since two volumes of hydrogen unite with one volume of oxygen to form two volumes of water vapor, the simplest mathematics shows, in the light of Arogadro's law, not only that each molecule of water must contain two hydrogen atoms (a point previously in dispute), but that the original molecules of hydrogen and oxygen must 
have been composed in each case of two atoms - else how could one volume of oxygen supply an atom for every molecule of two volumes of water?

What, then, does this imply? Why, that the elementary atom has an avidity for other atoms, a longing for companionship, an "affinity "--call it what you will-which is bound to be satistied if other atoms are in the neighborhood. Placed solely among atoms of its own kind, the oxygen atom seizes on a fellow oxygen atom, and in all their mad dancings these two mates cling together-possibly revolving about one another in miniature planetary orbits. Precisely the same thing occurs among the hydrogen atoms. But now suppose the various pairs of oxygen atoms come near other pairs of hydrogen atoms (under proper conditions which need not detain us here), then each oxygen atom loses its attachment for its fellow, and flings itself madly into the circuit of one of the hydrogen couplets, andpresto!-there are only two molecules for every three there were before, and free oxygen and hydrogen have become water. The whole process, stated in chemical phraseology, is summed up in the statement that under the given conditions the oxygen atoms had a greater affinity for the hydrogen atoms than for one another.

As chemists studied the actions of various kinds of atoms, in regard to their unions with one another to form molecules, it gradually dawned upon them that not all elements are satisfied with the same number of companions. Some elements ask only one, and refuse to take more; while others link themselves, when occasion offers, with two, three, four, or more. Thus we saiw that oxygen forsook a single atom of its own kind and linked itself with two atoms of hydrogen. Clearly, 


\section{THE CENTURY'S PROGRESS IN CHEMISTRY}

then, the oxygen atom, like a creature with two hands, is able to clutch two other atoms. But we have no proof that under any circumstances it could hold more than two. Its affinities seem satisfied when it has two bonds. But, on the other hand, the atom of nitrogen is able to hold three atoms of hydrogen, and does so in the molecule of ammonium $\left(\mathrm{NH}_{3}\right)$; while the carbon atom can hold four atoms of hydrogen or two atoms of oxygen.

Evidently, then, one atom is not always equivalent to another atom of a different kind in combining powers. A recognition of this fact by Frankland about 1852, and its further investigation by others (notably A. Kekulé and A. S. Couper), led to the introduction of the word equivalent into chemical terminology in a new sense, and in particular to an understanding of the affinities or "valency" of different elements, which proved of the most fundamental importance. Thus it was shown that, of the four elements that enter most prominently into organic compounds, hydrogen can link itself with only a single bond to any other element-it has, so to speak, but a single hand with which to grasp-while oxygen has capacity for two bonds, nitrogen for three (possibly for five), and carbon for four. The words monovalent, divalent, trivalent, tretravalent, etc., were coined to express this most important fact, and the rarious elements came to be known as monads, diads, triads, etc. Just why different elements should differ thus in valency no one as yet knows; it is an empirical fact that they do. And once the nature of any element has been determined as regards its valency, a most important insight into the possible behavior of that element has been secured. Thus a consideration of the fact that hydro- 
gen is monovalent, while oxygen is divalent, makes it plain that we must expect to find no more than three compounds of these tivo elements, namely, $\mathrm{H}-\mathrm{O}-$ (written $\mathrm{HO}$ by the chemist, and called hydroxyl); $\mathrm{H}-\mathrm{O}-\mathrm{H}\left(\mathrm{H}_{2} \mathrm{O}\right.$, or water $)$, and $\mathrm{H}-\mathrm{O}-\mathrm{O}-\mathrm{H}\left(\mathrm{H}_{2} \mathrm{O}_{2}\right.$, or hydrogen peroxide). It will be observed that in the first of these compounds the atom of oxygen stands, so to speak, with one of its hands free, eagerly reaching out, therefore, for another companion, and lience, in the language of chemistry, forning an unstable compound. Again, in the third compound, though all hands are clasped, yet one pair links oxygen with oxygen; and this also must be an unstable union, since the avidity of an atom for its own kind is relatively weak. Thus the well-known properties of hydrogen peroxide are explained, its easy decomposition, and the eagerness with which it seizes upon the elements of other compounds.

But the molecule of water, on the other hand, has its atoms arranged in a state of stable equilibrium, all their affinities being satisfied. Each hydrogen atom has satisfied its own affinity by clutching the oxygen atom; and the oxygen atom has both its bonds satisfied by clutching back at the two hydrogen atoms. Therefore the trio, linked in this close bond, have no tendency to reach out for any other companion, nor, indeed, any power to hold another should it thrust itself upon them. They form a "stable" compound, which under" all ordinary circumstances will retain its identity as a molecule of water, even though the physical mass of which it is a part changes its condition from a solid to a gas-from ice to vapor.

But a consideration of this condition of stable equilibrium in the molecule at once suggests a new question : 


\section{TIE CENTURY'S PROGRESS IN CHEMISTRY}

How can an aggregation of atoms, having all their aflinities satisfied, take any further part in chemical reactions? Seemingly such a molecule, whatever its physical properties, must be chemically inert, incapable of any atomic readjustments. And so in point of fact it is, so long as its component atoms cling to one another unremittingly. But this, it appears, is precisely what the atoms are little prone to do. It seems that they are fickle to the last degree in their indiridual attachments, and are as prone to break away from bondage as they are to enter into it. 'Thus the oxygen atom which has just flung itself into the circuit of two lyydrogen atoms, the next moment flings itself free again and seeks new companions. It is for all the world like the incessant change of partners in a rollicking dance.

This incessant dissolution and reformation of molecules in a substance which as a whole remains apparently unchanged was first fully appreciated by Ste.-Claire Derille, and by him named dissociation. It is a process which goes on much more actively in some compounds than in others, and very much more actively under some physical conditions (such as increase of temperature) than under others. But apparently no substances at ordinary temperatures, and no temperature above the absolute zero, are absolutely free from its disturbing influence. Ilence it is that molecules having all the valency of their atoms fully satisfied do not lose their chemical activity--since each atom is momentarily free in the exchange of partners, and may seize upon different atoms from its former partners, if those it prefers are at hand.

While, however, an appreciation of this ceaseless activity of the atom is essential to a proper understand- 
ing of its chemical efficiency, yet from another point of view the "saturated" molecule-that is, the molecule whose atoms have their valency all satisfied-may be thought of as a relatively fixed or stable organism. Even though it may presently be torn down, it is for the time being a completed structure; and a consideration of the valency of its atoms gives the best clew that has hitherto been obtainable as to the character of its architecture. How important this matter of architecture of the molecule-of space relations of the atoms-may be was demonstrated as long ago as 1823 , when Liebig and Wöhler proved, to the utter bewilderment of the chemical world, that two substances may have precisely the same chemical constitution-the same number and kind of atoms-and yet differ utterly in physical properties. The word isomerism was coined by Berzelius to express this anomalous condition of things, which seemed to negative the most fundamental truths of chemistry. Naming the condition by no means explained it, but the fact was made clear that something besides the mere number and kind of atoms is important in the architecture of a molecule. It became certain that atoms are not thrown together haphazard to build a molecule, any more than bricks are thrown together at random to form a house.

How delicate may be the gradations of architectural design in building a molecule was well illustrated about 1850, when Pasteur discovered that some carbon compounds-as certain sugars-can only be distinguished from one another, when in solution, by the fact of their twisting or polarizing a ray of light to the left or to the right, respectively. But no inkling of an explanation of these strange rariations of molecular structure 


\section{THE CENTURY'S IROGRESS IN CHENISTRI}

came until the discovery of the law of valency. Then much of the mystery was cleared away; for it was plain that since each atom in a molecule can hold to itself only a fixed number of other atoms, complex molecules must have their atoms linked in definite chains or groups. And it is equally plain that where the atoms are numerous, the exact plan of grouping may sometimes be susceptible of change without doing riolence to the law of valency. It is in such cases that isomerism is observed to occur.

By paying constant heed to this matter of the affinities, chemists are able to make diagrammatic pictures of the plan of architecture of any molecule whose composition is known. In the simple molecule of water $\left(\mathrm{H}_{2} \mathrm{O}\right)$, for example, the two hydrogen atoms must have released one another before they could join the oxygen, and the manner of linking must apparently be that represented in the graphic formula $\mathrm{H}-\mathrm{O}-\mathrm{H}$. With molecules composed of a large number of atoms, such graphic representation of the scheme of linking is of course increasingly difficult, yet, with the affinities for a guide, it is always possible. Of course no one supposes that such a formula, written in a single plane, can possibly represent the true architecture of the molecule : it is at best suggestive or diagrammatic rather than pictorial. Nevertheless, it affords hints as to the structure of the molecule such as the fathers of chemistry would not have thought it possible ever to attain.

VI

These utterly novel studies of molecular architecture may seem at first sight to take from the atom much of 


\section{'I'HE STORY OF' NINETEENTII-CENTURY SCIENCE}

its former prestige as the all-important personage of the chemical world. Since so much depends upon the mere position of the atoms, it may appear that comparatively little depends upon the nature of the atoms themselres. But such a view is incorrect, for on closer consideration it will appear that at no time has the atom been seen to renounce its peculiar personality. Within certain limits the character of a molecule may be altered by changing the positions of its atoms (just as different buildings may be constructed of the same bricks), but these limits are sharply defined, and it would be as impossible to exceed them as it would be to build a stone building with bricks. From first to last the brick remains a brick, whatever the style of architecture it helps to construct; it never becomes a stone. And just as closely does each atom retain its own peculiar properties, regardless of its surroundings.

Thus, for example, the carbon atom may take part in the formation at one time of a diamond, again of a piece of coal, and yet again of a particle of sugar, of wood fibre, of animal tissue, or of a gas in the atmosphere; but from first to last-from glass-cutting gem to intangible gas - there is no demonstrable change whatever in any single property of the atom itself. So far as we know, its size, its weight, its capacity for vibration or rotation, and its inherent affinities, remain absolutely unchanged throughout all these varying fortunes of position and association. And the same thing is true of every atom of all of the sixty-odd elementary substances with which the modern chemist is acquainted. Every one appears always to maintain its unique integrity, gaining nothing and losing nothing.

All this being true, it would seem as if the position of 


\section{THE CENTURY'S PROGRES'S IN CHEMISTRY}

the Daltonian atom as a primordial bit of matter, indestructible and non-transmutable, had been put to the test by the chemistry of our century, and not found wanting. Since those early days of the century when the electric battery performed its miracles and seeming. ly reached its limitations in the hands of Davy, many

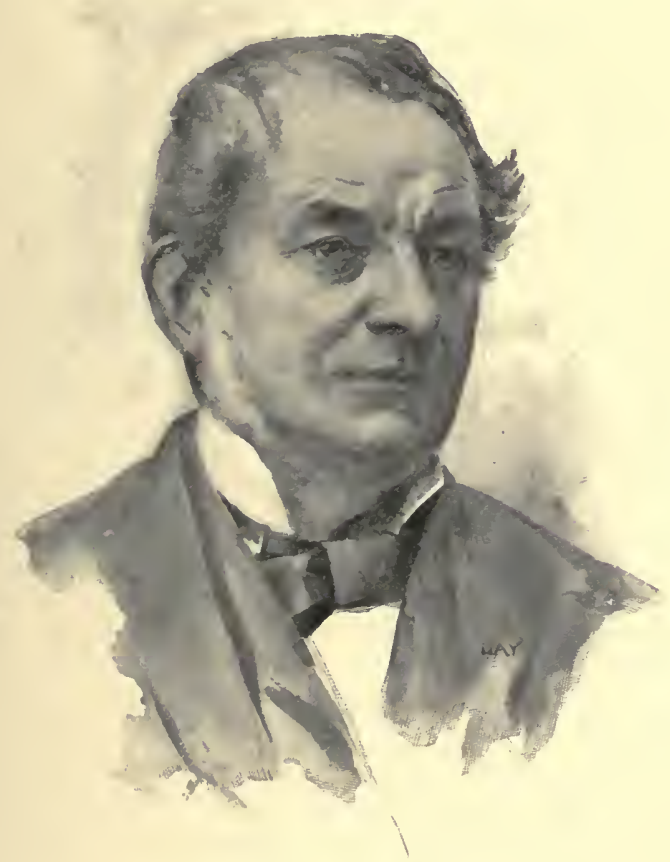

ROBERT WILLIAM BUNSEN

new elementary substances have been discovered, but no single element has been displaced from its position as an undecomposable body. Rather have the analyses of the 
chemist seemed to make it more and more certain that all elementary atoms are in truth what John Herschel called them, "manufactured articles" - primordial, changeless, indestructible.

And yet, oddly enough, it has chanced that hand in hand with the experiments leading to such a goal have gone other experiments and speculations of exactly the opposite tenor. In each generation there have been chemists among the leaders of their science who have refused to admit that the so-called elements are really elements at all in any final sense, and who have sought eagerly for proof which might warrant their scepticism. The first bit of evidence tending to support this view was furnished by an English physician, Dr. William Prout, who in 1815 called attention to a curious relation to be observed between the atomic weight of the various elements. Accepting the figures given by the authorities of the time (notably Thomson and Berzelius), it appeared that a strikingly large proportion of the atomic weights were exact multiples of the weight of hydrogen, and that others differed so slightly that errors of observation might explain the discrepancy. Prout felt that this could not be accidental, and he could think of no tenable explanation, unless it be that the atoms of the various alleged elements are made up of different fixed numbers of hydrogen atoms. Could it be that the one true element-the one primal matter-is hydrogen, and that all other forms of matter are but compounds of this original substance?

Prout advanced this startling idea at first tentatively, in an anonymous publication; but afterwards he espoused it openly and urged its tenability. Coming just after Davy's dissociation of some supposed elements, the idea 278 


\section{THE CENTURY'S PROGRESS IN CHEMISTRY}

proved alluring, and for a time gained such popularity that chemists were disposed to round out the observed atomic weights of all elements into whole numbers.

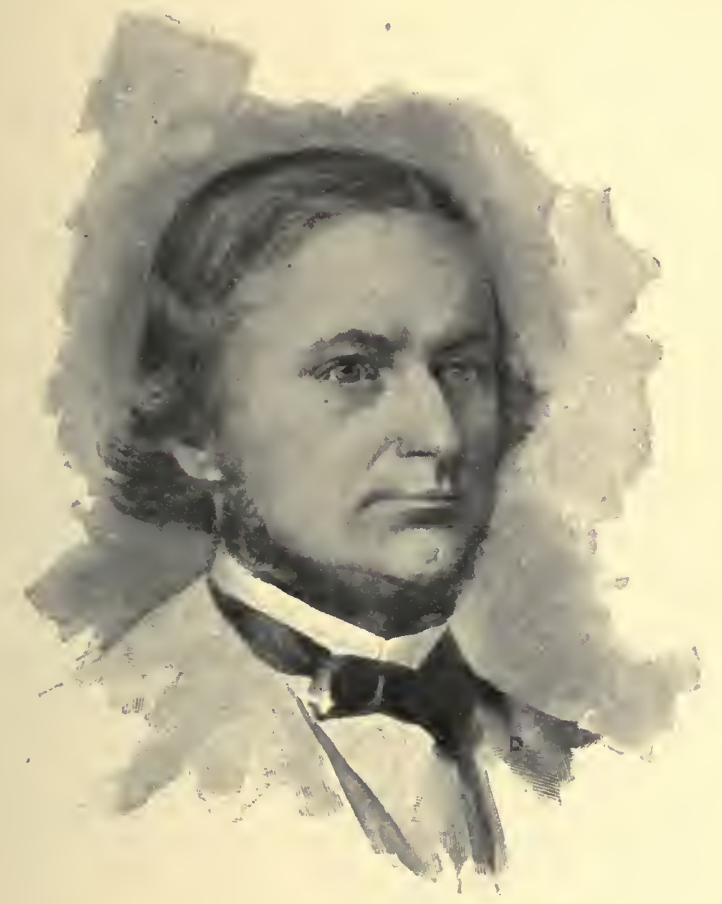

GUSTAVE ROBER'T KIRCHHOFF

But presently renewed determinations of the atomic weights seemed to discountenance this practice, and Prout's alleged law fell into disrepute. It was revived, however, about 1840, by Dumas, whose great authority secured it a respectful hearing, and whose careful redetermination of the weight of carbon, making it exactly twelve times that of hydrogen, aided the cause. 


\section{THE STORY OF NINETEENTH-CENTURY SCIENCE}

Subsequently Stas, the pupil of Dumas, undertook a long series of determinations of atomic weights, with the expectation of confirming the Proutian hypothesis. But his results seemed to disprove the hypothesis, for the atomic weights of many elements differed from whole numbers by more, it was thought, than the limits of error of the experiments. It is noteworthy, however, that the confidence of Dumas was not shaken, though he was led to modify the hypothesis, and, in accordance with previous suggestions of Clark and of Marignac, to recognize as the primordial element, not hydrogen itself, but an atom half the weight, or even one-fourth the weight, of that of hydrogen, of which primordial atom the hydrogen atom itself is compounded. But even in this modified form the hypothesis found great opposition from experimental observers.

In 1S6t, however, a novel relation between the weights of the elements and their other characteristics was called to the attention of chemists by Professor John A. R. Newlands, of London, who had noticed that if the elements are arranged serially in the numerical order of their atomic weights, there is a curious reculrence of similar properties at intervals of eight elements. This so-called "law of octaves" attracted little immediate attention, but the facts it connotes soon came under the observation of other chemists, notably of Professors Gustav Hinrichs in America, Dmitri Mendelèeff in Russia, and Lothar Meyer in Germany. Mendelèff gave the discovery fullest expression, expositing it in $\mathbf{1 5 6 9 ,}$ under the title of "periodic law."

Though this early exposition of what has since been admitted to be a most important discovery was very fully outlined, the generality of chemists gave it littlo 


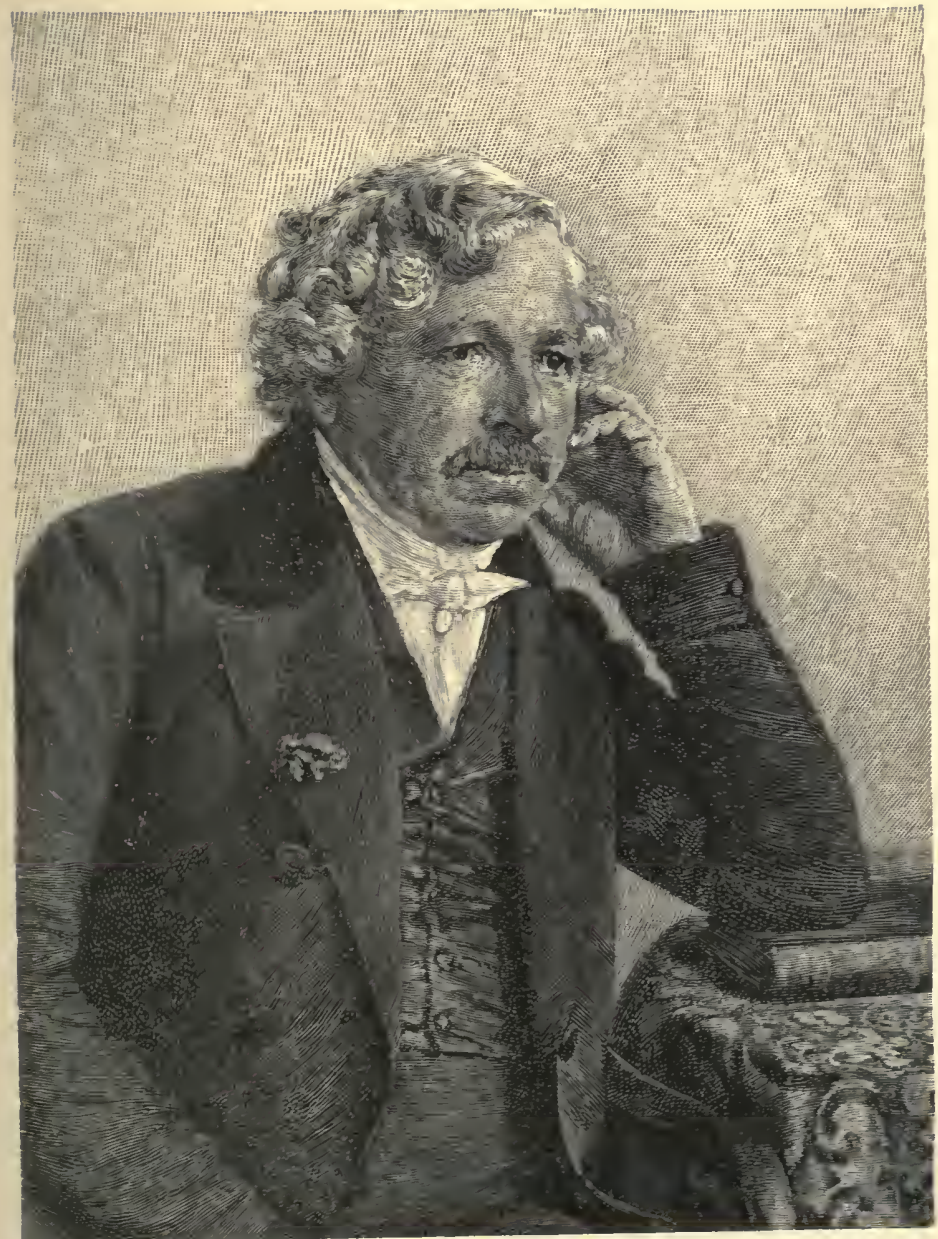

\section{LOUIS JACQUES MANDÉ DAGUERRE}

From a daguerreotype made in Paris for Meade Brothers, New York, now n possession of Abraham Bogardus, New York 



\section{THE CENTURY'S PROGRESS IN CHEMISTRY}

heed till a decade or so later, when three new elements, gallium, scandium, and germanium, were discovered, which, on being analyzed, were quite unexpectedly found to fit into three gauss which Mendelèeff had left in his periodic scale. In effect, the periodic law had enabled Mendelèeff to predicate the existence of the new elements years before they were discovered. Surely a system that leads to such results is no mere vagary. So very soon the periodic law took its place as one of the most important generalizations of chemical science.

This law of periodicity was put forward as an expression of observed relations independent of hypothesis; but of course the theoretical bearings of these facts could not be overlooked. As Professor J. H. Gladstone has said, it forces upon us "the conviction that the elements are not separate bodies created without reference to one another, but that they have been originally fashioned, or have been built up, from one another, according to some general plan." It is but a short step from that proposition to the Proutian hypothesis.

But the atomic weights are not alone in suggesting the compound nature of the alleged elements. Evidence of a totally different kind has contributed to the same end, from a source that could hardly have been imagined when the Proutian hypothesis was formulated, through the addition of a novel weapon to the armamentarium of the chemist-the spectroscope. The perfection of this instrument, in the hands of two German scientists, Gustav Robert Kirchhoff and Robert Wilhelm Bunsen, came about through the investigation, towards the middle of the century, of the meaning of the dark lines which had been observed in the solar spectrum by Fraunhofer as early as $\mathbf{1 8 1 5}$, and by Wollaston a decade 


\section{THE S'TORY OF NINETEENTH-CENTURY SCIENCE}

earlier. It was suspected by Stokes and by Fox Talbot in England, but first brought to demonstration by Kirchhoff and Bunsen, that these lines, which were known to occupy definite positions in the spectrum, are really indicative of particular elementary substances. By means of the spectroscope, which is essentially a magnifying lens attached to a prism of glass, it is possible to locate the lines with great accuracy, and it was soon shown that here was a new means of chemical analysis of the most exquisite delicacy. It was found, for example, that the spectroscope could detect the presence of a quantity of sodium so infinitesimal as the one twohundred-thousandth of a grain. But what was even more important, the spectroscope put no limit upon the distance of location of the substance it tested, provided only that sufficient light came from it. The experiments it recorded might be performed in the sun, or in the most distant stars or nebula; indeed, one of the earliest feats of the instrument was to wrench from the sun the secret of his chemical constitution.

To render the atility of the spectroscope complete, however, it was necessary to link with it another new chemical agency, namely, photography. This now familiar process is based on the property of light to decompose certain unstable compounds of silver, and thus alter their chemical composition. We have seen that Davy and Wedgwood barely escaped the discovery of the value of the photographic method. Their successors quite overlooked it until about 1826, when Louis J. M. Daguerre, the French chemist, took the matter in hand, and after many years of experimentation brought it to relative perfection in 1839 , in which year the famous daguerreotype first brought the matter to popular at- 


\section{THE CENTURY'S PROGRESS IN CIENISTRY'}

tention. In the same year Mr. Fox Talbot read a paper on the subject before the Royal Society, and soon afterwards the efforts of Herschel and numerous other natural philosophers contributed to the advancement of the new method.

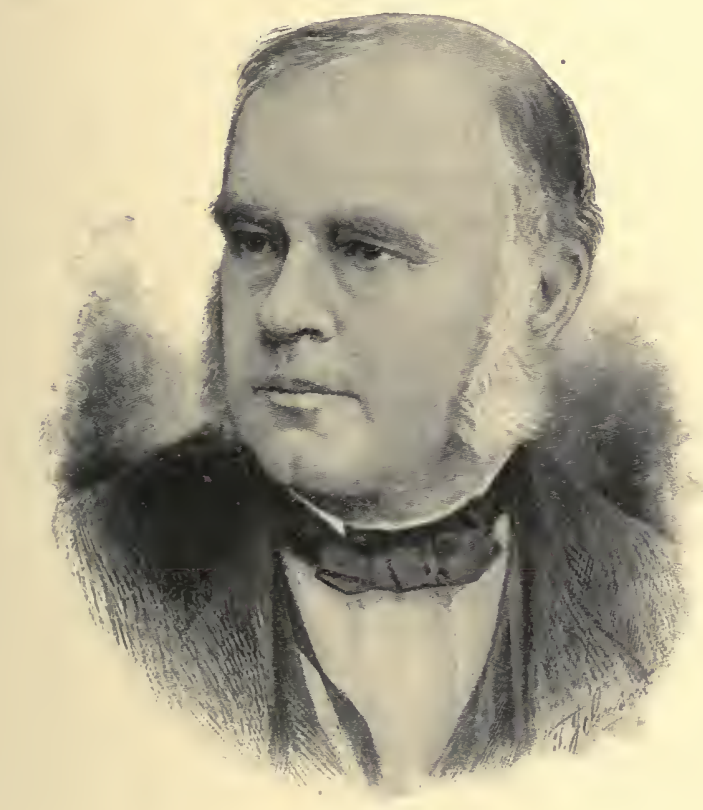

JOHX W. DRAPER

In 1843 Dr. John W. Draper, the famous EnglishAmerican chemist and physiologist, showed that by photography the Fraunhofer lines in the solar spectrum might be mapped with absolute accuracy; also proring that the silvered film revealed many lines invisible to the unaided eye. The value of this method of observation was recognized at once, and, as soon as the spectro. 


\section{THE STORY OF NINETEENTH-CENTURY SCIENCE}

scope was perfected, the photographic method, in conjunction with its use, became invaluable to the chemist. By this means comparisons of spectra may be made with a degree of accuracy not otherwise obtainable; and in case of the stars, whole clusters of spectra may be placed on record at a single observation.

As the examination of the sun and stars proceeded, chemists were amazed or delighted, according to their various preconceptions, to witness the proof that many familiar terrestrial elements are to be found in the celestial bodies. But what perhaps surprised them most was to observe the enormous preponderance in the sideral bodies of the element hydrogen. Not only are there vast quantities of this element in the sun's atmosphere, but some other suns appeared to show hydrogen lines almost exclusively in their spectra. Presently it appeared that the stars of which this is true are those white stars, such as Sirius, which had been conjectured to be the hottest; whereas stars that are only red-hot, like our sun, show also the vapors of many other elements, including iron and other metals.

In $187 \mathrm{~S}$ Mr. J. Norman Lockyer, in a paper before the Royal Society, called attention to the possible significance of this series of observations. He urged that the fact of the sun showing fewer elements than are observed here on the cool earth, while stars much hotter than the sun show chiefly one element, and that one hydrogen, the lightest of known elements, seemed to give color to the possibility that our aileged elements are really compounds, which at the temperature of the hottest stars may be decomposed into hydrogen, the latter "element" itself being also donbtless a compound, which might be resolved under yet more trying conditions. 
Here, then, was what might be termed direct experimental evidence for the hypothesis of Prout. Unfortunately, however, it is evidence of a kind which only a few experts are competent to discuss-so very delicate a matter is the spectral analysis of the stars. What is still more unfortunate, the experts do not agree among themselves as to the validity of Mr. Lockyer's conclusions. Some, like Professor Crookes, have accepted them with acclaim, hailing Lockyer as "the Darwin of the inorganic world," while others have sought a different explanation of the facts he brings forward. As yet it cannot be said that the controversy has been brought to final settlement. Still, it is hardly to be doubted that now, since the periodic law has seemed to join hands with the spectroscope, a belief in the compound nature of the so-called elements is rapidly gaining ground among chemists. More and more general becomes the belief that the Daltonian atom is really a compound radical, and that back of the seeming diversity of the alleged elements is a single unique form of primordial matter. But it should not be forgotten that this view, whatever its attractiveness, still lurks in the domain of theory. "There is no proof that the Daltonian atom has yet been divided in the laboratory. 


\section{CHAPTER IX}

\section{THE CENTURY'S PROGRESS IN BIOLOGY}

When Coleridge said of Humphry Dary that he might have been the greatest poet of his time had he not chosen rather to be the greatest chemist, it is possible that the enthusiasm of the friend outweighed the caution of the critic. But howerer that may be, it is beyond dispute that the man who actually was the greatest poet of that time might easily have taken the very highest rank as a scientist had not the Muse distracted his attention. Indeed, despite these distractions, Johann Wolfgang ron Goethe achieved successes in the field of pure science that would insure permanent recognition for his name had he never written a stanza of poetry. Such is the versatility that marks the highest genius.

It was in 1790 that Goethe published the work that laid the foundations of his scientific reputation-the work on the Metamorphoses of Plants, in which he advanced the novel doctrine that all parts of the flower are modified or metamorphosed leaves. This was followed presently by an extension of the doctrine of metamor- 


\section{THE CENTURY'S PROGRESS IN BIOLOGÝ}

phosis to the animal kingdom, in the doctrine which Goethe and Oken adranced independently, that the vertebrate skull is essentially a modified and developed vertebra. These were conceptions worthy of a poet; impossible, indeed, for any mind that had not the poetic faculty of correlation. But in this case the poet's rision was prophetic of a future view of the most prosaic science. The doctrine of metamorphosis of parts soon came to be regarded as a fundamental feature in the science of living things.

But the doctrine had implications that few of its early adrocates realized. If all the parts of a flowersepal, petal, stamen, pistil, with their countless deriations of contour and color-are but modifications of the leaf, such modification implies a marvellous differentiation and development. To assert that a stamen is a metamorphosed leaf means, if it means anything, that in the long sweep of time the leaf has by slow or sudden gradations changed its character through successive generations, until the offspring, so to speak, of a true leaf has become a stamen. But if such a metamorphosis as this is possible-if the seemingly wide gap between leaf and stamen may be spanned by the modification of a line of organisms - where does the possibility of modification of organic type find its bounds? Why may not the modification of parts go on along devious lines until the remote descendants of an organism are utterly unlike that organism? Why may we not thus account for the development of various species of beings all sprung from one parent stock? That too is a poet's dream; but is it only a dream? Goethe thought not. Out of his studies of metamorphosis of parts there grew in his mind the belief that the multitudinous species of 


\section{THE STORY OF NINETEENTH-CENTURY SCIENCE}

plants and animals about us have been evolved from fewer and fewer earlier parent types, like twigs of a giant tree drawing their nurture from the same primal

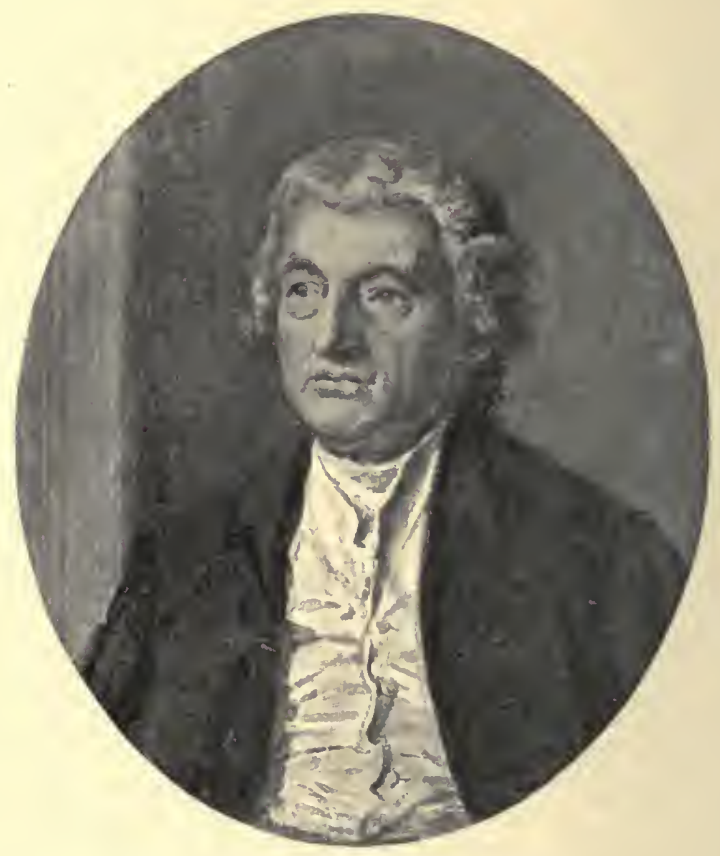

ERASMUS DARIVIN

root. It was a bold and revolutionary thought; and the world regarded it as but the vagary of a poet.

Just at the time when this thought was taking form in Goethe's brain, the same idea was germinating in the mind of another philosopher, an Englishman of international fame, Dr. Erasmus Darwin, who, while he lived, enjoyed the widest popularity as a poet, the rhymed couplets of his Botanic Garden being quoted every- 


\section{'THE CEN'TURY'S PROGRESS IN BIOLOGY}

where with admiration. And posterity, repudiating the verse which makes the body of the book, yet grants permanent value to the book itself, because, forsooth, its copious explanatory footnotes furnish an outline of the status of almost every department of science of the time.

But even though he lacked the highest art of the versifier, Darwin had, beyond peradventure, the imagination of a poet coupled with profound scientific knowledge; and it was his poetic insight, correlating organisms seemingly diverse in structure, and imbuing the lowliest flower with a vital personality, which led him to suspect that there are no lines of demarcation in nature. "Can it be," he queries," that one form of organism has developed from another; that different, species are really but modified descendants of one parent stock ?" The alluring thought nestled in his mind and was nurtured there, and grew into a fixed belief, which was given fuller expression in his Zoönomia, and in the posthumous Temple of Nature. But there was little proof of its validity forthcoming that could satisfy any one but a poet, and when Erasmus Darwin died, in 1802, the idea of transmutation of species was still but an unsubstantiated dream.

It was a dream, however, which was not confined to Goethe and Darwin. Even earlier the idea had come more or less vaguely to another great dreamer-and worker-of Gerinany, Immanuel Kant, and to several great Frenchmen, inclucling De Maillet, Maupertuis, Robinet, and the famous naturalist Buffon-a man who had the imagination of a poet, though his message was couched in most artistic prose. Not long after the middle of the eighteenth century Buffon had put forward 
the idea of transmutation of species, and he reiterated it from time to time from then on till his death in $17 \mathrm{SS}$. But the time was not yet ripe for the idea of transinutation of species to burst its bonds.

And yet this idea, in a modified or undeveloped form, had taken strange hold upon the generation that was upon the scene at the close of the eighteenth century. Vast numbers of hitherto unknown species of animals had been recently discovered in previously unexplored regions of the globe, and the wise men were sorely puzzled to account for the disposal of all of these at the time of the Deluge. It simplified matters greatly to suppose that many existing species had been dereloped since the episode of the Ark by modification of the original pairs. The remoter bearings of such a theory were overlooked for the time, and the idea that American animals and birds, for example, were modified descendants of Old World forms - the jaguar of the leopard, the puma of the lion, and so on-became a current belief with that class of humanity who accept almost any statement as true that harmonizes with their prejudices, without realizing its implications.

Thus it is recorded with éclat that the discovery of the close proximity of America at the northwest with Asia remores all difficulties as to the origin of the Occidental faunas and floras, since Oriental species might eassly have found their way to America on the ice, and have been modified as we find them by "the well-known influence of climate." And the persons who gave expression to this idea nerer dreamed of its real significance. In truth, here was the doctrine of evolution in a nutshell, and, because its ultimate bearings were not clear, it seemed the most natural of doctrines. 


\section{THE CENTURY'S PROGRESS IN BIOLOGY}

But most of the persons who advanced it would have turned from it aghast could they have realized its import. As it was, however, only here and there a man like Buffon reasoned far enough to inquire what might be the limits of such assumed transmutation; and only here and there a Darwin or a Goethe reached the conviction that there are no limits.

And even Goethe and Darwin had scarcely passed beyond that tentative stage of conriction in which they held the thought of transmutation of species as an ancillary belief, not yet ready for full exposition There was one of their contemporaries, however, who, holding the same conception, was moved to give it full explication. This was the friend and disciple of Buffon, Jean Baptiste de Lamarck. Possessed of the spirit of a poet and philosopher, this great Frenchman had also the widest range of technical knowledge, covering the entire field of animate nature. The first half of his long life was devoted chiefly to botany, in which he attained high distinction. Then, just at the beginning of our century, he turned to zoölogy, in particnlar to the lower forms of animal life. Studying these lowly. organisms, existing and fossil, he was more and more impressed with the gradations of form everywhere to be seen; the linking of diverse families through intermediate ones; and in particular with the predominance of low types of life in the earlier geological strata. Called upon constantly to classify the various forms of life in the course of his systematic writings, he found it more and more difficult to draw sharp lines of demarcation, and at 


\section{THE STORY OF NINETEENTH-CENTURY SCIENCE}

last the suspicion long harbored grew into a settled conviction that there is really no such thing as a species of organism in nature; that "species" is a figment of the

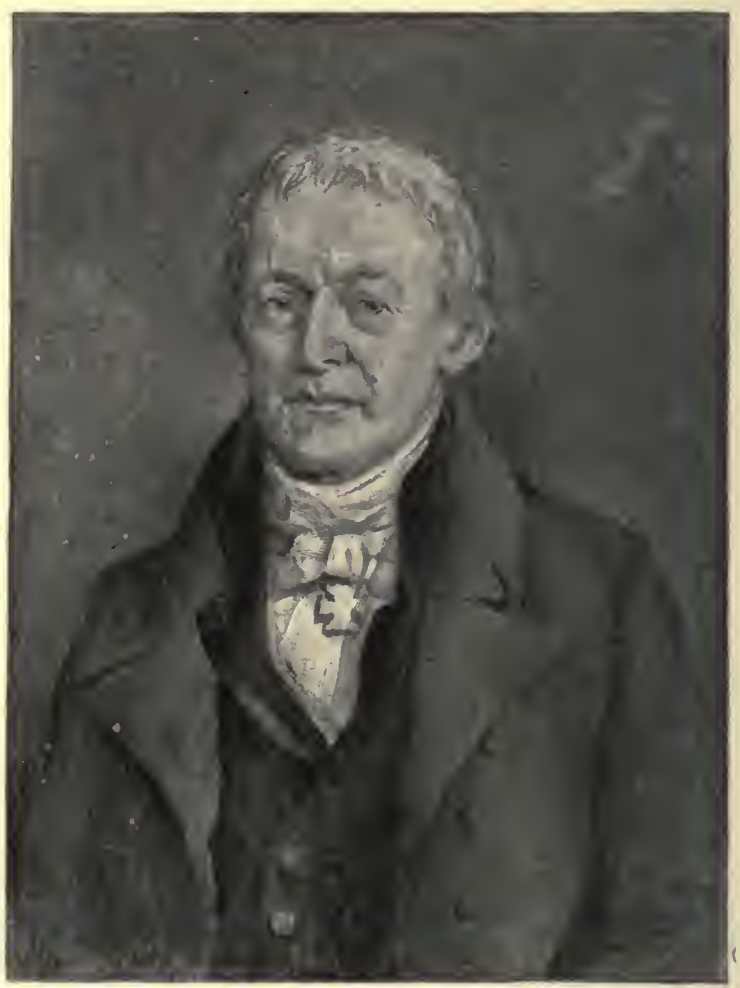

JEAN BAPTISTE DE LAMARCK

human imagination, whereas in nature there are only individuals.

That certain sets of individuals are more like one another than like other sets is of course patent, but this 


\section{THE CENTURY'S PROGRESS IN BIOLOGY}

only means, said Lamarck, that these similar groaps have had comparatively recent common ancestors, while dissimilar sets of beings are more remotely related in consanguinity. But trace back the lines of descent far enough, and all will culminate in one original stock. All forms of life whatsoever are modified descendants of an original organism. From lowest to highest, then, there is but one race, one species, just as all the multitudinous branches and twigs from one root are but one tree. For purposes of convenience of description, we may divide organisms into orders, families, genera, species, just as we divide a tree into root, trunk, branches, twigs, leaves; but in the one case, as in the other, the division is arbitrary and artificial.

In Philosophie Zoologique (1809), Lamarck first explicitly formulated his ideas as to the transmutation of species, though he had outlined them as early as 1801 . In this memorable publication not only did he state his belief more explicitly and in fuller detail than the idea had been expressed by any predecessor, but he took another long forward step, carrying him far beyond all his forerunners except Darwin, in that he made an attempt to explain the way in which the transmutation of species had been brought about. The changes have been wrought, he said, through the unceasing efforts of each organism to meet the needs imposed upon it by its environment. Constant striving means the constant use of certain organs, and such use leads to the development of those organs. Thus a bird running by the sea-shore is constantly tempted to wade deeper and deeper in pursuit of food; its incessant efforts tend to develop its legs, in accordance with the observed principle that the use of any organ tends to strengthen and develop it. 
But such slightly increased development of the legs is transmitted to the offspring of the bird, which in turn develops its already improved legs by its individual efforts, and transmits the improred tendency. Generation after generation this is repeated, until the surn of the infinitesimal variations, all in the same direction, results in the production of the long-legged wading-bird. In a similar way, through individual effort and transmitter tendency, all the diversified organs of all creatures have been developed-the fin of the fish, the wing of the bird, the hand of man ; nay, more, the fish itself, the bird, the man, even. Collectively the organs make up the entire organism; and what is true of the individual organs must be true also of their ensemble, the living being.

Whatever might be thought of Lamarck's explanation of the cause of transmutation - which really was that already suggested by Erasmus Darwin - the idea of the evolution for which he contended was but the logical extension of the conception that American animals are the modified and degenerated descendants of European animals. But people as a rule are little prone to follow ideas to their logical conclusions, and in this case the conclusions were so utterly opposed to the proximal bearings of the idea that the whole thinking world repudiated them with acclaim. The very persons who had most eagerly accepted the idea of transinutation of European species into American species, and similar liuited variations through changed environment, because of the relief thus given the otherwise overcrowded Ark, were now foremost in denouncing such an extension of the doctrine of transmutation as Lamarck proposed.

And, for that matter, the leaders of the scientific world were equally antagonistic to the Lamarckian hypothesis. 


\section{THE CENTURY'S PROGRESS IN BIOLOGY}

Cuvier in particular, once the pupil of Lamarck, but now his colleague, and in authority more than his peer, stood out against the transmutation doctrine with all his force. He argued for the absolute fixity of species, bringing to bear the resources of a mind which, as a mere repository of facts, perhaps never was excelled. As a final and tangible proof of his position, he brought forward the bodies of ibises that had been embalmed by the ancient Egyptians, and showed by comparison that these do not differ in the slightest particular from the ibises that visit the Nile to-day. Lamarck replied that this proved nothing except that the ibis had become perfectly adapted to its Egyptian surroundings in an early day, historically speaking, and that the climatic and other conditions of the Nile Valley had not since then changed. His theory, he alleged, prorided for the stability of species under fixed conditions quite as well as for transmutation under varying conditions.

But, needless to say, the popular verdict lay with $\mathrm{Cu}-$ vier; talent won for the time against genius, and Lamarck was looked upon as as impious visionary. His faith never wavered, however. He believed that he had gained a true insight into the processes of animate natule, and he reiterated his hypotheses over and over, particularly in the introduction to his Histoire naturelle des Animaux sans Vertèbres, in 1815, and in his Système des Connaissances positives de l'Ilomme, in 1820. He lived on till 1829, respected as a naturalist, but almost unrecognized as a prophet.

III

While the names of Darwin and Goethe, and in particular that of Lamarck, must always stand out in high 


\section{THE STORY OF NINETEENTH-CENTURY SCIENCE}

relief in this generation as the exponents of the idea of transmutation of species, there are a few others which must not be altogether overlooked in this connection. Of these the most conspicuous is that of Gottfried Reinhold Treviranus, a German naturalist physician, professor of mathematics in the lyceum at Bremen.

It was an interesting coincidence that Treviranus should have published the first volume of his Biologie, oder Philosophie der lebenden Natur, in which his views on the transmutation of species were expounded, in 1802, the same twelvemonth in which Lamarck's first exposition of the same doctrine appeared in his Recherches sur l'Organisation des Corps Vivants. It is singular, too, that Lamarck, in his Hydrogéologie of the same date, should independently have suggested "biology" as an appropriate word to express the general science of living things. It is significant of the tendenoy of thought of the time that the need of such a unifying word should have presented itself simultaneously to independent thinkers in different countries.

That same memorable year, Lorenz Oken, another philosophical naturalist, professor in the University of Zurich, published the preliminary outlines of his Philosophie der Natur, which, as developed through later publications, outlined a theory of spontaneous generation and of evolution of species. Thus it appears that this idea was germinating in the minds of several of the ablest men of the time during the first decade of our century. But the singular result of their various explications was to give sudden check to that undercurrent of thought which for some time had been setting towards this conception. As soon as it was made clear whither the concession that animals may be changed by 


\section{THE CENTURY'S PROGRESS IN BIOLOGY}

their environment must logically trend, the recoil from the idea was instantaneous and fervid. Then for a generation Curier was almost absolutely dominant, and his verdict was generally considered final.

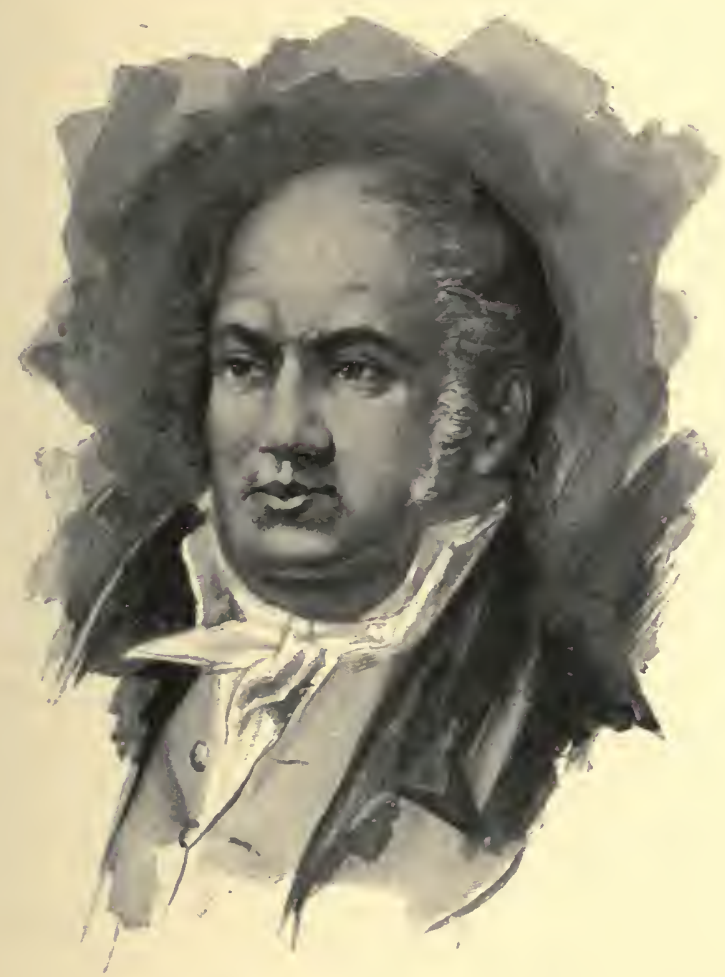

ÉTIENSE GEOFFROY SAINT-HIL.IIRE

There was, indeed, one naturalist of authority in France who had the hardihood to stand out against Cuvier and his school, and who was in a position to gain a hearing, though by no means to divide the fol299 
lowing. This was Etienne Geoffroy Saint-Hilaire, the famous author of the Philosophie Anatomique, and for many years the colleague of Lamarck at the Jardin des Plantes. Like Goethe, Geoffroy was pre-eminently an anatomist, and, like the great German, he had early been impressed with the resemblances between the analogous organs of different classes of beings. He conceived the idea that an absolute unity of type prevails throughout organic nature as regards each set of organs. Out of this idea grew his gradually formed belief that similarity of structure might imply identity of originthat, in short, one species of animal might have developed from another.

Geoffroy's grasp of this idea of transmutation was by no means so complete as that of Lamarck, and he seems never to have fully determined in his own mind just what might be the limits of such development of species. Certainly he nowhere includes all organic creatures in one line of descent, as Lamarck had done; nevertheless he held tenaciously to the truth as he saw it, in open opposition to Cuvier, with whom he held a memorable debate at the Academy of Sciences in 1530-the debate which so aroused the interest and enthusiasm of Goethe, but which, in the opinion of nearly every one else, resulted in crushing defeat for Geoffroy, and brilliant, seemingly final, victory for the advocate of special creation and the fixity of species.

With that all ardent controversy over the subject seemed to end, and for just a quarter of a century to come there was published but a single argument for transmutation of species which attracted any general attention whatever. This oasis in a desert generation was a little book called Vestiges of the Natural History of 


\section{THE CENTURY'S PROGRESS IN BIOLOGY}

Creation, which appeared anonymously in England in 1844, and which passed through numerous editions, and was the subject of no end of abusive and derisive comment. The authorship of this book remained for forty years a secret, but it is now conceded to have been the work of Robert Chambers, the well-known English author and publisher. The book itself is remarkable as being an avowed and unequivocal exposition of a general doctrine of evolution, its view being as radical and comprehensive as that of Lamarck himself. But it was a résumé of earlier efforts rather than a new departure, to say nothing of its technical shortcomings, and, while it aroused bitter animadversions, and cannot have been without effect in creating an undercurrent of thought in opposition to the main trend of opinion of the time, it can hardly be said to have done more than that. Indeed, some critics have denied it even this merit. After its publication, as before, the conception of transmutation of species remained in the popular estimation, both lay and scientific, an almost forgotten "heresy."

It is true that here and there a scientist of greater or ress repute-as Von Buch, Meckel, and Von Baer in Germany, Bory Saint Vincent in France, Wells, Grant, and Matthew in England, and Leidy in America-had expressed more or less tentative dissent from the doctrine of special creation and immutability of species, but their unaggressive suggestions, usually put forward in obscure publications, and incidentally, were utterly overlooked and ignored. And so, despite the scientific advances along many lines at the middle of the century, the idea of the transmutability of organic races had no such prominence, either in scientific or unscientific circles, as it had acquired fifty years befole. Special cre- 


\section{THE STORY OF NINETEENTH-CEN'TUY SCIENCE}

ation held the day, apparently unchallenged and unopposed.

IV

But even at this time the fancied security of the special-creation hypothesis was by no means real. Though it seemed so invincible, its real position was that of an apparently impregnable fortress beneath which, all unbeknown to the garrison, a powder-mine has been dug and lies ready for explosion. For already there existed in the secluded work-room of an English naturalist, a manuscript volume and a portfolio of notes which might have sufficed, if given publicity, to shatter the entire structure of the special-creation hypothesis. The naturalist who, by dint of long and patient effort, had constructed this powder-mine of facts was Charles Robert Darwin, grandson of the author of Zoönomia.

As long ago as July 1,1837, young Darwin, theri twenty-eight years of age, had opened a private journal, in which he purposed to record all facts that came to him which seemed to have any bearing on the moot point of the doctrine of transmutation of species. Four or five years earlier, during the course of that famous trip around the world with Admiral Fitzroy, as naturalist to the Beagle, Darwin had made the personal observations which first tended to shake his belief in the fixity of species. In South America, in the Pampean formation, he had discovered "great fossil animals covered with armor like that on the existing armadillos," and had been struck with this similarity of type between ancient and existing faunas of the same region. He was also greatly impressed by the manner in which closely related species of animals were observed to l'e- 
place one another as he proceeded southward over the continent; and "by the South American character of most of the productions of the Galapagos Archipelago, and more especially by the manner in which they differ slightly on each island of the group, none of the islands appearing to be very ancient in a geological sense."

At first the full force of these observations did not strike him; for, under sway of Lyell's geological conceptions, he tentatively explained the relative absence of life on one of the Galapagos Islands by suggesting that perhaps no species had been created since that island arose. But gradually it dawned upon him that such facts as he had observed "could only be explained on the supposition that species gradually become modified." From then on, as he afterwards asserted, the subject haunted him; hence the journal of 1837 .

It will thus be seen that the idea of the variability of species came to Charles Darwin as an inference from personal observations in the field, not as a thought borrowed from books. He had, of course, read the works of his grandfather much earlier in life, but the arguments of the Zoönomia and Temple of Nature had not served in the least to weaken his acceptance of the current belief in fixity of species. Nor had he been more impressed with the doctrine of Lamarck, so closely similar to that of his grandfather. Indeed, even after his South American experience had aroused him to a new point of view he was still unable to see anything of value in these earlier attempts at an explanation of the variation of species. In opening his journal, therefore, he had no preconceived notion of upholding the views of these or any other makers of hypotheses, nor at the time had he formulated any hypothesis of his own. His 


\section{THE STORY OF NINETEENTH-CENTURY SCIENCE}

mind was open and receptive; he was eager only for facts which might lead him to an understanding of a

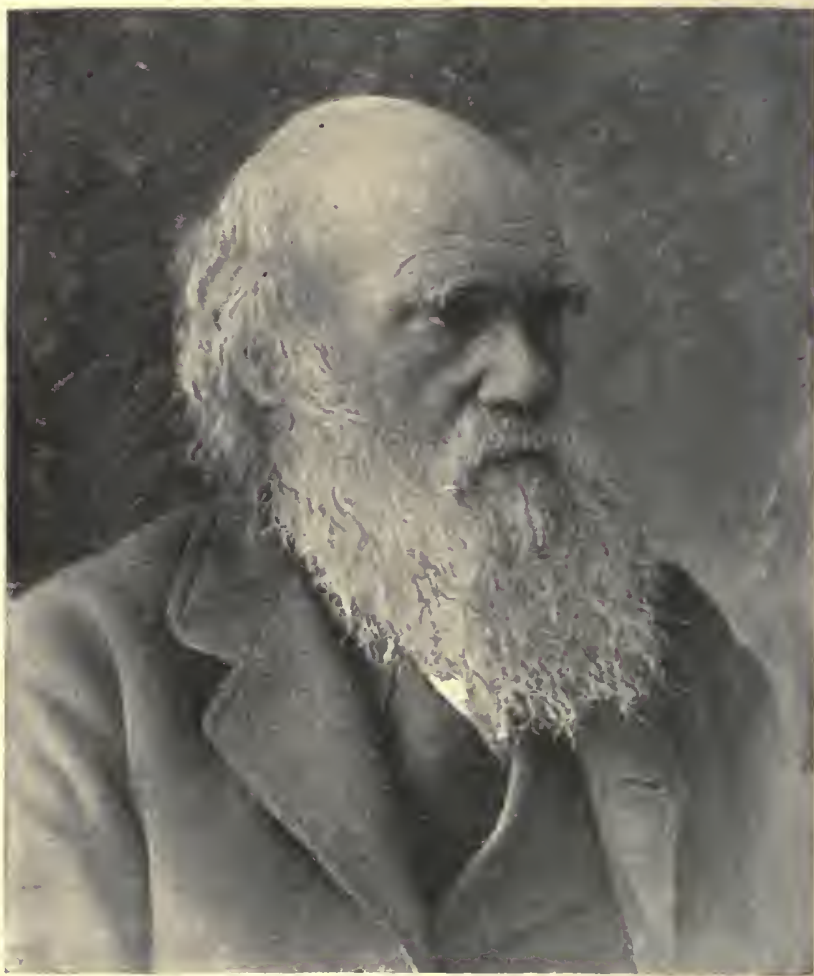

CHARLES ROBERT DARWIN

problem which seemed utterly obscure. It was something to feel sure that species have varied; but how have such variations been brought about?

It was not long before Darwin found a clew which he thought might lead to the answer he sought. In casting about for facts he had soon discovered that the 304 
most available field for observation lay among domesticated animals, whose numerous variations within specific lines are familiar to every one. Thus under domestication creatures so tangibly different as a mastiff and a terrier have sprung from a common stock. So have the Shetland pony, the thoroughbred, and the draughthorse. In short, there is no domesticated animal that has not developed varieties deviating more or less widely from the parent stock. Now how has this been accomplished? Why, clearly, by the preservation, through selective breeding, of seemingly accidental variations. Thus one horseman, by constantly selecting animals that "chance" to have the right build and stamina, finally develops a race of running-horses; while another horseman, by selecting a different series of progenitors, has dereloped a race of slow, heavy draught-animals.

So far so good; the preservation of "accidental" variations through selective breeding is plainly a means by which races may be developed that are very different from their original parent form. But this is under man's supervision and direction. By what process could such selection be brought about among creatures in a state of nature? Here surely was a puzzle, and one that must be solved before another step could be taken in this direction.

The key to the solution of this puzzle came into Darwin's mind through a chance reading of the famous essay on "Population" which Thomas Robert Malthus had published almost half a century before. This essay, expositing ideas by no means exclusively original with Malthus, emphasizes the fact that organisms tend to increase at a geometrical ratio through successire generations, and hence would overpopulate the earth if not 
somehow kept in check. Cogitating this thought, Darwin gained a new insight into the processes of nature. He saw that in virtue of this tendency of each race of beings to overpopulate the earth, the entire organic world, animal and vegetable, must be in a state of perpetual carnage and strife, individual against individual, fighting for sustenance and life.

That idea fully imagined, it becomes plain that a selective influence is all the time at work in nature, since only a few individuals, relatively, of each generation can come to maturity, and these few must, naturally, be those best fitted to battle with the particular circumstances in the midst of which they are placed. In other words, the individuals best adapted to their surroundings will, on the average, be those that grow to maturity and produce offspring. To these offspring will be transmitted the favorable peculiarities. Thus these pecul. iarities will become permanent, and nature will have accomplished precisely what the human breeder is seen to accomplish. Grant that organisms in a state of nature vary, howerer slightly, one from another (which is indubitable), and that such variations will be transmitted by a parent to its offspring (which no one then doubted); grant, further, that there is incessant strife among the various organisms, so that only a small proportion can come to maturity-grant these things, said Darwin, and we have an explanation of the preservation of variations which leads on to the transmutation of species themselves.

This wonderful coign of vantage Darwin had reached by 1839 . ITere was the full outline of his theory ; here were the ideas which afterwards came to be embalmed in familiar speech in the phrases "spontaneous varia- 
tion," and the "survival of the fittest," through "natural selection." After such a discovery any ordinary man would at once have run through the streets of science, so to speak, screaming " Eureka!" Not so Darwin. He placed the manuscript outline of his theory in his portfolio, and went on gatherıng facts bearing on his discovery. In 1844 he made an abstract in a manuscript book of the mass of facts by that time accumulated. Ile showed it to his friend Hooker, made careful provision for its publication in the event of his sudden death, then stored it away in his desk, and went ahead with the gathering of more data. This was the unexploded powder-mine to which I have just referred.

Twelve years more elapsed; years during which the silent worker gathered a prodigious mass of facts, answered a multitude of objections that arose in his own mind, vastly fortified his theory. All this time the toiler was an invalid, never knowing a day free from illness and discomfort, obliged to husband his strength, never able to work more than an hour and a half at a stretch; yet he accomplished what would have been vast achievements for half a dozen men of robust health. Two friends among the eminent scientists of the day knew of his labors-Sir Joseph Hooker, the botanist, and Sir Charles Lyell, the geologist. Gradually Hooker had come to be more than half a convert to Darwin's views. Lyell was still sceptical, yet he urged Darwin to publish his theory without further delay, lest he be forestalled. At last the patient worker decided to comply with this advice, and in 1856 he set to work to make another and fuller abstract of the mass of data he had gathered.

And then a strange thing happened. After Darwin had been at work on his "abstract" about two years, 
THE STORY OF NINETEENTH-CENTURY SCIENCE

but before he had pullished a line of it, there came to him one day a paper in manuscript, sent for his approval by a naturalist friend, named Alfred Russell Wallace, who had been for some time at work in the East India

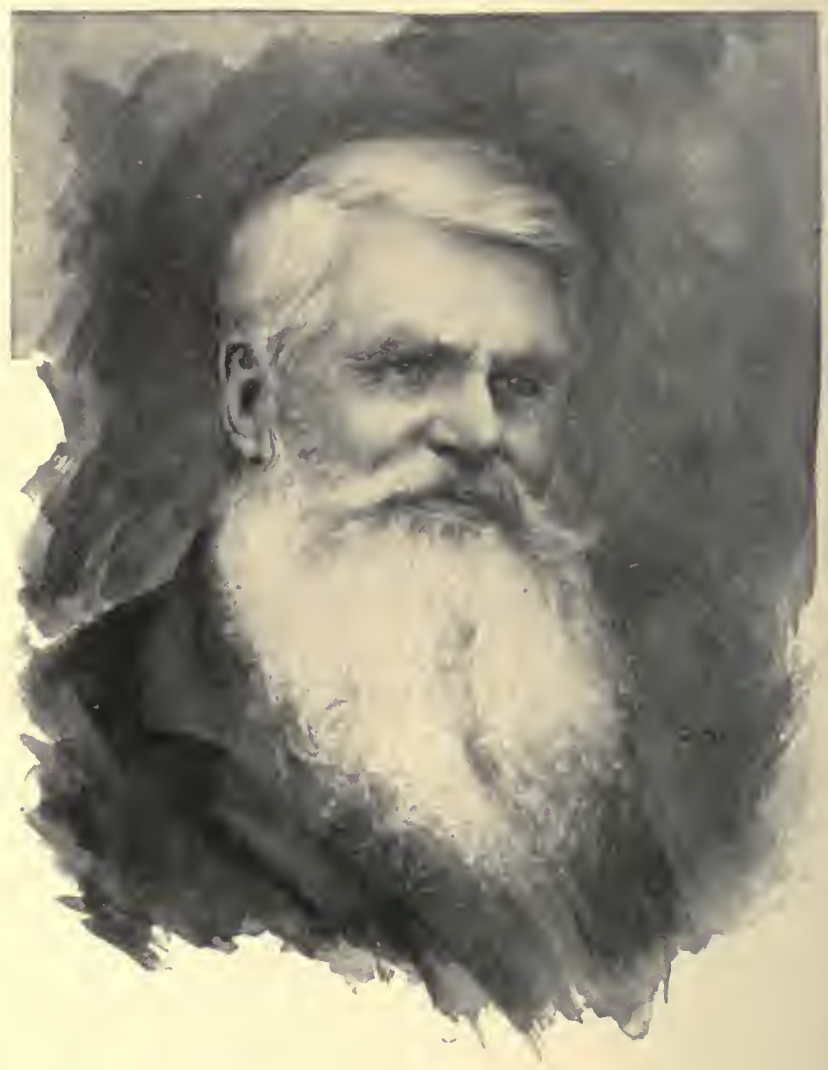

ALFRED RUSSELL WALLACE

Archipelago. He read the paper, and, to his amazement, found that it contained an outline of the same 308 


\section{THE CENTURY'S PROGRESS IN BIOLOGY}

theory of "natural selection" which he himself had originated and for twenty years had worked upon. Working independently, on opposite sides of the globe, Darwin and Wallace had hit upon the same explanation of the cause of transmutation of species. "Were Wallace's paper an abstract of my unpublished manuscript of 1844," said Darwin, "it could not better express my ideas."

Here was a dilemma. To publish this paper with no word from Darwin would give Wallace priority, and wrest from Darwin the credit of a discovery which he had made years before his co-discoverer entered the field. Yet, on the other hand, could Darwin honorably do otherwise than publish his friend's paper and himself remain silent? It was a complication well calculated to try a man's soul. Darwin's was equal to the test. Keenly alive to the delicacy of the position, he placed the whole matter before his friends Hooker and Lyell, and left the decision as to a course of action absolutely to them. Needless to say, these great men did the one thing which insured full justice to all concerned. They counselled a joint publication, to include on the one hand Wallace's paper, and on the other an abstract of Darwin's ideas, in the exact form in which it had been outlined by the author in a letter to Asa Gray in the previous year-an abstract which was in Gray's hands before Wallace's paper was in existence. This joint production, together with a full statement of the facts of the case, was presented to the Linnæan Society of London by Hooker and Lyell on the erening of July 1, 1858 , this being, by an odd coincidence, the twenty-first anniversary of the day on which Darwin had opened his journal to collect facts bearing on the "species ques- 
tion." Not often before in the history of science has it happened that a great theory has been nurtured in its author's brain through infancy and adolescence to its full legal majority before being sent out into the world.

Thus the fuse that led to the great powder-mine had been lighted. The explosion itself came more than a year later, in November, 1859, when Darwin, after thirteen months of further effort, completed the outline of his theory, which was at first begun as an abstract for the Linnæan Society, but which grew to the size of an independent volume despite his efforts at condensation, and which was given that ever-to-be-famous title, The Origin of Species by means of Natural Selection, or the Preservation of Favored Ruces in the Struggle for Life. And what an explosion it was! The joint paper of $185 \mathrm{~s}$ had made a momentary flare, causing the hearers, as Hooker said, to "speak of it with bated breath," but beyond that it made no sensation. What the result was when the Origin itself appeared, no one of our generation need be told. The rumble and roar that it made in the intellectual world have not yet altogether ceased to echo after forty years of reverberation.

To the Origin of Species, then, and to its author, Charles Darwin, must always be ascribed chief credit for that vast revolution in the fundamental beliefs of our race which has come about since 1859 , and made the second half of the century memorable. But it must not be overlooked that no such sudden metamorphosis could have been effected had it not been for the aid of a few notable lieutenants, who rallied to the standards of 


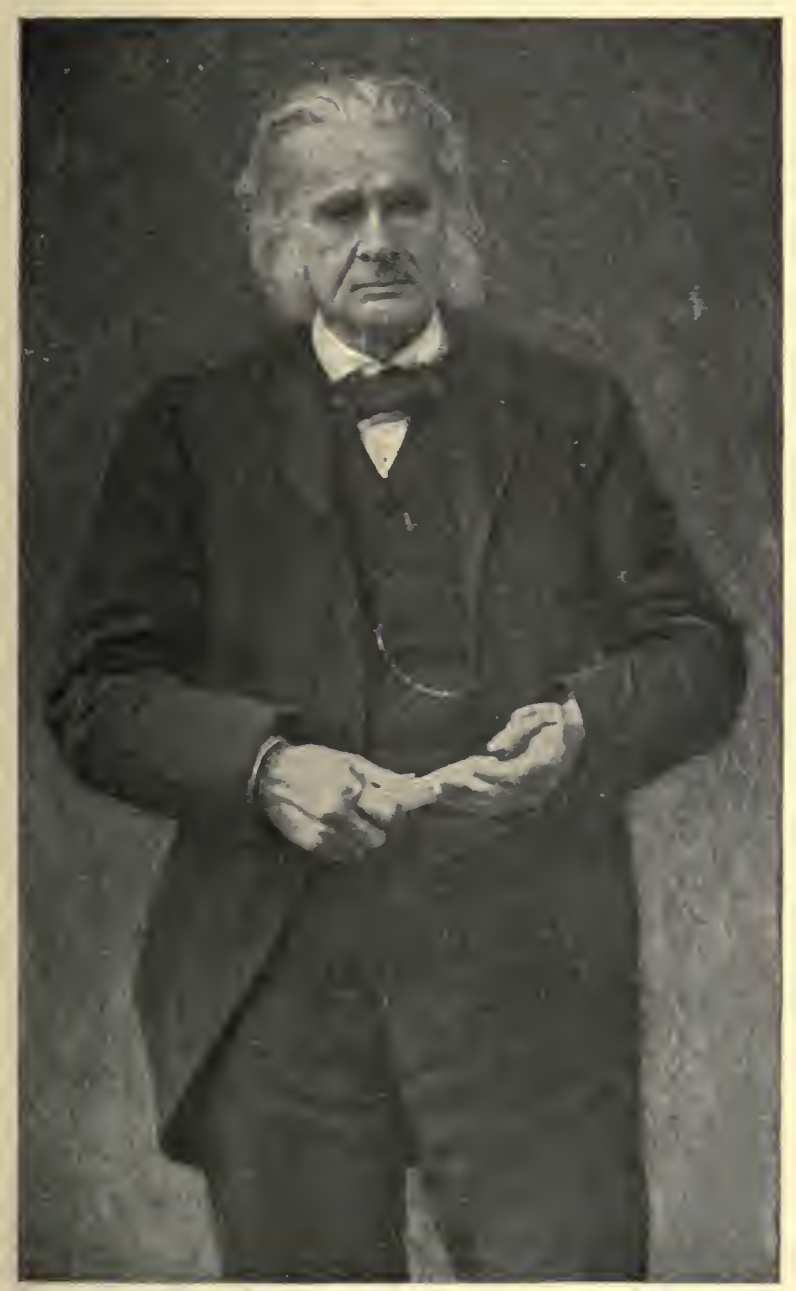

THOMAS HENRY HUXLEY

From a photograph by W. and D. Downey, London 



\section{THE CENTURY'S PROGRESS IN BIOLOGY}

the leader immediately after the publication of the Origin. Darwin had all along felt the utmost confidence in the ultimate triumph of his ideas. "Our posterity," he declared in a letter to Hooker, "will marvel as much about the current belief [in special creation] as we do about fossil shells having been thought to be created as we now see them." But he fully realized that for the present success of his theory of transmutation the championship of a few leaders of science was all-essential. He felt that if he could make converts of Hooker and Lyell and of Thomas Henry Huxley at once, all would be well.

His success in this regard, as in others, exceeded his expectations. Hooker was an ardent disciple from reading the proof-sheets before the book was published; Lyell renounced his former beliefs and fell into line a few months later; while IIuxley, so soon as he had mastered the central idea of natural selection, marvelled that so simple yet all-potent a thought had escaped him so long, and then rushed eagerly into the fray, wielding the keenest dialectic blade that was drawn during the entire controversy. Then, too, unexpected recruits were found in Sir John Lubbock and John Tyndall, who carried the war eagerly into their respective territories; while Herbert Spencer, who had advocated a doctrine of transmutation on philosophic grounds some years before Darwin published the key to the mystery - and who himself had barely escaped independent discovery of that key-lent his masterful influence to the cause. In America, the famous botanist Asa Gray, who had long been a correspondent of Darwin's, but whose advocacy of the new theory had not been anticipated, became an ardent propagandist; while in Germany Ernst Heinrich 
THE STORY OF NINETEENTH-CEN'TURY SCIENCE

Haeckel, the youthful but already noted zoölogist, took up the fight with equal enthusiasm.

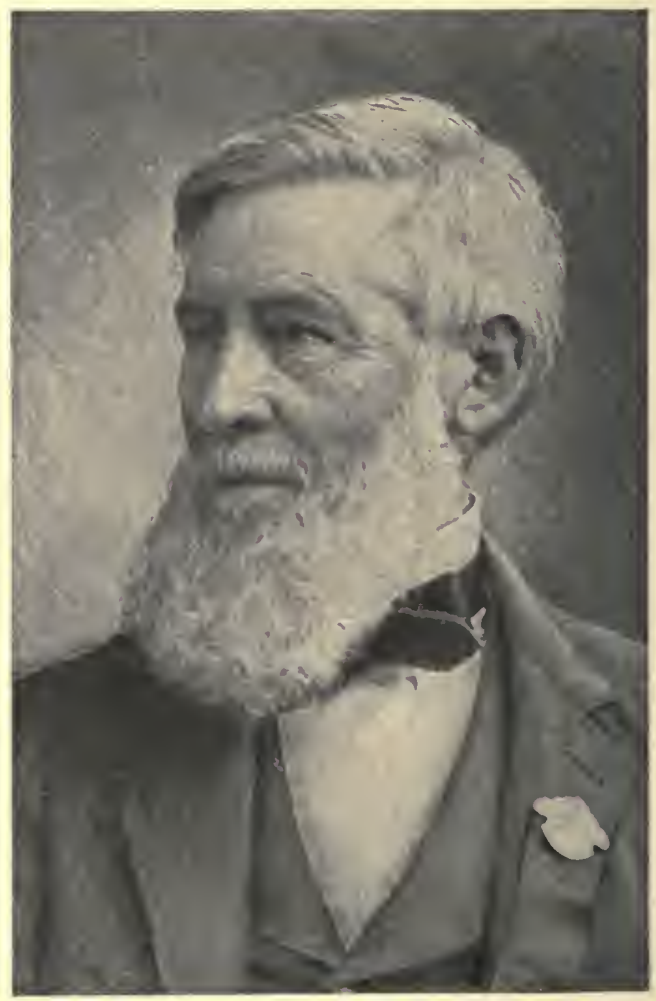

ASA GRAT

Against these few doughty champions-with here and there another of less general renown-was arrayed, at the outset, practically all Christendom. The interest of the question came home to every person of intelligence, whatever his calling, and the more deeply as it became more and more clear, how far-reaching are the real bear314 
ings of the doctrine of natural selection. Soon it was seen that should the doctrine of the survival of the favored races through the struggle for existence win, there must come with it as radical a change in man's estimate of his own position as had come in the day when, through the efforts of Copernicus and Galileo, the world was dethroned from its supposel central position in the universe. The whole conservative majority of mankind recoiled from this necessity with horror. And this conservative majority included not laymen merely, but a vast preponderance of the leaders of science also.

With the open-minded minority, on the other hand, the theory of natural selection made its way by leaps and bounds. Its delightful simplicity - which at first sight made it seem neither new nor important-coupled with the marvellous comprehensiveness of its implications, gave it a hold on the imagination, and secured it a hearing where other theories of transmutation of species had been utterly scorned. Men who had found Lamarck's conception of change through voluntary effort ridiculous, and the vaporings of the Vestiges altogether despicable, men whose scientific cautions held them back from Spencer's deductive argument, took eager hold of that tangible, ever-present principle of natural selection, and were led on and on to its goal. Hour by hour the attitude of the thinking world towards this new principle changed; never before was so great a revolution wrought so suddenly.

Nor was this merely because "the times were ripe" or "men's minds prepared for evolution." Darwin himself bears witness that this was not altogether so. All through the years in which he brooded this theory he sounded his scientific friends, and could find among 


\section{THE STORY OF NINETEENTH-CENTURY SCIENCE}

them not one who acknowledged a doctrine of transmutation. The reaction from the standpoint of Lamarck and Erasmus Darwin and Goethe had been complete, and when Charles Darwin avowed his own conriction he expected always to have it met with ridicule or contempt. In 1857 there was but one man speaking with any large degree of authority in the world who openly avowed a belief in transmutation of species-that man being Herbert Spencer. But the Origin of Species came, as Huxley has said, like a flash in the darkness, enabling the benighted royager to see the way. The score of years during which its author had waited and worked had been years well spent. Darwin had become, as he himself says, a veritable Crosus, "overwhelmed with his riches in facts "-facts of zoölogy, of selective artificial breeding, of geographical distribution of animals, of embryology, of paleontology. He had massed his facts about his theory, condensed them and recondensed, until his volume of five hundred pages was an encyclopædia in scope. During those long years of musing he had thought out almost erery conceivable objection to his theory, and in his book every such objection was stated with fullest force and candor, togrether with such reply as the facts at command might dictate. It was the force of those twenty years of effort of a master mind that made the sudden breach in the breastwork of current thought.

Once this breach was effected, the work of conquest went rapidly on. Day by day squads of the enemy capitulated and struck their arms. By the time another score of years had passed the doctrine of evolution had become the working hypothesis of the scientific world, The revolution had been effected. 
And from amid the wreckage of opinion and belief stands forth the figure of Charles Darwin, calm, imperturbable, serene; scatheless to ridicule, contumely, abuse ; unspoiled by ultimate success; unsullied alike by the strife and the victory - take him for all in all, for character, for intellect, for what he was and what he did, perhaps the most Socratic figure of the century. When, in 1882, he died, friend and foe alike conceded that one of the greatest sons of men had rested from his labor's, and all the world felt it fitting that the remains of Charles Darwin should be entombed in Westminster Abbey, close beside the honored grave of Isaac Newton. Nor were there many who would dispute the justice of Huxley's estimate of his accomplishment: "He found a great trutls trodden under foot. Reviled by bigots, and ridiculed by all the world, he lived long enough to see it, chiefly by his own efforts, irrefragably established in science, inseparably incorporated with the common thoughts of men, and only hated and feared by those who would revile, but ditre not."

VI

Wide as are the implications of the great truth which Darwin and his co-workers established, however, it leares quite untouched the problem of the origin of those "favored variations" upon which it operates. That such variations are due to fixed and determinate causes no one understood better than Darwin; but in his original exposition of his doctrine he made no assumption as to what these causes are. He accepted the observed fact of variation-as constantly witnessed, for example, in the differences between parents and offspring-and went ahead from this assumption. 
But as soon as the validity of the principle of natural selection came to be acknowledged, speculators began to search for the explanation of those variations which, for purposes of argument, had been provisionally called "spontaneous." Herbert Spencer had all along dwelt on this phase of the subject, expounding the Lamarckian conceptions of the direct influence of the environment (an idea which had especially appealed to Buffon and to Geoffroy Saint-Hilaire), and of effort in response to environment and stimulus as modifying the individual organism, and thus supplying the basis for the operation of natural selection. Haeckel also became an adrocate of this idea, and presently there arose a so-called school of neo-Lamarckians, which developed particular strength and prominence in America, under the leadership of Professors A. Hyatt and E. D. Cope.

But just as the tide of opinion was turning strongly in this direction, an utterly unexpected obstacle appeared in the form of the theory of Professor August Weismann, put forward in 1883 , which antagonized the Lamarckian conception (though not touching the Darwinian, of which Weismann is a firm upholder) by denying that individual variations, however acquired by the mature organism, are transmissible. The flurry which this denial created has not yet altogether subsicled, but subsequent observations seem to show that it was quite disproportionate to the real merits of the case. Notwithstanding Professor Weismann's objections, the balance of evidence appears to favor the view that the Lamarckian factor of acquired variations stands as the complement of the Darwinian factor of natural selection in effecting the transmutation of species.

Even though this partial explanation of what Pro- 


\section{'THE CEN'TURY'S PROGRESS IN BIOLOGY}

fessor Cope calls the "origin of the fittest" be accepted, there still remains one great life problem which the doctrine of evolution does not touch. The origin of species, genera, orders, and classes of beings through endless transmutations is in a sense explained; but what of the first term of this long series? Whence came that primordial organism whose transmuted descendants make up the existing faunas and floras of the globe?

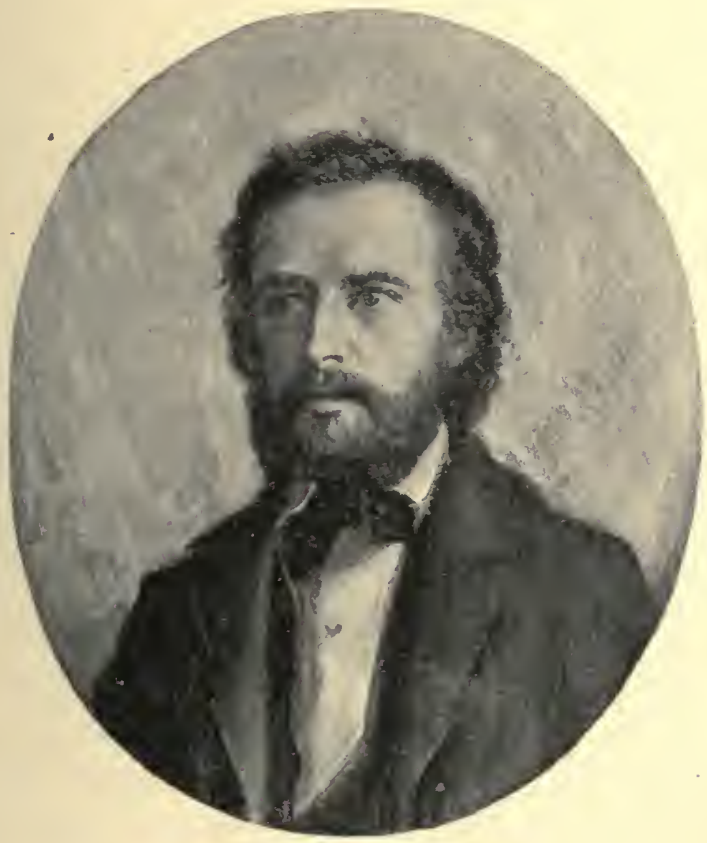

ERNEST HAECKFL

There was a time, soon after the loctrine of evolution gained a hearing, when the answer to that question seemed to some scientists of authority to have been 
given by experiment. Recurring to a former belief, and repeating some earlier experiments, the director of the Museum of Natural History at Rouen, M. F. A. Pouchet, reached the conclusion that organic beings are spontaneously generated about us constantly, in the familiar processes of putrefaction, which were known to be due to the agency of microscopic bacteria. But in 1862 Louis Pasteur proved that this seeming spontaneous generation is in reality due to the existence of germs in the air. Notwithstanding the conclusireness of these experiments, the claims of Pouchet were revived in England ten years later by Professor Bastian; but then the experiments of John Tyudall, fully corroborating the results of Pasteur, gave a final quietus to the claim of "spontaneous generation" as hitherto formulated.

There for the moment the matter rests. But the end is not yet. Fauna and flora are here, and, thanks to Lamarck and Wallace and Darwin, their development, through the operation of those "secondary causes" which we call laws of nature, has been proximally explained. The lowest forms of life have been linked with the highest in unbroken chains of descent. Meantime, through the efforts of chemists and biologists, the gap between the inorganic and the organic worlds, which once seemed almost infinite, has been constantly narrowed. Already philosophy can throw a bridge across that gap. But inductire science, which builds its own bridges, has not yet spanned the chasm, small though it appear. Until it shall have done so, the bridge of organic erolution is not quite complete: yet eren as it stands to-day it is the most stupendous scientific structure of our century. 


\section{CHAPTER $\mathrm{X}$}

\section{THE CENTURY'S PROGRESS IN ANATOII AND}

PHYSIOLOG Y

THE focal points of the physiological world towards the close of the eighteenth century were Italy and England, but when Spallanzani and Hunter passed away the scene shifted to France. The time was peculiarly propitious, as the recent advances in many lines of science had brought fresh data for the student of animal life which were in need of classification, and, as several minds capable of such a task were in the field, it was natural that great generalizations should have come to be quite the fashion. Thus it was that $\mathrm{Cuvier}$ came forward with a brand-new classification of the animal kingdom, establishing four great types of being, which he called vertebrates, molluscs, articulates, and radiates. Lamarck had shortly before established the broad distinction between animals with and those without a backbone; Cuvier's classification divided the latter-the inrertebrates-into three minor groups. And this division, familiar ever since to all students of zoölogy, has only in very recent years been supplanted, and then not by revolution, but by a further division, which the elaborate recent studies of lower forms of hife seemed to make desirable. 


\section{'THE STORY OF' NINETEEN'TH-CENTURY SCIENCE}

In the course of those studies of comparative anatomy which led to his new classification, Cuvier's attention was called constantly to the peculiar co-ordination of parts in each individual organism. Thus an animal with sharp talons for catching living prey-as a member of the cat tribe-has also sharp teeth, adapted for tearing up the flesh of its victim, and a particular type of stomach, quite different from that of herbirorous creatures. This adaptation of all the parts of the animal to one another extends to the most diverse parts of the organism, and enables the skilled anatomist, from the observation of a single typical part, to draw inferences as to the structure of the entire animal-a fact which was of vast aid to Curier in his studies of paleontology. It did not enable Cuvier, nor does it enable any one else, to reconstruct fully the extinct animal from observation of a single bone, as has sometimes been asserted, but what it really does establish, in the hands of an expert, is sufficiently astonishing.

Of course this entire principle, in its broad outlines, is something with which every student of anatomy had been familiar from the time when anatomy was first studied, but the full expression of the "law of co-ordination," as Curier called it, had never been explicitly made before; and notwithstanding its seeming obviousness, the exposition which Cuvier made of it in the introduction to his classical work on comparative anatomy, which was published during the first decade of the century, ranks as a great discovery. It is one of those generalizations which serve as guide-posts to other discovelries.

Much the same thing may be said of another generalization regarding the animal body, which the brilliant 


\section{PROGRESS IN ANATOMY AND PIIYSIOLOGY}

young French physician Marie François Bichat made in calling attention to the fact that each vertebrate organism, including man, has really two quite different sets of

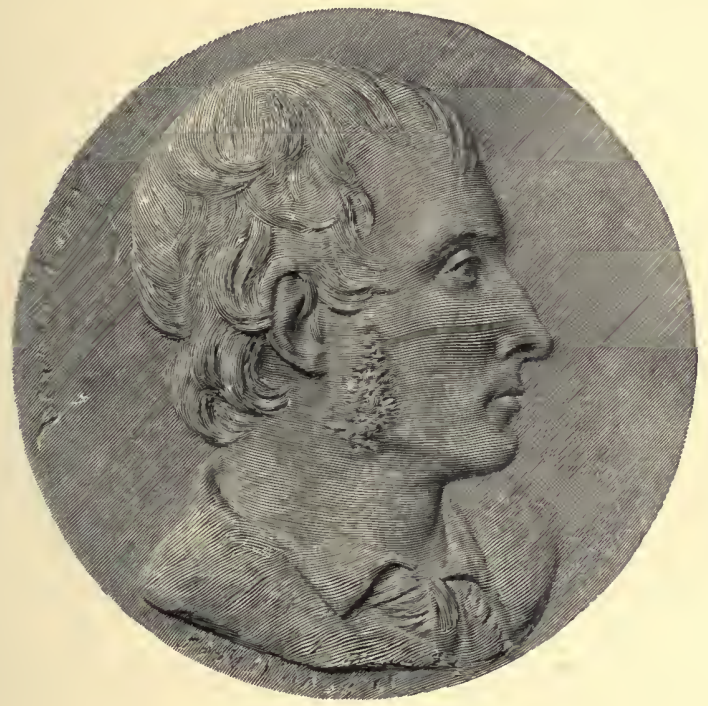

MARIE FRANÇOIS XAVIER BICILAT

From a medallion by David d'Angers

organs--one set under volitional control, and serving the end of locomotion, the other remored from volitional control, and serving the ends of the "vital processes" of digestion, assimilation, and the like. He called these: sets of organs the animal system and the organic system, respectively. The division thus pointed out was not quite new, for Grimaud, professor of physiology in the university of Montpellier, had earlier made what was substantially the same classification of the functions into "internal or digestive and external or locomotive"; 
but it was Bichat's exposition that gave currency to the idea.

Far more important, however, was another classification which Bichat put forward in his work on anatomy, published just at the beginning of the century. This was the division of all animal structures into what Bichat called tissues, and the pointing out that there are really only a few kinds of these in the body, making up all the diverse organs. Thus muscular organs form one system; membranous organs another; glandular organs a third; the vascular mechanism a fourth, and so on. The distinction is so obvious that it seems rather difficult to conceive that it could have been overlooked by the earliest anatomists ; but, in point of fact, it is only obrious because now it has been familiarly taught for almost a century. It had never been given explicit expression before the time of Bichat, though it is said that Bichat himself was somewhat indebted for it to his master, the famous alienist, Pinel.

Howererthat may be, it is certain that all subsequent anatomists have found Bichat's classification of the tis. sues of the utmost value in their studies of the animal functions. Subsequent advances were to show that the distinction between the rarious tissues is not really so fundamental as Bichat supposed, but that takes nothing from the practical value of the famous classification.

At the same time when these broad microscopical distinctions were being drawn there were other workers who were striving to go even deeper into the intricacies of the animal mechanism with the aid of the microscope. 
This undertaking, however, was beset with very great optical difficulties, and for a long time little advance was made upon the work of preceding generations. Two great optical barriers, known technically as spherical and chromatic aberration-the one due to a failure of the rays of light to fall all in one plane when focalized through a lens, the other due to the dispersive action of the lens in breaking the white light into prismatic colors-confronted the makers of microscopic lenses, and seemed all but insuperable. The making of achromatic lenses for telescopes had been accomplished, it is true, by Dolland in the previous century, by the union of lenses of crown glass with those of flint glass, these two materials having different indices of refraction and dispersion. But, aside from the mechanical difficulties which arise when the lens is of the minute dimensions required for use with the microscope, other perplexities are introduced by the fact that the use of a wide pencil of light is a desideratum, in order to gain sufficient illumination when large magnification is to be secured.

In the attempt to overcome these difficulties, the foremost physical philosophers of the time came to the aid of the best opticians. Very early in the century, Dr. (afterwards Sir Darid) Brewster, the renowned Scotch physicist, suggested that certain advantages might accrue from the use of such gems as have high refractive and low dispersire indices, in place of lenses made of glass. Accordingly lenses were made of diamond, of sapphire, and so on, and with some measure of success. But in 1812 a much more important innoration was introduced by Dr. William Hyde Wollaston, one of the greatest and most versatile, and since the death of Cavendish by far the most eccentric, of English natural philosopher's. 


\section{THE STORY OF NINETEENTH-CENTURY SCIENCE}

This was the suggestion to use two plano-convex lenses, placed at a prescribed distance apart, in lieu of the single double convex lens generally used. This combination largely overcame the spherical aberration, and it gained immediate fame as the "Wollaston doublet."

To obviate loss of light

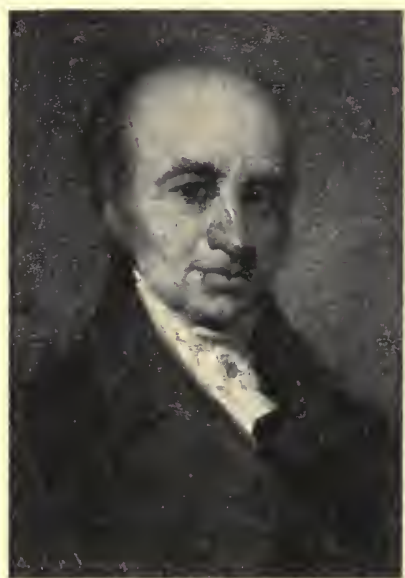

WILLIAM HYDE WOLLASTON in such a doublet from increase of reflecting surfaces, Dr. Brewster suggested filling the interspace between the two lenses with a cement having the same index of refraction as the lenses theinselves - an improvement of manifest advantage. An improvement yet more important was made by Dr. Wollaston himself, in the introduction of the diaphragm to limit the field of vision between the lenses, instead of in front of the anterior lens. A pair of lenses thus equipped, Dr. Wollaston called the periscopic microscope. Dr. Brewster suggested that in such a lens the same object might be attained with greater ease by grinding an equatorial groove about a thick or globular lens and filling the groove with an opaque cement. This arrangement found much favor, and came subsequently to be known as a Coddington lens, though Mr. Coddington laid no claim to being its inventor.

Sir John Herschel, another of the very great physicists of the time, also gave attention to the problem of improving the microscope, and in 1821 he introduced what 
was called an aplanatic combination of lenses, in which, as the name implies, the spherical aberration was largely done away witl. It was thought that the use of this Herschel aplanatic combination as an eye-piece, combined with the Wollaston doublet for the objective, came as near perfection as the compound microscope was likely soon to come. But in reality the instrument thus constructed, though doubtless superior to any predecessor, was so defective that for practical purposes the simple microscope, such as the doublet or the Coddington, was preferable to the more complicated one.

Many opticians, indeed, quite despaired of ever being able to make a satisfactory refracting compound microscope, and some of them had taken up anew Sir Isaac Newton's suggestion in reference to a reflecting microscope. In particular, Professor Giovanni Battista Amici, a very famous mathematician and practical optician of Modena, succeeded in constructing a reflecting microscope which was said to be superıor to any compound microscope of the time, though the events of the ensuing years were destined to rob it of all but historical value. For there were others, fortunately, who did not despair of the possibilities of the refracting microscope, and their efforts were destined before long to be crowned with a degree of success not even dreained of by any preceding generation.

The man to whom chief credit is due for directing those final steps that made the compound microscope a practical implement instead of a scientific toy was the English amateur optician Joseph Jackson Lister. Combining mathematical knowledge with mechanical ingenuity, and having the practical aid of the celebrated optician Tulley, he devised formulæ for the combination 
of lenses of crown glass with others of flint glass, so adjusted that the refractive errors of one were corrected or compensated by the other, with the result of producing lenses of hitherto unequalled powers of definition; lenses capable of showing an image highly magnified, yet relatively free from those distortions and fringes of color that had heretofore been so disastrous to true interpretation of magnified structures.

Lister had begun his studies of the lens in 182t, but i.t was not until 1830 that he contributed to the Royal Society the famous paper detailing his theories and experiments. Soon after this various Continental opticians who had long been working along similar lines took the matter up, and their expositions, in particular that of Amici, introduced the improved compound microscope to the attention of microscopists every where. And it required but the most casual trial to convince the experienced observers that a new implement of scientific research had, been placed in their hands which carried them a long step nearer the observation of the intimate physical processes which lie at the foundation of vital phenomena. For the physiologist, this perfection of the compound microscope had the same significance that the discovery of America had for the fifteenthcentury geographers - it promised a veritable world of utterly novel revelations. Nor was the fulfilment of that promise long delayed.

Indeed, so numerous and so important were the discoveries now made in the realm of minute anatomy that the rise of listology to the rank of an independent sci- 


\section{PROGRESS IN ANATOMY AND PHYSIOLOGY}

ence may be said to date from this period. Hitherto, ever since the discovery of magnifying-glasses, there had been here and there a man, such as Leuwenhoek or Malpighi, gifted with exceptional vision, and perhaps unusually happy in his conjectures, who made important contributions to the knowledge of the minute structure of organic tissues; but now of a sudden it became possible for the veriest tyro to confirm or refute the laborious observations of these pioneers, while the skilled observer could step easily beyond the barriers of vision hitherto quite impassable. And so, naturally enough, the physiologists of the fourth decade of our century rushed as eagerly into the new realm of the microscope as, for example, their successors of to-day are exploring the realm of the $\mathrm{X}$ ray.

Lister himself, who had become an eager interrogator of the instrument he had perfected, made many important discoveries, the most notable being his final settlement of the long-mooted question as to the true form of the red corpuscles of the human blood. In reality, as everybody knows nowadays, these are biconcave disks, but owing to their peculiar figure it is easily possible to misinterpret the appearances they present when seen through a poor lens, and though Dr. Thomas Young and various other observers had come very near the truth regarding them, unanimity of opinion was possible only after the verdict of the perfected microscope was given.

These blood corpuscles are so infinitesimal in size that something like fire millions of them are found in each cubic millimetre of the blood, yet they are isolated particles, each having, so to speak, its own personality. This, of course, had been known to microscopists since 329 
the days of the earliest lenses. It had been noticed, too, by here and there an observer, that certain of the solid tissues seemed to present something of a granular texture, as if they too, in their ultimate constitution, were made up of particles. And now, as better and better lenses were constructed, this idea gained ground constantly, though for a time no one saw its full signif. icance. In the case of vegetable tissues, indeed, the fact that little particles encased in a membranous covering, and called cells, are the ultimate risible units of structure had long been known.

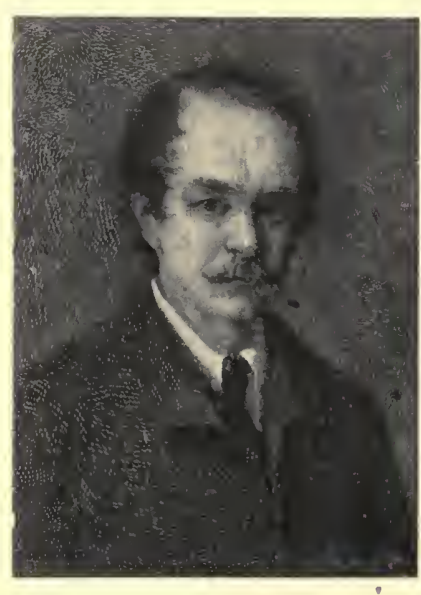

MATTHIAS JAKOH SCHLEIDEN

But it was supposed that animal tissues differed radically from this construction. The elementary particles of vegetables "were regarded to a certain extent as individuals which composed the entire plant, while, on the other hand, no such view was taken of the elementary parts of animals."

In the year 1833 a further insight into the nature of the ultimate particles of plants was gained through the observation of the English microscopist Robert Brown, who, in the course of his microscopic studies of the epidermis of orchids, discovered in the cells "an opaque spot," which he named the nucleus. Doubtless the same "spot" had been seen often enough before by other observers, but Brown was the first to recognize it as a component part of the vegetable cell, and to give it 330 
a name. That this newly recognized structure must be important in the economy of the cell was recognized by Brown himself, and by the celebrated German Meyen, who dealt with it in his work on vegetable physiology, published not long afterwards; but it remained for another German, 'the professol' of botany in the university of Jena, Dr. M. J. Sclleiden, to bring the nucleus to popular attention, and to assert its all-importance in the economy of the cell.

Schleiden freely acknowledged his indebtedness to Brown for first knowledge of the nucleus, but he soon carried his studies of that structure far beyond those of its discoverer. He came to believe that the nucleus is really the most important portion of the cell, in that it is the original structure from which the remainder of the cell is developed. Hence he namell it the cytoblast. He outlined his riews in an epochal paper published in Müller's Archives in 1835, under title of "Beitrage zur Phytogenesis." This paper is in itself of value, yet the most important outgrowth of Schleiden's observations of the nucleus did not spring from his own labors, but from those of a friend to whom he mentioned his discoveries the year previous to their publication. This friend was Dr. Theodor Schwann, professor of physiology in the university of Louvain.

At the moinent when these observations were communicated to him Schwann was puzzling over certain details of animal histology which he could not clearly explain. His great teacher, Johannes Müller, had called attention to the strange resemblance to vegetable cells shown by certain cells of the chorda dor'salis (the embryonic cold from which the spinal column is developed), and Schwann himself liad discovered a corre- 


\section{THE STORY OF NINETEENTH-CENTURY SCIENCE}

sponding similarity in the branchial cartilage of a tadpole. Then, too, the researches of Friedrich Henle had shown that the particles that make up the epiciermis of animals are very cell-like in appearance. Indeed, the cell-like character of certain animal tissues had come to be matter of common note among students of minute anatomy. Schwann felt that this similarity could not be mere coincidence, but he had gained no clew to further insight until Schleiden called his attention to the nucleus. Then at once he reasoned that if there really is the correspondence between vegretable and animal tissues that he suspected, and if the nucleus is so important in the regetable cell as Schleiden believed, the nucleus should also be found in the ultimate particles of animal tissues.

Schwann's researches soon showed the entire correctness of this assumption. A closer study of animal tissues uncler the microscope showed, particularly in the case of embryonic tissues, that "opaque spots" such as Schleiden described are really to be found there in abundance - forming, indeed. a most characteristic phase of the structure. The location of these nuclei at comparatively regular intervals suggested that they are found in definite compartments of the tissue, as Schleiden had shown to be the case with regetables; indeed, the walls that separated such cell.like compartments one from another were in some cases visible. Particularly was this found to be the case with embryonic tissues, and the study of these soon convinced Schwann that his original surmise had been correct, and that all animal tissues are in their incipiency composed of particles not unlike the ultimate particles of regetables-in short, of what the botanists termed cells. Adopting this name, 


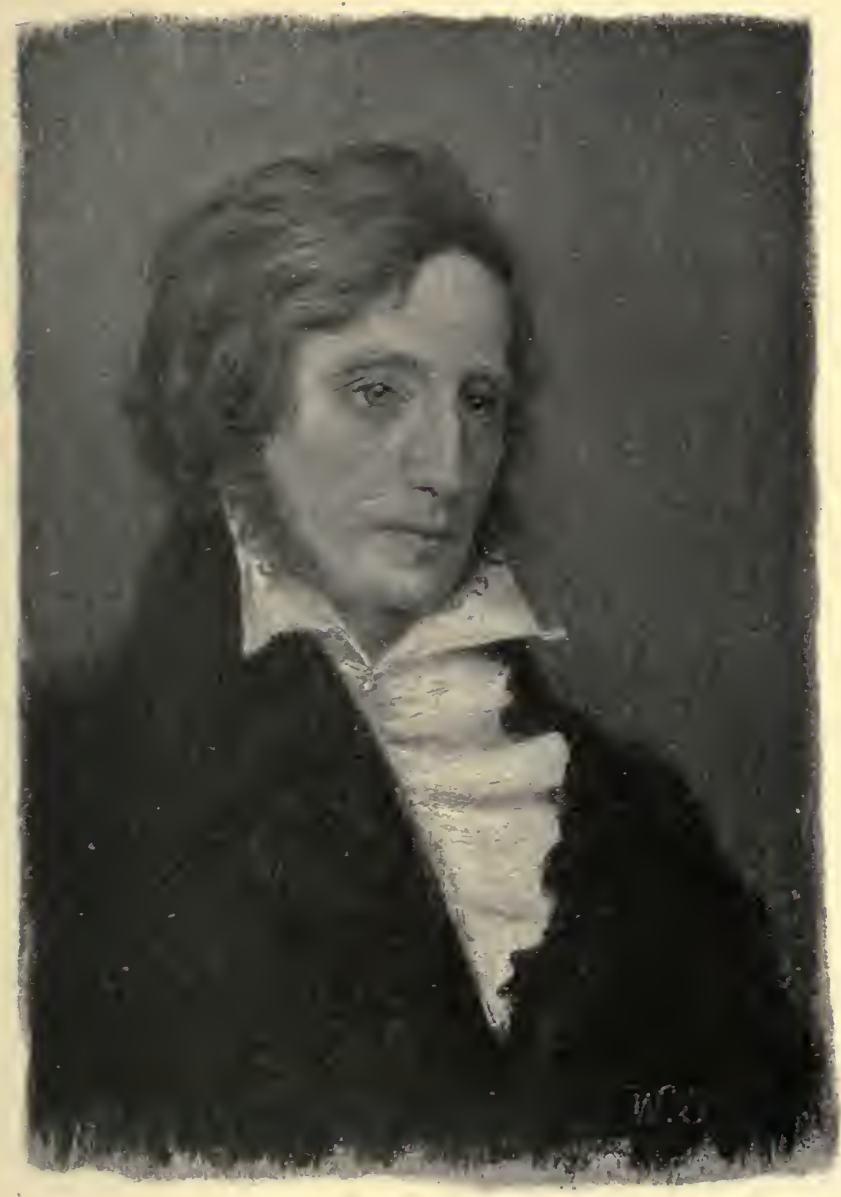

KARL EIRST VON BAER 

Schwann propounded what soon became famous as his cell theory, under title of Mikroskopische Untersuchungen über die Uebereinstimmung in der Structur und dem Wachsthum der Thiere und Pfanzen. So expeditious had been his work, that this book was published early in 1839 , only a few months after the appearance of Schleiden's paper.

As the title suggests, the main idea that actuated Schwann was to unify vegetable and animal tissues. Accepting cell-structure as the basis of all vegetable tissues, he sought to show that the same is true of animal tissues, all the seeming diversities of fibre being but the alteration and development of what were originally simple cells. And by cell Schwann meant, as did Schleiden also, what the word ordinarily implies - a cavity walled in on all sides. He conceived that the ultimate constituents of all tissues were really such minute cavities, the most important part of which was the cell wall, with its associated nucleus. He knew, indeed, that the cell might be filled with fluid contents, but he regarded these as relatively subordinate in importance to the wall itself. 'This, however, did not apply to the nucleus, which was supposed to lie against the cell wall, and in the beginning to generate it. Subsequently the wall might grow so rapidly as to dissociate itself from its contents, thus becoming a hollow bubble or true cell; but the nucleus, as long as it lasted, was supposed to continue in contact with the cell wall. Schleiden had even supposed the nucleus to be a constituent part of the wall, sometimes lying enclosed between two layers of its substance, and Schwann quoted this view with seeming approval. Schwann beliered, however, that in the mature cell the nucleus ceased to be functional, and disappeared. 
The main thesis as to the similarity of derelopment of regetable and animal tissues, and the cellular nature of the ultimate constitution of both, was supported by a mass of carefully gathered evidence which a multitude of microscopists at once confirmed, so Schwann's work became a classic almost from the moment of its publication. Of course various other workers at once disputed Schwann's claim to priority of discorery, in particu. lar the English microscopist Valentin, who asserted, not without some show of justice, that he was working closely along the same lines. But so, for that matter, were numerous others, as Henle, Turpin, Dumortier, Purkinje, and Müller, all of whom Schwann himself had quoted. Moreover, there were various physiologists who earlier than any of these had foreshadowed the cell theory; notably Kaspar Friedrich Wolff, towards the close of the previous century, and Treviranus about 1807 . But, as we hare seen in so many other departments of science, it is one thing to foreshadow a discorery, it is quite another to give it full expression and make it germinal of other discoveries. And when Schwann put forward the explicit claim that "there is one unirersal principle of derelopment for the elementary parts of organisms, however different, and this principle is the formation of cells," he enunciated a doctrine which was for all practical purposes absolutely'new, and opened up a novel field for the microscopist to enter. A most important era in physiology dates from the publication of his book in 1839 .

\section{IV}

That Schwann should have gone to embryonic tissues for the establishment of his ideas was no doubt due very 


\section{PROGRESS IN ANATONY AND PHYSIOLOGY}

largely to the influence of the great Russian, Karl Ernst von Baer, who about ten years earlier had published the first part of his celebrated work on embryology, and

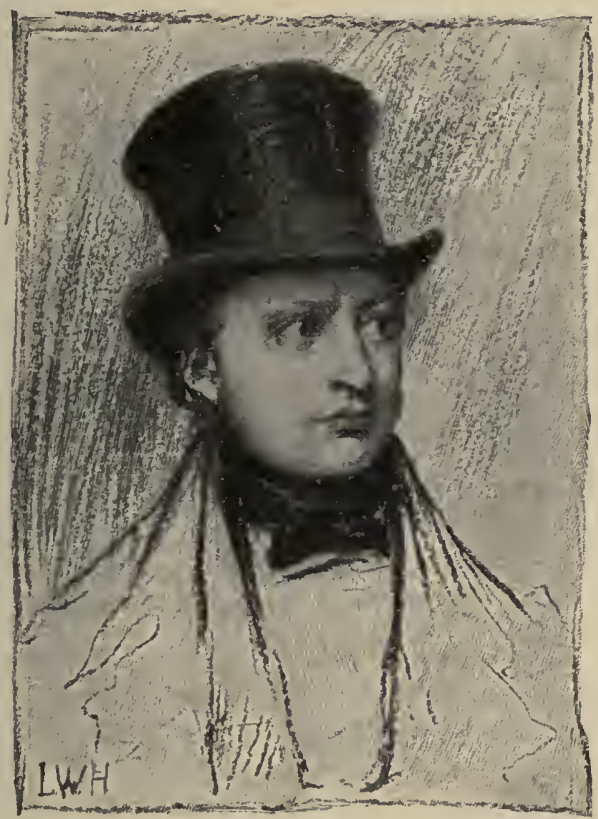

JOHANМES MÜLIER

whose ideas were rapidly gaining ground, thanks largely to the advocacy of a few men, notably Johannes Müller in Germany, and William B. Carpenter in England, and to the fact that the improved microscope had made minute anatomy popular. Schwann's researches made it plain that the best field for the study of the animal cell is here, and a host of explorers entered the field. The result of their obserrations was, in the main, to con- 
firm the claims of Schwann as to the unirersal prevalence of the cell. The long-current idea that animal tissues grow only as a sort of deposit from the bloodvessels was now discarded, and the fact of so-called plant-like growth of animal cells, for which Schwann contended, was universally accepted. Yet the full measure of the affinity between the two classes of cells was not for some time generally apprehended.

Indeed, since the substance that composes the cell walls of plants is manifestly very different from the limiting mombrane of the animal cell, it was natural, so long as the wall was considered the most essential part of the structure, that the divergence between the two classes of cells should seem very pronounced. And for a time this was the conception of the matter that was uniformly accepted. But as time went on many observers had their attention called to the peculiar characteristics of the contents of the cell, and were led to ask themselves whether these might not be more important than had been supposed. In particular Dr. Hugo von Mohl, professor of botany in the university of Tübingen, in the course of his exhaustive studies of the vegetable cell, was impressed with the peculiar and characteristic appearance of the cell contents. He observed universally within the cell "an opaque, viscid fluid, having granules intermingled in it," which made up the main substance of the cell, and which particularly impressed him because under certain conditions it could be seen to be actively in motion, its parts separated into filamentous streams.

Von Mohl called attention to the fact that this motion of the cell contents had been observed as long ago as 1774 by Bonaventura Corti, and rediscovered in 1807 
by Treviranus, and that these observers had described the phenomenon under the "most unsuitable name of 'rotation of the cell sap.'" Von Mohl recognized that the streaming substance was something quite different from sap. He asserted that the nucleus of the cell lies within this substance, and not attached to the cell wall as Schleiden had contended. He saw, too, that the chlorophyl granules, and all other of the cell contents, are incorporated with the "opaque, riscid fluid," and in 1846 he had become so impressed with the importance of this universal cell substance that he gave it

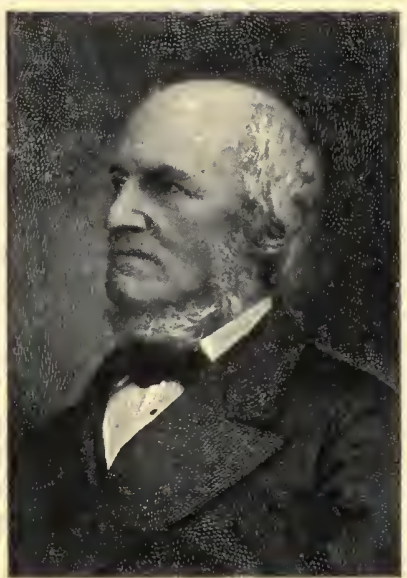

WILIAM BLNJAMIN CARPKSTER Photographed by Elliot and Fry, London the name of protoplasm. Yet in so doing he had no intention of subordinating the cell wall. The fact that Payen in 1844 , had demonstrated that the cell walls of all vegetables, high or low, are composed largely of one substance, cellulose, tended to strengthen the position of the cell wall as the really essential structure, of which the protoplasmic contents were only subsidiary produets.

Meantime, however, the students of animal histology were more and more impressed with the seeming preponderance of cell contents over cell walls in the tissues they studied. They too found the cell to be filled with a viscid, slimy fluid, capable of motion. To this $\mathrm{Du}$ jardin gave the name of sarcode. Presently it came to 


\section{THE STORY OF NINETEENTH-CENTURY SCIENCE}

be known, through the labors of Kölliker, Nägeli, Bis. choff, and various others, that there are numerous lower forms of animal life which seem to be composed of this sarcode, without any cell wall whaterer. The same thing seemed to be true of certain cells of higher organisms, as the blood corpuscles. Particularly in the case of cells that change their shape inarkedly, moving about in consequence of the streaming of their sarcode, did it seem certain that no cell wall is present; or that, if present, its rôle must be insignificant.

And so histologists came to question whether, after all, the cell contents rather than the enclosing wall must not be the really essential structure, and the weight of increasing observations finally left no escape from the conclusion that such is really the case. But attention being thus focalized on the cell contents, it was at once apparent that there is a far closer similarity between the ultimate particles of vegetables and those of animals than had been supposed. Cellulose and animal membrane being now regarded as mere by-products, the way was clear for the recognition of the fact that vegetable protoplasm and animal sarcode are marvellously similar in appearance and general properties. The closer the observation the more striking seemed this similarity; and finally, about 1860, it was demonstrated by Heinrich de Bary and by Max Schultze that the two are to all intents and purposes identical. Even earlier Remak had reached a similar conclusion, and applied ron Mohl's word protoplasm to animal cell contents, and now this application soon became universal. Thenceforth this protoplasm was to assume the utmost importance in the physiological world, being recognized as the universal "physical basis of life," regetable and animal 


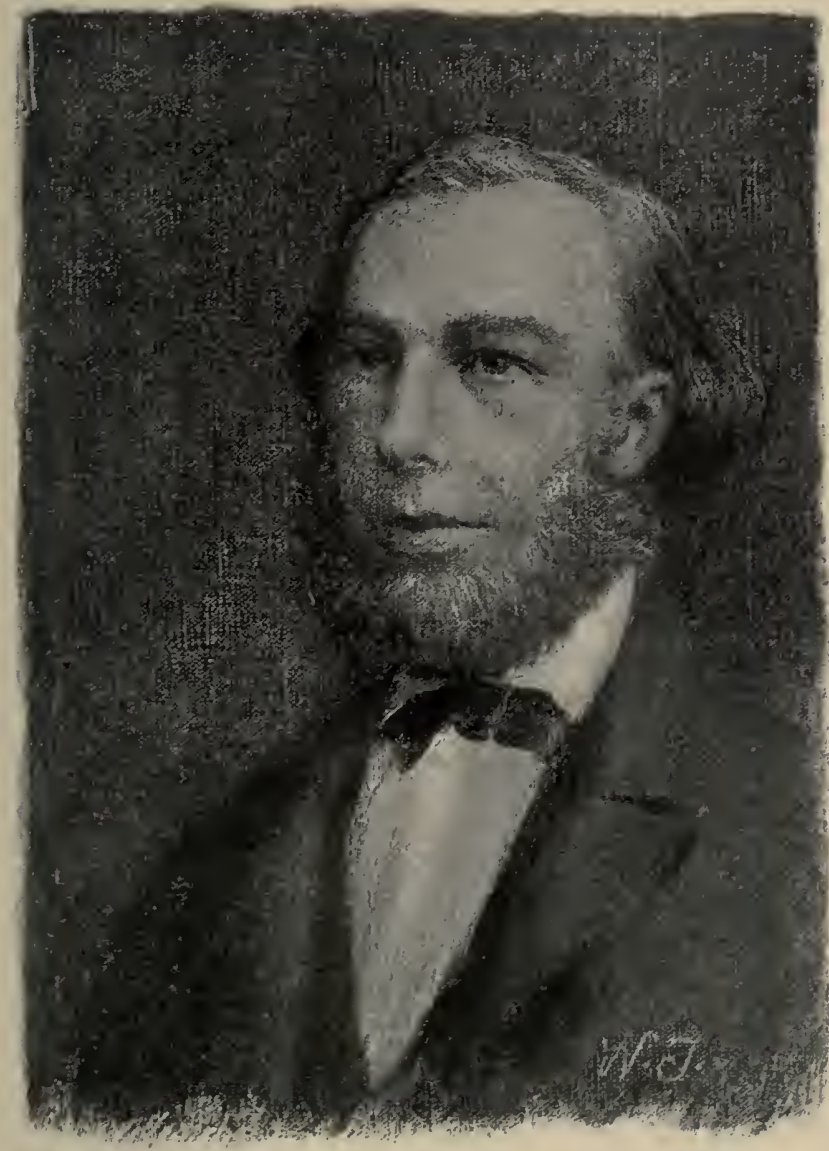

MAX SCHULTZE 

alike. This amounted to the logical extension and culmination of Schwanu's doctrine as to the similarity of development of the two animate kingdoms. Yet at the same time it was in effect the banishment of the cell that Schwann had defined. The word cell was retained, it is true, but it no longer signified a minute cavity. It now implied, as Schultze defined it, "a small mass of protoplasm endowed with the attributes of life." This definition was destined presently to meet with yet another modification, as we shall see; but the conception of the protoplasmic mass as the essential ultimate structure, which might or might not surround itself with a protective covering, was a permanent addition to physiological knowledge. The earlier idea had, in effect, declared the shell the most important part of the egg; this developed view assigned to the yolk its true position.

In one other important regard the theory of Schleiden and Schwann now became modified. This referred to the origin of the cell. Schwann had regarded cell growth as a kind of crystallization, beginning with the deposit of a nucleus about a granule in the intercellular substance - the cytoblastema, as Schleiden called it. But von Mohl, as early as 1835 , had called attention to the formation of new regetable cells through the division of a pre-existing cell. Ehrenberg, another high authority of the time, contended that no such division occurs, and the inatter was still in dispute when Schleiden came forward with his discovery of so-called free cell formation within the parent cell, and this for a long time diverted attention from the process of division which von Mohl had described. All manner of schemes of cell formation were put forward during the ensuing 343 
years by a multitude of observers, and gained currency notwithstanding von Mohl's reiterated contention that there are really but two ways in which the formation of new cells takes place, namely, "first, through division of older cells; secondly, through the formation of secondary cells lying free in the cavity of a cell."

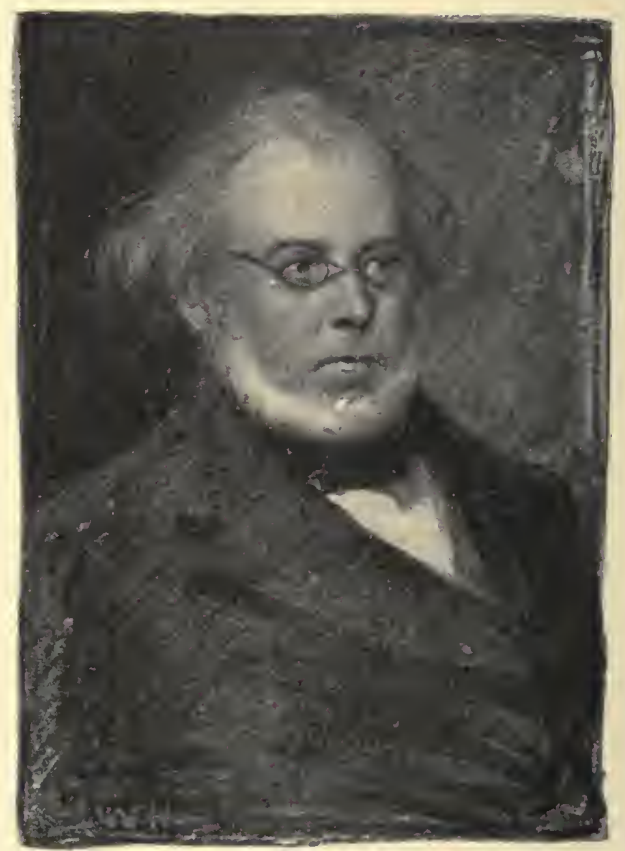

HUGO VON MOHL,

But gradually the researches of such accurate observ. ers as Unger, Nägeli, Kölliker, Reichart, and Remak tended to confirm the opinion of ron Mrohl that cells spring only from cells, and finally Rudolf Virchow brought the matter to demonstration about 1560 . His 344 


\section{PROGRESS IN ANATOMY AND PHYSIOLOGY}

Omnis cellula e cellula became from that time one of the accepted data of physiology. This was supplemented a little later by Fleming's Omnis nucleus e nucleo, when still more refined methods of observation had shown that the part of the cell which always first undergoes change preparatory to new cell formation is the allessential nucleus. Thus the nucleus was restored to the important position which Schwann and Schleiden had given it, but with greatly altered significance. Instead of being a structure generated de novo from non-cellular substance, and disappearing as soon as its function of cell-formation was accomplished, the nucleus was now known as the central and permanent feature of every cell, indestructible while the cell lives; itself the division-product of a pre-existing nucleus, and the parent, by division of its substance, of other generations of nuclei. The word cell received a final definition as "a small mass of protoplasm supplied with a nucleus."

In this widened and culminating general view of the cell theory it became clear that every animate organism, animal or vegetable, is but a cluster of nucleated cells, all of which, in each indiridual case, are the direct descendants of a single primordial cell of the ovum. In the developed individuals of higher organisms the successive generations of cells become marvellously diversified in form and in specific functions; there is a wonderful division of labor, special functions being chiefly relegated to definite groups of cells; but from first to last there is no function developed that is not present, in a primitive way, in every cell, however isolated; nor does the developed cell, however specialized, ever forget altogether any one of its primordial functions or capacities. All physiology, then, properly interpreted, becomes merely 


\section{THE STORY OF NINETEENTH-CENTURY SCIENCE}

a study of cellular activities; and the development of the cell theory takes its place as the great central generalization in physiology of our century. Something of the later developments of this theory we shall see in another connection.

$\nabla$

Just at the time when the microscope was opening up the paths that were to lead to the wonderful cell theory, another novel line of interrogation of the living organism was being

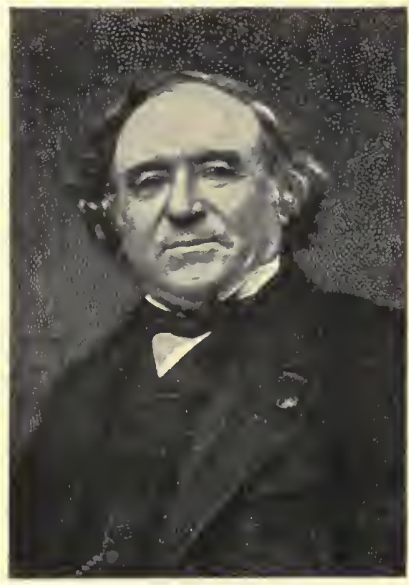

JEAN BAPTISTE DUMAS put forward'by a different set of observers. Two great schools of physiological chemistry had arisen - one under guidance of Liebig and Wöhler in Germany, the other dominated by the great French master Jean Baptiste Dumas. Liebig had at one time contemplated the study of medicine, and Dumas had achieved distinction in connection with Prevost at Genera in the field of pure physiology before he turned his attention especially to chemistry. Both these masters, therefore, and Wöhler as well, found absorbing interest in those phases of chemistry that have to do with the functions of living tissues; and it was largely through their efforts and the labors of their followers that the prevalent iclea that rital processes are dominated by unique laws was discarded and physiology 


\section{PROGRESS IN ANATONY AND PHISIOLOGY}

was brought within the recognized province of the chemist. So at about the time when the microscope had taught that the cell is the really essential structure of the living organism, the chemists had come to understand that every function of the organism is really the expression of a chemical change-that each cell is, in short, a miniature chemical laboratory. And it was this combined point of view of anatomist and chemist, this union of hitherto dissociated forces, that made possible the inroads into the unexplored fields of physiology that were effected towards the middle of our century.

One of the first subjects reinvestigated and brought to proximal solution was the long-mooted question of the digestion of foods. Spallanzani and Hunter had shown in the previous century that digestion is in some sort a solution of foods; but little advance was made upon their work until 1824, when Prout detected the presence of hydrochloric acid in the gastric juice. A decade later Sprott and Boyd detected the existence of peculiar glands in the gastric mucous membrane; and Cagniard la Tour and Schwann independently discovered that the really active principle of the gastric juice is a substance which was named pepsin, and which was shown by Schwann to be active in the presence of hydrochloric acid.

Almost coincidently, in 1836 , it was discovered by Purkinje and Pappenheim that another organ than the stomach-the pancreas, namely-has a share in digestion, and in the course of the ensuing decade it came to be known, through the efforts of Eberle, Valentin, and Claude Bernard, that this organ is all-important in the digestion of starchy and fatty foods. It was found, too, 


\section{THE STORY OF NINETEENTH-CENTURY SCIENCE}

that the liver and the intestinal glands have each an important share in the work of preparing foods for absorption, as also has the saliva-that, in short, a coalition of forces is necessary for the digestion of all ordinary foods taken into the stomach.

And the chemists soon discovered that in each one of the essential digestive juices there is at least one substance having certain resemblances to pepsin, though acting on different kinds of food. The point of resemblance between all these essential digestire agents is that each has the remarkable property of acting on relatively enormous quantities of the substance which it can digest without itself being destroyed or apparently even altered. In rirtue of this strange property, pepsin and the allied substances were spoken of as ferments, but more recently it is customary to distingush thein from such organized ferments as yeast by designating them enzymes. The isolation of these enzymes, and an appreciation of their mode of action, mark a long step towards the solution of the riddle of digestion, but it must be added that we are still quite in the dark as to the real ultimate nature of their strange activity.

In a comprehensive view, the digestive organs, taken as a whole, are a gateway between the outside world and the more intimate cells of the organism. Another equally important gateway is furnished by the lungs, and here also there was much obscurity about the exact method of functioning at the time of the revival of physiological chemistry. That oxygen is consumed and carbonic acid given off during respiration the chemists of the age of Priestley and Lavoisier had indeed made clear, but the mistaken notion prevailed that it was in the lungs themselves that the important burning of fuel 


\section{PROGRESS IN ANATOMY AND PHYSIOLOGY}

occurs, of which carbonic acid is a chief product. But now that attention had been called to the importance of the ultimate cell, this misconception could not long hold its ground, and as early as 1842 Liebig, in the course of his studies of animal heat, became convinced that it is not in the lungs, but in the ultimate tissues to which they are tributaly, that the true consumption of fuel takes place. Reviving Lavoisier's idea, with modifications and additions, Liebig contended, and in the face of opposition finally demonstrated, that the source of animal heat is really the consumption of the fuel taken in through the stomach and the lungs. He showed that all the activities of life are really the product of energy liberated solely through destructive processes, amounting, broadly speaking, to combustion occurring in the ultimate cells of the organism.

Further researches showed that the carriers of oxygen, from the time of its absorption in the lungs till its liberation in the ultimate tissues, are the red corpuscles, whose function had been supposed to be the mechanical one of mixing of the blood. It transpired that the red corpuscles are composed chiefly of a substance which Kiihne first isolated in crystalline form in 1865 , and which was named hæmoglobin-a substance which has a marvellous affinity for oxygen, seizing on it eagerly at the lungs, yet giving it up with equal readiness when coursing among the remote cells of the body. When freighted with oxygen it becomes oxyhæmoglobin, and is red in color; when freed from its oxygen it takes a purple hue; hence the widely different appearance of arterial and venous blood, which so puzzled the early physiologists.

This proof of the vitally important rôle played by the 349 
red blood corpuscles led, naturally, to renewed studies of these infinitesimal boclies. It was found that they may vary greatly in number at different periods in the life of the same individual, proving that they may be both devoloped and destroyed in the adult organism. Indeed, extended observations left no reason to doubt that the process of corpuscle formation and destruction may be a perfectly normal one; that, in short, every red blood corpuscle runs its course and dies like any more elaborate organism. They are formed constantly in the red marrow of bones, and are destroyed in the liver, where they contribute to the formation of the coloring matter of the bile. Whether there are other seats of such manufacture and destruction of the corpuscles is not yet fully determined. Nor are histologists agreed as to whether the red blood corpuscles themselves are to be regarded as true cells, or merely as fragments of cells budded out from a true cell for a special purpose; but, in either case, there is not the slightest doubt that the chief function of the red corpuscle is to carry oxygen.

If the oxygen is taken to the ultimate cells before combining with the combustibles it is to consume, it goes without saying that these combustibles themselves must be carried there also. Nor could it be in doubt that the chiefest of these ultimate tissues, as regards quantity of fuel required, are the muscles. A general and comprehensive view of the organism includes, then, digestive apparatus and lungs as the channels of fuelsupply; blood and lympli channels as the transportation system; and muscle cells, united into muscle fibres, as the consumption furnaces, where fuel is burned and energy transformed and rendered available for the pur$-350$ 


\section{PROGRESS IN ANATOMY AND PHYSIOLOGY}

poses of the organism, supplemented by a set of excretory organs, through which the waste productsthe ashes-are eliminated from the system.

But there remain, broadly speaking, two other sets of organs whose size demonstrates their importance in the economy of the organism, yet whose functions are not accounted for in this synopsis. These are those glandlike organs, such as the spleen, which have no duct and produce no visible secretions; and the nervous mechanism, whose central organs are the brain and spinal cord. What offices

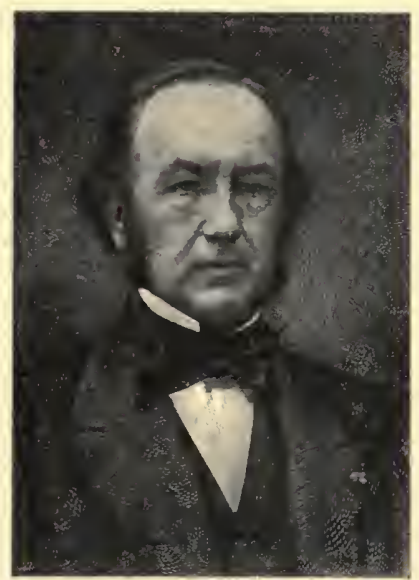

Clatbe bersaro do these sets of organs perform in the great labor-specializing aggregation of cells which we call a living organisin?

As regards the ductless glands, the first clew to their function was given when the great Frenchman Claude Bernard (the man of whom his admirers loved to say, "he is not a physiologist merely; he is physiology itself") discovered what is spoken of as the glycogenic function of the liver. The liver itself, indeed, is not a ductless organ, but the quantity of its biliary output seems utterly disproportionate to its enormous size, particularly when it is considered that in the case of the human species the liver contains normally about onefifth of all the blood in the entire body. Bernard discovered that the blood undergoes a change of composi- 
tion in passing through the liver. The liver cells (the peculiar forms of which had been described by Purkinje, Henle, and Dutrochet about 1838) have the power to convert certain of the substances that come to them into a starchlike compound called glycogen, and to store this substance away till it is needed by the organism. This capacity of the liver cells is quite independent of the bile-making power of the same cells; hence the discorery of this glycogenic function showed that an organ may have more than one pronounced and important specific function. But its chief importance was in giving a clew to those intermediate processes between digestion and final assimilation that are now known to be of such vital significance in the economy of the organism.

In the forty-odd years that have elapsed since this pioneer observation of Bernard, numerous facts have come to light showing the extreme importance of such intermediate alterations of food-supplies in the blood as that performed by the liver. It has been shown that the pancreas, the spleen, the thyroid gland, the suprarenal capsules are absolutely essential, each in its own way, to the health of the organism, through metabolic changes which they alone seem capable of performing; and it is suspected that various other tissues, including even the muscles themselves, have somewhat similar metabolic capacities in addition to their recognized functions. But so extremely intricate is the chemistry of the substances invol red that in no single case has the exact nature of the metabolisms wrought by these organs been fully made out. Each is in its way a chemical laboratory indispensable to the right conduct of the organism, but the precise nature of its operations re- 


\section{PROGRESS IN ANATOMY AND PHYSIOLOGY}

mains inscrutable. The rast importance of the operations of these intermediate organs is unquestioned.

A consideration of the functions of that other set of organs known collectively as the nervous system is reserved for a later chapter. 


\section{CHAPTER XI}

\section{THE CENTURY'S PROGRESS IN SCIENTIFIC MEDICINE}

Althovgr Napoleon Bonaparte, First Consul, was not lacking in self-appreciation, he probably did not realize that in selecting a physician for his own needs he was markedly influencing the progress of medical science as a whole. Yet so strangely are cause and effect adjusted in human affairs that this simple act of the First Consul had that very unexpected effect. For the man chosen was the envoy of a new method in medical practice, and the fame which came to him through being physician to the First Consul, and subsequently to the Emperor, enabled him to promulgate the method in a way otherwise impracticable. Hence the indirect but telling value to medical science of Napoleon's selection.

The physician in question was Jean Nicolas de Corvisart. His novel method was nothing more startling than the now familiar procedure of tapping the chest of a patient to elicit sounds indicative of diseased tissues within. Every one has seen this done commonly enough in our day, but at the beginning of the century Corvisart, and perhaps some of his pupils, were probably the only physicians in the world who resorted to 
this simple and useful procedure. Hence Napoleon's surprise when, on calling in Corvisart, after becoming somewhat dissatisfied with his other physicians, Pinel and Portal, his physical condition was interrogated in this strange manner. With characteristic shrewdness Bonaparte saw the utility of the method, and the physician who thus attempted to substitute scientific method for guess-work in the diagnosis of disease at once found favor in his eyes, and was installed as his regular medical adviser.

For fifteen years before this Corvisart had practised percussion, as the chest-tapping method is called, withont succeeding in convincing the profession of its value. The method itself, it should be added, had not originated with Corvisart, nor did the French physician for a moment clain it as his own. The true originator of the practice was the German physician Avenbrugger, who published a wook about it as early as 1761 . This book had eren been translated into French, then the language of international communication everywhere, by Rozière de la Chassagne, of Montpellier, in $17 \% 0$; but no one other than Corvisart appears to have paid any attention to either original or translation. It was far otherwise, however, when Corvisart translated A venbrugger's work anew, with important additions of his own, in 1808. By this time a reaction had set in against the metaphysical methods in medicine that had previously been so alluring; the scientific spirit of the time was making itself felt in medical practice; and this, combined with Corvisart's fame, brought the method of percussion into immediate and well-deserved popularity. Thus was laid the foundation for the method of so-called physical diagnosis, which is one of the corner-stones of modern medicine. 


\section{THE STORY OF NINETEENTH-CENTURY SCIENCE}

The method of physical diagnosis as practised in our day was by no means completed, howerer, with the work of Corvisart. Percussion alone tells much less than half the story that may be elicited from the organs of the chest by proper interrogation. The remainder of the story can only be learned by applying the ear itself to the chest, directly or indirectly. Simple as this seems, no one thought of practising it for some years after Corvisart had shown the value of percussion. Then, in 1815, another Paris physician, René Théophile Hyacinthe Laënnec, discovered, almost by accident, that the sound of the heart-beat could be heard surprisingly through a cylinder of paper held to the ear and against the patient's chest. Acting on the hint thus received, Laënnec substituted a hollow cylinder of wood for the paper, and found himself provided with an instrument through which not merely beart sounds, but murmurs of the lungs in respiration, could be heard with almost startling distinctness.

The possibility of associating the varying chest sounds with diseased conditions of the organs within appealed to the fertile mind of Laënnec as opening new vistas in therapeutics, which he determined to enter to the fullest extent practicable. His connection with the hospitals of Paris gave him full opportunity in this direction, and his labors of the next few years served not merely to establish the value of the new method as an aid to diagnosis, but laid the foundation also for the science of morbid anatomy. In 1819 Laënnec published the results of his labors in a work called Traité d'Auscultation Médiate, a work which forms one of the landmarks of scientific medicine. By mediate auscultation is meant of course the interrogation of the chest with the aid of the little 


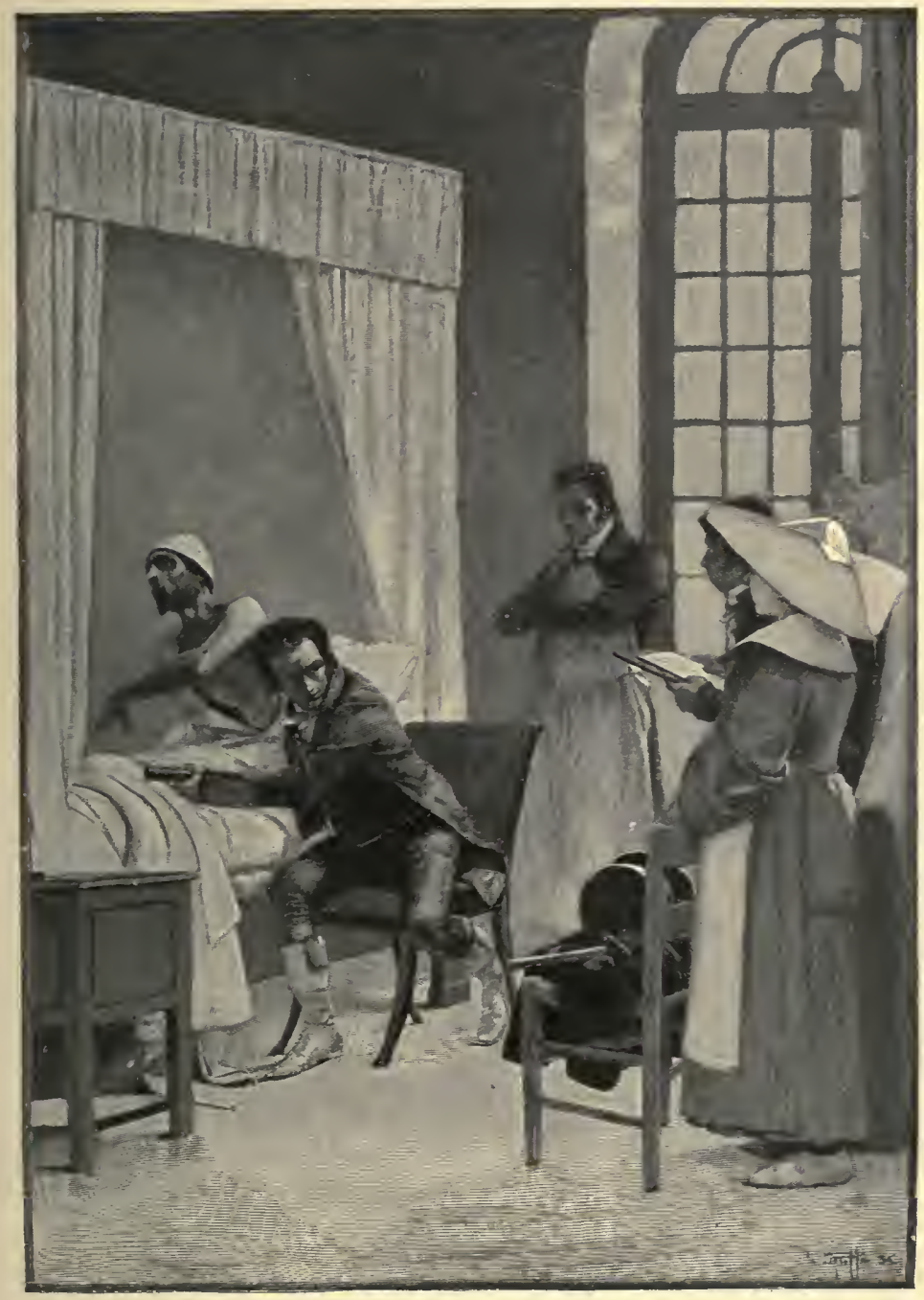

LAENAEC, INVENTOR OF THE STETUOSCOPE, AT THE NECKER HOSPITAL, PARIS 

instrument already referred to, an instrument which its originator thought hardly worth naming until various barbarous appellations were applied to it by others, after which Laënnec decided to call it the stethoscope, a name which it has ever since retained.

In subsequent years the form of the stetloscope, as usually employed, was modified, and its value augmented by a binauricular attachment; and in very recent years a further improvement has been made through application of the principle of the telephone; but the essentials of auscultation with the stethoscope were established in much detail by Laënnec, and the honor must always be his of thus taking one of the longest single steps by which practical medicine has in our century acquired the right to be considered a rational science. Laënnec's efforts cost him his life, for he died in 1826 of a lung disease acquired in the course of his hospital practice; but even before this his fame was universal, and the value of his method had been recognized all over the world. Not long after, in 1828, yet another French physician, Piorry, perfected the method of percussion by introducing the custom of tapping, not the chest directly, but the finger or a small metal or hard rubber plate held against the chest-mediate percussion, in short. This perfected the methods of physical diagnosis of diseases of the chest in all essentials; and from that day till this percussion and auscultation have held an unquestioned place in the regular armamentarium of the physician.

Coupled with the new method of physical diagnosis in the effort to substitute knowledge for guess-work came the studies of the experimental physiologists-in particular, Marshall Hall in England, and François Ma- 
gendie in France; and the joint efforts of these various workers led presently to the abandonment of those se. vere and often irrational depletive methods-blood-letting and the like-that had previously dominated medical practice. To this end also the "statistical method," introduced by Louis and his followers, largely contributed; and by the close of the first third of our century the idea was gaining ground that the province of therapeutics is to aid nature in combating disease, and that this may often be better accomplished by simple means than by the heroic measures hitherto thought necessary. In a word, scientific empiricism was beginning to gain a hearing in medicine, as against the metaphysical pleconceptions of the earlier generations.

II

I have just adverted to the fact that Napoleon Bonaparte, as First Consul and as Emperor, was the victim of a malady which caused him to seek the adrice of the most distinguished physicians of Paris. It is a little shocking to modern sensibilities to read that these physicians, except Corvisart, diagnosed the distinguished patient's malady as "gale répercutée"-that is to say, in idiomatic English, the itch "struck in." It is hardly necessary to say that no physician of to-day would make so inconsiderate a diagnosis in the case of a royal patient. If by any chance a distinguished patient were afflicted with the itch, the sagacious physician would carefully hide the fact behind circumlocutions, and proceed to eradicate the disease with all despatch. That the physicians of Napoleon did otherwise is evidence that at the beginning of the century the disease in ques- 
tion enjoyed a very different status. At that time, itch, instead of being a most plebeian malady, was, so to say, a court disease. It enjoyed a circulation, in high circles and in low, that modern therapeutics has quite denied it; and the physicians of the time gave it a fictitious added importance by ascribing to its influence the existence of almost any obscure malady that came under their observation. Long after Napoleon's time, gale continued to hold this proud distinction. For example, the imaginative Dr. Hahnemann did not hesitate to affirm, as a positive maxim, that three-fourths of all the ills that flesh is heir to were in reality nothing but various forms of "gale répercutée."

All of which goes to show how easy it may be for a masked pretender to impose on credulous humanity; for nothing is more clearly established in modern knowledge than the fact that "gale répelcutée" was simply a name to hide a profound ignorance; no such disease exists, or ever did exist. Gale itself is a sufficiently tangible reality, to be sure; but it is a purely local disease of the skin, due to a perfectly definite cause, and the dire internal conditions formerly ascribed to it have really no causal connection with it whatever. This definite cause, as every one nowadays knows, is nothing more or less than a microscopic insect which has found lodgment on the skin, and has burrowed and made itself at home there. Kill that insect, and the disease is no more; hence it has come to be an axiom with the modern physician that the itch is one of the three or four diseases that he positively is able to cure, and that very speedily. But it was far otherwise with the physicians of the first third of our century, because to them the cause of the disease was an absolute mystery. 


\section{THE STORY OF NINETEENTH-CENTURY SCIENCE}

It is true that here and there a physician had claimed to find an insect lodged in the skin of a sufferer from itch, and two or three times the claim had been made that this was the cause of the malady, but such views were quite ignored by the general profession, and in 1833 it was stated in an authoritative medical treatise that the "cause of gale is absolutely unknown." But even at this time, as it curiously happened, there were certain ignorant laymen who had attained to a bit of medical knowledge that was withheld from the inner circles of the profession. As the peasantry of England before Jenner had known of the curative value of cowpox over small-pox, so the peasant women of Poland had learned that the annoying skin disease from which they suffered was caused by an almost invisible insect, and, furthermore, had acquired the trick of dislodging the pestiferous little creature with the point of a needle. From them a youth of the country, F. Renucci by name, learned the open secret. He conveyed it to Paris when he went there to study medicine, and in 1834 demonstrated it to his master, Alibert. This physician, at first sceptical, soon was convinced, and gave out the discovery to the medical world with an authority that led to early acceptance.

Now the importance of all this, in the present connection, is not at all that it gave the clew to the method of cure of a single disease. What makes the discovery epochal is the fact that it dropped a brand-new idea into the medical ranks-an idea destined, in the longrun, to prove itself a veritable bomb-the idea, namely, that a minute and quite unsuspected animal parasite may be the cause of a well-known, widely prevalent, and important human disease. Of course the full force 
of this idea could only be appreciated in the light of later knowledge; but even at the time of its coming it sufficed to give a great impetus to that new medical knowledge, based on microscopical studies, which had but recently been made accessible by the inventions of the lens-makers. The new knowledge clarified one very turbid medical pool, and pointed the way to the clarification of many others.

Almost at the same time that the Polish medical student was demonstrating the itch mite in Paris, it chanced, curiously enough, that another medical student, this time an Englishman, made an analogous discovery, of perhaps even greater importance. Indeed, this English discovery in its initial stages slightly antedated the other, for it was in 1833 that the student in question, James Paget, interne in Saint Bartholomew's Hospital, London, while dissecting the muscular tissues of a human subject, found little specks of extraneous matter, which, when taken to the professor of comparative anatomy, Richard Owen, were ascertained, with the aid of the microscope, to be the cocoon of a minute and hitherto unknown insect. Owen named the insect Trichina spiralis. After the discovery was published, it transpired that similar specks had been observed by several earlier investigators, but no one had previously suspected, or, at any rate, demonstrated their nature. Nor was the full story of the trichina made out for a long time after Owen's discovery. It was not till 1847 that the American anatomist Dr. Joseph Leidy found the cysts of trichina in the tissues of pork; and another decade or so elapsed after that before German workers, chief among whom were Leuckart, Virchow, and Zenker, proved that the parasite gets into the human sys- 


\section{THE STORY OF NINETEENTH-CENTURY SCIENCE}

tem through ingestion of infected pork, and that it causes a definite set of symptons of disease, which hith-

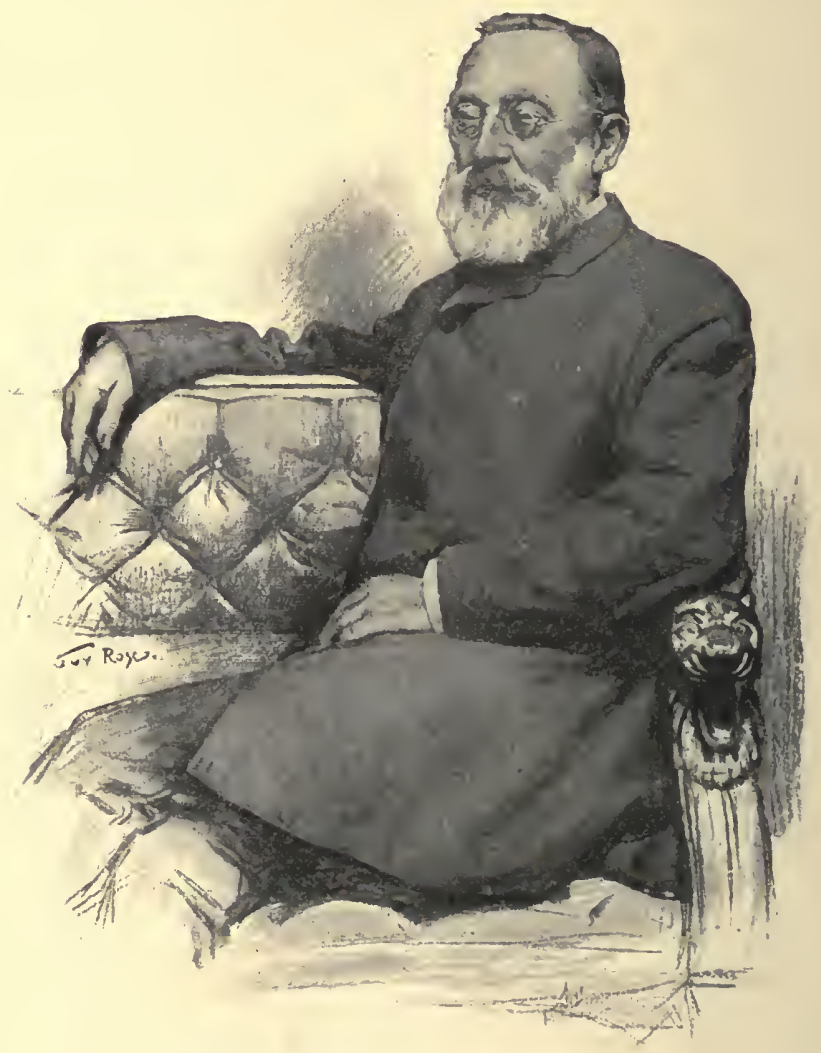

IRUDOLF VIRCHOW

erto had been mistaken for rheumatism, typhoid fever, and other maladies. Then the medical world was agog for a time over the subject of trichinosis ; govermment inspection of pork was established in some parts of Ger- 
many; American pork was excluded altogether from France; and the whole subject thus came prominently to public attention. But important as the trichina parasite proved on its own account in the end, its greatest importance, after all, was in the share it played in directing attention at the time of its discovery in 1833 to the subject of microscopic parasites in general.

The decade that followed that discovery was a time of great actirity in the study of microscopic organisms and microscopic tissues, and such men as Ehrenberg and Henle and Bory Saint Vincent and Kölliker and Rokitansky and Remak and Dujardin were widening the bounds of knowledge of this new subject with details that cannot be mole than referred to here. But the crowning achievement of the period in this direction was the discovery made by the German J. L. Schoenlein in 1839, that a very common and most distressing disease of the scalp, known as farus, is really due to the presence and growth on the scalp of a vegetable organisin of microscopic size. Thus it was made clear that not inerely animal but also regetable organisms of obscure, microscopic species have causal relations to the diseases with which mankind is afflicted. This knowledge of the parasites was another long step in the direction of scientific medical knowledge; but the heights to which this knowledge led were not to be scaled, or even recognized, until another generation of workers had entered the field.

\section{III}

Meantime, in quite another field of medicine, events were developing which led presently to a revelation of greater immediate importance to humanity than any 
other discovery that had come in the century, perhaps in any field of science whatever. This was the discorery of the pain-dispelling power of the vapor of sulphuric ether, inhaled by a patient undergoing a surgical operation. This discovery come solely out of America, and it stands curiously isolated, since apparently no minds in any other country were trending towards it even vaguely. Davy, in England, had indeed originated the method of medication by inhalation, and carried out some most interesting experiments fifty years earlier, and it was doubtless his experiments with nitrous oxide gas that gave the clew to one of the American investigators; but this was the sole contribution of preceding generations to the subject, and since the beginning of the century, when Dary turned his attention to other matters, no one had made the slightest advance along the same line until an American dentist renewed the in restigation. Moreover, there had been nothing in Davy's experiments to show that a surgical operation might be rendered painless in this way; and, indeed, the surgeons of Europe had acknowledged with one accord that all hope of finding a means to secure this most desirable end must be utterly abandoned-that the surgeon's knife must ever remain a synonym for slow and indescribable torture. By an odd coincidence it chanced that Sir Benjamin Brodie, the acknowledged leader of English surgeons, had publicly expressed this as his deliberate though regretted opinion at a time when the quest which he considered futile had already led to the most brilliant success in America, and while the announcement of the discovery, which then had no transatlantic cable to convey it, was actually on its way to the Old World. 


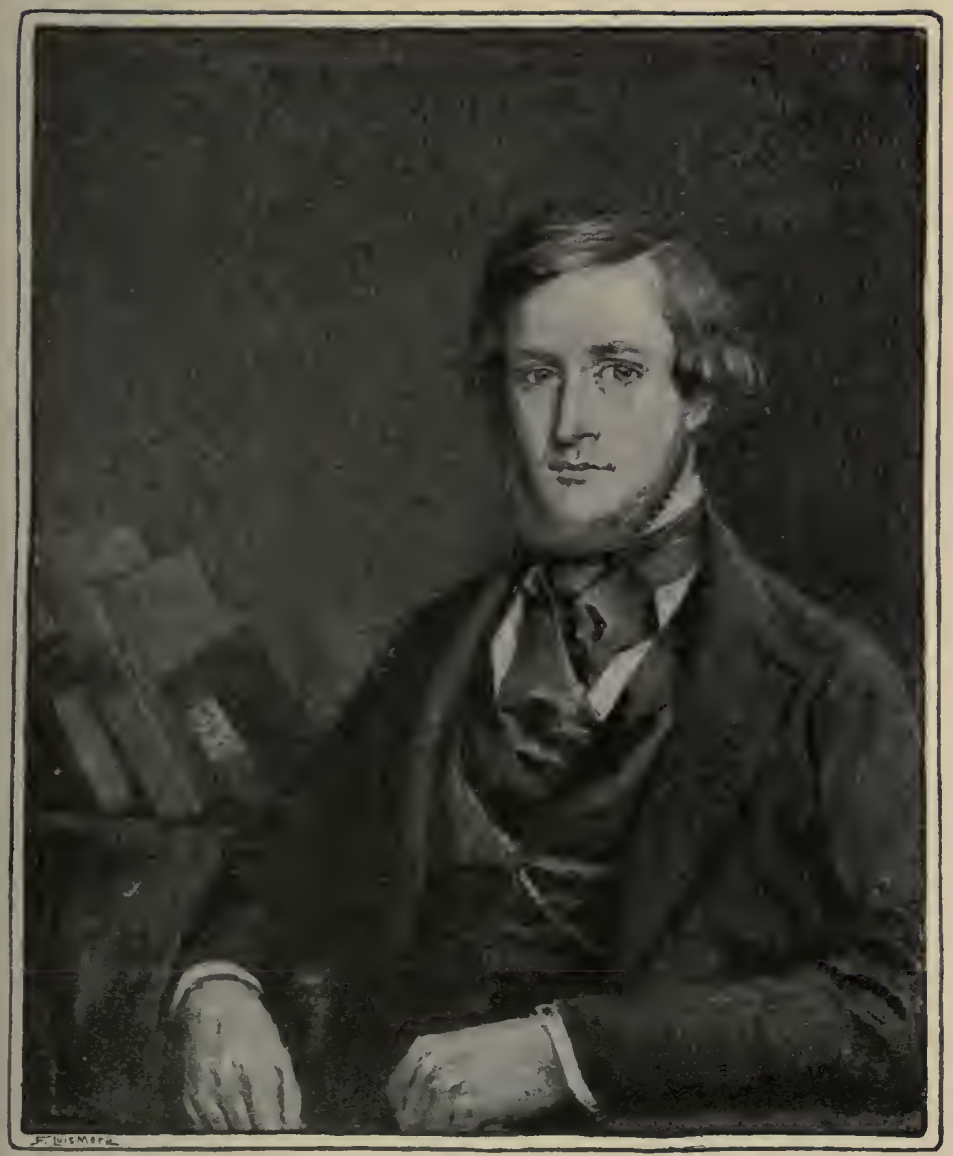

WILLIAM 'T. G. MORTON 

The American dentist just referred to, who was, with one exception to be noted presently, the first man in the world to conceive that the administration of a definite drug might render a surgical operation painless, and to give the belief application, was Dr. Horace Wells, of Hartford, Comnecticut. The drug with which he experimented was nitrous oxide; the operation which he rendered painless was no more important than the extraction of a tooth-yet it sufficed to mark a principle; the year of the experiment was 1844 .

The experiments of Dr. Wells, however, though important, were not sufficiently demonstrative to bring the matter prominently to the attention of the medical world. The drug with which he experimented proved not always reliable, and he himself seems ultimately to have given the matter up, or at least to have relaxed his efforts. But meantime a friend, to whom he had communicated his belief and expectations, took the matter up, and with unremitting zeal carried forward experiments that were destined to lead to more tangible results. This friend was another dentist, Dr. W. T. G. Morton, of Boston, then a young man, full of youthful energy and enthusiasin. He seems to have felt that the drug with which Wells had experimented was not the most practicable one for the purpose, and so for several months he experimented with other allied drugs, until finally he hit upon sulphuric ether, and with this was able to make experiments upon animals, and then upon patients in the dental chair, that seemed to him absolutely demonstrative.

Full of eager enthusiasm, and absolutely confident of his results, he at once went to Dr. J. C. Warren, one of the foremost surgeons of Boston, and asked permission to 
test his discorery decisively on one of the patients at the Boston Hospital during a severe operation. The request was granted; the test was made on October 16, 1S46, in the presence of several of the foremost surgeons of the city and of a body of medical students. The patient slept quietly while the surgeon's knife was plied, and awoke to astonished comprehension that the ordeal was over. The impossible, the miraculous, had been accomplished.

Swiftly as steam could carry it-slowly enough we should think it to-day - the news was heralded to all the world. It was received in Europe with incredulity, which vanished before repeated experiments. Surgeons were loath to believe that etlier, a drug that had long held a place in the subordinate armamentarium of the physician, could accomplish such a miracle. ' But scepticism vanished before the tests which any surgeon might make, and which surgeons all over the world did make within the next few weeks. Then there came a lingering outcry from a few surgeons, notably some of the Parisians, that the shock of pain was beneficial to the patient, hence that anæsthesia-as Dr. Oliver Wendell Holines had christened the new method-was a procedure not to be advised. Then, too, there came a lueand-cry from many a pulpit that pain was God-given, and hence, on moral grounds, to be clung to rather than renounced. But the outcry of the antediluvians of both hospital and pulpit quickly received its quietus; for soon it was clear that the patient who did not suffer the shock of pain during an operation rallied better than the one who did so suffer, while all humanity outside the pulpit cried shame to the spirit that would doom mankind to suffer needless agony. And so within a few 370 


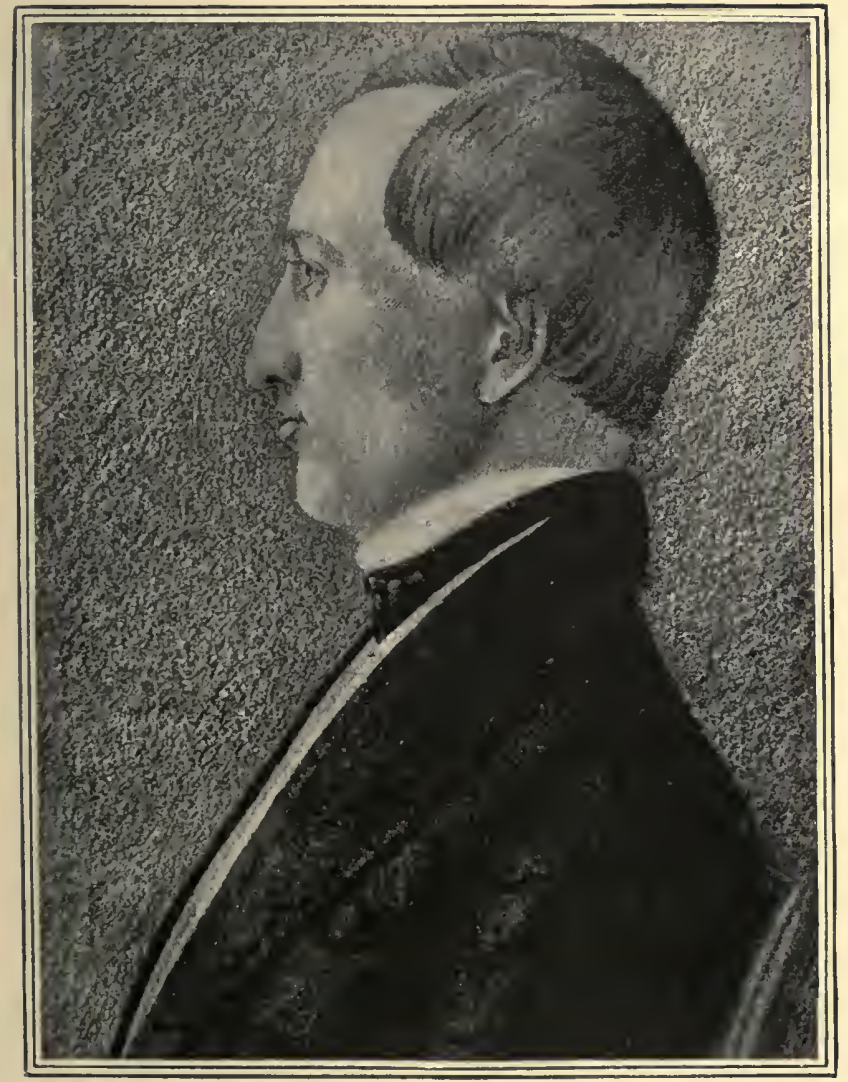

CRAWFORD W. LONG

After a crayon portrait taken at the time of his discovery of the anaesthetic properties of sulphuric ether. 

months after that initial operation at the Boston Hospital in 1846, ether had made good its conquest of pain throughout the civilized world. Only by the most active use of the imagination can we of this present day realize the full meaning of that victory.

It remains to be added that in the subsequent bickerings over the discovery-such bickerings as follow every great advance-two other names came into prominent notice as sharers in the glory of the new method. Both these were Americans - the one, Dr. Charles T. Jackson, of Boston; the other, Dr. Crawford W. Long, of Alabama. As to Dr. Jackson, it is sufficient to say that he seems to have had some vague inkling of the peculiar properties of ether before Morton's discovery. He even suggested the use of this drug to Morton, not knowing that Morton had already tried it; but this is the full measure of his association with the discovery. Hence it is clear that Jackson's claim to equal share with Morton in the discovery was unwarranted, not to say absurd.

Dr. Long's association with the matter was far different, and altogether honorable. By one of those coincidences so common in the history of discovery, he was experimenting with ether as a pain-destroyer simultaneously with Morton, though neither so much as knew of the existence of the other. While a medical student he had once inhaled ether for the intoxicant effects, as other medical students were wont to do, and when partially under influence of the drug he had noticed that a chance blow to his shins was painless. This gave him the idea that ether might be used in surgical operations; and in subsequent years, in the course of his practice in a small Georgia town, he put the idea into successful 373 
execution. There appears to be no donbt whatever that he performed successful minor operations under ether some two or three years before Morton's final demonstration; hence that the merit of first using the drug, or indeed any drug, in this way belongs to him. But unfortunately Dr. Long did not quite trust the evidence of his own experiments. Just at that time the medical journals were full of accounts of experiments in which painless operations were said to be performed through practice of hypnotism, and Dr. Long feared that his own success might be due to an incidental hypnotic influence rather than to the drug. Hence he delayed announcing his apparent discovery until he should have opportunity for further tests--and opportunities did not come every day to the country practitioner. And while he waited, Morton anticipated him, and the discovery was made known to the world without his aid. It was a true scientific caution that actuated Dr. Long to this delay, but the caution cost him the credit, which might otherwise have been his, of giving to the world one of the greatest blessings that science has ever conferred upon humanity.

A few months after the use of ether became general, the Scotch surgeon Sir J. Y. Simpson discovered that another drug, chloroform, could be administered with similar effects; that it would, indeed, in many cases produce anæsthesia more advantageously even than ether. From that day till this surgeons have been more or less divided in opinion as to the relative merits of the two drugs; but this fact, of course, has no bearing whatever upon the merit of the first discovery of the method of anæsthesia. Even had some other drug subsequently quite banished ether, the honor of the discovery of the 374 . 
beneficent method of anæsthesia would have been in no wise invalidated. And despite all cavillings, it is unequivocally established that the man who gave that inethod to the world was William T. G. Morton.

\section{IV}

This discovery of the anæsthetic power of drugs was destined presently, in addition to its direct beneficences, to aid greatly in the progress of scientific medicine, by facilitating those experimental studies of animals from which, before the day of anæsthesia, many humane physicians were withheld, and which in recent years have led to discoveries of such inestimable value to humanity. But for the moment this possibility was quite orershadowed by the direct benefits of anæsthesia, and the long strides that were taken in scientific medicine during the first fifteen years after Morton's discovery were mainly independent of such aid. These steps were taken, indeed, in a field that at first glance might seem to have a very slight connection with medicine. Moreover, the chief worker in the field was not himself a physician. He was a chemist, and the work in which he was now engaged was the study of alcoholic fermentation in vinous liquors. Yet these studies paved the way for the most important advances that medicine has made in any century towards the plane of true science; and to this man more than to any other single individual-it might almost be said more than to all other individuals-was due this wonderful advance. It is almost superfluons to add that the name of this marvellous chemist was Louis Pasteur.

The studies of fermentation which Pasteur entered 
upon in 1854 were aimed at the solution of a contro. versy that had been waging in the scientific world with varying degrees of activity for a quarter of a century. Back in the thirties, in the day of the early enthusiasm orer the perfected microscope, there had arisen a new interest in the minute forms of life which Leeuwenhoek and some of the other early workers with the lens had first described, and which now were shown to be of almost universal prevalence. These minute organisms had been studied more or less by a host of observers, but in particular by the Frenchman Cagniard Latour and the German, of cell-theory fame, Theolor Schwann. These inen, working independently, had reached the conclusion, about 1837 , that the micro-organisins play a vastly more important rôle in the economy of nature than any one previously had supposed. They held, for example, that the minute specks which largely make up the substance of yeast are living vegetable organisms, and that the growth of these organisms is the cause of the important and familiar process of fermentation. They even came to hold, at least tentatively, the opinion that the somewhat similar micro-organisms to be found in all putrefying matter, animal or vegetable, had a causal relation to the process of putrefaction.

This view, particularly as to the nature of putrefaction, was expressed even more outspokenly a little later by the French botanist Turpin. Views so supported naturally gained a following; it was equally natural that so radical an innovation should be antagonized. In this case it chanced that one of the most dominating scientific minds of the time, that of Liebig, took a firm and aggressive stand against the new doctrine. In 1539 he promulgated his famous doctrine of fermentation, in 


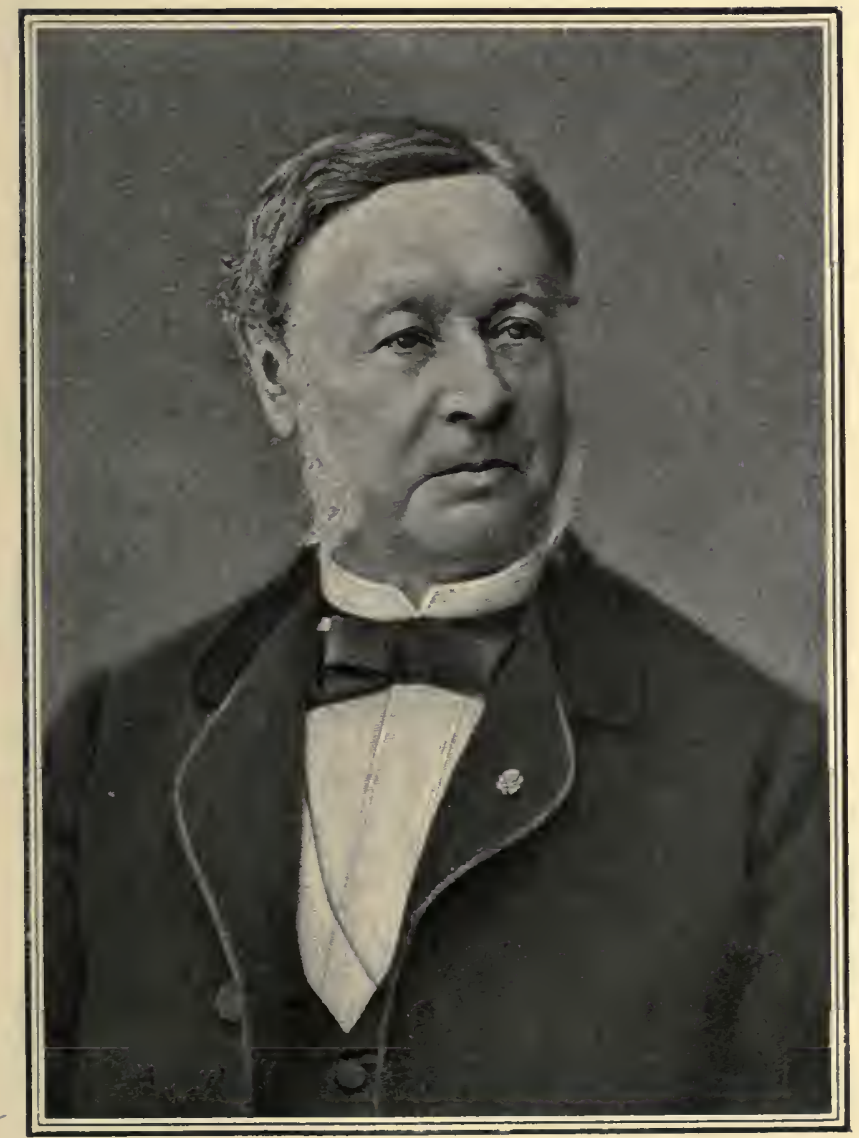

THEODOI SCHWANN 

which he stood out firmly against any "vitalistic" explanation of the phenomena, alleging that the presence of micro-organisms in fermenting and putrefying substances was merely incidental, and in no sense causal. This opinion of the great German chemist was in a measure substantiated by experiments of his compatriot Helmholtz, whose earlier experiments confirmed, but later ones contradicted, the observations of Schwann, and this combined authority gave the vitalistic conception a blow from which it had not rallied at the time when Pasteur entered the field. Indeed, it was currently regarded as settled that the early students of the subject had vastly overestimated the importance of micro-organisms.

And so it came as a new revelation to the generality of scientists of the time, when, in 1857 and the succeeding half-decade, Pasteur published the results of his researches, in which the question had been put to a selies of altogether new tests, and brought to unequivocal demonstration.

He proved that the micro-organisms do all that his most imaginative predecessors had suspected, and more. Without them, he proved, there would be no fermentation, no putrefaction-no decay of any tissues, except by the slow process of oxidation. It is the microscopic yeast plant which, by seizing on certain atoms of the inolecule, liberates the remaining atoms in the form of carbonic acid and alcohol, thus effecting fermentation; it is another microscopic plant-a bacterium, as Devaine had christened it-which in a similar way effects the destruction of organic molecules, producing the condition which we call putrefaction. Pasteur showed, to the amazement of biologists, that there are certain forms 


\section{THE STORY OF NINETEENTH-CENTURY SCIENCE}

of these bacteria which secure the oxygen which all organic life requires, not from the air, but by breaking up unstable molecules in which oxygen is combined; that putrefaction, in short, has its foundation in the activities of these so-called anaerobic bacteria.

In a word, Pasteur showed that all the many familiar processes of the decay of organic tissues are, in effect, forms of fermentation, and would not take place at all except for the presence of the living micro-organisms. A piece of meat, for example, suspended in an atınosphere free from germs, will dry up gradually, without the slightest sign of putrefaction, regardless of the temperature or other conditions to which it may have been subjected.

There was nothing in these studies bearing directly upon the question of animal diseases, yet before they were finished they had stimulated progress in more than one field of pathology. At the very outset they sufficed to start afresh the inquiry as to the rôle played by micro-organisms in disease. In particular, they led the French physician Devaine to return to some interrupted studies which he had made ten years before, in reference to the animal disease called anthrax, or splenic ferer, a disease that cost the farmers of Europe millions of francs annually through loss of sheep and cattle. In 1850 , Devaine had seen multitudes of bacteria in the blood of animals who had died of anthrax, but he did not at that time think of them as haring a causal relation to the disease. Now, howerer, in 1S63, stimulated by Pasteur's new revelations regarding the power of bacteria, he returned to the subject, and sonn became convinced, through experiments by means of inoculation, that the microscopic organisms he had discovered 380 
were the veritable and the sole cause of the infectious disease anthrax.

The publication of this belief in 1863 aroused a furor of controversy. That a microscopic vegetable could cause a virulent systemic disease was an idea altogether too startling to be accepted in a day, and the generality of biologists and physicians demanded more convincing proofs than Devaine as yet was able to offer.

Naturally a host of other investigators all over the world entered the field. Foremost among these was the German Dr. Robert Koch, who soon corroborated all that Devaine had observed, and carried the experiments further in the direction of the cultiration of successive generations of the bacteria in artificial media, inoculations being made from such pure cultures of the eighth generation, with the astonishing result that animals thus inoculated at once succumbed to the disease.

Such experiments seem demonstrative, yet the world was unconvinced, and in 1876, while the controversy was still at its height, Pasteur was prevailed upon to take the matter in hand. The great chemist was becoming more and more exclusively a biologist as the years passed, and in recent years his famous studies of thesilk-wor'm diseases, which he proved due to bacterial in. fection, and of the question of spontaneous generation, had given him unequalled resources in microscopical technique. And so when, with the aid of his laboratory associates Duclaux and Chamberland and Roux, he took up the mooted anthrax question, the scientific world awaited the issue with bated breath. And when, in 1877, Pasteul was ready to report on his studies of anthrax, he came forward with such a wealth of demonstrative experiments-experiments the rigid accuracy of which no 
one would for a moment think of questioning-going to prove the bacterial origin of anthrax, that scepticism was at last quieted for all time to come.

Henceforth no one could doubt that the contagious disease anthrax is due exclusively to the introduction into an animal's system of a specific germ-a microscopic plant - which develops there. And no logical mind could have a reasonable doubt that what is proved true of one infectious disease would some day be proved true also of other, perhaps of all, forms of infectious maladies.

Hitherto the cause of contagion, by which certain maladies spread from individual to individual, had been a total mystery, quite unillumined by the vague terms "miasm," "humor," "virus," and the like cloaks of ignorance. Here and there a prophet of science, as Sch wann and Henle, had guessed the secret; but guessing, in science, is far enough from knowing. Now, for the first time, the world knew, and medicine had taken another gigantic stride towards the heights of exact science.

\section{$\nabla$}

Meantime in a different, though allied, field of medicine there had been a complementary growth that led to immediate results of even more practical importance. I mean the theory and practice of antisepsis in surgery. This advance, like the other, came as a direct outgrowth of Pasteur's fermentation studies of alcoholic bererages, though not at the hands of Pasteur himself. Struck by the boundless implications of Pasteur's rerelations regarding the bacteria, Dr. Joseph Lister (the present Lord Lister), then of Glasgow, set about as early as 382 


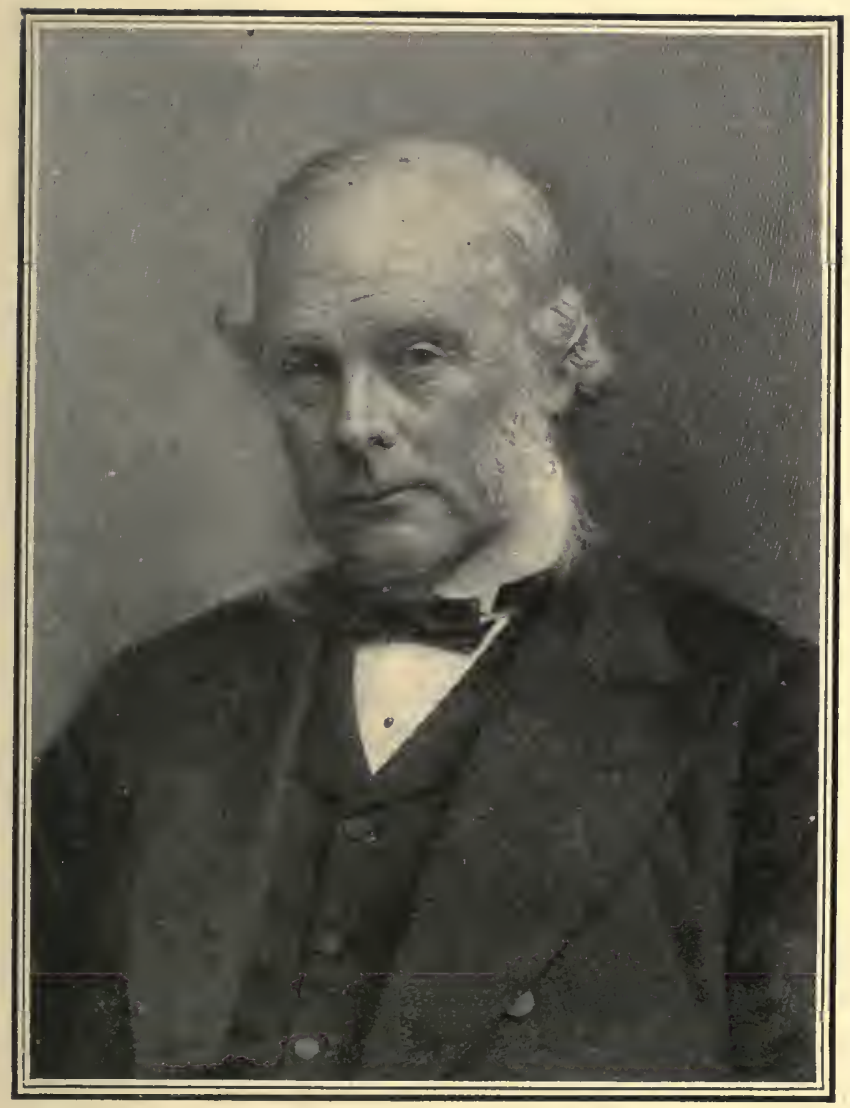

SIR JOSEPH LISTEI 

1860 to make a wonderful application of these ideas. If putrefaction is always due to bacterial development, he argued, this must apply as well to living as to dead tissues; hence the putrefactive changes which occur in wounds and after operations on the human subject, from which blood-poisoning so often follows, might be absolutely prevented if the injured surfaces could be kept free from access of the germs of decay.

In the hope of accomplishing this result, Lister began experimenting with drugs that might kill the bacteria without injury to the patient, and with means to prevent further access of germs once a wound was freed from them. How well he succeeded, all the world knows; how bitterly he was antagonized for about a score of years, most of the world has already forgotten. As early as 1867 , Lister was able to publish results pointing towards success in his great project; yet so incredulous were surgeons in general that even some years later the leading surgeons across the Channel had not so much as heard of his efforts. In 1870 the soldiers of Paris died, as of old, of hospital gangrene; and when in 1871 the French surgeon Alphonse Guérin, stimulated by Pasteur's studies, conceived the idea of dressing wounds with cotton in the hope of keeping germs from entering them, he was quite unaware that a British contemporary had preceded him by a full decade in this effort at prevention, and had made long strides towards complete success. Lister's priority, however, and the superiority of his method, were freely admitted by the French Academy of Science, which in 1881 officially crowned his achievement, as the Royal Society of London had done the year before.

By this time, to be sure, as everybody knows, Lister's $2 \mathrm{~B}$ 
new methods had made their way everywhere, revolutionizing the practice of surgery, and practically banishing from the earth maladies that hitherto had been the terror of the surgeon and the opprobrium of his art. And these bedside studies, conducted in the end by thousands of men who had no knowledge of microscopy, had a large share in establishing the general belief in the causal relation that micro-organisms bear to disease, which by about the year 1880 had taken possession of the medical world. But they did more; they brought into equal prominence the idea that, the cause of a diseased condition being known, it may be possible as never before to grapple with and eradicate that condition.

The controversy over spontaneous generation, which, thanks to Pasteur and Tyndall, had just been brought to a termination, made it clear that no bacterium need be feared where an antecedent bacterium had not found lodgment; Listerism in surgery had now shown how much might be accomplished towards preventing the access of germs to abraded surfaces of the body, and destroying those that already had found lodgment there. As yet, however, there was no inkling of a way in which a corresponding onslaught might be made upon those other germs which find their way into the animal organism by way of the mouth and the nostrils, and which, as was now clear, are the cause of those contagious diseases which, first and last, claim so large a proportion of mankind for their victims. How such means might be found now became the anxious thought of every imaginative physician, of every working micro-biologist.

As it happened, the world was not kept long in suspense. Almost before the proposition had taken shape 386 
in the minds of the other leaders, Pasteur had found a solution. Guided by the empirical success of Jenner, he, like many others, had long practised inoculation experiments, and on the 9th of February, 1880, he announced to the French Academy of Science that he had found a method of so reducing the virulence of a disease germ that, when introduced into the system of a sus. ceptible animal, it produced only a mild form of the disease, which, however, sufficed to protect against the usual virulent form exactly as vaccinia protects against small-pox. The particular disease experimented with was that infectious malady of poultry known familiarly as "chicken cholera." In October of the same year Pasteur announced the method by which this "attenuation of the virus," as he termed it, had been brought about-by cultivation of the disease germs in artificial media, exposed to the air; and he did not hesitate to assert his belief that the method would prove "susceptible of generalization"-that is to say, of application to other diseases than the particular one in question.

Within a fer months he made good this prophecy, for in February, 1881, he announced to the Academy that, with the aid, as before, of his associates MM. Chamberland and Roux, he had produced an attenuated virus of the anthrax microbe, by the use of which he could protect sheep, and presumably cattle, against that fatal malady.

This announcement was immediately challenged in a way that brought it to the attention of the entire world. The president of an agricultural society, realizing the enormous importance of the subject, proposed to Pasteur that his alleged discovery should be submitted to a decisive public test. He proposed to furnish a 
drove of fifty sheep, half of which were to be inoculated with the attenuated virus by Pasteur. Subsequently all the sheep were to be inoculated with virulent virus, all being kept together in one pen, under precisely the same conditions. The "protected" sheep were to remain healthy; the unprotected ones to die of anthrax; so read the terms of the proposition. Pasteur accepted the challenge; he even permitted a change in the programme by which two goats were substituted for two of the sheep, and ten cattle added ; stipulating, however, that since his experiments had not yet been extended to cattle, these should not be regarded as falling rigidly within the terms of the test.

It was a test to try the soul of any man, for all the world looked on askance, prepared to deride the maker of so preposterous a claim as soon as his claim should be proved baseless. Not even the fame of Pasteur could make the public at large, lay or scientific, believe in the possibility of what he proposed to accomplish. There was time for all the world to be informed of the procedure, for the first "preventive" inoculation, or vaccination, as Pasteur termed it, was made on the 5th of May, the second on the 17th; and another interval of two weels must elapse before the final inoculations with the unattenuated virus. Twenty-four sheep, one goat, and five cattle were submitted to the preliminary vaccinations. Then, on the 31st of May, all sixty of the animals were inoculated, a protecter and an unprotected one alternately, with an extremely virulent culture of anthrax microbes that had been in Pasteur's laboratory since 1877. This accomplished, the animals were left together in one enclosure, to a wait the issue.

'Two days later, the $2 \mathrm{~d}$ of June, at the appointed hour' 388 
of rendezrous, a vast crowd, composed of veterinary surgeons, newspaper correspondents, and farmers from far and near, gathered to witness the closing scenes of this scientific tourney. What they saw was one of the most dramatic scenes in the history of peaceful science-a scene which, as Pasteur declared afterwards, " amazed the assembly." Scattered about the enclosure, dead, dying, or manifestly sick unto death, lay the unprotected animals, one and all; while each and every "protected" animal stalked unconcernedly about with every appearance of perfect health. Twenty of the sheep and the one goat were already dead; two other sheep expired under the eyes of the spectators; the remaining victims lingered but a few hours longer. Thus in a manner theatrical enough, not to say tragic, was proclaimed the unequirocal rictory of science. Naturally enough, the unbeliever's struck their colors and surrendered without terms; the principle of protective vaccination, with a virus experimentally prepared in the laboratory, was established beyond the reach of controrersy.

That memorable scientific battle marked the beginning of a new era in medicine. It was a foregone conclusion that the principle thus established would be still further generalized; that it would be applied to human maladies; that, in all probability, it would grapple successfully, sooner or later, with many infectious diseases. That expectation has advanced rapidly towards realization. Pasteur himself made the application to the human subject in the disease hydrophobia, in 1855, since which time that hitherto most fatal of maladies has largely lost its terrors. Thousands of persons, bitten by mad dogs, have been snatched from the fatal consequences of that mishap by this method, at the Pasteur 389. 
Institute in Paris, and at the similar institutes, built on the model of this parent one, that have been established all over the world, in regions as widely separated as New York and Nha-Trang.

In the production of the rabies raccine Pasteur and his associates developed a method of attenuation of a virus quite different from that which had beell employed in the case of the vaccines of chicken cholera and of anthrax. The rabies virus was inoculated into the system of guinea-pigs or rabbits, and, in effect, cultivated in the systems of these animals. The spinal cord of these infected animals was found to be rich in the virus, which rapidly became attenuated when the cord was dried in the air. The preventive virus, of varying strengths, was made by maceration of these cords at varying stages of desiccation. This cultivation of a virus within the animal organism, suggested, no doubt, by the familiar Jennerian method of securing small-pox vaccine, was at the same time a step in the direction of a new therapeutic procedure which was destined presently to become of all-absorbing importance-the inethod, namely, of socalled serum-therapy, or the treatment of a disease with the blood serum of an animal that has been subjected to protective inoculation against that disease.

The possibility of such a method was suggested by the familiar observation, made by Pasteur and numerous other workers, that animals of different species differ widely in their susceptibility to various maladies; and that the virus of a giren disease may become more and more rirulent when passed through the systems of suc- 


\section{CENTURY'S PROGRESS IN SCIENTIFIC MEDICINE}

cessive individuals of one species, and, contrariwise, less and less virulent when passed through the systems of successive individuals of another species. These facts

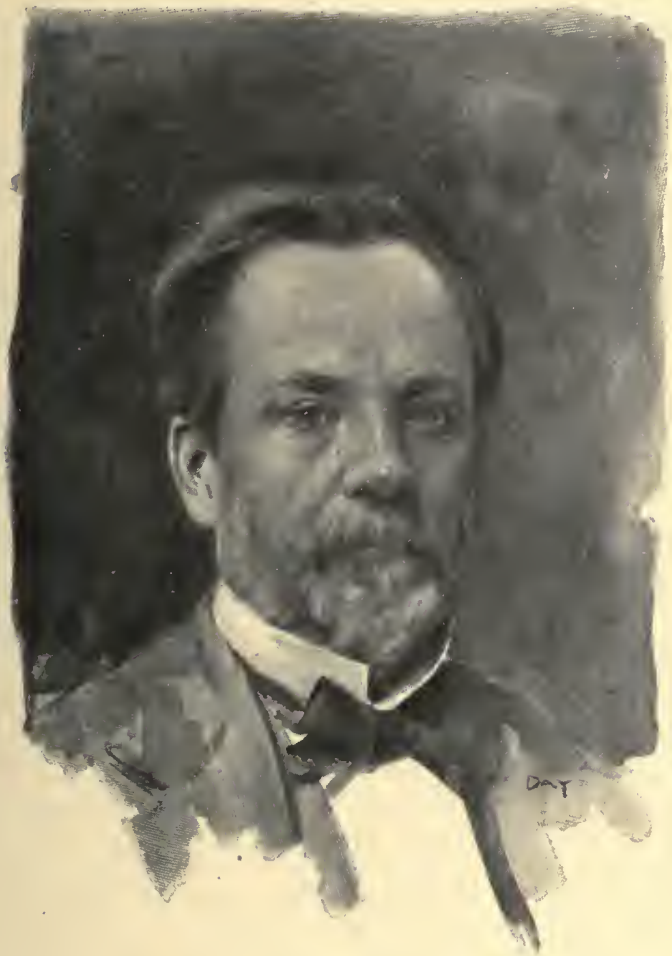

LOUIS PASTEUR

suggested the theory that the blood of resistant animals might contain something directly antagonistic to the virus, and the hope that this something might be transferred with curative effect to the blood of an infected susceptible animal. Numerous experimenters all over 


\section{THE STORY OF NINETEENTH-CENTURY SCIENCE}

the world made investigations along the line of this alluring possibility, the leaders perhaps being Drs. Behring and Kitasato, closely followed by Dr. Roux and his associates of the Pasteur Institute of Paris. Definite results were announced by Behring in 1892 regarding two important diseases - tetanus and diphtheria - but the method did not come into general notice until 1894, when Dr. Roux read an epoch-marking paper on the subject at the Congress of Hygiene at Buda-Pesth.

In this paper, Dr. Roux, after adrerting to the labors of Behring, Ehrlich, Boer, Kossel, and Wasserman, described in detail the methods that had been developed at the Pasteur Institute for the development of the curative serum, to which Behring had given the since familiar name antitoxine. The method consists, first, of the cultivation, for some months, of the diphtheria bacillus (called the Klebs-Loeffler bacillus, in honor of its discoverers) in an artificial bouillon, for the development of a powerful toxine capable of giving the disease in a virulent form.

This toxine, after certain details of mechanical treatment, is injected in small but increasing doses into the system of an animal, care being taken to graduate the amount so that the animal does not succumb to the disease. After a certain course of this treatment it is found that a portion of blood serum of the animal so treated will act in a curative way if injected into the blood of another animal, or a human patient, suffering with diphtheria. In other words, according to theory, an antitoxine has been developed in the system of the animal subjected to the progressive inoculations of the diphtheria toxine. In Dr. Roux's experience the animal best suited for the purpose is the horse, 
though almost any of the domesticated animals will serve the purpose.

But Dr. Roux's paper did not stop with the description of laboratory methods. It told also of the practical application of the serum to the treatment of numerous cases of diphtheria in the hospitals of Paris-applications that had met with a gratifying measure of success. He made it clear that a means had been found of coping successfully with what had been one of the most virulent and intractable of the diseases of childhood. Hence it was not strange that his paper made a sensation in all circles, medical and lay alike.

Physicians from all over the world flocked to Paris to learn the details of the open secret, and within a few months the new serum-therapy had an acknowledged standing with the medical profession everywhere. What it had accomplished was regarded as but an earnest of what the new method might accomplish presently when applied to the other infectious diseases.

Efforts at such applications were immediately begun in numberless directions-had, indeed, been under way in many a laboratory for some years before. It is too early yet to speak of the results in detail. But enough has been done to show that this method also is susceptible of the widest generalization. It is not easy at the present stage to sift that which is tentative from that which will be permanent; but so great an authority as Behring does not hesitate to affirm that to-day we possess, in addition to the diphtheria antitoxine, equally specific antitoxines of tetanus, cholera, typhus-fever, pneumonia, and tuberculosis-a set of diseases which in the aggregate account for a startling proportion of the general death-rate. Then it is known that Dr. Yersin, 
with the collaboration of his former colleagues of the Pasteur Institute, has developed, and has used with suc. cess, an antitoxine from the microbe of the plague which recently ravaged China.

Dr. Calmette, another graduate of the Pasteur Institute, has extended the range of the serum-therapy to include the prevention and treatment of poisoning by venoms, and has developed an antitoxine that has already given immunity from the lethal effects of snake bites to thousands of persons in India and Australia.

Just how much of present promise is tentative; just what are the limits of the methods-these are questions for the future to decide. But, in any erent, there seems little question that the serum treatment will stand as the culminating achievement in therapeutics of our century. It is the logical outgrow th of those experimental studies with the microscope begun by our predecessors of the thirties, and it represents the present culmination of the rigidly experimental method which has brought medicine from a level of fanciful empiricism to the plane of a rational experimental science. 


\section{CHAPTER XII}

I'HE CENTURY'S PROGRESS IN EXPERIMENTAL PSYCHOLOGY

I

A LITTLE over a hundred years ago a reform movement was afoot in the world in the interests of the insane. As was fitting, the movement showed itself first in America, where these unfortunates were humanely cared for at a time when their treatment elsewhere was worse than brutal, but England and France quickly fell into line. The leader on this side of the water was the famous Philadelphian, Dr. Benjamin Rush, "the Sydenham of America"; in England, Dr. William Tuke inaugurated the morement; and in France, Dr. Philippe Pinel, single-handed, led the way. Moved by a common spirit, though acting quite independently, these men raised a revolt against the traditional custom which, spurning the insane as demon-haunted outcasts, had condemned these unfortunates to dungeons, chains, and the lash. Hitherto few people had thought it other than the natural course of events that the "maniac" should be thrust into a dungeon, and perhaps chained to the wall with the aid of an iron band riveted permanently about his neck or waist. Many an unfortunate, thus manacled, was held to the narrow limits of his chain for years together in a cell to which full daylight never penetrated; sometimes-iron being expen- 


\section{'THE STORY OF NINETEENTH-CENTURY SCIENCE}

sive-the chain was so short that the wretched victim could not rise to the upright posture, or even shift his position upon his squalid pallet of straw.

In America, indeed, there being no Middle Age precedents to crystallize into established customs, the treatment accorded the insane had seldom or nerer sunk to this level. Partly for this reason, perluaps, the work of Dr. Rush, at the Philadelphia Hospital, in 1754, by means of which the insane came to be humanely treated, even to the extent of banishing the lash, has been but little noted, while the work of the European leaders, though belonging to later decades, has been made famous. And perhaps this is not as unjust as it seems, for the step which Rush took, from relatively bad to good, was a far easier one to take than the leap from atrocities to good treatment which the European reformers were obliged to compass. In Paris, for example, Pinel was obliged to ask permission of the authorities even to make the attempt at liberating the insane from their chains, and notwithstanding his recognized position as a leader of science, he gained but grudging assent, and was regarded as being himself little better than a lunatic for making so manifestly unwise and hopeless an attempt. Once the attempt had been made, however, and carried to a successful issue, the amelioration wrought in the condition of the insane was so patent that the fame of Pinel's work at the Bicetre and the Salpêtrière went abroad apace. It required, indeed, many years to complete it in Paris, and a lifetime of effort on the part of Pinel's pupil Esquirol and other's to extend the reform to the provinces; but the epochal turning-point had been reached with Pinel's labors of the closing years of the eighteenth century. 


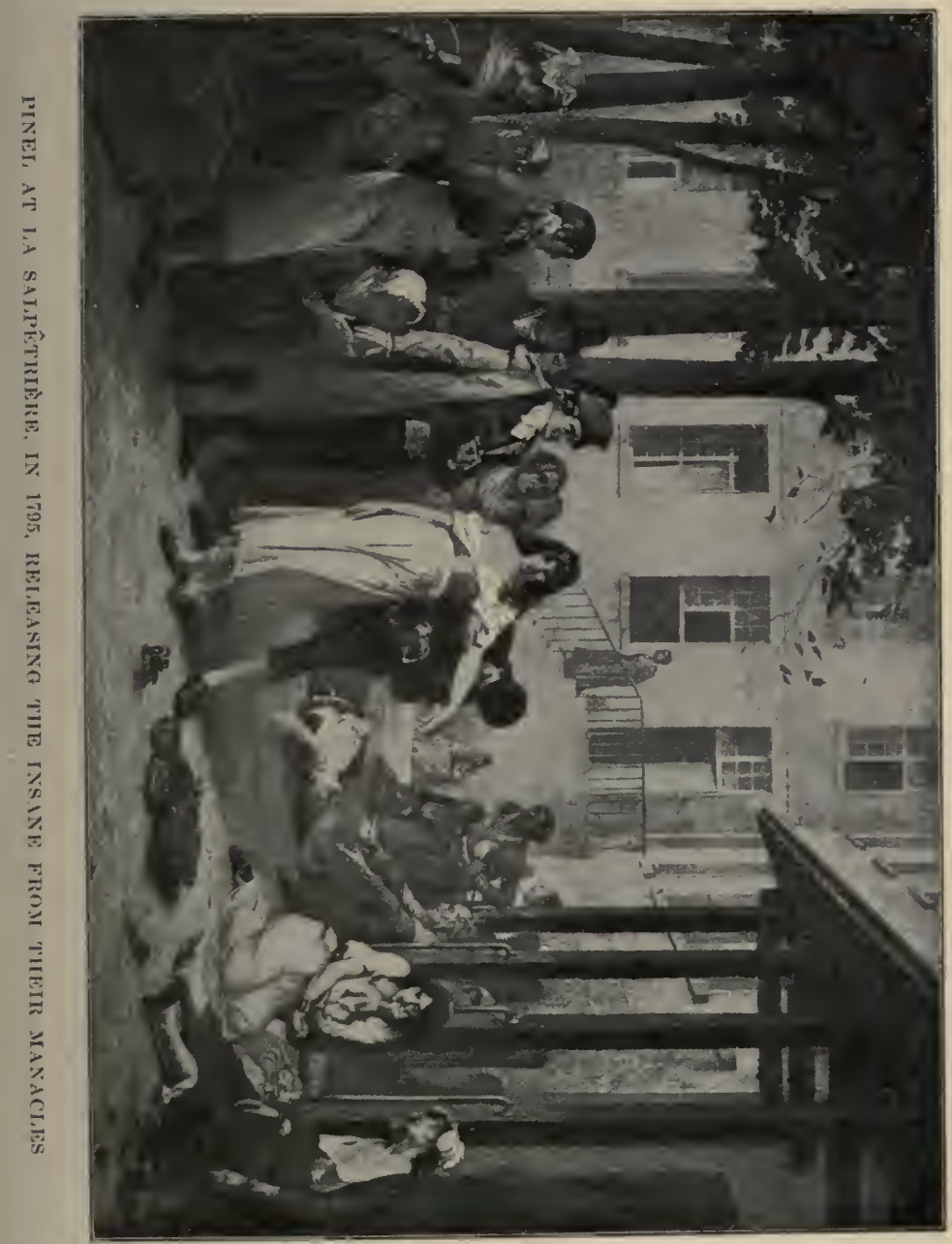



The significance of this wise and humane reform, in the present connection, is the fact that these studies of the insane gave emphasis to the novel idea, which by-and-by became accepted as beyond question, that "demoniacal possession" is in reality no more than the outward expression of a diseased condition of the brain. This realization made it clear, as never before, how intimately the mind and the body are linked one to the other. And so it chanced that in striking the shackles from the insane, Pinel and his confrères struck a blow also, unwittingly, at time-honored philosophical traditions. The liberation of the insane from their dungeons was an augury of the liberation of psychology from the musty recesses of metaphysics. Hitherto psychology, in so far as it existed at all, was but the subjective study of individual minds; in future it must become objective as well, taking into account also the relations which the mind bears to the body, and in particular to the brain and nervous system.

The necessity for this collocation was adrocated quite as earnestly, and even more directly, by another worker of this period, whose studies were allied to those of alienists, and who, eren more actively than they, focalized his attention upon the brain and its functions. This earliest of specialists in brain studies was a German by birth, but Parisian by adoption, Dr. Franz Joseph Gall, originator of the since notorious system of phrenology. The merited disrepute into which this system has fallen through the expositions of peripatetic charlatans should not make us forget that Dr. Gall himself was apparently a highly educated physician, a careful student of the brain and mind according to the best light of his time, and, withal, an earnest and honest be- 
liever in the validity of the system he had originated. The system itself, taken as a whole, was hopelessly fanlty, yet it was not without its latent germ of truth, as later studies were to show. How firmly its author himself believed in it is evidenced by the paper which he contributed to the French Acalemy of Science in 1808. The paper itself was referred to a committee of which Pinel and Cuvier were members. The verdict of this committee was adrerse, and justly so; yet the system condemned had at least one merit which its detractors failed to realize. It popularized the conception that the brain is the organ of mind. Moreover, by its insistence it rallied about it a band of scientific supporters, chief of whom was Dr. Kaspar Spurzheim, a man of no mean abilities, who became the propagandist of phrenology in England and in America. Of course such advocacy and popularity stimulated opposition as well, and out of the disputations thus arising there grew presently a greneral interest in the brain as the organ of mind, quite aside from any preconceptions whatever as to the doctrines of Gall and Spurzheim.

Prominent among the unprejudiced class of workers who now appeared was the brilliant young Frenchman, Louis Antoine Desmoulins, who studied first under the tutorage of the famous Magendie, and published jointly with him a classical work on the nerrous system of vertebrates in 1825 . Desmoulins made at least one discorery of epochal importance. He observed that the brains of persons dying in old age were lighter than the arerage, and gave visible evidence of atrophy, and he reasoned that such decay is a normal accompaniment of senility. No one nowadays would question the accuracy of this observation, but the scientific world was 
not quite ready for it in 1825 ; for when Desmoulins announced his discovery to the French Academy, that august and somewhat patriarchal body was moved to quite unscientific wrath, and forbade the young iconoclast the privilege of further hearings. From which it is evident that the partially liberated spirit of the new psychology had by no means freed itself altogether, at the close of the first quarter of our century, from the metaphysical cobwebs of its long incarceration.

II

While studies of the brain were thus being inaugurated, the nervous system, which is the channel of communication between the brain and the outside world, was being interrogated with even more tangible results. The inaugural discovery was made in 1811 by Dr. (afterwards Sir Charles) Bell, the famous English surgeon and experimental physiologist. It consisted of the observation that the anterior roots of the spinal nerves are given over to the function of conveying inotor impulses from the brain outward, whereas the posterior roots convey solely sensory impulses to the brain from without. Hitherto it had been supposed that all nerves have a similar function, and the peculiar distribution of the spinal nerves had been an unsolved puzzle.

Bell's discovery was epochal; but its full significance was not appreciater for a decade, nor, indeed, was its validity at first admitted. In Paris, in particular, then the court of final appeal in all matters scientific, the al. leged discovery was looked at askance, or quite ignored. But in 1823 the subject was taken up by the recognized $2 \mathrm{c}$ 401 .- 
leader of French physiology - François Magendie-in the course of his comprehensire experimental studies of the nervous system, and Bell's conclusions were subjected to the most rigid experimental tests, and found altogether valid. Bell himself,

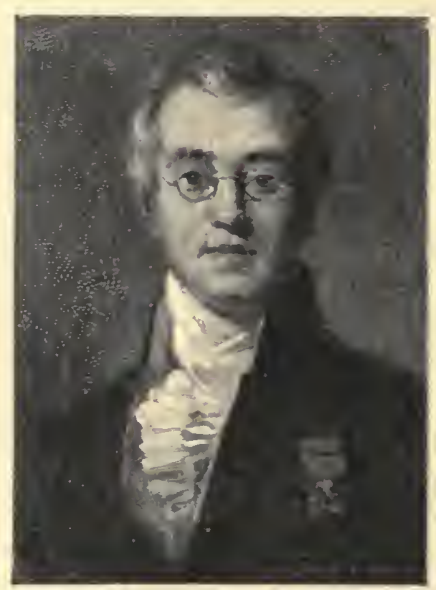

SIR CHARLES BELL

By permission of G. Bell and Sons, London meanwhile, had turned his attention to the cranial nerres, and had prored that these also are divisible into two sets-sensory and motor. Sometimes, indeed, the two sets of filaments are combined into one nerre cord, but, if traced to their origin, these are found to arise from different brain centres. Thus it was clear that a hitherto unrecognized duality of function pertains to the entire extracranial nerrous system. Any impulse sent from the periphery to the brain must be conveyed along a perfectly definite channel; the response from the brain, sent out to the peripheral muscles, must traverse an equally definite and altogether different course. If either channel is interrupted-as by the section of its particular nerre tract-the corresponding message is denied transmission as effectually as an electric current is stopped by the section of the transmitting wire.

Experimenters everywhere soon confirmed the observations of Bell and Magendie; and, as always happens after a great discovery, a fresh impulse was given to in402 


\section{PROGRESS IN EXPERIMENTAL PSYCHOLOGY}

restigations in allied fields. Nevertheless, a full decade elapsed before another discovery of comparable importance was made. Then Marshall Hall, the most famous of English physicians of his day, made his classical observations on the phenomena that henceforth were to be known as reflex action. In 1832, while experimenting

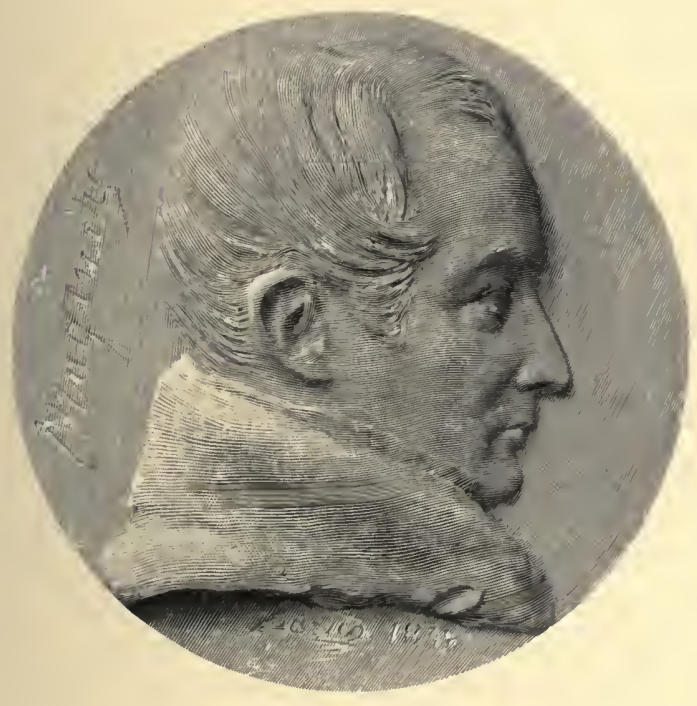

FRANÇOIS MAGENDIE

one day with a decapitated newt, he observed that the headless creature's limbs would contract in direct response to certain stimuli. Such a response could no longer be secured if the spinal nerves supplying a part were severed. Hence it was clear that responsive centres exist in the spinal cord capable of receiving a sensory message, and of transmitting a motor impulse in reply - a function hitherto supposed to be reserved for 
the brain. Further studies went to show that such phenomena of reflex action on the part of centres lying outside the range of consciousness, both in the spinal cord and in the brain itself, are extremely common; that, in short, they enter constantly into the activities of every living organism, and have a most important share in the sum total of vital morements. Hence, Hall's discorery must always stand as one of the great mile-stones of the advance of neurological science.

All these considerations as to nerve currents and nerve tracts becoming stock knowledge of science, it was natural that interest should become stimulated as to the exact character of these nerve tracts in themselves; and all the more natural in that the perfected microscope was just now claiming all fields for its own. A troop of observers soon entered upon the study of the nerves; and the leader here, as in so many other lines of microscopical research, was no other than Theodor Schwann. Through his efforts, and with the invaluable aid of such other workers as Remak, Purkinje, Henle, Müller, and the rest, all the mystery as to the general characteristics of nerre tracts was cleared away. It came to be known that in its essentials a nerve tract is a tenuous fibre or thread of protoplasm, stretching between two terminal points in the organism-one of such termini being usually a cell of the brain or spinal cord: the other, a distribution point at or near the peripheryfor example, in a muscle or in the skin. Such a fibril may have about it a protective covering, which is known as the sheath of Schwann; but the fibril itself is the essential nerve tract; and in many cases, as Remale presently discovered, the sheath is dispensed with, particularly in case of the nerves of the so-called sympathetic system. 


\section{PROGRESS IN EXPERIMENTAL PSYCHOLOGY}

This sympathetic system of ganglia and nerves, bythe-bye, had long been a puzzle to the pliysiologists. Its ganglia, the seeming centres of the system, usually minute in size, and never very large, are found every where through the organism, but in particular are gathered into a long double chain which lies within the body cavity, outside the spinal column, and represents the sole nervous system of the non-rertebrated organisms. Fibrils from these ganglia were seen to join the cranial and spinal nerve fibrils, and to accompany them everywhere, but what special function they subserved was long a mere matter of conjecture, and led to many absurd speculations. Fact was not substituted for conjecture until about the year 1851, when the great Frenchman Claude Bernard conclusively proved that at least one chief function of the sympathetic fibrils is to cause contraction of the walls of the arterioles of the system, thus regulating the blood-supply of any given part. 'Ten years earlier Henle had demonstrated the existence of annular bands of muscle fibres in the arterioles, hitherto a much mooted question, and several tentative explanations of the action of these fibres had been made, particularly by the brothers Weber, by Stilling, who, as early as 1840 , had ventured to speak of "vaso-motor" nerves, and by Schiff, who was hard upon the same track at the time of Bernard's discovery. But a clear light was not thrown on the subject until Bernard's experiments were made in 1851 . The experiments were soon after confirmed and extended by Brown-Séquard, Waller, Budge, and numerous others, and henceforth physiologists felt that they understood how the bloodsupply of any given part is regulated by the nervous system. 


\section{THE STORY OF NINETEENTH-CENTURY SCIENCE}

In reality, however, they had learned only half the story, as Bernard himself proved only a few years later by opening up a new and quite unsuspected chapter. While experimenting in $185 \mathrm{~S}$ he discovered that there are certain nerves supplying the heart which, if stimulated, cause that organ to relax and cease beating. As the heart is essentially nothing more than an aggregation of muscles, this phenomenon was utterly puzzling and without precedent in the experience of physiologists. An impulse trarelling along a motor nerve had been supposed to be able to cause a muscular contraction and to do nothing else; yet here such an impulse had exactly the opposite effect. The only tenable explanation seemed to be that this particular impulse must arrest or inhibit the action of the impulses that ordinarily cause the heart muscles to contract. But the idea of such inhibition of one impulse by another was utterly novel, and at first difficult to comprehend. Gradually, howerer, the idea took its place in the current knowledge of nerve physiology, and in time it came to be understood that what happens in the case of the heart nerve-supply is only a particular case under a rery general, indeed universal, form of nervous action. Growing out of Bernard's initial discovery came the final understanding that the entire nerrous system is a mechan. ism of centres subordinate and centres superior, the action of the one of which may be counteracted and annulled in effect by the action of the other. This applies not merely to such physical processes as heart. beats and arterial contraction and relaxing, but to the most intricate functionings which have their counterpart in psychical processes as well. Thus the observation of the inhibition of the heart's action by a nervous impulse 


\section{PROGRESS IN EXPERIMENTAL PSYCHOLOGY}

furnished the point of departure for studies that led to a better understanding of the modus operandi of the mind's activities than had ever previously been attained by the most subtle of psychologists.

III

The work of the nerve physiologists had thus an important bearing on questions of the mind. But there was another company of workers of this period who made an even more direct assault upon the "citadel of thought." A remarkable school of workers had developed in Germany, the leaders being men who, having more or less of innate metaphysical bias as a national birthright, had also the instincts of the empirical scientist, and whose educational equipment included a profound knowledge not alone of physiology and psychology, but of physics and mathematics as well. These men undertook the norel task of interrogating the relations of body and mind from the stand-point of physics. They sought to apply the vernier and the balance, as far as might be, to the intangible processes of mind.

The movement had its precursory stages in the early part of the century, notably in the mathematical psychology of Herbart, but its first definitive output to attract general attention came from the master-hand of Hẹrmann Helmholtz in 1851. It consisted of the accurate measurement of the speed of transit of a nervous impulse along a nerve tract. To make such measurement had been regarded as impossible, it being supposed that the flight of the nervous impulse was practically instantaneous. But Helmholtz readily demonstrated the contrary, showing that the nerve cord is a relatively sluggish message- 
bearer. According to his experiments, first performed upon the frog, the nervous "current" travels less than one hundred feet per second. Other experiments performed soon afterward by Helmholtz himself, and by

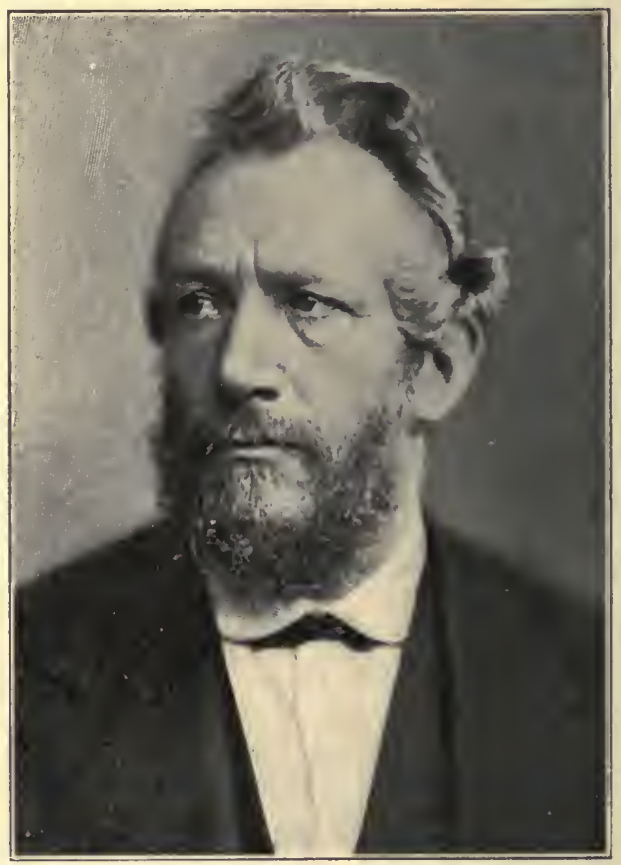

EMIL DU HOIS RAYMIOND

various followers, chief among whom was Du Bois-Reymond, modified somewhat the exact figures at tirst obtained, but did not change the general bearings of the early results. Thus the nerrous impulse was shown to be something far different, as regards speed of transit, at any rate, from the electric current to which it had 408 
been so often likened. An electric current would flash half-way round the globe while a nerrous impulse could travel the length of the human body-from a man's foot to his brain.

The tendency to bridge the gulf that hitherto had separated the physical from the psychical world was further evidenced in the following decade by Helmholtz's remarkable but highly technical study of the sensations of sound and of color in connection with their physical causes, in the course of which he revived the doctrine of color vision which that other great physiologist and physicist, Thomas Young, had advanced half a century before. The same tendency was further evidenced by the appearance, in 1852, of Dr. Hermann Lotze's famous Medizinische Psychologie, oder Physiologie der Seele, with its challenge of the old myth of a "vital force." But the most definitive expression of the new movement was signalized in 1860, when Gustav Fechner published his classical work called Psychophysik. That title introduced a new word into the vocabulary of science. Fechner explained it by saying, "I mean by psychophysics an exact theory of the relation between spirit and body, and, in a general way, between the physical and the psychic worlds." The title became famous, and the brunt of many a controversy. So also did another phrase which Fechner introduced in the course of his book-the phrase "physiological psychology." In making that happy collocation of words Fechner virtually christened a new science.

The chief purport of this classical book of the German psycho-physiologist was the elaboration and explication of experiments based on a method introduced more than twenty years earlier by his countryman E. II. Weber, but 
which hitherto had failed to attract the attention it deserved. The method consisted of the measurement and analysis of the definite relation existing between external stimuli of varying degrees of intensity (various sounds, for example) and the mental states they induce. Weber's experiments grew out of the familiar observation that the nicety of our discriminations of various sounds, weights, or visual images depends upon the magnitude of each particular cause of a sensation in its relation with other similar causes. Thus, for example, we cannot see the stars in the daytime, though they shine as brightly then as at night. Again, we seldom notice the ticking of a clock in the day time, though it may become almost painfully audible in the silence of the night. Yet again, the difference between an ounce weight and a two-ounce weight is clearly enough appreciable when we lift the 'two, but one cannot discriminate in the same way between a five-pound weight and a weight of one ounce over five pounds.

This last example, and similar ones for the other senses, gave Weber the clew to his novel experiments. Reflection upon every-day experiences made it clear to him that whenerer we consider two visual sensations, or two auditory sensations, or two sensations of weight, in comparison one with another, there is always a limit to the keenness of our discrimination, and that this degree of keenness varies, as in the case of the weights just cited, with the magnitude of the exciting cause.

Weber determined to see whether these common experiences could be brought within the pale of a general law. His method consisted of making long series of experiments aimed at the determination, in each case, of what came to be spoken of as the least observable dif- 


\section{PROGRESS IN EXIERLNENTAL PSYCHOLOGY}

ference between the stimuli. Thus if one holds an ounce weight in each hand, and has tiny weights added to one of them, grain by grain, one does not at first perceire a difference; but presently, on the addition of a certain grain, he does become aware of the difference. Noting now how many grains have been added to produce this effect, we have the weight which represents the least appreciable difference when the standard is one ounce.

Now repeat the experiment, but let the weights be each of fire pounds. Clearly in this case we shall be obliged to add not grains, but drachms, before a difference between the two heavy weights is perceived. But whatever the exact amount added, that amount represents the stimulus producing a just perceirable sensation of difference when the standard is five pounds. And so on for indefinite series of weights of rarying magnitudes. Now came Weber's curious discovery. Not only did he find that in repeated experiments with the same pair of weights the measure of "just perceivable difference" remained approximately fixed, but he found, further, that a remarkable fixed relation exists between the stimuli of different magnitude. If, for example, he had found it necessary, in the case of the ounce weights, to add onefiftieth of an ounce to the one before a difference was detected, he found also, in the case of the five-pound weights, that one-fiftieth of five pounds must be added before producing the same result. And so of all other weights; the amount added to produce the stimulus of "least appreciable difference" always bore the same mathematical relation to the magnitude of the weight used, be that magnitude great or small.

Weber found that the same thing holds good for the 411 


\section{THE STORY OF NINETEENTH-CENTLRY SCIENCE}

stimuli of the sensations of sight and of hearing, the differential stimulus bearing always a fixed ratio to the total magnitude of the stimuli. Here, then, was the law he had sought.

Weber's results were definite enough, and striking enough, yet they failed to attract any considerable measure of attention until they were revived and extended by Fechner, and brought before the world in the famous work on psycho-physics. Then they precipitated a reritable mêlée. Fechner had not alone rerified the earlier results (with certain limitations not essential to the present consideration), but had invented new methods of making similar tests, and had reduced the whole question to mathematical treatment. He pronounced Weber's discovery the fundamental law of psycho-physics. In honor of the discoverer, he christened it Weber's Iaw. He clothed the law in words and in mathematical formulæ, and, so to say, launched it full tilt at the heads of the psychological world. It made a fine commotion, be assured, for it was the first widely heralded bulletin of the new psychology in its march upon the strongholds of the time-honored metaphysics. The accomplishments of the microscopists and the nerve plyysiologists had been but preliminary-mere border skirmishes of uncertain import. But here was proof that the iconoclastic movement meant to invade the very heart of the sacred territory of mind-a territory from which tangible objective fact had been supposed to be forever barred.

Hardly had the alarm been sounded, however, before a new movement was made. While Fechner's book was fresh from the press, steps were being taken to extend the methods of the physicist in yet another way to the intimate processes of the mind. As Helmboltz had shown 


\section{PROGRESS IN EXI'ERMENTAL PSTCHOLOGY}

the rate of nervous impulsion along the nerve tract to be measurible, it was now sought to measure also the time required for the central nervous mechanism to perform its work of receiring a message and sending out a

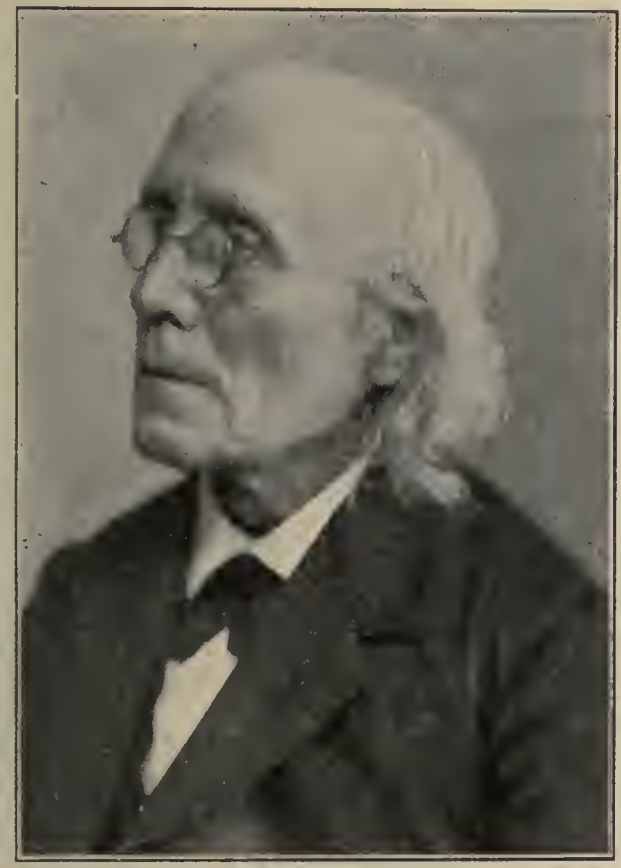

GUSTAV THEODOIR FECHNEIR

response. This was coming down to the rery threshold of mind. The attempt was first made by Professor Donders, in 1S61, but definitive results were only obtained after many years of experiment on the part of a liost of observers. The chicf of these, and the man who has stood in the forefront of the new movement, and 
has been its recognized leader throughout the remainder of the century, is Dr. Wilhelm Wundt, of Leipzig.

The task was not easy, but, in the long run, it was accomplished. Not alone was it shown that the nerve centre requires a measurable time for its operations, but much was learned as to conditions that modify this time. Thus it was found that different persons vary in the rate of their central nervous activity - which explained the "personal equation" that the astronomer Bessel had noted a half-century before. It was found, too, that the rate of activity raries also for the same person under different conditions, becoming retarded, for example, under influence of fatigue, or in case of certain diseases of the brain. All details aside, the essential fact emerges, as an experimental demonstration, that the intellectual processes-sensation, apperception, volition-are. linked irrerocably with the activities of the central nerrous tissues, and that these activities, like all other physical processes, have a time element. To that old school of psychologists, who scarcely cared more for the human head than for the heels-being interested only in the mind-such a linking of mind and body as was thus demonstrated was naturally disquieting. But whatever the inferences, there was no escaping the facts.

Of course this new movement has not been confined to Germany. Indeed, it had long had exponents elsewhere. Thus in England, a full century earlier, Dr. Hartley had championed the theory of the close and indissoluble dependence of mind upon the brain, and formulated a famous vibration theory of association that still merits careful consideration. Then, too, in France, at the beginning of the century, there was Dr. Cabanis 
with his tangible, if crudely phrased, doctrine that the brain digests impressions and secretes thought as the stomach digests food and the liver secretes bile. Moreorer, Herbert Spencer's Principles of Psychology, with its avowed co-ordination of mind and body and its ritalizing theory of evolution, appeared in 1855 , half a decade before the work of Fechner. But these influences, though of vast educational value, were theoretical rather than demonstrative, and the fact remains that the experimental work which first attempted to gauge mental operations by physical principles was mainly done in Germany. Wundt's Physiological Psychology, with its full preliminary descriptions of the anatomy of the nervous system, gave tangible expression to the growth of the new morement in 1874; and four years later, with the opening of his laboratory of Physiological Psychology at the Unirersity of Leipzig, the new psychology may be said to have gained a permanent foothold, and to have.forced itself into official recognition. From then on its conquest of the world was but a matter of time.

It should be noted, however, that there is one other method of strictly experimental examination of the mental field, latterly much in rogue, which had a different origin. This is the scientific inrestigation of the phenoinena of hypnotism. This subject was rescued from the hands of charlatans, rechristened, and subjected to accurate investigation by Dr. James Braid, of Manchester, as early as $18+1$. But his results, after attracting momentary attention, fell from view, and, despite desultory efforts, the subject was not again accorded a general hearing from the scientific world until 1878, when Dr. Charcot took it up at the Salpêtrière in Paris, followed soon afterwards by Dr. Rudolf Heidenhain, of 
Breslau, and a host of other experimenters. The value of the method in the study of mental states was soon apparent. Most of Braid's experiments were repeated, and in the main his results were confirmed. His explanation of hypnotism, or artificial somnambulism, as a

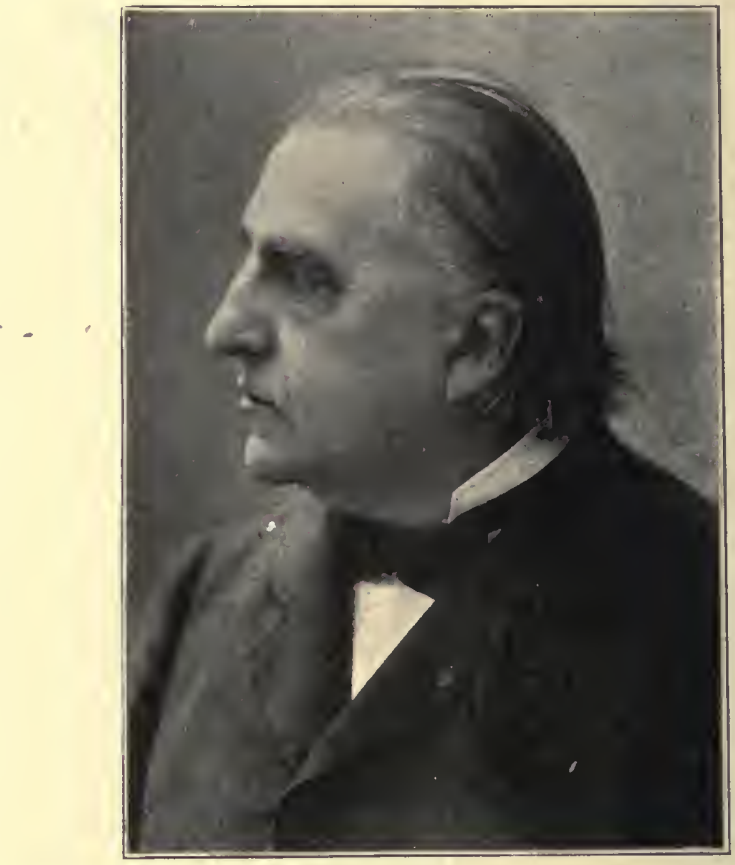

JEAN MARTIN CIIALCT

self-induced state, independent of any occult or supersensible influence, soon gained general credence. His belief that the initial stages are due to fatigue of nelvous centres, usually from excessive stimulation, has not been supplanted, though supplemented by notions grow416 
ing out of the new knowledge as to subconscious mentality in general, and the inhibitory influence of one centre over another in the central nerrous mechanism.

\section{IV}

These studies of the psychologists and pathologists bring the relations of mind and body into sharp relief. But even more definite in this regard was the work of the brain physiologists. Chief of these, during the middle period of the century, was the man who is sometimes spoken of as the "father of brain physiology," Marie Jean Pierre Flourens, of the Jardin des Plantes of Paris, the pupil and worthy successor of Magendie. His experiments in nerve physiology were begun in the first quarter of the century, but his local experiments upon the brain itself were not culminated until about 1542. At this time the old dispute orer phrenology had broken out afresh, and the studies of Flourens were aimed, in part at least, at the strictly scientitic investigation of this troublesome topic.

In the course of these studies Flourens discorered that in the medulla oblongata, the part of the brain which connects that organ with the spinal cord, there is a centre of minute size which cannot be injured in the least without causing the instint death of the animal operated upon. It may be added that it is this spot which is reached by the needle of the garroter in Spanish executions, and that the same centre also is destroyed when a criminal is "successfully" hanged, this time by the forced intrusion of a process of the second cervical vertebra. Flourens named this spot the "vital knot." Its extreme importance, as is now understood, is due to the 


\section{'IHE STORY OF NINETEENTH-CENTURY SCIENCE}

fact that it is the centre of nerves that supply the heart; but this simple explanation, annulling the conception of a specific "life centre," was not ai once apparent.

Other experiments of Flourens seemed to show that the cerebellum is the seat of the centres that co-ordinate muscular activities, and that the higher intellectual faculties are relegated to the cerebrum. But beyond this, as regards localization, experiment faltered. Negative results, as regards specific faculties, were obtained from all localized irritations of the cerebrum, and Flourens was forced to conclude that the cerebral lobe, while being undoubtedly the seat of higher intellection, performs its functions with its entire structure. This conclusion, which incidentally gave a quietus to phrenology, was accepted generally, and became the stock doctrine of cerebral physiology for a generation.

It will be seen, howerer, that these studies of Flourens had a double bearing. They denied localization of cerebral functions, but they demonstrated the localization of certain nervous processes in other portions of the brain. On the whole, then, they spoke positively for the principle of localization of function in the brain, for which a certain number of students contended; while their evidence against cerebral localization was only negative. There was here and there an observer who felt that this negative testimony was not conclusive. In particular, the German anatomist Meynert, who had studied the disposition of nerve tracts in the cerebrum, was led to believe that the anterior portions of the cerebrum must have motor functions in preponderance; the posterior portions, sensory functions. Somewhat similar conclusions were reached also by $\mathrm{Dr}$. Hughlings. 418 . 


\section{PROGRESS IN EXPERIMENTAL PSYCHOLOGY}

Jackson, in England, from his studies of epilepsy. But no positive evidence was forth-coming until 1861, when Dr. Paul Broca brought before the Academy of Medicine in Paris a case of brain lesion which he regarded as having most important bearings on the question of cerebral localization.

The case was that of a patient at the Bicêtre, who for twenty years had been deprived of the power of speech, seemingly through loss of memory of words. In 1861 this patient died, and an autopsy revealed that a certain convolution of the left frontal lobe of his cerebrum had been totally destroyed by disease, the remainder of his brain being intact. Broca felt that this observation pointed strongly to a localization of the memory of words in a definite area of the brain. Moreover, it transpired that the case was not without precedent. As long ago as 1825 Dr. Boillard had been led, through pathological studies, to locate definitely a centre for the articulation of words in the frontal lobe, and here and there other observers had made tentatives in the same direction. Boillard had even followed the matter up with pertinacity, but the world was not ready to listen to him. Now, however, in the half-decade that followed Broca's announcements, interest rose to feverheat, and through the efforts of Broca, Boillard, and numerous others it was proved that a veritable centre having a strange domination over the memory of articulate words has its seat in the third convolution of the frontal lobe of the cerebrum, usually in the left hemisphere. That part of the brain has since been known to the English-speaking world as the convolution of Broca, a name which, strangely enough, the discoverer's compatriots have been slow to accept. 


\section{THE STORY OF NINETEENTH-CENTURY SCIENCE}

This discovery very naturally reopened the entire subject of brain localization. It was but a short step to the inference that there must be other definite centres worth the seeking, and various observers set about searching for them. In 1867 a clew was gained by Eckhard, who, repeating a forgotten experiment of Haller and Zinn of the previous century, remored portions of the brain cortex of animals, with the result of producing convulsions. But the really vital departure was made in 1870 by the German investigators Fritsch and Hitzig, who, by stimulating.definite areas of the cortex of animals with a galvanic current, produced contraction of definite sets of muscles of the opposite side of the body. These most important experiments, received at first with incredulity, were repeated and extended in 1873 by Dr. David Ferrier, of London, and soon afterwards by a sinall army of independent workers every where, prominent among whom were Franck and Pitres in France, Munck and Goltz in Germany, and Horsley and Schafer in England. The detailed results, naturally enough, were not at first all in harmony. Some observers, as Goltz, even denied the validity of the conclusions in toto. But a consensus of opinion, based on multitudes of experiments, soon placed the broad general facts for which Fritsch and Hitzig contended beyond controversy. It was found, indeed, that the cerebral centres of motor activities have not quite the finality at first ascribed to them by some observers, since it may often happen that after the destruction of a centre, with attending loss of function, there may be a gradual restoration of the lost function, proving that other centres have acquired the capacity to take the place of the one destroyed. There are limits to this capacity for substitution, howerer, and 
PROGRESS IN EXPERLMENAL PSYCHOLOGY

with this qualification the definiteness of the localization of motor functions in the cerebral cortex has become an accepted part of brain physiology.

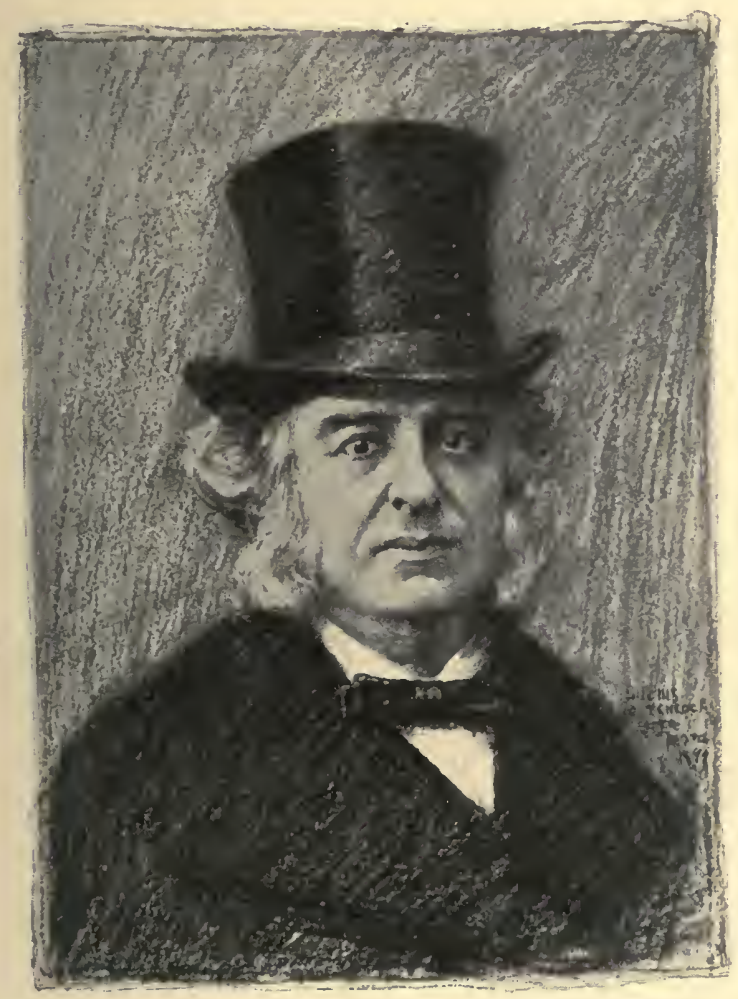

PAUL BROCA

Nor is such localization confined to motor centres. Later experiments, particularly of Ferrier and of Munck, proved that the centres of vision are equally restricted in their location, this time in the posterior lobes of the 
brain, and that hearing has likewise its local habitation. Indeed, there is every reason to believe that each form of primary sensation is based on impressions which mainly come to a definitely localized goal in the brain. But all this, be it understood, has no reference to the higher forms of intellection. All experiment has proved futile to localize these functions, except indeed to the extent of corroborating the familial fact of their dependence upon the brain, and, somewhat problematically, upon the anterior lobes of the cerebrum in particular. But this is precisely what should be expected, for the clearer insight into the nature of mental processes makes it plain that in the main these alleged "faculties" are not in themselves localized. Thus, for example, the "faculty" of language is associated irrevocably with centres of vision, of hearing, and of muscular activity, to go no further, and only becomes possible through the association of these widely separated centres. The destruction of Broca's centre, as was early discovered, does not altogether deprive a patient of his knowledge of language. $\mathrm{He}$ may be totally unable to speak (though as to this there are all degrees of variation), and yet may comprehend what is said to.him, and be able to read, think, and even write correctly. Thus it appears that Broca's centre is peculiarly bound up with the capacity for articulate speech, but is far enough from being the seat of the faculty of language in its entirety.

In a similar way, most of the supposed isolated "faculties" of higher intellection appear, upon clearer analysis as complex aggregations of primary sensations, and hence necessarily dependent upon numerous and scattered centres. Some "faculties," as memory and volition, may be said in a sense to be primordial endowments of erery 
nerve cell-even of every body cell. Indeed, an ultimate analysis relegates all intellection, in its primordial adum. brations, to erery particle of living matter. But such refinements of analysis, after all, cannot hide the fact that certain forms of higher intellection involve a pretty definite collocation and elaboration of special sensations. Such specialization, indeed, seems a necessary accompaniinent of mental evolution. That every such specialized function has its localized centres of co-ordination, of some such significance as the demonstrated centres of articulate speech, can hardly be in doubt-though this, be it understood, is an induction, not as yet a demonstration. In other words, there is every reason to beliere that numerous "centres," in this restricted serise, exist in the brain that have as yet eluded the investigator. Indeed, the current conception regards the entire cerebral cortex as chiefly composed of centres of ultimate co-ordination of impressions, which in their cruder form are received by more primitive nerrous tissues-the basal ganglia, the cerebellum, and medulla, and the spinal cord. This of course is equivalent to postulating the cerebral cortex as the exclusive seat of higher intellection. This proposition, however, to which a safe induction seems to lead, is far afield from the substantiation of the old conception of brain localization, which was based on faulty psychology, and equally faulty inductions from few premises. The details of Gall's system, as propounded by generations of his mostly unworthy followers, lie quite beyond the pale of scientific discussion. Yet, as I have said, a germ of truth was there-the idea of specialization of cerebral functions-and modern investigators have rescued that central conception from the phrenological rubbish heap in which its discorerel unfortunately left it buried. 
The common ground of all these various lines of investigations of pathologist, anatomist, physiologist, physicist, and psychologist is, clearly, the central nervous system-the spinal cord and the brain. The importance of these structures as the foci of nervous and mental activities has been recognized more and more with each new accretion of knowledge, and the efforts to fathom the secrets of their intimate structure has been unceas. ing. For the earlier students, only the crude methods of gross dissections and microscopical inspection were available. These could reveal something, but of course the inner secrets were for the keener insight of the microscopist alone. And even for him the task of investigation was far from facile, for the central nerrous tissues are the most delicate and fragile, and on many accounts the most difficult of manipulation of any in the body.

Special methods, therefore, were needed for this essiy, and brain histology las progressed by fitful impulses, each forward jet marking the introduction of some ingenious improvement of mechanical technique, which placed a new weapon in the hands of the investigators.

The very beginning was made in $152 t$ by Rolando, who first thonght of cutting chemically hardened pieces of brain tissues into thin sections for microscopical examination-the basal structure upon which almost all the later adrances have been conducted. Miiller presently discorered that bichromate of potassium in solution makes the best of fluids for the preliminary preservation and hardening of the tissues. Stilling, in 1842, perfected the method by introducing the custom of cutting a series of consecutive sections of the same tissue. 
in order to trace nerve tracts and establish spacial relations. Then from time to time mechanical ingenuity added fresh details of improrement. It was found that pieces of hardened tissue of extreme delicacy can be made better subject to manipulation by being impregnated with collodion or celloidine, and embedded in paraffine. Latterly it has become usual to cut sections also from fresh tissues, unchanged by chemicals, by freezing them suddenly with raporized ether, or, better, carbonic acid. By these methods, and with the aid of perfected microtomes, the worker of recent periods avails himself of sections of brain tissues of a tenuousness which the early investigators could not approach.

But more important eren than the cutting of thin sections is the process of making the different parts of the section visible, one tissue differentiated from another. The thin section, as the early workers examined it, was practically colorless, and eren the crudest details of its structure were made out with extreme difficulty. Remak did, indeed, manage to discorer that the brain tissue is cellular, as early as 1833, and Ehrenberg in the same year saw that it is also fibrillar, but beyond this no great advance was made until 1555 , when a sudden impulse was received from a new process introduced by Gerlach. The process itself was most simple, consisting essentially of nothing more than the treatment of a microscopical section with a solution of carmine. But the result was wonderful, for when such a section was placed under the lens, it no longer appeared homogeneous. Sprinkled through its substance were seen irregular bodies that had taken on a beautiful color, while the matrix in which they were embeddeil remained unstained. In a word, the central nerve cell had sprung suddenly into clear view. 


\section{THE STORY OF NINETEENTH-CENTURY SCIENCE}

A most interesting body it proved, this nerve cell, or ganglion cell, as it came to be called. It was seen to be exceedingly minute in size, requiring high powers of the microscope to make it visible. It exists in almost infinite numbers, not, however, scattered at random through the brain and spinal cord. On the contrary, it is confined to those portions of the central nervous masses which to the naked eye appear gray in color, being altogether wanting in the white substance which makes up the chief mass of the brain. Even in the gray matter, though sometimes thickly distributed, the ganglion cells are never in actual contact one with another; they always lie embedded in intercellular tissues, which came to be known, following Virchow, as the neuroglia.

Each ganglion cell was seen to be irregular in contour, and to have jutting out from it two sets of minute fibres, one set relatively short, indefinitely numerous, and branching in every direction; the other set limited in number, sometimes even single, and starting out directly from the cell as if bent on a longer journey. The numerous filaments came to be known as protoplasmic processes; the other fibre was named, after its discoverer, the axis cylinder of Deiters. It was a natural inference, though not clearly demonstrable in the sections, that these filamentous processes are the connecting links between the different nerve cells, and also the channels of communication between nerve cells and the periphery of the body. The white substance of brain and cord, apparently, is made up of such connecting fibres, thus bringing the different ganglion cells everywhere into communication one with another.

In the attempt to trace the connecting nerve tracts through this white substance by either macroscopical or 
microscopical methods, most important aid is given by a method originated by Waller in 1852. Earlier than that, in 1839 , Nasse had discovered that a severed nerve cord degenerates in its peripheral portions. Waller discovered that every nerve fibre, sensory or motor, has a nerve cell to or from which it leads, which dominates its nutrition, so that it can only retain its vitality while its connection with that cell is intact. Such cells he named trophic centres. Certain cells of the anterior part of the spinal cord, for example, are the trophic centres of the spinal motor nerves. Other trophic centres, governing nerve tracts in the spinal cord itself, are in the various regions of the brain. It occurred to Waller that by destroying such centres, or by severing the connection at various regions between a nervous tract and its trophic centre, sharply defined tracts could be made to degenerate, and their location could subsequently be accurately defined, as the degenerated tissues take on a changed aspect, both to macroscopical and microscopical observation. Recognition of this principle thus gave the experimenter a new weapon of great efficiency in tracing nervous connections. Moreover, the same principle has wide application in case of the human subject in disease, such as the lesion of nerve tracts or the destruction of centres by localized tumors, by einbolisms, or by traumatisms.

All these various methods of anatomical examination combine to make the conclusion almost unavoidable that the central ganglion cells are the veritable "centres" of nervous activity to which so many other lines of research have pointed. The conclusion was strengthened by experiments of the students of motor localization, which showed that the veritable centres of their 
discorery lie, demonstrably, in the gray cortex of the brain, not in the white matter. But the full proof came from pathology. At the hands of a multitude of observers it was shown that in certain well-known diseases of the spinal cord, with resulting paralysis, it is the ganglion cells themselves that are found to be destroyed. Similarly, in the case of sufferers from chronic insanities, with marked dementia, the ganglion cells of the cortex of the brain are found to have undergone degeneration. The brains of paretics in particular show such degeneration, in striking correspondence with their mental decadence. The position of the ganglion cell as the ultimate centre of nervous activities was thus placed beyond dispute.

Meantime, general acceptance being given the histological scheme of Gerlach, according to which the mass of the white substance of the brain is a mesh-work of intercellular fibrils, a proximal idea seemed attainable of the way in which the ganglionic activities are correlated, and, through association, built up, so to speak, into the higher mental processes. Such a conception accorded beautifully with the ideas of the associationists, who had now become dominant in psychology. But one standing puzzle attended this otherwise satisfactory correlation of anatomical observations and psychic analyses. It was this: Since, according to the histologist, the intercellular fibres, along which impulses are conreyed, connect each brain cell, directly or indirectly, with every other brain cell in an endless mesh-work, how is it possible that various sets of cells may at times be shut off from one another? Such isolation must take place, for all normal ideation depends for its integrity quite as much upon the shutting out of the great 


\section{PROGRESS IN EXPERIMEN'TAL PSTCHOLOGY}

mass of associations as upon the inclusion of certain other associations. For example, a student in solving a mathematical problem inust for the moment become quite oblivious to the special associations that have to do with geography, natural history, and the like. But does histology give any clew to the way in which such isolation may be effected?

Attempts were made to find an answer through consideration of the very peculiar character of the bloodsupply in the brain. Here, as nowhere else, the terminal twigs of the arteries are arranged in closed systems, not anastomosing freely with neighboring systems. Clearly, then, a restricted area of the brain may, through the controlling influence of the vaso-motor nerves, be flushed with arterial blood, while neighboring parts remain relatively anæmic. And since vital activities unquestionably depend in part upon the supply of arterial blood, this peculiar arrangement of the vascular mechanism may very properly be supposed to aid in the localized activities of the central nerrous ganglia. But this explanation left much to be desired -in particular when it is recalled that all higher intellection must in all probability involve multitudes of widely scattered centres.

No better explanation was forth-coming, however, until the year 1859 , when of a sudden the mystery was cleared away by a fresh discovery. Not long before this the Italian histologist, Dr. Camille Golgi, had discovered a method of impregnating hardened brain tissues with a solution of nitrate of silver, with the result of staining the nerve cells and their processes almost infinitely better than was possible by the method of Gerlach, or by any of the multiform methods that other 
workers had introduced. Now for the first time it became possible to trace the cellular prolongations definitely to their termini, for the finer fibrils had not been rendered visible by any previous method of treatment. Golgi himself proved that the set of fibrils known as protoplasmic prolongations terminate by free extremities, and have no direct connection with any cell save the one from which they spring. He showed also that the axis cylinders give off multitudes of lateral branches not hitherto suspected. But here he paused, missing the real import of the discovery of which he was hard on the track. It remained for the Spanish histologist, Dr. S. Ramon y Cajal, to follow up the investigation by means of an improved application of Golgi's method of staining, and to demonstrate that the axis cylinders, together with all their collateral branches, though sometimes extending to a great distance, yet finally terminate, like the other cell prolongations, in arborescent fibrils having free extremities. In a word, it was shown that each central nerve cell, with its fibrillar offshoots, is an isolated entity. Instead of being in physical connection with a multitude of other nerve cells, it has no direct physical connection with any other nerre cell whatever.

When Dr. Cajal announced his discovery, in 1889, his revolutionary claims not unnaturally amazed the mass of histologists. There were some fer of them, howerer, who were not quite unprepared for the revelation; in particular His, who had half suspected the independence of the cells, because they seemed to develop from dissociated centres ; and Forel, who based a similar suspicion on the fact that he had never been able actually to trace a fibre from one cell to another. These observers 
then came readily to repeat Cajal's experiments. So also did the veteran histologist Kölliker, and soon afterwards all the leaders everywhere. The result was a practically unanimous confirmation of the Spanish histologist's claims, and within a few months after his announcements the old theory of union of nerve cells into an endless mesh-work was completely discarded, and the theory of isolated nerve elements-the theory of neurons, as it came to be called-was fully established in its place.

As to how these isolated nerve cells functionate, Dr. Cajal gave the clew from the very first, and his explanation has met with universal approval.

In the modified view, the nerve cell retains its old position as the storehouse of nervous energy. Each of the filaments jutting out from the cell is held, as before, to be indeed a transmitter of impulses, but a transmitter that operates intermittently, like a telephone wire that is not always "connected," and, like that wire, the nerve fibril operates by contact and not by continuity. Under proper stimulation the ends of the fibrils reach out, come in contact with other end fibrils of other cells, and conduct their destined impulse. Again they retract, and communication ceases for the time between those particular cells. Meantime, by a different arrangement of the various conductors, different sets of cells are placed in communication, different associations of nervous impulses induced, different trains of thought engendered. Each fibril when retracted becomes a nonconductor, but when extended and ill contact with another fibril, or with the body of another cell, it conducts its message as readily as a continuous filament could do -precisely as in the case of an electric wire. 


\section{'THE S'TOLY OF NINETEEN'TH-CENIULY SCIENCE}

This conception, founded on a most tangible anatomical basis, enables us to answer the question as to how ideas are isolated, and also, as Dr. Cajal points out, throws new light on many other mental processes. One can imagine, for example, by keeping in mind the flexible nerve prolongations, how new trains of thought may be engendered through novel associations of cells; how facility of thought or of action in certain directions is acquired through the habitual making of certain nerve cell connections; how certain bits of knowledge may escape our memory, and refuse to be found for a time, because of a temporary incapacity of the nerve cells to make the proper connections; and so on indefinitely. If one likens each nerve cell to a central telephoneoffice, each of its filamentous prolongations to a telephone wire, he can imagine a striking analogy between the modus operandi of nervous processes and of the telephone system. The utility of new connections at the central office, the uselessness of the mechanism when the connections cannot be made, the "wires in use" that retard your message, perhaps even the crossing of wires, bringing you a jangle of sounds far different from what you desire-all these and a multiplicity of other things that will suggest themselves to every user of the telephone may be imagined as being almost ludicrously paralleled in the operations of the nerrous mechanism. And that parallel, startling as it may seem, is not a mere futile imagining. It is sustained and rendered plausible by a sound substratum of knowledge of the anatomical conditions under which the central nerrous mechanism exists, and in default of which, as pathology demonstrates with no less certitude, its functionings are futile to produce the normal manifestations of higher intellection. 


\section{CHAPTER XIII}

\section{SOME UNSOLVED SCIENTIFIC PROBLEMS}

Is the preceding chapters I hare endeavored to outline the story of the achievements of our century in the various fields of pure science. In so broad an attempt, within such spacial limits, it has of course been impossible to dwell upon details, or eren to hint at every minor discovery. At best one could but summarize the broad sweep of progress somewhat as a battle might be described by a distant eye-iritness, telling of the general direction of action, of the movements of large masses, the names of leaders of brigades and divisions, but necessarily ignoring the lesser fluctuations of advance or recession and the individual gallantry of the rank and file. In particular, interest has centred upon the storming of the various special strongholds of ignorant or prejudiced opposition, which at last hare been triumphantly occupied by the band of progress. In each case where such a stronghold has fallen, the victory has been achieved solely throngh the destructive agency of newly discovered or newly marshalled facts - the only weapons which the warrior of science seeks or cares for. Facts must be marshalled, of course, about the guidon of a hypothesis, but that guidon can only lead on to victory if the facts themselves support 
it. Once planted victoriously on the conquered ramparts, the hypothesis becomes a theory - a generalization of science-marking a fresh coign of vantage, which can never be successfully assailed unless by a new host of antagonistic facts. Such generalizations, with the events leading directly up to them, have chiefly occupied our attention.

But a moment's reflection makes it clear that the battle of science, thus considered, is ever shifting ground and never ended. Thus at any given period there are many unsettled skirmishes undel way; many hypotheses are yet only struggling towards the strongholds of theory, perhaps never to attain it; in many directions the hosts of antagonistic facts seem so evenly matched that the hazard of war appears uncertain; or, again, so few facts are available that as yet no attack worthy the name is possible. Such unsettled controversies as these have, for the most part, been ignored in our survey of the field. But it would not be fair to conclude our story without adverting to them, at least in brief; for some of them have to do with the most comprehensive and important questions with which science deals, and the aggregate number of facts involved in these unfinished battles is often great, even though as yet the marshalling has not led to final victory for any faction. In some cases, doubtless, the right hypothesis is actually in the field, but its supremacy not ret conclusirely proved-perhaps not to be prored for many years or decades to come. Some of the chief scientific results of our century have been but the gaining of supremacy for hypotheses that were mere forlorn hopes, looked on with general contempt, if at all heeded, when the eighteenth century came to a close-witness the doctrines of 434. 
the great age of the earth, of the immateriality of heat, of the undulatory character of light, of chemical atomicy, of organic evolution. Contrariwise, the opposite ideas to all of these had seemingly a safe supremacy until the new facts drove them from the field. Who shall say, then, what forlorn hope of to-day's science may not be the conquering host of to-morrow? All that one dare attempt is to cite the pretensions of a few hypotheses that are struggling over the still contested ground.

\section{I}

SOLAR AND TELLURIC PROBLEMS

Our sun being only a minor atom of the stellar pebble, solar problems in general are of course stellar problems also. But there are certain special questions regarding which we are able to interrogate the sun because of his proximity, and which have, furthermore, a peculiar interest for the residents of our little globe because of our dependence upon this particular star. One of the most far-reaching of these is as to where the sun gets the heat that he gires off in such liberal quantities. We have already seen that Dr. Mayer, of conservation-ofenergy fame, was the first to ask this question. As soon as the doctrine of the persistence and convertibility of energy was grasped, about the middle of the century, it became clear that this was one of the most puzzling of questions. It did not at all suffice to answer that the sun is a ball of fire, for computation showed that, at the present rate of heat-giving, if the sun were a solid mass of coal, he would be totally consumed in about five thousand years. As no such decrease in size as this implies 
had taken place within historic times, it was clear that some other explanation must be sought.

Dr. Mayer himself hit upon what seemed a tenable solution at the very outset. Starting from the observed fact that myriads of tiny meteorites are hurled into the earth's atmosphere daily, he argued that the sun must receive these visitants in really enormous quantitiessufficient, probably, to maintain his temperature at the observed limits. There was nothing at all unreasonable about this assumption, for the amount of energy in a swiftly moring body capable of being transformed into heat if the body be arrested is relatirely enormous. Thus it is calculated that a pound of coal dropped in to the sun from the mathematician's favorite starting-point, infinity, would produce some six thousand times the heat it could engender if merely burned at the sun's surface. In other words, if a little over two pounds of material from infinity were to fall into each square yard of the sun's surface each hour, his observed heat would be accounted for; whereas almost seven tons per square yard of stationary fuel would be required each hour to produce the same effect.

In view of the pelting which our little earth receives, it seemed not an excessive requisition upon the meteoric supply to suppose that the requisite amount of natter may fall into the sun, and for a time this explanation of his incandescence was pretty generally accepted. But soon astronomers began to make calculations as to the amount of matter which this assumption added to our solar system, particularly as it aggregated near the sun in the converging radii, and then it was clear that no such mass of matter could be there without interfering demonstrably with the observed course of the interior 
planets. So another source of the sun's energy had to be sought. It was found forthwith by that other great German, Helmholtz, who pointed out that the falling matter through which heat may be generated might just as well be within the substance of the sun as without; in other words, that contraction of the sun's heated body is quite sufficient to account for a long-sustained heatsupply which the mere burning of any known substance could not approach. Noreover, the amount of matter thus falling towards the sun's centre being enormousnamely, the total substance of the sun-a relatively small amount of contraction would be theoretically sufficient to keep the sun's furnace at par, so to speak.

At first sight this explanation seemed a little puzzling to many laymen and some experts, for it seemed to imply, as Lord Kelvin pointed out, that the sun contracts because it is getting cooler, and gains heat because it contracts. But this feat is not really as paradoxical as it seems, for it is not implied that there is any real gain of heat in the sun's mass as a whole, but quite the reverse. All that is sought is an explanation of a maintenance of heat-giving capacity relatively unchanged for a long, but not an interminable, period. Indeed, exactly here comes in the novel and startling feature of Helmholtz's calculation. According to Mayer's meteoric hypothesis, there were no data at hand for any estimate whatever as to the sun's permanency, since no one could surmise what might be the limits of the meteoric supply. But Helmholtz's estimate implied an incandescent body cooling-lieeping up a somewhat equable temperature through contraction for a time, but for a limited time only; destined ultimately to become liquid, solid; to cool below the temperature of incandescence-to die. Not only so, but it 
became possible to calculate the limits of time within which this culmination would probably occur. It was only necessary to calculate the total amount of heat which could be generated by the total mass of our solar system in falling together to the sun's centre from "infinity" to find the total heat-supply to be drawn upon. Assuming, then, that the present observed rate of heatgiving has been the average maintained in the past, a simple division gives the number of years for which the original supply is adequate. The supply will be exhausted, it will be observed, when the mass comes into stable equilibrium as a solid body, no longer subject to contraction, about the sun's centre-such a body, in short, as our earth is at present.

This calculation was made by Lord Kelvin, Professor Tait, and others, and the result was one of the most truly dynamitic surprises of the century. For it transpired that, according to mathematics, the entire limit of the sun's heat-giving life could not exceed something like twenty-five millions of years. The publication of that estimate, with the appearance of authority, brought a reritable storm about the heads of the physicists. The entire geological and biological worlds were up in arms in a trice. Two or three generations before, they hurled brickbats at any one who even hinted that the solar system might be more than six thousand years old; now they jeered in derision at the attempt to limit the lifebearing period of our globe to a paltry fifteen or twenty millions.

The controversy as to solar time thus raised proved one of the most curious and interesting scientific disputations of the century. The scene soon shifted from the sun to the earth; for a little reflection made it clear 
that the data regarding the sun alone were not sufficiently definite. Thus Dr. Croll contended that if the parent bodies of the sun had chanced to be "flying stars" before collision, a rastly greater supply of heat would have been engendered than if the matter merely fell together. Again, it could not be overlooked that a host of meteors are falling into the sun, and that this source of energy, though not in itself sufficient to account for all the heat in question, might be sufficient to vitiate utterly any exact calculations. Yet again, Professor Lockyer called attention to another source of rariation, in the fact that the chemical combination of elements hitherto existing separately must produce large quantities of heat, it being even suggested that this source alone might possibly account for all the present output. On the whole, then, it became clear that the contraction theory of the sun's heat must itself await the demonstration of observed shrinkage of the solar disc, as riewed by future generations of observers, before taking rank as an incontestable theory, and that computations as to time based solely on this hypothesis must in the meantime be viewed askance.

But, the time controversy having taken root, new methods were naturally found for testing it. The geologists sought to estimate the period of time that must have been required for the deposit of the sedimentary rocks now observed to make up the outer crust of the earth. The amount of sediment carried through the mouth of a great river furnishes a clew to the rate of denudation of the area drained by that river. Thus the studies of Messrs. Humphreys and Abbot, made for a different purpose, show that the average level of the territory drained by the Mississippi is being reduced by 
about one foot in six thousand years. The sediment is, of course, being piled up out in the Gulf at a proportionate rate. If, then, this be assumed to be an average rate of denudation and deposit in the past, and if the total thickness of sedimentary deposits of past ages were known, a simple calculation would show the age of the earth's crust since the first continents were formed. But unfortunately these "ifs" stand mountain-high here, all the essential factors being indeterminate. Nevertheless, the geologists contended that they could easily make out a case proving that the constructive and destructive work still in evidence, to say nothing of anterior revolutions, could not have been accomplished in less than from twenty-five to fifty millions of years.

This computation would have carried little weight with the physicists had it not chanced that another computation of their own was soon made which had even more startling results. This computation, made by Lord Kelvin, was based on the rate of loss of heat by the earth. It thus resembled the previous solar estimate in method. But the result was very different, for the new estimate seemed to prove that since the final crust of the earth formed a period of from one hundred to two hundred millions of years has efapsed.

With this all controversy ceased, for the most grasping geologist or biologist would content himself with a fraction of that time. What is more to the point, however, is the fact, which these varying estimates hare made patent, that computations of the age of the earth based on any data at hand are little better than rough guesses. Long before the definite estimates were undertaken, geologists had proved that the earth is very, very 
old, and it can hardly be said that the attempted computations have added much of definiteness to that proposition. They have, indeed, proved that the period of time to be drawn upon is not infinite; but the nebular liypothesis, to say nothing of common-sense, carried us as far as that long ago.

If the computations in question have failed of their direct purpose, however, they have been by no means lacking in important collateral results. To mention but one of these, Lord Kelvin was led by this controversy over the earth's age to make his famous computation in which he proved that the telluric structure, as a whole, must have at least the rigidity of steel in order to resist the moon's tidal pull as it does. Hopkins had, indeed, made a somewhat similar estimate as early as 1539 , proving that the earth's crust inust be at least eight hundred or a thousand miles in thickness; but geologists had utterly ignored this computation, and the idea of a thin crust on a fluid interior had continued to be the orthodox geological doctrine. Since Lord Kelvin's estimate was made, his claim that the final crust of the earth could not have formed until the mass was solid throughout, or at least until a honeycomb of solid matter had been bridged up from centre to circumference, has gained pretty general acceptance. It still remains an open question, however, as to what proportion the lacunx of molten matter bear at the present day to the solidified portions, and therefore to what extent the earth will be subject to further shrinkage and attendant surface contortions. That some such lacuna do exist is demonstrated daily by the phenomena of volcanoes. So, after all, the crust theory has been supplanted by a compromise theory rather than completely overthrown, and 
our knowledge of the condition of the telluric depths is still far from definite.

If so much uncertainty attends these fundamental questions as to the earth's past and present, it is not strange that open problems as to her future are still more numerous. We have seen how, according to Professor Darwin's computations, the moon threatens to come back to earth with destructive force some day. Yet Professor Darwin himself urges that there are elements of fallibility in the data involved that rob the computation of all certainty. Much the same thing is true of perhaps all the estimates that have been made as to the earth's ultimate fate. Thus it has been suggested that, even should the sun's heat not forsake us, our day will become month-long, and then year-long; that all the water of the globe must ultimately filter into its depths, and all the air fly off into space, learing our earth as dry and as devoid of atmosphere as the moon; and, finally, that ether-friction, if it exist, or', in default of that, meteoric friction, must ultimately bring the earth back to the sun. But in all these prognostications there are possible compensating factors that vitiate the estimates and leave the exact results in doubt. The last word of the cosmic science of our century is a prophecy of evil-if annihilation be an evil. But it is left for the science of another generation to point out more clearly the exact terms in which the prophecy is most likely to be fulfilled. 
In regard to all these cosmic and telluric problems, it will be seen, there is always the same appeal to one central rule of action-the law of gravitation. When we turn from macrocosm to microcosm it would appear as if new forces of interaction were introduced in the porrers of cohesion and of chemical action of molecules and atoms. But Lord Kelvin has argued that it is possible to form such a conception of the forms and space relations of the ultimate particles of matter that their mutual attractions may be explained by involing that same law of gravitation which holds the stars and planets in their course. What, then, is this all-compassing power of gravitation which occupies so central a position in the scheme of mechanical things?

The simple answer is that no man knows. The wisest physicist of to-day will assure you that he knows absolutely nothing of the why of gravitation-that he can no more explain why a stone tossed into the air falls back to earth than can the boy who tosses the stone. But while this statement puts in a nutshell the scientific status of explanations of gravitation, yet it is not in human nature that speculative scientists should refrain from the effort to explain it. Such efforts have been made; yet, on the whole, they are surprisingly few in number; indeed, there are but two that need claim our attention here, and one of these has hardly more than historical interest. One of these is the so-called ultramundane-corpuscle hypothesis of Le Sage; the other is based on the vortex theory of matter. 
The theory of Le Sage assumes that the entire universe is filled with infinitely minute particles flying in right lines in every direction with inconceivable rapidity. Every mass of tangible matter in the universe is incessantly bombarded by these particles, but any two noncontiguous masses (whether separated by an infinitesimal space or by the limits of the universe) are mutually shielded by one another from a certain number of the particles, and thus impelled towards one another by the excess of bombardment on their opposite sides. What applies to two masses applies also, of course, to any number of masses-in short, to all the matter in the universe. To make the hypothesis workable, so to say, it is necessary to assume that the "ultra-mundane" parlticles are possessed of absolute elasticity, so that they rebound from one another on collision without loss of speed. It is also necessary to assume that all tangible matter has to an almost unthinkable degree a sieve-like texture, so that the vast proportion of the coercive particles pass entirely through the body of any mass they encounter-a star or world, for example-without really touching any part of its actual substance. This assumption is necessary because gravitation takes no account of mere corporeal bulk, but only of mass or ultimate solidarity. Thus a very bulky object may be so loosely meshed that it retards relatively few of the corpuscles, and hence gravitates with relative feebleness-or, to adopt a more familiar mode of expression, is light in weight.

This is certainly heaping hypotheses together in a reckless way, and it is perhaps not surprising that Le Sage's conception did not at first arouse any very great amount of interest. It was put forward about a century 
ago, but for two or three generations remained prartically unnoticed. The philosophers of the first half of our century seem to have despaired of explaining gravitation, though Faraday long experimented in the hope of establishing a relation between gravitation and electricity or magnetism. But not long after the middle of the century, when a new science of dynamics was claiming paramount importance, and physicists were striving to express all tangible phenomena in terms of matter in motion, the theory of Le Sage was revived and given a large measure of attention. It had at least the merit of explaining the facts without conflicting with any known mechanical law, which was more than could be said of any other guess at the question that had ever been made.

More recently, however, another explanation has been found which also meets this condition. It is a conception based, like most other physical speculations of the last generation, "pon the hypothesis of the rortex atom, and was suggested, no doubt, by those speculations which consider electricity and magnetism to be conditions of strain or twist in the substance of the universal ether. In a word, it supposes that gravitation also is a form of strain in this ether-a strain that may be likened to a suction which the vortex atom is supposed to exert on the ether in which it lies. According to this view, gravitation is not a push from without, but a pull from within; not due to exterior influences, but an inherent and indissoluble property of matter itself. The conception has the further merit of correlating gravitation with electricity, magnetism, and light, as a condition of that strange ethereal ocean of which modern physics takes so much account. But here, again, clearly, we are but 
heaping hypothesis upon hypothesis, as before. Still, a hypothesis that violates no known law and has the warrant of philosophical probability is always worthy of a hearing. Only we must not forget that it is hypothesis only, not conclusive theory.

The same caution applies, manifestly, to all the other speculations which hare the vortex atom, so to say, for their foundation-stone. Thus Professors Stewart and Tait's inferences as to the destructibility of matter, based on the supposition that the ether is not quite frictionless, Professor Dolbear's suggestions as to the creation of matter through the development of new ether ripples, and the same thinker's speculations as to an upper limit of temperature, based on the mechanical conception of a limit to the possible vibrations of a rortex ring, not to mention other more or less fascinating speculations based on the vortex hypothesis, must be regarded, whatever their intrinsic interest, as insecurely grounded, until such time as new experimental methods shall give them another footing. Lord Kelvin himself holds all such speculations utterly in abeyance. "The vortex theory," he says, "is only a dream. Itself unproven, it can prove nothing, and any speculations founded upon it are mere dreams about a dream."

That certainly must be considered an unduly modest pronouncement regarding the only workable hypothesis of the constitution of matter that has ever been imagined; yet the fact certainly holds that the vortex theory, the great contribution of our century towards the solution of a world-old problem, has not been carried beyond the stage of hypothesis, and must be passed on, with its burden of interesting corollaries, to another generation for the experimental evidence that will lead 
to its acceptance or its refutation. Our century has given experimental proof of the existence of the atom, but has not been able to fathom in the same way the exact form or nature of this ultimate particle of matter.

Equally in the dark are we as to the explanation of that strange affinity for its neighbors which erery atom manifests in some degree. If we assume that the power which holds one atom to another is the same which in case of larger bodies we term gravitation, that answer carries us but a little way, since, as we have seen, gravitation itself is the greatest of mysteries. But again, how chances it that different atoms attract one another in such varying degrees, so that, for example, fluorine unites with everything it touches, argon with nothing? And how is it that different kinds of atoms can hold to themselves such varying numbers of fellow-atoms-oxygen one, hydrogen two, and so on? These are questions for the future. The wisest chemist does not know why the simplest chemical experiment results as it does. Take, for example, a water-like solution of nitrate of silver, and let fall into it a few drops of another water-like solution of hydrochloric acid; a white insoluble precipitate of chloride of silver is formed. Any tyro in chemistry could have predicted the result with absolute certainty. But the prediction would have been based purely upon previous empirical knowledge-solely upon the fact that the thing had been done before orer and orer, always with the same result. Why the silver forsook the nitrogen atom, and grappled the atom of oxygen, no one knows. Nor can any one as yet explain just why it is that the new compound is an insoluble, colored, opaque substance, whereas the antecedent ones were soluble, colorless, and transparent. Nore than that, no one can 
explain with certainty just what is meant by the familiar word soluble itself. That is to say, no one knows just what happens when one drops a lump of salt or sugar into a bowl of water. We may beliere with Professor Ostwald and his followers, that the molecules of sugar merely glide everywhere between the molecules of water, without chemical action; or, on the other hand, dismissing this mechanical explanation, we may say with Mendeleef that the process of solution is the most active of chemical phenomena, involving that incessant interplay of atoms known as dissociation. But these two explanations are mutually exclusive, and no one can say positively which one, if either one, is right. Nor is either theory at best more than a half-explanation, for the why of the strange mechanical or chemical actirities postulated is quite ignored. How is it, for example, that the molecules of water are able to loosen the intermolecular bonds of the sugar particles, enabling them to scamper apart?

But, for that matter, what is the nature of these intermolecular bonds in any case? And why, at the same temperature, are some substances held together with such enormous rigidity, others so loosely? Why does not a lump of iron dissolve as readily as the lump of sugar in our bowl of water? Guesses may be made today at these riddles, to be sure, bnt anything like tenable solutions will only be possible when we know much more than at present of the nature of intermolecular forces, and of the mechanism of molecular structures. As to this last, studies are under way that are full of promise. For the past ten or fifteen years Professor Van 't Hoof of Amsterdain (now of Berlin), with a company of followers, has made the space relations of atoms 


\section{SONE UNSOLVED SCIENTIFIC PROBLEMS}

a special study, with the result that so-called stereochemistry has attained a firm position. A truly amazing insight has been gained into the space relations of the molecules of carbon compounds in particular, and other compounds are under investigation. But these results, wonderful though they seem when the intricacy of the subject is considered, are, after all, only tentative. It is demonstrated that some molecules have their atoms arranged in perfectly definite and unalterable schemes, but just how these systems are to be mechanically pictured-whether as miniature planetary systems or what not-remains for the investigators of the future to determine.

It appears, then, that whicherer way one turns in the realm of the atom and molecule, one finds it a land of mysteries. In no field of science have more startling discoveries been made in our century than here; yet nowhere else do there seem to lie wider realms yet unfathomed.

\section{III}

\section{LIFE PROBI.EMS}

In the life history of at least one of the myriad star systems there has come a time when, on the surface of one of the minor members of the group, atoms of matter have been aggregated into such associations as to constitute what is called living matter. A question that at once suggests itself to any one who conceives even vaguely the relative uniformity of conditions in the different star groups is as to whether other worlds than ours have also their complement of living forms. The question has interested speculative science more 
perhaps in our century than ever before, but it can hardly be said that much progress has been made towards a definite answer. At first blush the demonstration that all the worlds known to us are composed of the same matter, subject to the same general laws, and probably passing through kindred stages of evolution and decay, would seem to carry with it the reasonable presumption that to all primary planets, such as ours, a similar life-bearing stage must come. But a moment's reflection shows that scientific probabilities do not carry one safely so far as this. Living matter, as we know it, notwithstanding its capacity for variation, is conditioned within very narrow limits as to physical surroundings. Now it is easily to be conceived that these peculiar conditions have never been duplicated on any other of all the myriad worlds. If not, then those more complex aggregations of atoms which we must suppose to have been built up in some degree on all cooling globes must be of a character so different from what we term living matter that we should not recognize them as such. Some of them may be infinitely more complex, more diversified in their capacities, more widely responsive to the influences about them, than any living thing on our earth, and yet not respond at all to the conditions which we apply as tests of the existence of life.

This is but another way of saying that the peculiar limitations of specialized aggregations of matter which characterize what we term living matter may be mere incidental details of the evolution of our particular star group, our particular planet even-haring some such relative magnitude in the cosmic order as, for example, the exact detail of outline of some particular leaf of a 
tree bears to the entire subject of vegetable life. But, on the other hand, it is also conceivable that the conditions on all planets comparable in position to ours, though never absolutely identical, yet pass at some stage through so similar an epoch that on each and every one of them there is developed something measurably comparable, in human terms, to what we here know as living matter; differing widely, perhaps, from any particular form of living being here, yet still conforming broadly to a definition of living things. In that case the life-bearing stage of a planet must be considered as having far more general significance; perhaps eren as constituting the time of fruitage of the cosmic organism, though nothing but human egotism gives warrant to this particular presumption.

Between these two opposing views every one is free to choose according to his preconceptions, for as yet science is unable to give a deciding vote. Equally open to discussion is that other question, as to whether the evolution of universal atoms into a "vital" association occurred but once on our globe, forming the primitire mass from which all the diversified forms erolved, or whether such shifting from the so-called non-vital to the vital was many times repeated-perhaps still goes on incessantly. It is quite true that the testimony of oul century, so far as it goes, is all against the idea of "spontaneous generation" under existing conditions. It has been clearly enough demonstrated that the bacteria and other low forms of familiar life which formerly were supposed to originate "spontaneously" had a quite different origin. But the solution of this special case leares the general problem still far from solved. Who knows what are the conditions necessary to the evolution of the 
ever-present atoms into "vital" associations? Perhaps extreme pressure may be one of these conditions; and, for aught any man knows to the contrary, the "spontaneous generation" of living protoplasm may be taking place incessintly at the bottom of evely ocean of the globe.

This of course is a mere bald statement of possibilities. It may be met by anotlier statement of possibilities, to the effect that perlaps the conditions necessary to the erolution of living matter here may lave been fulfilled but once, since which time the entire current of life on our globe has been a diversified stream from that one source. Observe, please, that this assumption does not fall within that category which I mention above as contraband of science in speaking of the origin of worlds. The existence of life on our globe is only an incident limited to a relatirely insignificant period of time, and whether the exact conditions necessary to its erolution pertained but one second or a luundred million years does not in the least matter in a philosophical analysis. It is merely a question of fact, just as the particular temperature of the earth's surface at any given epoch is a question of fact, the one condition, like the other, being temporary and incidental. But, as I hare said, the question of fact as to the exact time of origin of life on our globe is a question science as ret cannot answer.

But, in any event, what is rastly more important than this question as to the duration of time in which living matter was evolved is a comprehension of the philosophical status of this evolution from the "non-rital" to the "vital." If one assumes that this evolution was brought about by an interruption of the play of forces hitherto working in the universe-that the correlation of forces 
involved was unique, acting then and then only-by that assumption he remores the question of the origin of life utterly from the domain of science-exactly as the assumption of an initial push would remove the question of the origin of worlds from the domain of science. But the science of to-day most emphatically demurs to any such assumption. Every scientist with a wide grasp of facts, who can think clearly and without prejudice over the field of what is known of cosmic evolution, must be driven to believe that the alleged wide gap between vital and non-vital matter is largely a figment of prejudiced human understanding. In the broader view there seem no gaps in the scheme of cosmic evolution-no break in the incessant reciprocity of atomic actions, whether those atoms be floating as a "fire mist" out in one part of space, or aggregated into the brain of a man in another part. And it seems well within the range ofscientific expectation that the laboratory worker of the future will learn how so to duplicate telluric conditions that the play of universal forces will build living matter out of the inorganic in the laboratory, as they havedone, and perhaps still are doing, in the terrestrial oceans.

To the timid reasoner that assumption of possibilities may seem startling. But assuredly it is no more so than seemed, a century ago, the assumption that man has evolved, through the agency of "natural laws" only, from the lowest organism. Yet the timidity of that elder day has been obliged by the progress of our century to adapt its conceptions to that assured sequence of events. And some day, in all probability, the timidity of to-day will be obliged to take that final logical step which to-day's knowledge foreshadows as a future if not a present necessity. 


\section{'THE STORY OF NINETEEN'TH-CENTURY SCIENCE}

Whatever future science may be able to accomplish in this direction, however, it must be admitted that present science finds its hands quite full, without going farther afield than to observe the succession of generations among existing forms of life. Since the establishment of the doctrine of organic evolution, questions of heredity, always sufficiently interesting, have been at the very focus of attention of the biological world. These questions, under modern treatment, have resolved themselves, since the mechanism of 'such transmission has been proximately understood, into problems of cellular activity. And much as has been learned about the cell of late, that interesting microcosm still offers a multitude of intricacies for solution.

Thus, at the very threshold, some of the most elementary principles of mechanical construction of the cell are still matters of controversy. On the one hand, it is held by Professor $O$. Bütschli and his followers that the substance of the typical cell is essentially alveolar, or foamlike, comparable to an emulsion, and that the observed reticular structure of the cell is due to the intersections of the walls of the minute ultimate globules. But another equally authoritative school of workers holds to the view, first expressed by Frommann and Arnold, that the reticulum is really a system of threads, which constitute the most important basis of the cell structure. It is even held that these fibres penetrate the cell walls and connect adjoining cells, so that the entire body is a reticulum. For the moment there is no final decision between these opposing views. Professor Wilson of Columbia has suggested that both may contain a measure of the truth.

Again, it is a question whether the finer granules seen 454 
within the cell are or are not typical structures, "capable of assimilation, growth, and division, and hence to be regarded as elementary units of structure standing between the cell and the ultimate molecules of living matter." The more philosophical thinkers, like Spencer, Darwin, Haeckel, Michael Foster, August Weismann, and many others, believe that such "intermediate units must exist, whether or not the microscope reveals them to view. Weismann, who has most fully elaborated a hy pothetical scheme of the relations of the intracellular units, identifies the larger of these units not with the ordinary granules of the cell, but with a remarkable structure called chromatin, which becomes aggregated within the cell nucleus at the time of cellular divisiona structure which dirides into definite parts, and goes through some most suggestive manœurres in the process of cell multiplication. All these are puzzling structures; and there is another minute body within the cell, called the centrosome, that is quite as much so. This structure, discovered by Van Beneden, has been regarded as essential to cell division, yet some recent botanical studies seem to show that sometimes it is altogether wanting in a dividing cell.

In a word, the architecture of the cell has been shown by modern researches to be wonderfully complicater, but the accumulating researches are just at a point where much is obscure about many of the observed phenomena. The immediate future seems full of promise of arlvances upon present understanding of cell processes. But for the moment it remains for us, as for preceding generations, about the most incomprehensible, scientifically speaking, of observer phenomena, that a single microscopic egg cell should contain within its substance all 


\section{THE STORY OF NINETEENTH-CENTURY SCIENCE}

the potentialities of a highly differentiated adult being. The fact that it does contain such potentialities is the most familiar of every-day biological observations, but not even a proximal explanation of the fact is as yet at tainable.

Turning from the cell as an individual to the mature organism which the cell composes when aggregated with its fellows, one finds the usual complement of open questions, of greater or less significance, focalizing the attention of working biologrists. Thus the evolutionist, secure as is his general position, is yet in doubt when it comes to tracing the exact lineage of various forms. He does not know, for example, exactly which order of invertebrates contains the type from which vertebrates sprang, though several hotly contested opinions, each exclusive of the rest, are in the field. Again, there is like uncertainty and difference of opinion as to just which order of lower vertebrates formed the direct ancestry of the mammals. Among the mammals themselves there are several orders, such as the whales, the elephants, and even man himself, whose exact lines of more immediate ancestry are not as fully revealed by present paleontology as is to be fully desired.

All these, however, are details that hardly take rank with the general problems that we are noticing. There are other questions, however, concerning the history and present evolution of man himself, that are of wider scope, or at least of seemingly greater importance from a human stand.point, which within recent decades have come for the first time within the scope of truly inductive science. These are the problems of anthropology -a science of such wide scope, such far-reaching col- 
lateral implications, that as yet its specific field and functions are not as clearly defined or as generally recognized as they are probably destined to be in the near future. The province of this new science is to correlate the discoveries of a widle range of collateral sciencespaleontology, biology, medicine, and so on-from the point of view of human history and human welfare. To this end all observable races of men are studied as to their physical characteristics, their mental and moral traits, their manners, customs, languages, and religions. A mass of data is already at hand, and in process of sorting and correlating. Out of this effort will probably come all manner of useful generalizations, perhaps in time bringing sociology, or the study of human social relations, to the rank of a veritable science. But great as is the promise of anthropology, it can hardly be denied that the broader questions with which it has to deal-questions of race, of government, of social evolution-are still this side the fixed plane of assured generalization. No small part of its interest and importance depends upon the fact that the great problems that engage it are as yet unsolved problems. In a word, anthropology is perhaps the most important science in the hierarchy to-day exactly because it is an immature science. Its position to-day is perhaps not unlike that of paleontology at the close of the eighteenth century. May its promise find as full fruition! 



\section{N D E X}

ADams, Jous, lis determination of the exact location of Neptune, 48 ; corrects Laplace in reference to the moon's acceleration, 51.

Adams, Professor, his investigation of meteor showers, 59.

Aerial currents, their classification and the laws governing them, 182191.

Aerolites, study of their origin and cliaracter, 157-162.

Atrassiz, Jean Louis Rodolplre, his belief in the special-creation lypothesis, 105 ; lis advocacy and cstablishment of the glacial theory, 134-136; on the reception of scientifie truth, 153.

Alibert, Jean Louis, makes known the cause and cure of the itch, 362 .

Alpha Centauri, its comparative dis. tance from the earth, 66 .

Amici, Giovanni Battista, lis iuvention of the reflecting mieroseope, $327,328$.

Ampère, André Marie, establishes the connection of magnetism and electricity, 207; confirms the atomic theory of Arogadro, 258; discovers the properties of ammonium, 267.

Anasthesia, discovery of the method of, $365-375$.

Anatomy, eightcentl - century progress in the science, 36 . See Anat. omy and physiology.

Anatomy and physiology, their progress in the nineteenth century, 321-353 ; Cuvier's classification of the animal kingtom and his "law of co-ordination," 321,322 ; Bicliat's generalization of the animal organs, 322,323 ; and his division of all animal structures into tissues, 324 ; improvements in micro. seopes and lenses, and the invelltion of the compound microscope, 324-328; rise of listology and its triumphs, 328-336; establishment and development of the cell therr'y, $336-346$; iuvestigations of the processes of digestion and respiration and of the functions of the huntan organs, 346-353.

Anthrax, discovery of its cause and remedy, 380, 381, 387-389.

Anthropology, its far-reating possibilities and its unsolved problems, 456, 457 .

Anti-cyclone, description of, 190 .

Antisepsis, the theory and practice of, 382-386.

Antitoxine, its diseovery and application, 390-392.

Anti-trade-winds, their eause and effects, 178, 185, 186.

Arago, Dominique François, his pioneer work in celestial plotograpliy, 76 ; champions Fresnel's undulatory theory of light and the ferd which his advocacy engendered, 202-204, 225 ; discovers that magnets may be produced by electrical ind uction, 208.

Arcturus, its comparative brightness, 69.

Asteroids, their discovery and theories regarding, 44-48.

Astronomy, its development during the eigliteenth century, 5-17; the "nebular hypothesis," its amplification and completion, 13-17; progress of the science during the 


\section{INDEX}

nineteenth century, 44-87; dis- Auenbrugger ron Auenbrog, his incovery of Ceres, by Piazzi, 44; of Pallas and Vesta, by Olbers, 44, 47 ; and of Juno, by Harding, 47 ; Hencke's discovery of a fiftl asteroid is followed by a thorough investigation of the asteroidal system, 47; how the asteroids are accounted for, 47,48 ; discovery of Neptune, predicated by Bessel and Leverier, is accomplished by Dr. Galle, 48, 49 ; Leverrier's predication of a trans-Neptunian planet, 49; discovery of the moons of Mar's by Professor Hall, 49 ; discovery of Saturn's crape ring, 49 , 50; Saturn's rings discussed and their nature determined, 50 ; theories regarding the acceleration of the moon, and how it is accounted for, 50-53 ; speculations regarding comets and the discovery of their nature and constituents, $53-60$; the study of double stars by Wilkiam and John Herschel and otliers, 63-65; star distance determined, $65-69$; and star motion, mass, and brightmess reckoned, 69,70 ; solar and sidereal investigations by means of the spectroscope, 70-76; discovery of "invisible" or" dark stars, 74-76; trinmphs of celestial photography, $76-83,285,286$; Lockyer's "meteoric lıypotlıesis," $83-86$; speculations as to the potentialitics of the stellar universe, 86, 87; some unsolved solar and telluric problems, 435-442.

Atomic theory, discovery and developinent of, 252-262.

Atoms, Boscovicli's speculations regarling, 241; their combining weights determined and the method of expressing them invented, 254 , $255,259,260$; law of the specific heat of, 260-262; establishment of the law of valency, 269-275; their character and properties investigated, 275-278; Pront's theors of the atonic weights and compound nature of the elements, 278-280, 283-257; some unsolved problems regarding, 447-449. vention of the percussion method for studying disease, 355.

Aurora, the, speculations regarding cause of, $162-16 \%$.

Auscultation, its discovery and development as an aid to diagnosis, 356,359 .

Avogadro, Amadeo, his liypothesis as to the numbers of ultimate particles in volunes of guses, and his invention of the term "molecule" as the unit of physical structure, $258,269$.

BACTKRIA, in restigations relating to, 379-386.

Baer, Karl Ernst ron, his anatomical researches, 337.

Bary, Ileinrich Anton de, his discovery of the identity of the animal and vegetable cell, 340 .

Bastian, Henry Charlton, revives Pouchet's thcory of "spontaneuus generation," 320 .

Beammont, Elie de, his contention as to the origin of mountains, $130,145$.

Behring, Dr., his discoveries in scrumtherapy, 392.

Bell, Sir Charles, his epochal psychological discoverv, 401, 402.

Bernard, Claude, his study of the pancreas, 347 ; his discovery of the glycogenic function of the liver, 351,352 ; his discoverics relating to the nerrons system, 405,406 .

Bernoulli, Daniel, originator of the kitutic theory of gases, $242,243$.

Berthollet, Claude Louis, aids in the development of a new cliemistry, 32 ; his theory of chemical combination, 255.

Berzelius, Johan Jacob, confirms and advocates Dalton's atomic theory, 256, 259; his extension of the binary theory and establishment of theoretical chemistry, 264, 265, 267, 268.

Bessel, Friedrich Wilhelm, predicts the existence of a trans-Uranian planet, 48 ; his successful measurement of the parallax of a star, 66 ; his discorery of "invisible" stars, 74. 
Bichat, Marie François Xavier, his generalization of the animal organs, 322,323 ; his elassification of all animal structures into tissnes, 324.

Biela, Wilhelm von, his discovery of the comet bearing his name, 58 ; and its after career and destruction, 58, 59.

Binary composition of all chemical compounds, theory of, 262-265.

Biology, the great advances in the science made possible thronglı eighteent li-century explorations, 35, 36 ; its progress during the ninetecnth century, 288-320; eighteenthcentury theories of organic evolution, 288-293; Lamarek's theory of the transmutation of species, 293-297; Cuvier's theory of specinl creation and fixity of species, 297302; Oken's theory of "spontaneous generation" and of evolution of species, 298, 320; Darwin's theory of the origin of species by natural selcetion, or the "survival of the fittest," $302-310$; triumph of Darwin's theory and how it was effected, $310-317$; theories regrarding the "origin of the fittest," 317-319; consideration of the next step in organic evolution, 320.

Biot, Jean Baptiste, his investigation of the L'Aigle aerolite, 158; opposes the undulatory theory of light, $203,223$.

Black, Joseph, discoverer of latent heat, 34,171 .

Blook, the, discoveries relating to, $329,349,350$.

Boerhanve, Ifermanu, his thcory of the respiratory function, 39 .

Boillari, Dr., his researclies in eercbral physiology, 419.

Bois-Rermond, Fmil du, his psychopliysiological researches, 408.

Bond, William C., his discovery of S: turn's inner ring, 49.

Boscovich, Ruggielo Ginseppe, his speculation as to the ultimate constitution of matter, 241.

Braid, James, lis investigation of hypnotism, 41 \%.

Brain, the, Cabanis's conception of the action and functions of, 414 , 415. See Psrchology.

Bredichin's conietary theory, 54, 55 .

Brewster, Sir David, refuses to accept the theory of the conservation of energy, 218; his suggested inprovement of lenses, 325,326 .

Broca, Paul, his discovery of cerebral localization, 419, 422.

Brodie, Sir Benjamin, his untimelv pre. diction regalding anæesthetics, $\mathbf{3 6 6}$.

Bronguiart, Alexindre, how he accounted for the bowlders on the Juri, 131; his study of strata aromind Paris, 138.

Brontotheridee, or Titanotheres, their line of descent, 121.

Brown, Robert, his discovery of the nuclen- of the vegretible celi, 330, 331 .

Brown-Séquard, Charles Édouard, lis investigations of the nervous system, 405 .

Bruno, Gioldano, believed some of the planets inhabited, 12 ; burned at the stake for teaching that our earth is not the centrc of the universe, 16.

Buch, Leopold von, lis conception of the origin of mountains and of the en'atic bowlders on the Jura, 130 ; dissents from the doctrine of specinl creation, 301.

Buckliund, William, his discovery of fossil bones at Kirkdale, Yorkshire, and his deductions therefrom, 95; how he accounted for the bowlders on the Jura, 131 ; adopts the glacial theory, 135.

Buffon, Comte de (Georges Louis Ise. clerc), his early advocacy of the thcory of transmutation of species, 291, 292, 318.

Bunsell, Robert Wilhelm, with the assistance of Kirch hoff, perfects the spectroscope, 70, 283.

Buruham, S. W., his entluusiastic search for double stars, 65.

Biitschli, Professor, his theory of cell formation, 454.

Cabanis, Pigrre Jean Grorge, his conception of the action and functions of the braill, 414,415 . 


\section{INDEX}

Carnot, Sadi, discovers that heat and mechanical work are mutually convertible, 213.

Carpenter, William Benjamin, his theory of oceanic circulation, 180 ; his advocacy of Baer's anatomical theories, 337.

Catastrophism, discussions regarding the theory of, $97-99,126,130$.

Cavendish, Henry, discovers hydrogen gas and the composition of water, $31,34,253$.

Cell theory, the, its conception and development, $330-346$; sume of its unsolved problems, 454-456.

Chambers, Robert, his anonymous argument for tlie theory of tiansmutation of species, 300,301 .

Charcot, Jean Martin, his revival of hypnotism, 415.

Clrarpentier, Jean de, first ridicules and then becomes an enthusiastic adrocate of the glacial theory, 134.

Chemistry, the contest it gave rise to and its advances in the eighteenth century, 29-35; the plilogiston theory, 29-31 ; discovery of hydrogen gas, 31 ; discovery of oxygen, which led to the development of the "new chemistry," 31-35; solving the mysteries of respiration, 39-41; progress of the science during the nineteenth century, 252-287; discovery and development of the atomic theory, 252-255; discovery of the laws of atomic weights, the specific heat of atoms, and of isomorphism, 255-262; stndy of the theory of the binary composition of clsemi. cal compounds and the establishment of theoretical chemistry, 262265 ; discoveries in organic chemistry and the establishment of the law of molecular structure, 265-269; discovery of the law of valency, and the establishment and development of isomerism, 269-275; determination of the character and properties of atoms and molecules, $275-278$; discovery of the law of atomic weights and of the "law of octaves" lead to an investigation of the probable compound nature of the elements, 278-287.

Chladni, Erust F. F., his theory of ineteorites, 159, 160, 161, 162.

Chloroform, discovery of its anæsthetic properties, 374 .

Christol, M., his discovery of human fossils in the south of France, 111 . Cluristy, Henry, his important find in the caves of Dordogne, 113.

Clark, Alvan, Jr., his discovery of a "dark star," the companion of Sirius, 75.

Clausius, Rudolph Julius Fmanuel, aids in establishing the doctrine of the conservation of energy, 223225 ; investigates the kinetic theory of gases, 242-244; points out the way to mcasure the size of inolecules, 244 ; measures the energy of a molecule of gas, 245 .

Climate, and the stndy of the influences which affect it, 172-182; how that of northern India is affected by the inonsoons, 191 .

Clouds, classification of, and their formation, 169-172.

Cumets, theories regarding, and the determination of their character and origin, 53-60; photographed, 79.

Conservation of energy, discovery of the law of, 209-221.

Contagion, its cause discovered, 380382.

Co-ordination, Cuvier's law of, 322 .

Cope, Edward Drinker, his important discoveries in the Rocky Mountain region, and the story they tell, 114121 ; aivocates Lamarck's theory of the origin of favored species, 318 . 319.

Corpuseles, red blood, discovery of, 349,350 ,

Corvisart, Jean Nicholas de, introduces the perenssion method into medical practice, 354-356.

Couper, A. S., his investigations of the affinities of different elements, 271.

Croll, James, his "pre-nebular theory," 86 ; contends for many lcc ages, 136; his estimate of the 


\section{INDEX}

weight of the iee-sheet over New England, 150; lis theory of the Gulf Stream, 180, 181, 182; his theory of solar heat, 439 .

Crookes, William, his ultra-gaseous theory of mitter, 247; adroeates the Proutian theory of the compound nature of the so-ealled elements, 287.

Cuvier, Georges, his doetrine of the correlation of parts, 36 ; his study and investigation of fossil bones, which lead to the establishment of vertebrate paleontology, 91-94, 96 ; his belief in catastrophism, 98, 131 ; his disbelief in the authenticity of human fossils, 111; his investigation of strata near Paris, 138 ; his theory of special ereation and fixity of speeies, 297, 299-302 ; his classification of the animal kingdom, 321 ; his law of eo-ordination, 322 ; opposes Gall's phrenologieal system, 400 .

Cyclone, deseription of, 186.

Daguerre, Lodis Jacques Mandé, his perfeetion of plotography, 284 .

Dalton, Jolın, his solution of the problem of evaporation and precipitation, $168,169,171,172,252$, 253 ; his explanation of the tradewinds, 178, 182; his coneeption of the ehemienl atom and his atomic theory, 253-255, 259, 260, 262.

Darwin, Charles Robert, and his Origin of Species, 105-108, 302311; ; eited by Lyell to prove a change of lerel in eontinental areas, 126; his theory of latent lieat, 171; his eonstruetion and establishment of the theory of the origin of speeies by natural seleetion, 302-317.

Darwill, Frasmus, low he accounted for the aurora, 163; his prophetic conception of the transmutation of speeies, 290, 291, 296.

Darwin, Professor G. H., his determinations as to the comparative motion of the earth and moon, 51,52.

Davy, Humphry, his experiments in photography, 2 ; endorses Thomp- son's theory of heat, 27 ; experiments on respiration, 40 ; his suggestion to account for the molten eondition of the earth, 125 ; discovers that the eause of chemical and of electrical attraction are identicil, 206; proves the trausformation of labor into heat, 210 ; melts ice by friction, 225 ; lis tlieory of the properties of particles of matter (or atoms), 241, 242 ; noncommittal as to Dalton's atomie theory, 259; his remarkable discoveries which led to the theory of the binary eomposition of eliemical compounds, $262-265$; originates the method of niedieation by inhalation, 366.

Dawes, Rev. IV. R., his diseovery of a new ring around Saturn, 49, 50.

Dawson, Sir WVilliam, his study of the Laurentian srstem of Canada, 1 a. Delue, Guillaume Antoine, his theory of evaporation, 168, 170 .

Desmoulins, Louis Antoine, his psyelıologieal researelies, 400 .

Devaine, a Freneh physieian, diseovers the eanse of the infeetious disease anthrax, $380,381$.

Deville, Sainte Claire, his investigntion of the ehemical proeess known as dissociation, 273.

Dew, the problem of its formation solved, 167-172.

Digestion, investigation of its proeesses, 39, 347-352.

Diphtheria, the serum treatment for, 392,393 .

Dissociation of moleenles and atoms, investigated by Deville, 273; an unsolved problem, 447, 448 .

Donati, Giovanni Battista, speetroseopie researehes of, 70 .

Douders, Frans Cornelis, makes the first attempt to time nervous aetion, 413 .

Dove, Heinrich Wilhelm, his study of the winds, 182, 183.

Draper, Henry, sueeessfully photographs a nebula, 79 .

Draper, John William, his pioneer work in eelestial photography, 76; lis applieation of photography to spectrum analysis, 285. 


\section{INDEX}

Dubois, Eugène, his find of the apeman fossil in the island of Jara, 120.

Dujardin, Félix, his histological re. searches, 339 .

Dulong and Petit's discovery of the specific heat of atoms, 260, 261.

Dumas, Jean Baptiste André, lis work in organic chemistry, 266, $268,279,250,346,347$.

Dunn, Sergeant, his principal work in weather observation, 190.

Dutrochet, Reıé Joachim Heıri, his study of the processes of digestion, 352.

Earth, the, Thomson's estimate of its longevity, 74, 154; some unsolred problems regarding, 435-442.

Elırenberg, Christian Gottfried, disputes Mohl's cell theory, 343 ; discovers the fibrillar character of brain tissue, 425 .

Electricity, conception of, in the eighteentlı century, 24; how affected by the discovery of Volta, 28,29 ; its relationship to galvanism demoustrated, 204, 205; the cause of chemical and electrical action demonstrated to be identical, and the science of maguetoelectricity established, 206-209; its first use in signalling, 207.

Electro-chemistry, its accidental discovery through the experiments of Niclıolson and Carlyle, 28 ; Davy's theory of, 206.

Electro-magnetism, Helmboltz and Hertz's study and derelopment of, 227,228 .

Enckc, Joliann Franz, determines the orbital morement of comets, 57 .

Espy, James Pollard, his theory of wind storms, 190.

Eller, sulphuric, discorery of its anæsthctic properties, $36 \dot{9}-374$.

Ether, the, and ponderable mitter, its displacement of the "imponderables," 228, 229 ; its discovery, and speculations as to its constitution and properties, 230-236 ; experiments of Helinholtz and Thomson to prove the vortex theory of atoms.
236-240; theories as to the distribution, mutual relations, properties, and dimensions of molecules, 241245 ; also as to their ontline, action, tem perature, and energy, 245251 ; the hrpothesis that the vortex whirl is the essence of matter itself, 251. See Cliemistry.

Euler, Leonhard, lis extraordinary conclusion is to the midnight teinperature at the equator, 175 .

Evans, Jolı, aids Prestwich in making report on the paleolitlic implements found at Abbeville, 109.

Eraporation and precipitation, theories regarding, and the determination of their caluses, 167-172.

Evolution, theories of, 288-297, 302$310,317-320$; some unsolved problems regarding, 454-456.

Falconer, Hzgh, rerifies the paleolithic find of Perthes at Abbeville, 109.

Faralay, Michael, attributes the aurora to magnetism, 164 ; establislıes and develops the science of magnetoelectricity, 208, 209, 226 ; refuses to accept the doctrine of the conservation of energr, 218 ; his conception of an invisible, all-perrading plenum, 234 ; liquefies carbonicacid gas, 249 ; confirms Berzelius's theory of binary combinations, 265.

Favus, its canse discovered, 365.

Fechuer, Gustav Thcodor, his researches in the new science of "physiological psychology," 409412.

Fermentation and putrefaction, investigation of the processes of, 375380.

Ferrel, William, his rediscovery of the cause of atmosplieric circulation, 183, 184.

Ferrier, David, his experiments in bruin localization, 420,421 .

Fizeau, Hippolyte L., his experiments on liglit, 222 ; his experiments on ether, 234.

Flourens. Mraric Jean Pierre, his experinents in nerre physiology, $417,418$. 


\section{INDEX}

Forbes, James David, proves that radiant heat and light conform to the same laws, 223,225 .

Forster, George, his remarkable cliinatic observations, 176.

Forster, Thomas, lis theory of aerolites, 161.

Foucault, Léon, his experiments to prove the undulatory nature of light, 222.

Fourcroy, Autoine François, aids Lavoisier in the development of a new ehemistry, 32.

Frankland, Edwarl, liscovers the difference in combining power of different atoms, which leads to the law of valency, 271 .

Franklin, Benjainin, tries to account for evaporation, 168.

Fraunhofer, Joseplı, perfects the refracting telescope and invents the heliometer, 65 ; suggests the improvement of the spectroscopc, 70 .

Fresnel, Augustin Jean, lis investigations of the phenomena of light, 200-204, 225.

Fritsch, Gustav, his researches relating to brain localization, 420.

Frommann, Professor, his theory of cell formation, 454.

Fullirott, Dr., his discorery of the Neanderthal skull, 110.

Gall, Franz Joseph, originates the system of plı'enology, $399,400,423$.

Galle, Johann Gottfried, direeted by Leverrier, discovers Neptune, 49.

Galrani, Luigi, and the invention and applieation of the galvanic battery, $27,28$.

Gilvanic battery, the far-reacling effects of its invention, 27-29.

Galvanism, its discovery and far-reaching effects, 27-29; its kinship to electricity demonstrated, 204-206.

Gauss, Karl Friedrick, lis first test of the electric telegraph, 207.

Gay-Lussac, Joseph Lonis, his experiments with gases, which lead to the discovery of the molecule, 256258 ; his discovery of cyanogell, $266,267$.

Geology, its ghostly character in the eighteenth century, 17-19; Hutton labors to systematize the seienee, but lis Theory of the Earth is pronouneed lieretical, 19-23; William Sinith's first geological map of Einglind, 90; progress of the science during the nineteenth century, 123-156 ; colltroversy between the Neptunists and the Plutonists regarding terrestrial plienomena, and the establislıneut of the theory of the latter, 123-125; discussion regarding the changes in land surfaces, whether cataclysmic or gradual, 125-130; establislıment of the glacial theory, 130-136 : study of the earth's strata, and their elassification, 136-145; consideration of the evidence which shows the age and growth of momn. tains and coutinents, 145-150; evidences of the glacial epoch, 150 , 153; reasons for believing in the gradual diminution of changes in the surface of the earth owing to its refrigeration, 153-156.

Gerhardt, Charles Fıédéric, working in the ficld of organic eliemistry, 266268 ; revives Avogadro's law, 269.

Gerlach's histological scheme of the brain, 428.

Germ theory, Pastenr's and Tyndall's advocaey of, $320,386$.

Gill, David, plıotograplis a comet, 79.

Glacial theory, the establishiment of, 130-136; the work of the ice-sheet in New England, 150.

Goetle, Johann Wolfgang von, his doctrine of the metamorphoses of parts, 36, 102, 288-291.

Golgi, Camille, his metlod of staining nerve cells and their processes, $429,430$.

Gravitation, its eause an unsolved problem, 443-446.

Gray, Asa, an ardent propagandist of the Darwinian theory, 313 .

Gulf Stream, the, speculations as to its effect on climate, 178-181, 182.

Hanler, Jons, his explanation of the tracle-wints, 178.

Haeckel, Erust Heinrich, an enthusi. 


\section{INDEX}

astic adrocate of the Darwinian theory, 313, 414; favors the Lamarckian theory of the origin of favored species, 318 .

Hahnemann, Christian Samuel Friedrich, his belief in the prevalence of the itch, 361 .

Hall, Asaph, his diseovery of the moons of Mars, 49.

Hall, Marshall, his services in the practice of medicine, 359,360 ; his important psychological discovery, $403,404$.

Haller, Albrecht ron, his idea of the funetion of respiration, 39.

Harding, of Lilienthal, his discovery of Juno, 47.

Hartley, David, his associational theorv of psychology, 414.

Heat, how regarded in the eighteentl century, 24; Thompson's vibratory theory of, 26,27 ; the investigation of, helps to solve the problem of evaporation and precipitation, 171 ; Humboldt's study of its distribution on the surface of the globe, 175-177; discovery of its nature and properties, 222-224; the source of animal heat discovered, 349 .

Heidenhain, Rudolf, his experiments in hypuotism, 415, 416.

Helmholtz, Hermanu Ludwig Ferdi. nand ron, his thcory as to the discrepancy between the motion of the earth and the moon, 51; lis theory of solar energy, 74, 437; his share in the discovery of the doctrine of the couservation of energy, 214, 217, 221, 225, 437; his eleetro-magnetic theory of light, 227,228 ; his calculations to prove the vortex theory of atoms, 238; opposes the vitalistic conception of fermentation, 379 ; his researches and discoveries in psycho-physics, $407-409$.

Hencke, an amatenr astronomer, discovers a fifth asteroid, 47 .

Henderson, Thomas, Astronomer Roy. al of Scotland, the first to suceessfully measure a star's parallax, 66 . Henle, Friedrich Gustav Jaliob, his anatomical researches, 332336 ,
352 ; his study of the nerrous sys. tem, 404.

Herbart, Johaun Friedrich, founder of mathematical psychology, 407.

Herschel, Caroline, aiding William in his investigations, 6,7 .

Herseliel, Sir John, his study of double stars, $63,64,65$; refuses to accept the doctrine of the conservation of energy, 218 ; his intprovemellt of the microseope, 326,327 .

Hersehel, Sir IVilliam, his improvement of the telescope and his astronomical discoveries, $5-12$, 226 ; his nebular hypothesis, 1316 ; his theory of the asteroids, 47 ; his study of double stars and dis. covery of their relative change of positious, 63,65 ; his unsuceessful efforts to solve the problem of star distance, 65 ; his study of sullspots, 166 .

Hertz, Hein rich, confirms Helmholtz's electro-magnetic theory of lightit, $227,228$.

Hinrichs, Gustar, his investigations confirm the "law of octares," 280.

Histology. See Anatomy and Physiology ; Psychology.

Hooke, Robert, his happy guess as to the nature of light, 198.

Hooker, Sir Joseph Dalton, his aid sought by Darwin in the publieation of lis Origin of Species, $307,309,310$; becomes his collvert and diseiple, 313.

Howard, Edward, his conclusion as to aerolites, 158.

Howard, Lnke, his elassifiention of clouds and his theory of their formation, 169, 170; his thcory of dew formation, 170 .

Huggins, William, his spectroscopic researches, 70, 80 .

Humboldt, Alexander ron, his discoreries in terrestrial magnetism, 167; his study of heat distribution and its climatic effects, 175-177.

Hunter, Jolı, discovers the processes of digestion, 39,347 .

Hutton, James, lis genlogical investigations and his Theory of the Earth, 19-23, 123, 129, 153; gell- 


\section{INDEX}

eral aceeptance of his proposition that "time is long," 97, 102; his followers known as Plutonist., 123 ; and their final success in proving the igneous origin of rocks, 125 ; his theory of rain, 169, 172 .

Huxley, Thomas Hemry, the lesson lie draws from the evidence of paleontology, 117, 118; his estimate of Darwin, 317.

IIuygens, Christian, originator of the undulatory theory of light, 198; conceives the existence of the true ether, 231.

Hyatt, A., advocates the theory of Lamarck as to the origin of favored species, 318.

Hydrogen gas, discovery of, 31 .

Hydrophobia, discovery of its cure by protective vaceination, 389,390 .

Hypuotism, investigation of its plenomena, 41 $5-417$.

ICEBERG THEORY, the, diseussion regarding, 130-136; the effects of the iee-sheet in New England, 150.

"Iinponderables," the, eigliteenthcentury controversy regarding the niture. of, $24-27$; the study of, in the nineteenth century, 192-228; their abolishment, 228, 229.

Inhalation originated by Davy as a method of medieation, 366 .

Insane, the, reform in treatment of, $395-401$.

Isomerism, diseovery of, 274.

Isomorphism, discovery of, 261.

Itch ("gale rćperentće"), its cause and cure discovered, 360-363.

Jackson, Cunri.ks T., his claims to the diseovery of the anresthetic properties of ether, 373 .

Jenner, Elward, and his discovery of vaccination, $42,43$.

Joule, James Prescott, discovers the law of the mechanical equivalent of heat, the corner-stone of the law of the conservation of energy, 213 , $214,217,218,221,223,225$.

Kant, Immanurt, conceires the idea of the transmutation of speeies, 291.
Keeler, Professor, his eonelusions as to the eharacter of nebulæ, 83 .

Kekulé, A., his investigations lead to the establishment of the law of valency, 271.

Kelvin, Lord. See Thomson, William. Kinetie theory of gases investigated by Clausius and Maxwell, 242-245.

Kirelılıoff, Gustav liobert, with Bunsen, perfects the spectroscope and invents the method of spectrum analysis, 70, 283.

Kirkdale, Yorkshire, England, discovery of fossil bones in cave at, 95.

Kirwan, Richard, calculates empirieally the temperatures of all latitndes, 175.

Kitasato, Dr., a leader in the development of serum-therapy, 392 .

Kocli, Robert, his bacterial investigations, 381 .

Kölliker, Rudolf Albert, confirms the theory of isolated nerve cells, 431 .

Laennec, René Théophile Hyacintue, discovers and practises the auscultation method in diagnosing diseases of the lieart and lungs, 356 , 359.

Lagrange, Joseph Lonis, systematizes Newton's liypothesis of universal gravitation, 15; acconnts for the accelerated motion of the moon, 50 .

Lamirck, Jean Baptiste, opposes the theory of special -creation, 103; his theory of the transmutation of species, 293-297; his seleetion of the word "biology" to express the science of living things, 298.

Langley, Samucl Pierpont, speetroscopie researches of, 70 .

Laplace, Pierre Simon de, solves the problems of universal gravitation, 15 ; completes Herschel's nebula' hypothesis, 15, 16: his theoly of Siturn's rings, 50; how he accornted for the moon's aceeleration, 50 ; how he accounted for aerolites, 158 ; opposes Fresnel's undulatory theory of light, 203.

Lartet, Édouard, his important find in the caves of Dordogne, 113. 
Latour, Caguiard, discoverer of pepsin, 347 ; lis microscopical .researches, 376 .

Laurent, Augustıs, his work in orgauic eheınistry, $266,268$.

Lavoisier, Antoine Laurent, his chemical experiments and discoveries, $26,31-33$; his tragic fate and the triumph of his doctrines, 33-35; his experinents on respiration, 40 .

"Law of octares," the, its discovery and dcrelopment, 280, 283.

Leeuwenhoek, Antouius von, his microscopical researches, 329,376 .

Leidy, Joseph, his discoveries of the Tertiary period in the Rocky Mountain region and the truth chey teach, 114-121; his inrestigation of the Trichina spiralis, 363.

Lenz, Professor, first proposer of gravitation as the cause of oceanic circulation, 180.

Le Sage's hypothesis of the cause of gravitation, 443-445.

Leuckart, Karl Georg Friedriclı Rudolf, lis investigations of the Trichina spiralis, 363, 364.

Leverrier, Urbain Jenn Josepl, his calculations lead to the discovery of Neptune, 4S, 49 ; his furtlier calculations as to the location of a hypothetical planet known as $\mathrm{Vul}$. can, 49.

Liebig, Justus von, foremost among the workers in organic cliemistry, $266,268,274$; his in postaut chemical researches, 346,347 ; discovers the source of animal lieat, 349 ; opposes Pasteur's doctrine of fermentation, 376, 379 .

Life, some unsolved problems of cosmic and telluric, 449-453.

Light, how regarded in the eighteenth century, 24; establisliment of the undulatory theory of, 192-204, 223; Helmho'tz's electro-ınagnetic theory of, $227,228$.

Liquefaction of air, of carbonic-acid gas, hydrogen, and of other permanent gascs, 249; the question as to the liquefaction of air in our outer atmosphere, 250.

Lister, Sir Joseph, his improvement of the compound microscope, 327 , 328 ; his discovery of the true form of red blood corpuscles, 329 ; his discovery and development of antisepsis in surger'y, 382-386.

Lockyer, J. Noman, his "Ineteoric hypothesis," $83-86$; his endorsement of the theory that oll socalled elenents have a compound nature, 286,287 ; his theory of solar heat, 439.

Lodge, J. Oliver, his theory of two etliers, 235.

Logiın, Williaun I., lis geological investigations in Canada, 139.

Long, Crawford W., his iuvestiga. tions of the anrsthetic properties of ether, $373,374$.

Lotzc, Rudolf Hermann, his'adrocacy of psyclio-physiology, 409.

Louis, Pierre Charles Alexandre, his introduction of the "statistical method" into the practice of medicine, 360 .

Lıbbock, Sir Jolın Willian, adrocates the Darwinian theory of natural selection, 313.

Lvell, Charles, the apostle of uniform. itarianism, 99-102, 125, 126, 130); convinced by Darwin, endorses the transmutation theorr, $10 \%, 108$, 313 ; his advocacy of the glacial theory, 131, 132; lis citation of a fact from Playfair which is undisputed, 153; his aid sought by Darwin in the publication of his Origin of Species, 307, 309.

Magendir, Fraxcois, his services in the rational piactice of medicine, 359,360 ; his studies of the nervous systein, 400,402 .

Magnetisın, its relations to electricity discovered, and the science of magneto-electricity founder, 207-209.

Magneto-electricity, Faraday cstablishes and develops the science of, 208, 209.

Malıhus, Thomas Robert, low his Essay on Population aided Darwin in formulating his theory of the origin of species by natural selection, $305,306$. 


\section{INDEX}

Jarais, M., his description of a nineteenth-century miracle, 157.

Mar's, discovery of its seven moons, 49.

Marsh, Othniel Charles, his discovery of new Tertiary species in the Rocky Jountain region, and what they signify, 114-121.

II astodon, the Warren, description of, 119.

Maury, Matthew Fontaine, his theory of the Gulf Stream, 178-180.

Mir xwell, James Clerk, determines the charicter of Saturn's rings, 50 ; his theories in reference to electricity and magnetism, and to light and electro-magnetism, 227; his testimony as to the existence of an allpervading plenum, 230, 234; his investigation of the kinetic theory of gases, 242-244.

Misyer, Julius Robert von, his share in establishing the doctrine of the conservation of energy, 214, 215$217,221,225,435,436$.

Medical science: Jenner's eighteenthcentury discovery of the method of preventing sinall-pox, 42,43 ; progress of the science during the nineteenth century, 354-394; discovery and development of percussion and anscultation in the diagnosing of disense, 354-359; introduction of the "statistical method," 360 ; causes of "gale répercutćc" (itch), of trichinosis, and of favus dis. covered, 360-365; discovery of auæsthcsia, 365-375; processes of fermentation and putrefaction in. vestigated, $375-380$; cause of contagion discovered, $380-382$; discovery and establislimcut of antisepsis in surgcry, 382-386; discovery and development of protective vaccination by virus prepared in the laboratory $386-390$; discovery and development of the selum-therapy inethod of curing diseasc, $390-394$.

Meldrum, Mr., on the effects of sunspots, 166 .

Mendèleeff, Dmitri, confirms the "law of octaves" under" the title of "periodic law," 280, 283 ; his dissociation theory of atoms, 448.

"Meteoric hypothesis," the, of J. Norman Lockyer, 83-86.

Meteorites. See Aerolites.

Metcorology, its cightcentlı - century students' vicws of the imponderables, 25, 26; its triumphs and failures in the uinetcenth century, $157-191$; study and determination of the origin and nature of aerolites, 157-162; speculations regarding the aurora 162-167; problem of dew formation solved, and of clouds, rain, snow, and hoar-frost, 167-172; study of climatic conditions, and speculations as to the influences which affect them, 172182,191 ; aerial currents iuvestigated, and their laws determined, 182-191; the greatest triumph of practical meteorology, 191.

Meteors, determination of their origin and character, 59, 60.

Meyer, Lothar, his confirmation of the "law of uctaves," 280.

Microscope, nineteenth - century im. provements in, $324-328$; the invention of the compound microscope, $327,328$.

Miller, William Allen, his spectroscopic investigations, 70 .

Mitscherlich, Filhard, his discovery of isomorphism, 261.

Mohl, Hugo vou, his disenvery of protoplasm, 338, 339 ; his theory of cell formation, 343,344 .

Mohr, Karl Friedricl, lis share in the discovery of the doctrine of the conservation of energy, 214, 215, $221,225$.

Iolecules, theories as to their distribution, properties, dimensions, ctc., $242-251,275-278$; thcir isomolphous property, 261 ; establishment of the law of molecular structure, 265-269, 272-275; some unsolved problems regarding, 448, 449 .

Moon, the, how its acceleration is accounted for, 50-53.

Iorton, William, T. G., demonstrates the practicability and benefit of anæsthesia, $369,370,375$. 


\section{INDEX}

Morveau, Guyton de, and the new ehemistry, 32.

Müller, Johannes, his discovery of the resemblanee between animal and vegetable cells, $331,332,337$; his study of the nervous system, 404 ; his discovery of the means of lardening and preserving brain tissues, 424."

Murchison, Roderiek Impey, eombats the uniformitarianism of Lyell, 130; his elassification of transition rocks int to chronologieal groups, 138.

Napoleon Bonaparte, how his choice of a physician influenced the progress of medieal science, 354,355 , 360.

Neanderthal slull, its discovery and description, 110.

Nebulæ, investigation of, and theories conceluing, 13-17, 79-87.

"Nebular liypothesis," the, its eolrception and completion, $\cdot 13-17,84$.

Neptume, how it was diseovered, 48, 49.

Neptunists, theory of the, 123-125.

Nervous system, the, diseoveries relatiug to, 401-407.

Neurons, the theory of, $430,431$.

New photograply, the, 2, 5, 284-286.

Newburg. New York, deseription of the mastodon fonnd there, 119.

Newlands, John A. $\dot{R}$., diseorers the "law of octaves," 280.

Newton, Professor, determines the true cliaracter of meteor sliowers, 59.

Newton, Sir Isaae, his hypothesis of universal gravitation, systematized by Laplaee and Lagrange, 15 ; pronouneed impious and heretical in 1700,16 ; his blow at the supernatural elaraeter of eomets, 54 .

Ochan currents, speculations as to their effeets oll climate, 178-182.

Oersted, Hans Christian, his discorery of the deflection of the magnetie needle by eleetrie enrreuts, 207 .

Oken, Lorenz, his extensious of the theory of metamorphoses of parts to the animal kingdom, 289; lis theory of spontaneous generation and of the evolution of species, 298 .

Olbers, Heinrich Wilheln Matthias, his discovery of Pallas, 44, 47; his explosion theory of the asteroids, and the objections to it, 47 ; his discovery of Vesta, 47 ; teaches the true eharacter of the eomet's tail, 54 ; his theory of atrolites, 158.

Olmsted, Denison, determines the ('osmical origin of shooting-stars, 16 ].

Origin of species by natural seleetion, theory of, 302-310.

"Origin of the fittest," speeulations recrardiıg, 317-319.

Owen, Sir Richard, sustains Lyell's hypothesis of speeinl ereation, 105 ; his discovery of the Trichina spiralis, 363 .

PALEONTOL.OGY, the work of its (ighteentli-eentury devotees, 23 ; the story of its progress during the uneteenth eentury, 88-122; the true character of fossils first recognized by $\mathrm{Da}$ Viıei, 88; Williain Smitlı's early paleon tologieal discoveries and his deduetions therefrom, 89-91; Curier's studies and inves. tigations, which result in the cstublishment of rertebrate paleontology, 91-94, 96 ; Buckland's Kirkdale discovery and the contention regarding it, 95 ; otlıer fussil discover. jes, and the general aeceptanee of Hutton's proposition that "time is long," 95-97; the theory of eatas. trophism orerthrow and the doetrine of uniformitarianism cstablislsed, 97-102; controversy regarding the theory of special ereation, 102-105; Darwin's Origin of Species, and the greneral acceptance of his transmutation thenry, 105-109; fossil disenveries of Fal. eoner, Fulılıot, Selımerling, and others, which demorstrate the existence of paleolithie man, 109114; discovery of new Tertialy species in the Rocky Mountain region, and of vertebrate fossils elsewhere, whieh prove the truth of evolution, 114-121. 


\section{INDEX}

Pappenheim, Gottfried Heinrich, his discovery of the function of the pancreas, 347.

Pasteur, Lonis, his services in the cause of organic chemistry, 266, 274, 375; refutes Pouchet's thcory of spontaneous generation, 320 , 386 ; his study of fermentation and putrefaction, $375-380$; his discovery and establishıment of protective vaccination, 387-390.

Peirce, Benjamin, disproves Laplace's theory of Saturn's rings, 50.

Peun, Granville, how he accounted for the fossil discoverics at Kirk. dale, 95.

Pepsin, its discovery, 347 .

Percussion, its discovery and developmeut as a method of diagnosing disease, 354-356, 359 .

Perrausin, a chamois-hunter of the Alps, conceives the grlacial theory, 132-134.

Perthes, M. Buncher des, his paleolithic discoveries at Abbeville, 109.

Plılogiston, the eighteenth-century theory of, 29-32.

Photogiraply, experiments in, by Davy and Wedgwood, 2 ; its services in spectrum analysis, 284-286; perfected by Daguerre and Draper, 284, 285.

Phrenology, origin of the system, 399.

Pliysics, advances made in the science during the eigliteenth century, 2329 ; controversy over the nature of the "imponderables," 24-27; discovery of the galvanic battery and its far-reaching results, 27-29; progress made in the science during the nineteenth century, 192229 ; study of liglit and colors, and the establishment of the indulatory theory, 192-204; identity of galvanic aitd electrical action demonstrated, 204-206; the link betrieen magnetism and electricity discovered, and the science of magneto-electricity founded, 207-209; discovery of the law of the conservation of energy, 209-221 ; discovery of the nature and properties of heat, and the establishment of the science of thermo-dynamics, 222224 ; Helmlıoltz's el ectro-maguetic tlicoly of light, 227,228 ; displacement of the imponderables in favor of an all-pervading ether, 228, 229; some unsolved problems, 443-449.

Physiology, its eighteenth - century triumphs, 39-41; discoverics in brain physiology, 417-423. See Anatomy and physiology; Medical science.

Piazzi, Giuseppe, his discovery of Ceres, 44.

Pickering, Edward Charies, his spectroscopic researches, 70,73 .

Pinel, Philippe, his anatomical investigations, 324; inangurates in France a reform in the treatment of the insane, 395-399; opposes the system of plirenology, 400 .

Pithecanthropus erectus, the ape-man fossil from the island of Java, 120.

Playfair, John, his advocacy of the Huttonian theory of the earth, 123, 126.

Pleiades, the, facts concerning, 64, 80.

Plutonists, theory of the, 123-125.

Poisson, Simeon Denis, discovers the canse of the atmospheric circulation, 184; opposes the undulatory theory of light, 203.

Pouchet, M. F. A., his theory of "spontaneous generation," 320 .

Prestwicl, Joseph, investigates the Abbeville find and makes report thereon, 109.

Priestley, Joseph, his discovery of oxygen, 31 ; his inexplicable opposition to the doctrines of Lavoisier, 34,35 ; lis experiments on respiration, 40.

Protoplasm, its discovery by Molıl and Dujardin, 338-340.

Proust, Louis Joseph, his theory of the combination of chemical elemelits, 255, 256.

Pront, William, his theory of the compound nature of the so-called elements, 278-287; his discovery of hydroclıloric acid in the gastric juice, 347. 


\section{INDEX}

Psyehology, experimental, its advances during tlie present century, 395 -432 ; the reform in the treatment of the insane, $395-401$; discoveries regarding the nervous system, 401-407; establishment and development of psycho-plysies, 407-417; discoveries in brain physiology, 417-423 ; establishment and devclopment of brain histology, 423-432.

Psycho-pliysics, diseoveries relating to, 407-417.

Putrefaetion and fermentation, their proeesses investigated, 375-380.

RAIN, theorics regarding, and the determination of its causes, 167-172.

Ramon y Cajal, S., his discoverics relating to nerve cells, 430, 431, 432.

Ramsay, Andrew Crombic, how he aceounted for many of the lake basins, 153.

Runkine, William Joln Macquorn, his researehes prove the law of the conservation of energy, 223, 224, 225.

Reınak, Professor, his mieroseopieal researches of the braiu and nervous system, 404, 425.

Respiration, its processes investigated, $39-41,349,350$.

Röntgen, Professor, and the $\mathbf{X}$ ray, $1,2,228$.

Rosse, Lord, his stndies of nebula through his six-foot reflcetor, 80 .

Roux, Dr., his services in the cause of serum-therapy, $392,393$.

Rumford, Count, see Tliompson, Benjamin.

Rush, Benjamin, his reform in the treatment of the insane, $395,396$.

Rutherford, Dauiel, his diseovery of nitrogen, 34.

Rutherford, Lewis Morris, his speetroseopic researches, 70, 72 .

Saint-Hilaire, Geoffroy, his advocacy of the transmutation theory, 104 ; opposes Cuvier's special-creation hypothesis, and partially endorses the Lamarekian theory", 300 , 318.
Saturn, diseoveries relating to 49,50 .

Savary, M., accounts for the elliptical orbits of double stars by the laws of gravitation, 64.

Scheele, Karl Wilhehn, his discovery of oxygen, 31 ; his physiological experiments, 40 .

Schiaparelli, Giovanni Virginio, his establislnnent of the cometary origin of meteors, 59.

Sehleiden, Matthias Jakob, his discovery of the function of the cell nueleus, $331,332,345$; his discovery of so-ealled free-eell formation, 343.

Schmerling, Anton von, his important discoveries at Engis, Westphalia, 111.

Schoenlein, J. L., discovers the eause of favus, 365 .

Schultze, Max Jolrann Sigismund, discovers the identical character of vegetable and animal cells, 340 .

Schwam, Theodor, lis cell theory, $331-336,337,338,343,345$; his discovery of pepsin, 347 ; his ini. eroseopieal researehes, 376, 404.

Scientific problems, some unsolved, 433-457; regarding the sun and eartl, 435-442; in physics, 443449 ; of life and the evolution of living matter, 444-456; of anthiopology, 456, 457.

Scrope, G. Poulett, his work accounting for the origin of volcanoes, 124.

Sccchi, Father Angelo, his researches in spectrum analysis, 70, 72.

Sedgwick, Adam, his classifieation of transition roeks into chronologieal groups, 138.

Serum-therapy, discovery and development of the system of, 390 394.

Shooting-stars, determination of their origin, 59,60 .

Simpson, Sir J. Y., his diseovery of chloroform as an anasthetie, 374.

Sirius and its "invisible " eompanion, 74,75 .

Six, Mr., his theory of dew formation, 171.

Small-pox, Jenner's diseovery of the means of its prevention, 42, 43 . 


\section{INDEX}

Snith, William, "the father of Euglish geology," his paleontologieal discoveries and his deductions thelefrom, 89-91; his study of strata as a key to the earth's chronology, 137, 138.

South, James, aids John Herschel in lis inrestigation of double stars, 64 .

Spallanzani, Abbé, discovers the processes of digestion, 39,347 ; his experiments on respiration, 40 .

Special creation, discussions relating to the hypothesis of, 91-97, 104, $105,297-302$.

Spectroscope, its perfection by Kirchhoff and Bunsen, and its solar and sidereal analyses, $70-76,283,284$; its necromantic power, 76 ; its application to nebulae, 80 .

Spectrum analysis, its remarkable disclosiles, 70-76, 283-287.

Spencer, Herbert, adrocates the Darwinian theory, 313,316 ; favors the Lamarckian conception of the origin of favored species, 318 ; his theoretical study of psrchologv, 415 .

Spontaneous generation, Pouchet's hypothesis of, 320 .

Spurzheim, Kaspar, adrocates phrenology, 400.

Stars, double or multiple stars, and star clusters, the investigations of the nineteentlı century relating to, $60-76$.

"Statistical method," the, its introduction into medical practice, 360 .

Stetloscope, its inrention and improremellt, 356,359 .

Storm-centre, description of, 186, 189.

Struve, F. G. W., his discovery of donble stars, 64 ; solves the problem of star distance, 66 .

Sun, the, its elements discorered by spectrum analysis, 70-72; IIelmholtz's theory of solar cnergy, 74 ; some unsolred problems regarding, 435-442; estimate as to its heat. giving life, 438 .

Sun-spots, effects of, 166 .

Tait, Peter Guthrie, his measurement of the frec path of molecules, 247.
Talbot, William Henry Fox, his services in the perfection of photog. raphy, 285 .

Temperature, the, absolute zero of, 250.

Tetanus, the serum treatment for, 392 . Theory of the Earth, James Hutton's, 20-23.

Thermo-dynamies, and how the science originated, 223,224 .

Thompson, Benjamin (Cuunt Rumford), lis vibiatory theory of heat, 26,27 ; he proves the transformation of labor iuto lieat, 210 .

Thomson, Thomas, adroca tes Dalton's atomic theory, 259.

Thomson, Willian (Lord Kelvin), his estimate of the eartli's longevity, $74,154,441$; aids Joule in estab. lishing the doctrine of the conservation of energy, 218-223, 225 ; lis doctrine of the dissipation of energy, 223, 224; his studies in thermo-dynamies, $223,224,227$; his calculation of the probable density and rigidity of ether, 235 ; his conception of the vortex theory of atoms, and his verifying experiments, 238-240; calculates the dimensions of a molecule, 244, 245 ; refuses to recognize any repulsive power in molecules, 246 ; his estimate of the heat-giving life of the sun, 438 .

Titanotheres, or Brontolherida, erolu. tion of, 121.

Tournal, M., lis discovery of human fossils in the sonth of France, 111.

Toxine and antitoxine, their discovery and introduction, 390-394.

Trade-winds, study of their origin and effects, 177, 178, 182.

Transnutation of species, doctrine of, 105-108, 293-297, 302-310, 317320.

Treviranus, Gottfried Reinhold, his theory of the transmutation of specics published the same year in which Lamarck's first appeared, 395 ; foreshadows the cell theory, 336.

Trichina spiralis, its discovery, 363365. 
Triclinosis, character of the disease and its cause discovered, 363-365.

Tuke, William, inaugurates reform in treatment of the insane, 395.

Tyndall, John, his advocacy of Mayer's doctrine of the conservation of energy, 221, 223; and of Darwiu's theory of natural selection, 313 ; his endorsement of the germ theory, $320,386$.

Ultra-gaseovs or fourth state of matter, theory of, 247.

Undulatory theory of light, establish. ment of, 192-204.

Uniformitarianism, Sir Charles Lyell's adrocacy of the doctrine of, $99-102,127,131$.

Vaccination, its discovery as a means of preventing small-pox, 42 ; its application as a preventative of other disenses by virus prepared in the laboratory, 386-390.

Valency, development of the law of, $269,275$.

Valentin, Gabriel Gustav, his study of pancreas, 347 .

Van 't Hoof, Professor, his establishment of stereo-chemistry, $448,449$.

Venetz, M., an early believer in and advocate of the glacial theory, 134 .

Vertebrate paleontology, establishment of, 91-97.

Vinci, Leonardo da, his early recognition of the true character of fos. sils, 88 .

Virchow, Rudolf, lis demonstration of Schwaun's cell theory, 344, 345; his researches which lead to the discovery of trichinosis, 363,364 .

Volta, Count Alessandio, his invention of the voltaic pile, $27,28$.

Vortex theory of atoms, the, experiments to prove, $236-240$; an unsolved problem, 446, 447.

Vulcan, a hypothetical planet located by Leverier, 49.

Wallace, Alrred Russfri, his remarkable conception of the theory of natural selection contemporaneonsly with Darwin, 307-310.
Waller, Professor, his discovery of "trophic centres," 427.

Warren, John C., nounted, described, and gave name to the mastodon fonnd at Newburg, N. Y., 119.

Water, its composition discovered, 31 , $34,253$.

Weatler bureaus, their principal occupation, 186, 191.

Weber, Ernst Heinrich, his experiments and discovery in psychophysics, 409-412.

Weber, Wilhelm Eduard, makes a practical test of the electric telegraph, 207; lis study of the nervous system, 405 .

Wedgwood, Jusiall, invents the pyroineter, 24.

Wedgwood, Thomas, his experiments in pliotography, 2, 5.

Weismann, August, opposes Lamarck's theory of acquired variations in the origin of favored species, 318 ; elaborites a hypothetical sclieme of the relations of intracellular units, 455.

Wells, C. W., his solution of the problem of dew formation and of the precipitation of watery vapor in any form, 170-172.

Wells, Horace, the first to administer an anzstletic in a surgical operaation, 369 .

Weruer, Abraham Gottlob, the propounder of the Neptunian theory, his belief in the aqueous origin of the solids of the eartli's crust, 123; his belief in the uniformity of strata over thewhole eartl, $136,137$.

IVilson, Patrick, his theory of dew formation, 171.

Winds. See Aerial currents.

Wöhler, Friedricl, his syuthesization of urea, 265,266 ; his investigation substantiates the binary theory of Berzelius, 268; his discovery of isomerism, 274; lis important services to physiology, 346,347

Wolff, Kaspar Friedrich, founder of the science of embryology, 36 ; foreshadows the cell theory, 336 .

Wollaston, William Hyde, discover's the identity of galvanism and elec- 


\section{INDEX}

tricity, 205; his observatio's of Young, Thomas, his establishnent of chemical combinations cuntirms. Dalton's atomic theory, 256, 259; his improvement of leuses, 325 , $326,327$.

Wortman, J. L., his fossil linenge of the elleutates, 121.

Wundt, Wilhelm Max, his psychological discoveries, 414,415 .

"X RAY," its discovery, 1, 2, 228.

Young, Ciarles Atroustes, his spectroscopic rescarches, 70 . the undulatory theory of light, 27 , 192-204, 225; confirms the identity of galvanism and electricity, 205; practising medicine and studying Egyptian hieroglyphics, 206; tlıe real discoverer of the ether $23 i$, 232.

Zöllner, Johany Kart Friedrich, lis cometary theory, 54,55 ; his interpretation of the diversities in the spectra of stars, 73 . 
(3) 



\title{
PLEASE DO NOT REMOVE
}

CARDS OR SLIPS FROM THIS POCKET

\author{
UNIVERSITY OF TORONTO LIBRARY
}


